Illinois State University

ISU ReD: Research and eData

Theses and Dissertations

$5-1-2014$

\title{
In Search of Ubuntu: An Examination of Enslaved African Domestic and Labor Environments on St. Eustatius
}

Deanna Lynn Byrd

Illinois State University, deannahamblin@ilstu.edu

Follow this and additional works at: https://ir.library.illinoisstate.edu/etd

Part of the African Languages and Societies Commons, African Studies Commons, History of Art, Architecture, and Archaeology Commons, Latin American Languages and Societies Commons, and the Latin American Studies Commons

\section{Recommended Citation}

Byrd, Deanna Lynn, "In Search of Ubuntu: An Examination of Enslaved African Domestic and Labor Environments on St. Eustatius" (2014). Theses and Dissertations. 232.

https://ir.library.illinoisstate.edu/etd/232

This Thesis is brought to you for free and open access by ISU ReD: Research and eData. It has been accepted for inclusion in Theses and Dissertations by an authorized administrator of ISU ReD: Research and eData. For more information, please contact ISUReD@ilstu.edu. 


\title{
IN SEARCH OF UBUNTU: AN EXAMINATION OF ENSLAVED AFRICAN DOMESTIC AND LABOR ENVIRONMENTS ON ST. EUSTATIUS
}

\author{
Deanna L. Byrd
}

272 Pages

December 2014

The discovery of dry stone rock features in the northern hills on the Dutch island of St. Eustatius presented a unique opportunity to investigate an enslaved African environment during the time of enslavement. Abandoned after emancipation, the area has remained virtually undisturbed by eco-tourism, making it an archaeological gem. The intact nature of the sites held potential to add significantly to our understanding of choices enslaved Africans made in slave village design, orientation, and the construction of their dwellings, as well as the labor activities of daily life. In doing so, this investigation attempted to detect whether higher levels of ideological freedom afforded under Dutch colonial rule translated into greater cultural continuity among enslaved communities. Research for this project assessed slave village patterning and spatial orientation in comparison to other slave domestic environments in the Caribbean, United States and West Africa. Historical maps, regional comparisons, structural, feature and spatial comparisons, and an examination of artifact distribution provided essential 
diagnostic characteristics to determine whether dry stone rock features were associated with a domestic environment. Analysis failed to provide supporting evidence to classify dry stone rock features as former dwellings or part of a domestic village environment, however, the lack of consistency in dry stone rock features across the four sites under investigation when subjected to further scrutiny at individual site locations revealed uniformity associated with inclusion in a broader landscape of labor. Half-constructed walls, extensive terracing, lack of artifacts, and uniformity in size and shape of dry stone rock piles suggest the landscape in the northern hills was likely provision grounds for enslaved populations working on the island. The following thesis is important in setting the groundwork for future investigations to understand how underlying community building principles, like Ubuntu, directed and shaped the landscape enslaved Africans built for themselves in the New World. 
IN SEARCH OF UBUNTU: AN EXAMINATION OF ENSLAVED AFRICAN DOMESTIC AND LABOR ENVIRONMENTS ON ST. EUSTATIUS

DEANNA L. BYRD

A Thesis Submitted in Partial Fulfillment of the Requirements for the Degree of

MASTER OF SCIENCE

Department of Sociology and Anthropology

ILLINOIS STATE UNIVERSITY 
Copyright 2014 Deanna L. Byrd 
IN SEARCH OF UBUNTU: AN EXAMINATION OF ENSLAVED AFRICAN DOMESTIC AND LABOR ENVIRONMENTS ON ST. EUSTATIUS

DEANNA L. BYRD

COMMITTEE MEMBERS:

Kathryn Sampeck, Chair

Elizabeth Scott 


\section{ACKNOWLEDGMENTS}

I would like to extend the following gratitude to the people who have made a difference through this lengthy and arborous process. Dr. Trina Hope, I credit you for encouraging me to pursue a graduate education, so thank you. Dr. Gina Hunter, thank you for introducing me to the world of ethnography this last year and for your continued support. Dr. Kathryn Sampeck, thank you for tolerating my uncanny ability to make things more difficult than need be and for being there to guide me through the pitfalls of this process. Thank you, Dr. Elizabeth Scott for your support and willingness to give back in Ste. Genevieve. Ruud Stelten, thank you for your advice, consultation, and assisting me with my research; without your help, this would have not been possible.

I would like to extend a special thank you to my parents, Don and Irene Byrd, for their continued moral support throughout this lengthy process; especially my father for his insane wizardry skills against my Excel dragons. To Kristen Walczesky, thank you for giving me the gift of the Caribbean, our dear friendship, laughs, and memories. I cannot thank you enough for all of your help on the island - I would never have made it up that mountain most days without you! To Sean Stretton for our friendship, advice, GIS and Archmap consultations, and trust in taking a $\$ 3000$ piece of equipment out of the country. Collin Gillenwater, thank you, for always supporting the road less traveled as well as giving last minute instruction and pacing details before I set off into no-man's land, it came in handy after all. Finally, to my cohort for being the most awesome bunch of crazies 
to traverse this journey with - I wish you well. I dedicate this thesis to my three beautiful children: Haley Rain, Emma Rose, and Miles Enzo. Thanks for putting up with Momma's time and dedication to this. It is all over now. I hope that it was inspiring to you to go after your dreams too. No more juggling, let us play!

D.L.B. 


\section{Final Thoughts}

I am incredibly grateful for the encouragement of my advisors, both Dr. Sampeck and Dr. Scott, while embarking on this fantastic research endeavor in historical archaeology. The opportunity to travel out of the country and work with other historical archaeologists was immensely exciting. I am quite pleased with the result of my research and the foundation it laid in future research on the labor activities of enslaved Africans both in the Caribbean and in the United States. This project's success would not have been possible without the dedication and continual support of my advisor, Dr. Sampeck, both in the field and through the analysis and writing processes. As I conclude, two ideas resonate with me, enough so that I feel inclined to share them in closing.

As this project progressed, it became ever apparent that our bias, albeit with good intentions, clouds the research process. Repeatedly, over the duration of the graduate program, professors attempted to dissuade us from engaging in this highly problematic reasoning, and although I attested to the importance of its absence from our research endeavors, I am afraid that I too succumbed to temptation. At the onset of my research on the island I desperately wanted to find the infamous lost evidence of not only slave life, encapsulated in a pristine slave village, but evidence of cultural continuity as well. In doing so, I almost missed the fascinating discovery of the landscape of labor in the northern hills. Having shed the hindrance of my bias, I was able to appreciate the telling evidence before me. Enslaved Africans worked as communities within highly organized and well planned landscapes to construct dry stone walls and agricultural terracing. 
While we might never be sure of their exact intended purpose, these activities speak to their daily life, just as much as domestic village environments, if not more so in some cases. It was an important lesson to me as a budding archaeologist that we must approach our research with not only an open mind, but with the ability to value the data before us, despite our intellectual cravings.

After this valuable realization, it makes the memory of a moment with Dr. Scott at her field school in St. Genevieve, Missouri, that more compelling. Over the course of the six weeks, my unit held particular interest as a feature emerged. Slowly, bit by bit, with every painstaking $10 \mathrm{~cm}$ increment, it surfaced as I resurrected a piece of the past. After a level, it was clearly metal, but identification was impossible. In fun, I joked that it was a priceless treasure chest, buried by historic pirates for safekeeping in the backyard of this prominent tavern. Dr. Scott first chuckled, then smiled and said, "It is nothing, until the evidence proves otherwise." This would come to swirl in my mind countless times over the course of my research.

The impetus for this project was the identification of slave villages during a pedestrian survey in 2009. While I took this classification in good faith from the seasoned island archaeologist, as field work progressed, Dr. Scott's words rang through the mountain as I collected more and more data. With each passing day, each 90-minute hike up and down the mountain, photograph, measurement, and observation helped to remind me of the importance of archaeological research, first, and identification, second. While the dry stone rock features might share some possible similarities to identified vernacular architecture in other enslaved African communities, the overwhelming evidence, in my opinion, associates these features 
with labor activities rather than domestic ones; it was only careful analysis back in the laboratory that brought answers. Her lesson, and subsequent life experience, taught me the importance of letting the evidence speak for itself. I will continue my research with this valuable lesson in mind, ever content if evidence from the past never fully discloses its secrets. 


\section{CONTENTS}

$\begin{array}{lr} & \text { Page } \\ \text { ACKNOWLEDGMENTS } & \text { i } \\ \text { CONTENTS } & \text { vi } \\ \text { TABLES } & \text { xi } \\ \text { FIGURES } & \text { xiii }\end{array}$

CHAPTER

I. INTRODUCTION 1

Sugar and Slavery $\quad 6$

Historical Background of St. Eustatius - A Historic Gem 9

Previous Archaeological Research: St. Eustatius 10

STENAPA: St. Eustatius National Parks 14

Gilboa Trail 14

Summary 16

II. THEORETICAL APPROACH AND BACKGROUND 17

Hypothesis $\quad 20$

Research Questions $\quad 21$

Unification: Ubuntu 24

Cultural Continuity, Identity and Modernity 27

The Origin of Dutch Slaves 28

$\begin{array}{ll}\text { Ethnography } & 31\end{array}$

Power and Agency $\quad 32$

Landscape Archaeology 34

Enslaved African Labor Environments $\quad 37$

Cultural Practices: Yard Sweeping 37 
Dry Stone Rock Construction $\quad 39$

Provisioning Grounds $\quad 41$

Terracing $\quad 46$

Agave $\quad 47$

Enslaved African Domestic Environments 49

Domestic Structures $\quad 53$

Material Culture $\quad 58$

Ceramics $\quad 58$

Networks $\quad 60$

Summary 62

III. $\quad$ METHODOLOGY 64

Historical Maps $\quad 66$

Field Work on Gilboa Hill $\quad 70$

Field Investigation Summary and Goals $\quad 70$

Pedestrian Survey and Surface Collection $\quad 71$

Observations and Subsurface Testing $\quad 73$

$\begin{array}{ll}\text { Summary } & 74\end{array}$

Excavation Methodology $\quad 74$

Schotsenhoek Slave Village $\quad 75$

Free Black Village $\quad 75$

West African Ethnographic Examples $\quad 76$

Methods of Analysis $\quad 76$

Regional $\quad 76$

$\begin{array}{ll}\text { Structural } & 77\end{array}$

Feature Comparisons $\quad 77$

Dry Stone Rock Feature Dimensions $\quad 80$

Broader Architectural Comparisons $\quad 81$

Post Hole Analysis $\quad 82$

$\begin{array}{ll}\text { Spatial } & 83\end{array}$

$\begin{array}{lr}\text { Spatial Orientation } & 83\end{array}$ 
Artifact

Material Cultural Analysis

Taskscapes

Limitations of the Study

Summary

IV. REGIONAL COMPARISONS AND ARCHITECTURAL ANALYSIS

Historical Maps

Summary

Regional Comparisons

Upland Regions

Upland Region One

103

Upland Region Two

Gilboa Hill

Potential Activity Area and GH15

GH14

120

GH9

124

GH10

Lowland Regions

135

Lowland Region One: Schotsenhoek Slave Village

Lowland Region Two: Free Black Village

138

Summary

Structural Analysis

Typological Attributes: Shape and Size

Circular

Summary

Oval

Summary

158

Rectangular

164

Summary

170

Square and Irregular

Summary

Broader Comparative Analysis: Structural Dimensions 
Schotsenhoek Slave Village: Post Hole Analysis

Summary

V. SPATIAL ORIENTATION, FEATURE, AND ARTIFACT ANALYSIS

Spatial Orientation

Circular

Summary

Oval

Summary

193

Rectangular

194

Summary

Feature Analysis at GH9 and GH15

Summary

202

Artifact Analysis and Taskscapes

202

Summary

224

Discussion

VI.

DISCUSSION AND CONCLUSIONS

Research Questions

Plantation Affiliation and Function of Dry Stone Rock Features

Regional

Upland and Lowland Comparisons

Structural

Broader Architectural and Feature Comparisons

Spatial

Settlement Pattern

Comparative Material Culture

Taskscapes 
Traditional Continuity 243

Future Research 245

Geophysical and Paleoethnobotanical Analysis: Identification of Crops in Terracing Areas at GH14 and GH15 on Gilboa Hill

Experimental Archaeology: Recreation of Enslaved African Provision Grounds

Broader Comparisons of Landscape of Labor:

Dry Stone Rock Features

REFERENCES

APPENDIX A: Field Map Gilboa Hill: Sites GH14 and GH15 266

APPENDIX B: Field Map Gilboa Hill: Sites GH9 and GH10 267

APPENDIX C: Gilboa Hill 50cm X 50cm Test Pit Profiles/Depths 268

APPENDIX D: Free Black Village Plan Map 269

APPENDIX E: Schotsenhoek Slave Village Plan Map 270

APPENDIX F: Schotsenhoek Slave Village Posthole Profiles 271

APPENDIX G: Schotsenhoek Slave Village Posthole Depths 272 


\section{TABLES}

Table

Page

1. Circular Typology Dimensions 145

2. Oval Typology Dimensions

3. Rectangular Typology Dimensions

4. Comparison of Slave Quarter Dimensions in the United States and Caribbean

5. Minimum Distances of Circular Structures and Features

6. Maximum Distances of Circular Structures and Features

7. Minimum Distances of Oval Structures and Features

8. Maximum Distances of Oval Structures and Features

9. Minimum Distances of Rectangular Structures and Features

10. Maximum Distances of Rectangular Structures and Features

11. GH9 and GH15 Feature Comparisons to Human Height

12. Mean Ceramic Date: Gilboa Hill Sites (GH9, GH10, GH14 and GH15)

13. Mean Ceramic Date: Schoesenhoek Slave Village

14. Ceramic Concentration at the Schoesenhoek Slave Village

15. Decoration and Color Prevalence at Schoesenhoek Slave Village

16. Mean Ceramic Date: Free Black Village

17. Ceramic Concentrations at the Free Black Village 
18. Decoration Prevalence at the Free Black Village

19. Color Prevalence at the Free Black Village 


\section{FIGURES}

Figure

Page

1. Third Ridge Trails on Gilboa Hill

2. Overlay of Historical and Topographic Maps of the Northern Hills with GPS Coordinates of the Sites on Gilboa Hill

3. Historical Map of St. Eustatius, 1781

4. Historical Map of St. Eustatius, 1795

5. Historical Map of St. Eustatius, 1829

6. Aerocarto KLM Composite Image of the Northern Hills, 1963

7. Overlay of Maps from 1795 and 1963 of Gilboa Hill of Upland Regions

102

8. Vista Looking to Boven Hill

9. Third Ridge Vista Facing South

105

10. Terracing at GH15

106

11. Top of Dry Stone Terracing Wall at GH14

12. Dry Stone Rock Features at GH9

13. Rectangular Dry Stone Rock Features in Radial Pattern at GH9

14. Vista Looking East to the Ocean from GH9

15. Vista Looking to Northeast from GH10

16. Vista Looking South to First and Second Ridges from GH9

17. Terracing at GH15 
18. Activity Area at GH15

19. Three of the Five Dry Stone Rock Features at GH15

20. Unfinished Dry Stone Rock Wall at GH14

21. Large Agave Grove at GH14

22. Dry Stone Rock Features Placement on the Landscape

23. Natural Water Catch with Lid at GH9

24. Natural Water Catch with Lid at GH9

25. Natural Water Catch without Lid at GH9

26. Seagrapes at GH9

27. Isolated Dry Stone Rock feature at GH10

28. Dry stone rock feature at GH10 Similar to Fort on Second Ridge

29. Fort Started in 1687 on the Second Ridge

30. Vista from the Far Western Edge of the Third Ridge at GH10

31. 1781 Map of St. Eustatius Lowland Regions

32. Schotsenhoek Slave Village Excavation

33. Dry Stone Rock Feature at GH14

34. Dry Stone Rock Feature at GH9

35. Circular Rock Feature 8 at GH14 on Gilboa Hill

36. Oval Dry Stone RF4 at GH14

37. Rectangular Dry Stone Rock Feature 11 at GH14

38. Schotsenhoek Slave Village Settlement Posthole and Post molds

39. GH9: Dry Stone Rock Features and Human Height Comparison

40. GH15: Dry Stone Rock Features and Human Height Comparison 
41. Tin Glazed Sherds Found at GH9

42. Aqua blue body glass found at GH10 204

43. Olive Green Flat Body Bottle Glass Found at GH14 205

44. Stoneware Bottle Fragments from GH15 205

45. Delftware, Polychrome Plates, 1571-1790 207

46. Chinese Export Porcelain, 1644-1912. 217

47. Transfer Print 1830-present 1784-1840 217

48. Ink Well and Slate at the FBV 219

49. Ink Well and Slate at the FBV 219

50. Crystals at the FBV 220

51. Crystals at the FBV 220

52. Crystals at the FBV 220

53. Crystals at the FBV 220

54. Crystals at the FBV 220

55. Activity Areas Depicted as Concentrations of Artifacts near Potential Structures at the SSV 


\section{CHAPTER I}

\section{INTRODUCTION}

Previous research in the study of enslaved communities in the African Diaspora focused on four main themes of inquiry: enslaved African living conditions, the plantation landscape, the relationships between the dominant power of the planter class and subservient slave class (as well as their resistance to this power), and the creation of distinct identities (Singleton 1995). The initial premise for this investigation centered on the latter, identity formation in the New World. Scholars have used a myriad of terms to define this complex process of identity formation in enslaved African communities: creolization, acculturation, cultural ethnogenesis, hybridity, cultural transformation, modernity, and cultural continuity (Fennell 2010). For the purpose of this study, I conducted the following research to determine whether cultural continuity could be identified in enslaved domestic and labor environments from the archaeological record.

Colonial powers in the New World varied in their approach to dominate enslaved populations, but the historical record is clear: French, British, and Spanish colonial rule was by far the most severe accounting for the pervasive control of every aspect of daily life. Set regimented and enforced standards dictated every aspect of the daily lives of enslaved Africans under their rule from the clothing they wore to the houses they built, even the food they consumed. 
The Dutch, however, were not as strict with their slaves mainly because of a pervasive economic ethos that dominated Dutch life. While the Dutch were more willing to take economic risks than their French and English counterparts were, this enthusiasm did not include risks with the potential detriment to their slaves, what the Dutch ultimately viewed as capital (Pons 2007). This coupled with their excellent "management of capital and transportation networks, as well as their dominant position in the slave trade, allowed them to play an important role in the transformation of the Lesser Antilles from a tobacco economy to a sugar industry" (Pons 2007:65). It was this emphasis on economic pursuits, I believe, spared enslaved African populations under Dutch colonial rule from the severe restrictions and harsh conditions other slaves experienced.

This is not to say that enslaved Africans under Dutch colonial rule experienced no brutality or hardship, they certainly did, but since the Dutch placed an even higher value on slaves as commodities and as a means to gain capital they chose to treat them differently. So much so, that in the late eighteenth century slave ports on the islands of Curacao and St. Eustatius standardized accommodations to afford slaves better living conditions while awaiting sale (Hartog 1976; Pons 2007; Postma 1990). Women and children were given comfortable living space separate from men, and all slaves were awarded luxuries like clean clothes, access to hygiene, and adequate nutrition (Hartog 1976; Postma 1990). The Dutch in meeting the basic needs of slaves in captivity ensured themselves a higher price when slaves were sold at each of their bustling ports.

I think this treatment extended to Dutch plantations upon the sale of these slaves as well. Viewing enslaved labor as a valuable asset, slaves on St. Eustatius were noted to have certain liberties unparalleled to other enslaved communities in the New World. 
They were able to own and benefit from animal husbandry and sell excess provisions from their own gardens, as well as handcrafted pottery and other wares, at the local market in Oranjestand. The sales of their surplus goods was so great that the Dutch government passed a law restricting slaves from selling their main commodity, yams, because it's sale competed too much with local Dutch merchants. More importantly, because of less surveillance and restrictions in daily life, enslaved Africans on Dutch islands likely experienced a higher degree of ideological freedom.

If so, this increase in levels of ideological freedom in enslaved African populations likely influenced the level of cultural continuity in forming new communities. When the discovery of dry stone rock features in the Northern Hills on the Dutch island of St. Eustatius, part of a domestic or labor environment of enslaved Africans, was presented as a potential research topic for my Master's research I seized the opportunity to investigate. Given that the landscape is the "spatial manifestation of the relations between humans and their environments," this initial landscape analysis provided the preliminary groundwork for future research in examining Dutch slave life in the Caribbean and the relationship to their shaped environment. Additionally, this research identified levels of ideological freedom in enslaved African communities. Understanding each of the four sites on Gilboa Hill with respect to their degree of standardization, spatial patterning, and general characteristics in comparison to other villages recovered archaeologically (on the island, in the Caribbean, in the United States, as well as to ethnographic examples in West Africa) was essential in identifying expressions of cultural continuity. It is the aim of this research to add to the discourse of displaced Africans in the broader African Diaspora. 
This thesis discusses the investigation of four archaeological sites in the northern hills, on the third and highest ridge of Gilboa Hill, associated with plantations that were first documented on historical maps in 1742. Previous identification of archaeological features in the vicinity consisted of house foundations, cisterns, and other physical structures potentially owned by either the Widow Ducas (Dijkers) or Michael Cuvilljes (Cuvelje). Until fieldwork on Gilboa Hill, conducted over the summer of 2012, previous archaeological investigations of this mountainous landscape consisted of pedestrian survey and speculation about archaeological potential. It was necessary, given the lack of work in the northern hills and the nature of the investigation, to build upon previous research and develop a substantial theoretical framework; a discussion in chapter two broadly outlines this process. The extensive mapping and systematic survey of the third ridge provided a rich dataset for further analysis, discussed in detail in chapter three.

From 2012 to 2013, analysis included the careful examination of historical documentation (including historic maps) and plan maps of previous archaeological excavations of villages on the island. A wide breadth of data on slave dwellings, recovered archaeologically, both in the United States and in the Caribbean compared to structures on St. Eustatius and offered correlations that improved understanding of enslaved village environments. Ethnographic examples from the western tip of Africa, the location where most Dutch slaves originated also offered comparisons and close correlates to structures recovered on the island. While the function of the newly recorded archaeological features on Gilboa Hill in the constructed mountainous landscape is uncertain, it is clear these archaeological features are unique and can contributed to our understanding of the landscape of labor experienced by enslaved Africans once living on 
the island. Chapters four and five detail the process of multiple, comprehensive analyses including regional, structural, spatial, and artifact.

James Delle (1999) during his work in assessing the spatial arrangements of slave village sites in Jamaica determined that between 1834-1865 British planters standardized slave quarters on plantations, and this shift from traditional spatial organization to standardized village patterning is evident in the archaeological record. According to Douglas Armstrong (2009) and his work in St. John, however, the Dutch were quite different in their colonial conquests in that they lacked a specific colonization mission so plantation owners never adopted a standardized slave village design, and may have had greater autonomy to choose settlement locations (Armstrong 2009). This research will evaluate the degree of standardization in St. Eustatius settlements as well as the emphasis of communal identity. African slaves may not have seen themselves as individuals, but rather upheld values of ubuntu or community through spatial organization of their environment over time (Swanson 2005). We can consider how slaves living on the island of St. Eustatius on Gilboa Hill would have fostered social cohesion and created a sense of community by social structuring their environment. In chapter six I discuss how analysis failed to provide supporting evidence to classify dry stone rock features as former dwellings or part of a domestic village environment, however, I also detail how the lack of consistency in dry stone rock features across the four sites under investigation revealed uniformity associated with inclusion in a broader landscape of labor. Half-constructed walls, extensive terracing, lack of artifacts, and uniformity in size and shape of dry stone rock piles suggest the landscape in the northern hills was likely used in part for provision grounds for enslaved populations working on the island. This was a key find in detecting 
cultural continuity, this will be discussed in chapter six as well as the results from extensive analyses that helped answer the research questions posed by this investigation; chapter six also provides conclusions along with considerations for future research. First, it is important to consider a few broader contextual elements central to this investigation.

\section{Sugar and Slavery}

West Indian islands were an important source of economic wealth for England, France, and Spain; all fertile land was dedicated to the production of cash crops beginning in the mid-eighteenth century (Blakely 1993; Dunn 2000; Eltis and Richardson 2010; Farnsworth 2001; Gilmore 2005, 2009; Gomez 2003; Goslinga 1973; Kandle 1985; Haviser 1999; Hartog 1976; Kandle 1985; Miller 2008). Investors, in an attempt to increase profits, pushed for the importation of more and more slaves to the Caribbean to assist with production (Altis and Richardson 2010; Armstrong et al. 2011; Blakely 1993; Dunn 2000; Gilmore 2009; Gomez 2003; Goslinga 1973; Kandle 1985; Kelly 2004; Okepewho, et al. 2000; Painter 2007; Palmer 2000; Wolf 2010). Over the course of 350 years, beginning in 1619, 12.5 million enslaved Africans were transported across the Atlantic Ocean; 10 million between 1492 and 1867 with 50,000 of these slaves transported to the Dutch Caribbean (Blakely 1993; Eltis and Richardson 2010; Gilmore 2009; Gomez 2003; Goslinga 1973; Kandle 1985; Painter 2007). Of the millions of enslaved Africans embarked for the New World, their origin stemmed from three major regions in Africa (Upper Guinea (Senegambia to Sierra Leone), Lower Guinea (the Gold Coast to the Bight of Benin), and Kongo-Angola (West Central Africa) (Painter 2007; Eltis and Richardson 2010). Slaves destined for the Dutch Caribbean were primarily from the western portion of the first region in Upper Guinea (Eltis and Richardson 2010). 
Eltis and Richardson (2010) commented that the Trans-Atlantic slave trade was so prevalent between the years 1501 to 1867 , that any nation with a coastline along the Atlantic participated in the transportation of Africans from Africa to the Americas. The slave trade lasted 366 years and from the beginning, the Caribbean played an integral role. Spain's first shipment of captives from Africa to trade with colonies in the Greater Antilles arrived in 1501 (Altis and Richardson 2010; Armstrong et al. 2011; Blakely 1993; Dunn 2000; Gilmore 2009; Gomez 2003; Kandle 1985; Kelly 2004; Okepewho, et al. 2000; Painter 2007; Palmer 2000; Wolf 2010). Human beings became commodities high in demand and historians contribute the startling success of the slave trade to three factors. First, African traders reciprocated the desire to participate in the trade, which in turn provided amble opportunities along the African coast to do so (Altis and Richardson 2010; Goslinga 1973; Okepewho, et al. 2000; Painter 2007; Wolf 2010). Second, favorable sailing conditions in the Atlantic (winds and currents) provided merchants with ideal conditions for transport (Altis and Richardson 2010; Blakely 1993; Dunn 2000; Gilmore 2009; Gomez 2003; Goslinga 1973). Finally, an intense competition driven by greed escalated exponentially from the beginning of the sixteenth century between European colonizers to exploit the cheapest labor in order to produce and export their goods (Altis and Richardson 2010; Goslinga 1973; Wallerstein 2004).

Interest in the history of the African diaspora has steadily increased over the past three decades with historians like Edmund Morgan (2003), Michael Gomez (1998, 2003), Isidore Okpewho et al. (2000), Charles Orser (2007) and Sterling Stuckey (1987) generating discourse among multiple disciplines. The goal was to understand the social, economic, and political conditions for enslaved African living in the New World from the 
beginning to the end of the trans-Atlantic slave trade. In the beginning, attention focused on broader issues like the Middle Passage, the horrendous treatment of slaves upon and during enslavement, and the power dynamics that existed on antebellum plantations. More recently, however, scholars have more closely examined daily slave life particularly the formation of identities, consequences of racialization, the visibility of agency and resistance, as well as other more intricate aspects of enslaved individuals.

Okpewho et al. (2000) concentrated on slaves' interaction with their physical, cultural and intellectual environments in order to reconstruct the daily lives of slaves living in captivity. The reconstruction of their daily lives has even challenged assumptions about enslaved Africans and their experiences. For instance, contrary to previous assumptions, Michael Gomez (1998) proposed that the distribution of slaves in the New World from eastern ports inland was surprisingly clustered along ethnic and cultural similarities that resulted in slaves experiencing a strong sense of solidarity during their transition. More importantly, his work suggested that displaced African slaves were active participants in the New World and made critical decisions in order to ensure the survival of their families (Gomez 2003). Pons (2007:310) insisted, "One has to recognize, however, that beneath the unifying framework of the sugar plantation system distinct inclusion of traditions from their homelands helped shape these new societies. Others continue to investigate a wide breadth of diaspora topics that enrich our understanding of slave life in the past (Morgan 2003; Orser 2007; Stuckey 1987). 


\section{Historical Background: St. Eustatius - A Historic Gem}

The Dutch facilitated the trans-Atlantic trade and pan-Caribbean trade of slaves from Africa in Portuguese, British, French, American and Dutch ships through their hub on the Dutch islands of St. Eustatius and Curaçao, with St. Eustatius (known locally as Statia) taking the lead in slave transport by the mid-eighteenth century (Eltis and Richardson 2010; Gilmore 2005; Hartog 1976; Haviser 1999; Heath 1999). The Leeward Islands held a crucial role in this Caribbean network, receiving some of the highest proportions of slaves known in colonial societies, and St. Eustatius was a key player (Eltis and Richardson 2010; Hartog 1976; Peterson et al 1999:159).

The Dutch seized the opportunity to establish a free port as early as 1675 on St. Eustatius that provided the French, Spanish, and English islands with slaves (Hartog 1976:49). While the Dutch offered equal opportunities to other countries for tax-free trade, St Eustatius' free port provided the Dutch with increasing economic gain through the export of slaves and other goods (finished goods from Europe, raw materials like lumber and tobacco from North America, and commodities for export including tanned hides) (Hartog 1976; Gilmore 2005). The demand for sugar soared and those plantations once growing coffee, cotton, tobacco, and other export crops on the island were converted into strictly sugar cane plantations. A 1742 map of the island depicts 88 plantations; James Delle (1988) revealed their slow decline over the next 40 years and in 1781, only 20 remained; by 1840 , only 10 dotted the island. In just four decades, a clear economic shift from agriculture to trade occurred and continued to shape the landscape of the island. European immigrants hoping to cash in on the expansive opportunities for wealth flocked to the island, and in the eighteenth century over 22,000 residents occupied 
the island of just seven miles. St. Eustatius, known in the Dutch West Indies as being a prominent free port, had at one time over 600 warehouses lining Oranjestad Bay, and later expanded the bay area to include more (the sea reclaimed these efforts and walls can be seen underwater today) (Hartog 1976; Gilmore 2005).

Given this, it is not surprising that plantations only served two purposes; they processed illegal sugar for re-export or grew provisions for re-supplying ships that came into port with the use of slave labor on St. Eustatius and other islands. By 1725, the Dutch shipped 2,000 to 3,000 slaves per year to the island to meet both the need for planters/processors and the slave trade's demands (Hartog 1976). Slave ships brought their cargo to Statia and auctioned it to buyers from the surrounding islands. The slave trade reached its peak in the early 1770s, but towards the end of the eighteenth century, countries began to protest against the trade. The slave trade in the Dutch colonies ended in 1814, but it was not until 1863 that the Dutch abolished slavery (Hartog 1976; Gilmore 2005). St. Eustatius, with its rich, expansive history, both with the transatlantic slave trade and as a highly sought free port (taken 22 times over the course of 200 years) is the ideal location for archaeological investigations in the Caribbean.

\section{Previous Archaeological Research: St. Eustatius}

This research is a first attempt to comprehend the human experience of slaves living on Gilboa Hill on the island of St. Eustatius, in the vein that Barbara Heath (1999:3) suggested: “...even a partial story opens a fascinating window into the past, creating new understandings and raising fresh questions." Previous research in St. Eustatius has provided vital evidence through the use of the archaeological record that a diverse population resided on the island, however, to date, no archaeological 
investigations on any of the sugar plantations' slave villages in the mountainous landscape have been studied on the island. In 2008, nine slave sites were discovered during a pedestrian survey by volunteers working with St. Eustatius Center for Archaeological Research (SECAR) under the direction of Grant Gilmore to assess archaeological significance during the preliminary construction planning of a golf course/resort in the northern hills. This landscape analysis of four slave sites, including the examination of dry stone rock features found in the northern hills, hoped to assess the living environment of the people who made the success of the plantation possible.

Grant Gilmore (2010) asserted, “African Diaspora architecture and landscapes are perhaps the most accessible expressions of agency and the creolisation process to be found in the Americas." He defined and documented the variations in foundations, flooring, roofs, windows and doors, as well as the methods for heating and cooking on plantations throughout the Caribbean. He noted the plantation spatial patterning and architectural patterns in slave villages as well. His work was important in determining the differences between symmetrical spatial arrangements, spatial patterns that were affected by geographic location or environmental factors, and those that represented adherence or a continuation of traditional African design (Gilmore 2010). His use of documents as well as the archaeological reports from spatial analyses and excavations from the Spanish, English, French and Dutch-owned islands in the eighteenth century created a useful comparative framework for examining vernacular architecture.

Similar work, conducted on the adjacent island of Nevis, contributed to this investigation as well. The Colonial Landscape Project on Nevis has focused on the social processes that shaped the use of space and physical landscape patterns from colonization 
to the rise of a plantation economy (Galle 2011). Insight into the way slaves lived and interacted in the mountain settlements on the island of Nevis, gleaned from the archaeological investigations that have been conducted over the past several years, have forced researchers to consider multiple interpretations for physical characteristics or landmarks. For instance, a road has variable meanings to different communities living on the island. The same road used for a transportation route for goods might be a link in the continuation of social networking (Galle 2011). Their main focus was to examine periods of development (and the settlement patterns that reflect these periods) on Nevis through analyzing data from landscape surveys, economic data, and historical documents in order to understand these processes within a Caribbean historical framework (Galle 2011).

Archaeological research on St. Eustatius really took off in the 1980s with Norman Barka's research and excavations. Over the course of a decade, her work concentrated on the warehouses in Lower Town and provided detailed information on smuggling activities that enhanced our understanding of historic Oranjestad; extensive material assemblages are housed at the College of William and Mary's Department of Anthropology (Barka 1989; Gilmore 2009). In conjunction with this research on the mainland, between 1982 and 1988, graduate students with the College of William and Mary conducted archaeological investigations of Dutch, French, and British anchorage in Orange Bay, retrieving large quantities of material culture associated with maritime trade and seafaring during this time (Karklins and Barka 1989). During the same period, Jay Haviser and James Delle painstakingly documented most archaeological sites, both prehistoric and historic, and excavated across the entire island. Later, Grant Gilmore (2009) excavated one of the few pristine examples of a Jewish Synagogue established in 
the New World and discovered an intact ritualistic mikveh with its associated material culture. As Gilmore continued to serve the island through the maintenance of SECAR, archeologists joined him from around the world to participate in study and excavation. Examples of research include the discovery of a leper colony settlement, maritime activities (including shipwrecks), fort construction, vernacular architecture, brick oven kilns and bake ovens, prehistoric shell middens, plantations and their associated buildings, distilleries, and countless other historical gems (Delle 1989; Gilmore 2005; Gilmore 2009; Kandle 1985; Stelton 2010; Miller 2008). Gilmore (2009) also discovered the archaeological remains of a free black village (this plan map and the first 100 proveniences of excavation were used in this investigation).

Recently, in 2012, during an assessment for a new proposed oil tank site, island archaeologist, Ruud Stelten, at SECAR discovered the remains of the slave village associated with the Schotsenhoek cattle plantation; the plan map and material assemblage (approximately 2000 artifacts) were used for this project. The Schotsenhoek plantation was originally owned by Johannes de Graaf Seelig and Frances Seelig Mussenden (Hellebrand 2011). Their daughter, Alice Eliza Duggan Seelig (1816-1873), married Daniel James Hassell Every (1811-1897) and had a son, Johannes George Carl Every Sr., (1851) at the Schotsenhoek plantation who would later become not only the owner, but also a successful international entrepreneur. His marriage to the widow Anna Catharina Dijkers Farwell is interesting as her parents were Casper de Veer and Ann Cuvelje, kin to Michael Cuvelje that owned the land adjacent to the Widow Ducas' property in the Northern Hills. Are "Dijkers" and "Ducas" one in the same? This pronunciation difference is of interest and explored further in chapter six. 


\section{STENAPA: St. Eustatius National Parks}

With the increased need to protect the biodiversity and tropical ecosystems of St. Eustatius, in 1996 the island government created the national parks system to study, maintain and ultimately protect habitats on and around the island (STENAPA 2013). The islands' habitats can be divided into three main regions: the marine environment (naturally encompasses the underwater land surrounding the island), the dormant volcano, the Quill (Dutch for pit), and the five hills that comprise the Northern Hills: Boven, Venus, Gilboa Hill, Signal Hill, and Bergje (STENAPA 2013). Because of extensive agricultural pursuits in the Northern Hills in the past, lush vegetation, like the dense evergreen seasonal forest still evident in the crater of the Quill, does not exist anywhere else on the island. Instead, a thorny woodland environment exists with bromeliads, orchids, tall cactus, small cactus and pope cactus, flowering bushes and trees, cashsa trees (acacia). Other varieties of thorn bushes, gumbo limbo trees, mangrove trees, mango trees, wild grapes, and Mexican creeper dominate the landscape.

\section{Gilboa Trails}

As previously mentioned, the location of emphasis for this project was based on the findings of a survey conducted in 2009. Gilboa Hill has three main ridges that carve the mountain and STENAPA maintains three hiking trails that wind up and down the mountain. Figure 1 depicts Gilboa Trail in purple with the three ridge trails up the mountain (identified in blue, green, and red); the red trail is the third ridge of Gilboa Hill where this investigation focused. 


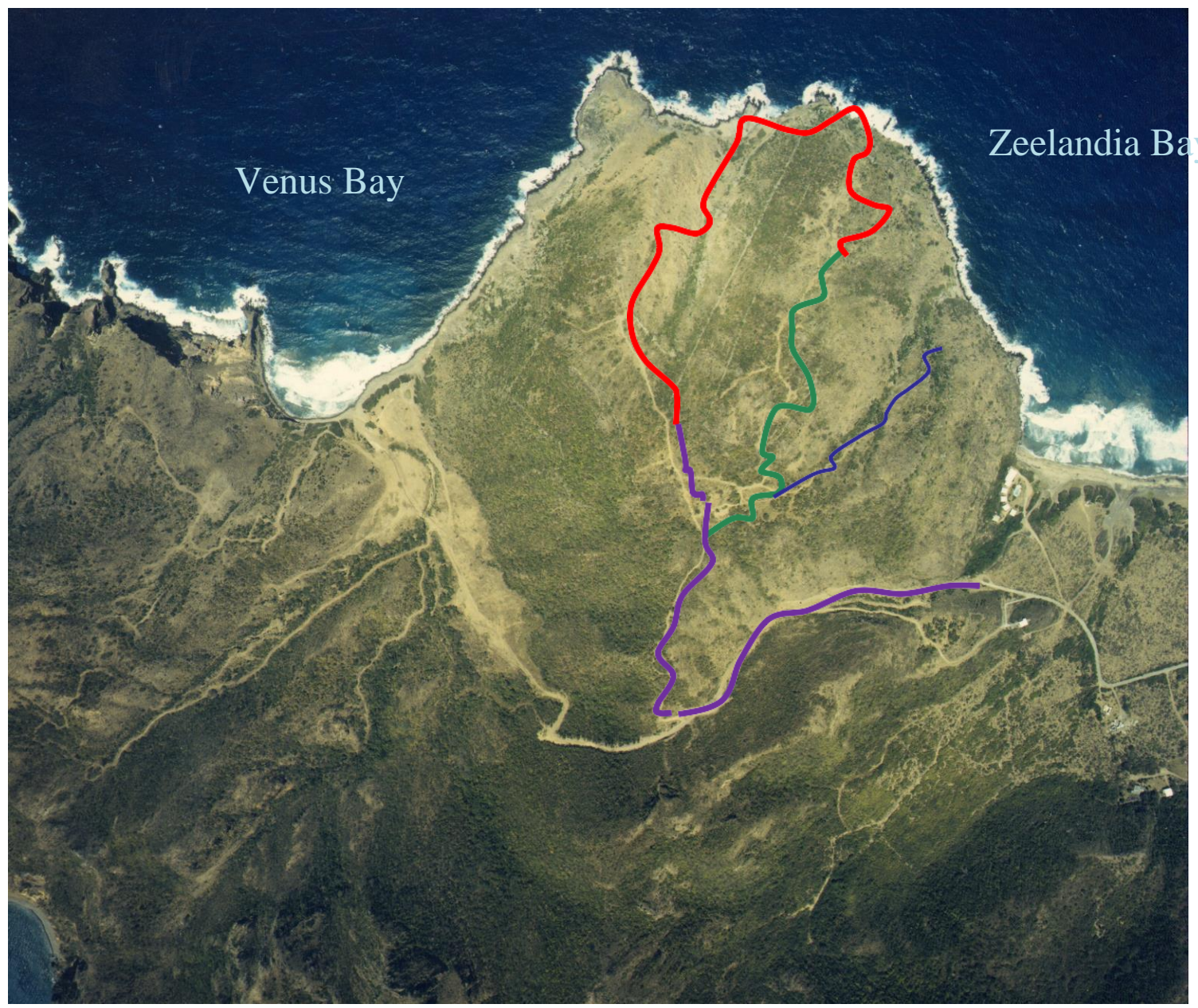

Figure 1. Third Ridge Trails on Gilboa Hill 


\section{Summary}

This chapter discussed the setting for this project and reasons for initial interest in understanding Dutch slave life in the Caribbean. The lack of surveillance and strict standardization under Dutch colonial rule I think afforded enslaved African communities higher levels of ideological freedom. Because of this, this investigation held promise in discovering marked expressions of cultural continuity in the domestic and labor environments of slaves living on the island. The next chapter will discuss in detail the theoretical underpinnings for my research as well as previous research and discourse that influenced this thesis including, but not limited to cultural continuity, power and agency, enslaved African environments, ethnographic studies, domestic structures and village environment spatial design, and the landscape of labor including terracing and provision grounds. 


\section{CHAPTER II}

\section{THEORETICAL APPROACH AND BACKGROUND}

The preceding chapter noted considerable interest in topics related to the African Diaspora and more specifically my interest in assessing whether Dutch colonial rule influenced the level of ideological freedom that enslaved Africans on St. Eustatius experienced. This chapter will discuss in detail the theoretical approaches I took and supporting research that helped to shape my investigation.

For this investigation, my research centered on two main theoretical underpinnings: cultural continuity with respect to identity and the agency enslaved populations used in shaping new communities in the New World shaped within the patronage of landscape archaeology. The archaeological record provides rich detail to explain "the use of space to the internal infrastructure of the community" and if evidence of cultural continuity exists in the archaeological record, identifying underlying ideological principles that shaped communities in enslaved African domestic and labor environments appear to be the best vantage point for such inquiry (Armstrong 1999:178).

With this, acculturation suggests a potential loss of African heritage with the adaptation and incorporation into European communities. Instead, by negotiating the oppressive conditions of slavery with their own "internally defined terms" enslaved Africans actively responded to social, historical and environmental conditions through 
more of a cultural transformation in order to foster a sense of well-being, form families and communities, and a "sense of place" (Armstrong 1999:178; Vlach 1993:236). It is these internally defined terms, Fennell (2003) suggested become emblematic symbols in community development. These symbols or expressions are "a conglomerate of ideas and feelings" and represent an underlying ideology from which new communities were organized (Fennell 2003; Ortner 1973: 1339).

For this investigation, it was important to consider how these expressions manifested across the landscape. Wolf (1971:165) suggested, "If all plantations are classstructured and conform to a basic spatial plan, they nevertheless differ in character of this class-structure and in characteristic sub-cultures of these classes." This means while a standard existed, unique deviations from this standard are evidence of possible cultural retentions and in turn reflect a population actively shaping the landscape in accordance with set characteristics of an underlying ideology. Additionally, Wolf (1971) implied labor activities on plantations were less coercive and grueling if planters afforded certain liberties to slaves from their labor and hard work. Provision grounds, or plots of land used to supplement their subsistence, certainly was one reward and is important in this investigation. While the dry stone rock features were not associated with domestic environments, they were associated with labor activities of enslaved Africans working in the area, most likely provision grounds. By focusing less on the restrictive oppressive daily regimented life dictated by the planter class and more on the value of enslaved laborers placed on community and a sense of wellbeing, we begin to open a dialogue about opportunities enslaved communities seized as a means to mediate the harsh 
conditions of slavery. These opportunities, stamped on to the landscape are important in understanding the higher levels of ideological freedom among Dutch enslaved communities.

Examining the environments of enslaved Africans in Dutch colonies holds the potential to identify tangible characteristics as evidence of higher degrees of ideological freedom. Unlike the French, British, and Spanish colonial powers suppression of ideological freedom through strict adherence to set standards in the daily lives of slaves from their dress, provisions, labor, housing and behavior, the Dutch colonial power's oversight and lack or rigidity afforded enslaved Africans greater leniency in creating their communal domestic and labor environments. With the enticement of potentially pristine archaeological environments, an established pattern of large material assemblages, and the opportunity to contribute to Statian history, fieldwork at the four sites located at the highest elevation, on the third ridge, began July 22012 and lasted six weeks. This chapter will discuss several key elements that shaped my research. I will discuss the origin of Dutch slaves, the use of ethnography, landscape archaeology, and cultural continuity in enslaved African communities: how this is defined and ways it is recovered archaeologically. Additionally, I will discuss power and agency with respect to ways it allowed enslaved Africans to be active participants in the shaping of new built environments and enslaved African domestic environments with an emphasis on domestic structures, cultural practices, provision grounds, terracing, and their material culture. 


\section{Hypothesis}

As the previous chapter has indicated interest in this project began with the potential to understand more about Dutch slave life in the Caribbean and to identify whether an increase in ideological freedom could be detected archaeologically. I propose that after a series of extensive, multi-faceted analyses, the dry stone rock features on Gilboa Hill will reveal that enslaved Africans did experience greater levels of freedom in choosing their built environments and characteristics of marked cultural continuity in enslaved African domestic or labor environments will surface. For this, I further propose subjecting the sites under investigation to multiple scales of analysis including regional, structural, spatial, and artifact. By designing my research in this way, I hoped to consider as many elements of the rich data set collected by other archaeologists, historians, ethnographers, and myself in order to address points of inquiry. I discuss these research questions in detail in the next section. 


\section{Research Questions}

The ultimate goal of my research was to determine whether enslaved Africans living under Dutch colonial rule experienced a higher degree of ideological freedom in their everyday lives and if this translated to an increased ability to be active participants in the shaping of their domestic and/or labor environments. This question can be best answered through the careful interpretation of data collected on Gilboa Hill (setting, size and shape of dry stone rock features, spatial patterning, etc.) in comparison to previous archaeological work of domestic enslaved environments on the island, in the Caribbean, in the United States, as well as to ethnographic studies conducted in West Africa. This is after I address the following questions.

First, were the four sites on Gilboa Hill associated with the Michael Curvelje plantation? This is important in helping to determine the sites' function in the mountainous landscape and my thorough examination of historical maps of the northern hills during the time of enslavement answers this question. They were not. Since sugar plantations were organized into well-planned arrangements, the location of the sites on the third ridge of Gilboa Hill appear to conflict with efficient spatial patterning noted on sugar plantations in the Caribbean. However, if they were affiliated with another sugar plantation in the vicinity, it is possible the noted terracing and half constructed walls give a clue to the dry stone rock piles' purpose in domestic or labor related activities (the building of a cistern, mill, etc.).

Second, will there be variability in artifact type, quantity, and concentration at each of the four sites? And how does this compare to other sites on the island? Given thatlarge material culture assemblages (those with slavery contexts and those without) at 
domestic environments recovered archaeologically on Statia is the norm, it is important to discern whether the artifact concentrations at these locations adhere to this pattern. They did not, but had they then the dry stone rock stone features would have been a part of a domestic context. Instead, I think the sites on Gilboa Hill were part of a labor rather than domestic environment. Additionally, by analyzing the material culture assemblages from both the Schoesenhoek slave village and the Free Black Village in addressing these two questions I can detect differences in the material culture during the transition from enslavement to freedom on the island; this is a rare opportunity.

Third, were the four sites on Gilboa Hill be consistent with known domestic or labor environments recovered archaeologically or do they share similarities with ethnographic examples? If their characteristics (setting, artifact concentrations, presence or absence of domestic architectural debris, and spatial patterning (nucleation and dispersion) are similar to two domestic village environments in the lowland region on the island, as well as to other examples in a broader comparison, then I can conclude the four sites serves a domestic function in the plantation landscape. Understanding how the sites on Gilboa Hill are different or similar not only serves to classify their function or their part in the management of labor practices, but also helps to answer whether Dutch control extended to both domestic and labor environments.

Finally, did the Dutch colonial planter class' oversight influence the levels of ideological freedom of enslaved build environments? This question is by far the most complex. To answer it, data used to answer the previous questions will first help determine if the four sites were similar to other known village environments recovered archaeologically and ethnographically. Then, the shape, size, and spatial patterning of the 
dry stone rock features when compared to other dwellings' dimensions and village spatial designs in the study will reveal whether set patterns exist. If a strong pattern of similarity exists and all dwellings on the island appear to be uniform in size, shape, not vernacular construction, not set in rows, and share similar nucleation and dispersion within the village environment, then this reflects Dutch standardization. This standardization would indicate Dutch slaves likely experienced as much control in their daily lives as other slaves did under other colonial powers in the Caribbean and in the United States. If however, the presence of standardization on the Dutch planter class is not found, like the data showed in this investigation, then conclusions can be drawn about an increased level of ideological freedom enslaved Africans on Statia experienced that helped facilitate their active participation in the design and subsequent construction of their domestic or labor environments.

With the classification of the four sites in the study as having domestic or labor context, noted marked similarities and differences to other built domestic environments recovered archaeologically and ethnographically, and the presence (or absence) of a Dutch standardization in the archaeological record on the island evaluated, my main point of inquiry can readily be addressed. Do the settlement patterns on Gilboa Hill reflect traditional continuity? The absence of a standardization in the dry stone rock features shape, size, and placement on the landscape suggests this is likely the case. More importantly, the unique deviations from an expected standardized pattern evident on other islands then become evidence of conscious and deliberate activity on the part of the enslaved community living and working in the area. 
A heated discourse centers on whether traditional African practices in the New World can be traced to a specific region in Africa. Because most of the millions of Africans transported during the transatlantic slave trade started their horrific journey at one of a few ports along the coast of Western Africa, critics claim that it is impossible to confirm specific origins of ethnicity or specific cultural affiliation. While this may be true, research that was instrumental in my research addressed this issue and I will discuss this in the next section.

\section{Unification: Ubuntu}

Community building in the New World among enslaved populations varied according to an infinite number of variables: variations in conditions of enslavement, levels of control by the planter class, size of the plantation, population size, physical, economic, and social environments, to name a few. For this project, however, I call attention to one community building principle, the African indigenous ideology of

\section{Ubuntu.}

The underlying philosophical principle of Ubuntu (prevalent in traditional societies in Africa) may have been important in slave identity formation; rather than viewing themselves as individuals displaced Africans would have preferred a communal identity; one that fostered an "interconnectedness of being" (Balcomb 2004: 70; Gade 2011; Kurzweil 2011; Sanson 2007; Van den Heuvel 2007). Since 1846, scholars have discussed Ubuntu and its ties to communities in Africa. In this century, it was cited as being influential in the development of Zimbabwe in 1980 and the new government in South Africa in 1990 by the Nobel Prize laureate archbishop Desmond Tutu and Nelson Mandala; even the former president Bill Clinton included Ubuntu in his advocacy for the 
unification of communities (Gade 2011; Van den Heuvel 2007). It has permeated and dictated the social behavior in village communities in Africa for 1500 years and has remained a pervasive philosophical underpinning of life in Africa (Gade 2011).

Ubuntu has various linguistic correlates in Africa. In West Africa for instance, this unifying principle is called Teranga, however, for the purpose of this research rather than concentrate on the etymology of the word and its variations I chose the term most found in the literature to describe this communal principle (Balcomb 2004; Gade 2011; Kurzweil 2011; Mbiti 1990; Ndaba 1994; Prinsloo 1994; Sanson 2007; Van den Heuvel 2007). It can be defined simply as humanity and explained as "a person is a person through other persons" or "I am because we are" from local African community members (Balcomb 2004; Gade 2011; Kurzweil 2011; Mbiti 1990; Ndaba 1994; Prinsloo 1994; Sanson 2007; Van den Heuvel 2007 ). Swanson (2007) and Van den Heuvel (2007) offer more; that in this African worldview a cosmic entity governs the universe and to keep the balance of the universe, human beings must live a harmonious life. To do this, humans must "seek to show respect to all living things (both those that are seen, and those that are not seen)...At times it would be necessary for a person, or group of persons, to perform some ritual action to restore equilibrium in creation, or to influence or change a state of affairs" (Kudajie and Osei 2004:37; Swanson 2007; Van den Heuvel 2007).

Scholars in the United States in an attempt to understand African folk religious expression among enslaved populations search for archaeological evidence of the rituals slaves performed to achieve this balance (Brown 2001; Deetz 2006; Edwards-Ingram 2001; Fennell 2010; 2007, 2003; Kryder-Reid 1996; Leone and Fry 1999; Norman 2009; Orser et al. 2001; Orser 1994; Ruppel at al. 2003; Samford 1994, 1994; Scott 1990; Stine 
et al. 1996; Young 2007). Rituals gave individuals a way to mediate the effects of negative influences in their life and restored balance to not only the individual, but the community too. In this light a community is built upon the role of its members and their contribution to the "wholeness" of the community; forging social relationships and cohesion was essential to the entire community's success and a harmonious life (Balcomb 2004; Gade 2011; Kolb 1997; Kurzweil 2011; Mbiti 1990; Ndaba 1994; Prinsloo 1994; Sanson 2007; Van den Heuvel 2007). A life where Africans hold "conceptions of the world where everything is intimately connected" as well as a deep relationship to their built environment meant they would have shaped their domestic and labor environments with this principle or a principle like it in mind (Balcomb 2004; Van den Heuvel 2007). Young (2007) claimed, "Certain aspects of African religions and spiritual culture were broad enough to be understood and elaborated by enslaved Africans from various regions" and I assert that this is true of an underlying community building principle like Ubuntu. Within the harsh and intrusive conditions of slavery, slaves stitched together a life for themselves grounded in communal traditions they brought from their homelands; I propose that Ubuntu would have been a uniting element in the social reorganization of displaced African slaves. Social reorganization, according to Neil Norman (2011) was occurring for thousands of years in the African homeland among various tribes. Tribes and village communities continually renegotiated, adopted, and creatively reworked social frameworks to include new and innovative members over the course of African history (Norman 2011; Wolf 2010). Ubuntu is one of the underlying philosophies of African life and is a consistent foundational element during these changes (Gade 2011). 
Mintz (1996) has suggested something similar in his research of various culturally constructed social frameworks across the Caribbean. He defines Oikoumene as the end result of a series of continual processes of social reorganization on plantations whereby slaves from various ethnic backgrounds would have structured themselves around an underlying worldview. Despite vast differences, slaves living under the harsh institution of slavery would have found commonalities to restructure themselves socially as well as acculturating incoming new members to the community around centralized philosophies, beliefs, etc. into what some archaeologists have deemed as the process of modernity (Mintz 1996).

\section{Cultural Continuity, Identity and Modernity}

According to James Delle (2008:88) modernity is the "social and intellectual cable woven from multiple strands" by which societies structure or organize their physical, social, economic, and political environments that is visible in the archaeological record. Modernity, then, can be interpreted as the process by which slaves would have incorporated or even renegotiated their personal environments during enslavement while a part of the larger plantation environment. Delle (2009) considered modernity at Marshall's Pen in Jamaica by examining the shifting definitions of relationships between space and social organization and through the spread of mass-produced goods. Julian Thomas (2004:11) argued that "the experience of modernity is one of increasing heterogeneity, hybridity, and instability," which can be understood as the complex entanglement of cultures in the process of syncretism, or creative mixing and formation of a complex, distinct new culture. 
He added as archaeology shifts away from viewing people of the past, as passive individuals and more a part of a collective cultural whole, new research will discover ways enslaved Africans shaped their physical environments to adhere to underlying motivations in social construction to foster the formation of identity in the New World (Thomas 2004). Scholars suggest as historical archaeologists, were are in a position to "work out how these connections shift and recombine" in our investigations of the creolization process (Dawdy 2000: 121). Silliman (2006: 150) cited a major problem with historical archaeological investigations, because studies favor a narrow concentration on the laborers themselves rather with respect to the larger social processes they were a part of, including the formation or retention of identity. Enslaved African laborers possibly used cultural elements, a part of their communal heritage, as "community anchors."

Palmer (2000:49) insisted, however, “Africans brought their languages, religious beliefs, musical styles, cooking practices, and a thousand other aspects of their societies with them," and given that slave communities consisted of many different ethnic groups from Africa, one can safely propose that many different "cultural forms went into the making and shaping" of slave societies in the New World (Kolb 1997). The research presented thus far suggests that Dutch enslaved Africans most likely incorporated more cultural forms associated from ethnicities in West Africa in shaping new communities.

\section{The Origin of Dutch Slaves}

While understanding unique deviations from a standard are evident of cultural continuity, this alone does not provide solid characteristics to pursue a diagnostic inquiry. A wealth of scholars caution against defining blanketed affiliation or origin to African cultural attributes when investigating and further identifying these ideological 
components of enslaved African communities in the New World (Armstrong et al. 2011; Brown 2001; Carney 200; Deetz 2006; Edwards 1994; Farnsworth 2001; Ferguson 1991,1992; Fernandez Olmos 2003; Fennell 2010; Gomez 1998; Heath 1999; Holland et al. 1998; Kahn 2003; Kelly 2008; Leone and Fry 1999; Littlefield 1981; Mullin 1992; Norman 2009: Orser 1994, 1995, 2001; Howson 1990, Orser 2004, Painter 2007; Peterson et al. 1999; Ruppel et al. 2003; Samford 1994, 1995; Vlach 1993; Wolf 1971, 2010; Wood 2003; Young 2007). Kelly (2004:230) suggested a solution, however, with the genuine comprehension of community building, or cultural creation, warranting an "appreciation of the appropriate historical contexts of African homelands." I tend to agree. In recent years, archaeologists have embarked on projects in Africa to investigate indigenous cultural traditions (foodways, architecture, folk religion, political development, settlement strategies) expressed by enslaved Africans in the New World in order to better understand the building blocks in the formation of transplanted communities, much like one would break down a recipe of its ingredients (Balcomb 2003; Beswick 2010; Bourdier and Minh-ha 1996, 201; Denyer 1978; Kelly 2004; Norman 2012; Okepewho 2000; Schoenbrun 2006). Similarly, Edwards (1994:189) suggested it is possible to "trace both the patterns of long-distance cultural diffusion and the struggles for adaption that contributed to the makeup of the new cultural landscape" by analyzing not only the evolution of this process but its base components.

Despite debate, most scholars admit research focused on West Africa as the potential origin of characteristics retained by enslaved populations in the New World is of merit. I agree. After examining ten historical maps and the research collected by David Etis (2010) and his colleague David Richardson (2010) for an exhaustive literature 
review for my thesis it appears West Africa was the location Dutch slaves originated from. This is not to say that inland villages were not exploited, they were, but even in this region several miles to transport captive human cargo for trade at coastal ports seems reasonable, but hundreds or thousands of miles as would be the case from locations in central, north, and east Africa does not. In their research of historical maps, nautical trade routes, ship manifests, and Captain's logs, Etis and Richardson (2010:241) noted from 1658 to 1825295,000 slaves were transported from the following areas specifically by the Dutch: Sengambia, Sierra Leone, the Windward coast, the Gold coast, Bight of Benin, and from West Central Africa. Additional historical documentation they examined included evidence of 150,000 slaves were transported from these regions to the Dutch islands of St. Eustatius and Curacao between the years 1657 and 1794 (Etis and Richardson 2010:239). Later, documents noted Dutch traders concentrated their exploits in West Central Africa and the Bight of Benin in transporting an additional 46,000 slaves to the Dutch West Indies annually between the years of 1676 and 1700 (Etis and Richardson 2010:239). More historical maps and documentation could only raise the totals of slaves transported to Dutch islands in the Caribbean. With this literature, it is safe to assume that the majority of Africans that comprised enslaved communities on St. Eustatius were from regions in West Africa. Because of this I considered this region in West Africa as a location to examine documented village design and dwelling construction in village environments for comparison to those found on the island. For this, the ethnographic study of vernacular architecture was extremely beneficial to my research. 


\section{Ethnography}

Orser (1996:241) insisted ethnographies “created on discrete, manageable communities" help archaeologists gather information about a site or sites and define the boundaries of a community. For this project, these boundaries appeared to reach across the Atlantic into newly formed enslaved African communities in the New World given slaves in creating new societies would have relied on previous knowledge if allowed. I chose the four ethnographic villages from Senegal found in Jean Pail Bourdier and Trinh Minh-ha's (2011) ethnographic study of the vernacular architecture of West Africa for comparison because of their location in West Africa and elements in their village design and spatial patterning are representative of the variability in the region. While climate likely played a role in construction in different West African villages as well as the access to differing building materials, the four villages have enough characteristics to suffice as a representative sample. In examining the Jaxanke (Diaxa, Madina, Senegal), Bassari (Ekes, Senegal), Sereer (Njafaj Province, Senegal), and Fulbe (Tieole, Senegal) characteristics of domestic village environments shared similar patterns. These included the generally dispersion of dwellings several meters apart with either nucleation around a central yard space or no central yard space with wider dispersion between groupings of dwellings (Bourdier and Minh-ha 2011). Other West African villages in Benin and Nigeria shared a preference for circular, square, or rectangular domestic structures with earthfast construction with readily available materials (Beswick 2010; Bourdier and Minh-ha 2011; Denyer 1978). This was of interest given dwellings in the investigation on the island, in the Caribbean, and the United States had similar shaped dwellings to West African preferences while the majority of dry stone rock features on Gilboa Hill did not; 
they were oval shaped. West African villages appear to have close proximity or nucleation with structures places only a few meters apart and close dispersions to other buildings in the village environment. While dry stone rock features did not conform to the shape of dwellings in West African villages, their nucleation and dispersion closely resembled the spatial pattern of a village. I decided to examine the setting, dry stone rock features, and the spatial patterning at each of the four sites on Gilboa Hill more closely to understand why this was the case.

\section{Power and Agency}

Michael Mann's (1986) theory of social power suggests that as one group asserts power over another (as with the case of plantation owners and slaves) they do so on three distinct levels: economic, militaristic, and ideological. Slaves living on southern antebellum plantations in the United States slaves would have been heavily controlled by their masters, most certainly in a militaristic fashion with beatings, confinement and physical constraint, but also economically. Only some slaves made and sold pottery or had the privilege of having provision grounds to sell surplus food; others were forbidden to do so. Slaves relied heavily on their ideological freedom to maintain religious practices and quite possibly spatial organization in their villages. James S. Scott (1990) suggested hidden transcripts were used to resist the oppressive nature of stated, suggested, and imposed forms of power (Leone and Fry 1999). Slaves living on plantations would undermine this power through the daily and subtle expressions of ideological freedom. For this study, I assessed whether spatial organization of the slave villages on Gilboa Hill had identifiable characteristics attributed to the formation of hidden transcripts. 
Sherry Ortner (2006) viewed agency as the forms of power individuals or communities have at their disposal, their ability to make decisions or act on their own behalf, influence other people and events in accordance with this will, and maintain some kind of control over their own lives. She noted that agency is never a thing in itself but is always a part of a process of structuration, the making and remaking of social and cultural formations (Giddens 1979; Ortner 2006). I further add that intentional collective action on the part of the slaves living on Gilboa Hill challenged the plantation owner and slavery system's dominance over them and allowed for greater autonomy to maintain ideological practices that contrasted and even undermined the society within which they were embedded (Dobres and Robb et al. 2000).

Naturally, enslaved Africans would have to adapt to the possibilities and limits of the landscape and climate they found themselves in, as well as physical hardship and constant repression, but the isolating and confining world of work made it necessary to forge links that would allow families to form and communities to develop (Wood 2003). Peter H. Wood (2003) suggested families played a vibrant and essential role in the continuity of African values and cultural patterns. "Without their community to confirm and reinforce their families, religion, and folk beliefs," (as well as other traditions) "the individual slaves would have had only the master's definition of their existence" (White 2000:190). Human nature ultimately resists complete dominance, and through the establishment of communities resistance took many forms: calculated, spontaneous, covert, direct, physical, psychological, individual and collective (Wood 2003).

For this investigation, I wanted to discern the level of influence of Dutch colonial power had on enslaved populations' ability to maintain traditional community 
construction both in the domestic and labor environments on St. Eustatius and I think examining the landscape on Gilboa Hill provided the opportunity to assess the labor of enslaved Africans working on the island.

Work dominated the lives of enslaved Africans on Statia, but the nature of that work varied based on the owner and necessity. Wood (2003:56) suggested the Africans who survived the middle passage "brought numerous skills with them" to this work and upon arrival into this new labor community "built upon an existent knowledge base" by acquiring new skills. Archaeological investigations consider skills enslaved Africans possessed, built upon, and used in labor to make Afro-Caribbean wares (colono-wares in the United States), crafted metalwork, basketry, herd management, provision grounds and domestic gardens, textiles, etc. (Adams 1989; Bates 2002; Deetz 2006; Ferguson 1992; Haviser 1999; Heath 1999; Heath and Bennet 2009; Ruppel et al 2003; Young 2003). Some reveal enslaved Africans were chosen specifically for their noted skills, like those on South Carolina rice plantations for their technical skills in the cultivation, harvesting, and processing of rice; skills they had acquired farming in the "rice coast" (Senegal to Liberia) (Atha 2012; Carney 2001; Littlefield 1981; Silliman 2006; Wood 2003). Unfortunately, the lack of extensive research into the landscape whereby enslaved Africans would have used these skills, either old or new, presents a problem and warrants further research. My research attempts to add to this important topic of study.

\section{Landscape Archaeology}

In order to investigate the mountainous, plantation landscape in the northern hills on the island of St. Eustatius effectively, I approached my research using principles in landscape archaeology. Landscape archaeology, defined by Renfrew and Bahn (2000), is 
the study of human activity patterns over a wide area by examining features that are part of a wider, much broader perspective. Focus has broadened in archaeology in part to the awareness of non-site evidence, artifacts and field boundaries, to study whole landscapes rather than just individual sites on the landscape (Ashmore and Knapp 1999; Crumley and Marquardt 1990; Bruno and Thomas 2008; Deetz 1990; Delle 1999; Hall 1966; Heath and Bennett 2009; Hodder and Orten 1976; Hood 1996; Ingold 1993; Kolb Kryder-Reid 1996; Madry 1990; Mitchell 2002; Orser 1995; Pulsipher 1994; Renfrew and Bahn 2000; Ruppel at al. 2003; Strang 2008; Tilley 2010; Yamin 1996; Yentsch 1996; Young 2003). In this approach, visible traces on the surface offer clear evidence to understand how humans exploited their environments through land management and use (Ashmore and Knapp 1999; Crumley and Marquardt 1990; Bruno and Thomas 2008; Deetz 1990; Delle 1999; Hall 1966; Heath and Bennett 2009; Hodder and Orten 1976; Hood 1996; Ingold 1993; Kryder-Reid 1996; Madry 1990; Mitchell 2002; Orser 1995; Pulsipher 1994; Renfrew and Bahn 2000; Ruppel at al. 2003; Strang 2008; Tilley 2010; Yamin 1996; Yentsch 1996; Young 2003). Further, Renfrew and Bahn (2000) insist landscape archeology allows for the identification, and further investigation, of multiple dimensions within a particular landscape; rather than merely examining utilitarian dimensions revealed in land-use analysis and interpretations, cognitive dimensions emerge that offer potential insight about the people living in those environments in the past.

James Deetz (1990:4) suggested, "The cultural landscape is the largest and most pervasive artifact with which we as archaeologists must deal.” Some archaeologists have suggested that the physical elements of the landscape work to constitute human society as 
"the physical landscape is incorporated into culture" and an approach that considers the interaction between the physical and cultural reveal evidence of "complex and multivocal layers of meaning" (Hood 1996:123, 125). Hood (1996:125) proposed that "the material world of dwellings, routes of movement, zones of resources, work areas, play areas, fields, and wilderness not only frames daily experience, but also provides the physical infrastructure with which material production is carried out." Cosgrove (1985:14) wrote, “...the impact of human agency in altering the physical environment serves to remind us that landscape is a social product, the consequence of a collective human transformation of nature.” Yentsch (1996) similarly advocated for the careful search for symbolic messages that are an integral part of wooden fences and dirt paths because it is in the subtle details of the physical attributes of our daily lives within which our culture is richly embedded.

Tim Ingold (1993) viewed a landscape as a story and saw merit in understanding the daily activities that make up its body. Further, he believed that people living at a particular location as a community work together to complete everyday activities through "taskscapes" (Ingold 1993:64). A landscape, therefore, "is not a natural feature of the environment but a synthetic space, a man-made system functioning and evolving not according to natural laws but to serve a community" (Jackson 1986:68).

Archaeologists have suggested the location of slave villages reinforced slaves' inferior position in the landscape and in turn, they resisted the surveillance and other means of maintaining control the planter class used in a variety of ways (Edwards-Ingram 2001; Epperson 1990; McKee 1992; Lehik 2012). One way was by establishing gardens with traditional medicinal herbs used for healing thereby embedding symbolic meaning 
in their garden spaces (Edwards-Ingram 2001; Epperson 1990; McKee 1992; Lehik 2012). Because two of the four sites (those with identifiable terracing) had large Agave groves likely planted during the time of slavery, I thought their presence on the landscape might have been symbolic in some regard. This was heightened by the discovery of their placement in the landscape in more rugged terrain, on the outer boundary of the plantation, and behind a large structure out of view. Given the majority of activity in the daily lives of enslaved Africans centered on labor, I chose to examine labor environments more closely.

\section{Enslaved African Labor Environments}

\section{Cultural Practices: Yard Sweeping}

One consideration in the internal spatial organization of village environments is the use of yard space. Edward Hall (1966) and Amos Rapoport (1993) defined these spaces as arenas; these arenas include the existing architectural components, the furnishings and behavior (see also Heath and Bennett 2000). Yard sweeping (ritually sweeping the dirt and debris in one's yard from the house to the gate) was used by African slaves to direct the power of spirits in their yard away from their dwellings and was an assertion of the ability to defend oneself and their family (Heath and Bennett 2000; Ruppel et al. 1999). Ruppel et al. (1999) have detected yard sweeping through archaeological investigations (artifact concentrations away from structures and near site boundaries) and suggested yard sweeping is one of many ways enslaved Africans' traditional beliefs resulted in cultural continuity.

If plotted surface collection distributions show visible concentrations away from existing architectural components, then the slaves living on Gilboa Hill during its 
occupation might have practiced the traditional African practice of yard sweeping in their domestic or labor environments. Because surface collections suffer less from horizontal displacement than vertical displacement, it may be possible to detect the traditional African ritual of yard sweeping (Heath and Bennett 2000; Ruppel et. al 1999).

In the Caribbean, men were cited as examining and clearing the land, while woman worked the provision grounds and sold surplus provisions at markets; this suggests within enslaved African communities there was a sexual division of labor (Hauser et al. 2011; Reeves 2011:187; Berlin and Morgan 1993:33). Additionally, children and the elderly worked in gardens or provision grounds alongside the women (Hauser et al. 2011; Reeves 2011:187; Berlin and Morgan 1993:33). For this investigation, the gender of enslaved Africans in the labor force was not fully explored, but this does offer insight that not only were each of the sites possibly attributed to different labor activities, but each community member likely had a role in the landscape of labor as well. 


\section{Dry Stone Rock Construction}

Mariana Cook’s (2011) photographic project on dry stone rock walls from various cultures offered insight into the variability of dry stone wall function all over the world and her photographic study aided in my ability to interpret the dry stone rock features I found on Gilboa Hill. Dry stone walls are definitive in their construction of only fitted dry stones (or rocks), lack of mortar for adhesive, strength (often enduring hundreds of years), and variability in function (Cook 2011). Working walls reflect the history of their location and often built using stones nearby (Cook 2011). She accounted, slave walls (dry stone rock walls built by enslaved workers) on a former Kentucky plantation share striking similarities to slave walls constructed in England (on land once owned by a Jamaican sugar baron) (Cook 2011). Similarities in dry stone wall construction cross cultural boundaries it would seem given they share similar basic components that are reworked by the labor force that built them.

"Every wall can tell a story about its maker once we understand the language that stone speaks," expert dry stone wall artist, Dan Snow (2001:100), professed. His experience in examining, rebuilding, and creating dry stone walls in the United States and across Europe for over fifty years offers insight into the use of dry stones in the landscape of labor and I used his architectural study to help interpret the dry stone rock features I found on Gilboa Hill as well. Snow (2001:25) claimed, “...what might look to you and me like an arbitrary mound of fieldstone can, when stone is removed, reveal the logic in its location: a blister of bedrock... because grass couldn't grow there anyway, it was a natural spot to deposit picked stone (or drift stone)." In his work, he ultimately seeks "treasure troves" of these loose stones for construction; he alleged these stones are "the 
ancient crumblings" of the ledge face located downslope on steep terrain and can be spread for hundreds of yards to create "blockfields" or spans of scattered stones across the landscape (Snow 2001:25).

Sydney Mintz (1974:236) said, the methods for "removal of stones for walls...were developed, again probably by combining different traditions of land use" brought with enslaved Africans from their homelands, taught at the plantation, or reworked within enslaved African communities; ultimately dry stone rock features served two purposes across the plantation landscape: to construct walls or to tan hides. With this, reflecting on Jay Haviser's (2012) account of dry stone rock features on the island of Curacao is important. When consulted to assist with the identification of the dry stone rock features in the northern hills, he said all dry stone rock features on the island shared striking similarities to the size and shape of dry stone rock features used on Curacao to construct dry stone walls or pile up to tan hides; given the location in the northern hills, this was certainly a possibility to consider, in his opinion (Haviser 2012).

For tanning, dry stones were piled into small, solid mounds and hides were laid atop of them to dry and harden. In St. Eustatius, 756,000 hides were exported in the year of 1779 alone (Mintz 1974:138). While it can be assumed a great majority of these hides originated from other islands and then were exported from Statia's freeport in the bay, at least some were likely tanned by the labor force at one of the cattle plantations on the island (like the Schoenshoek plantation). Dry stone rock features on Gilboa Hill shared similar size (circular and oval) and spatial patterning at each of the sites; this is not expected if the dry stone rocks were simply gathered to clear the land. Instead, I think they were intentionally grouped by enslaved Africans working in the area for an intended 
purpose, including tanning hides. Unfortunately, the historical record was silent on what labor activities were conducted in the northern hills and no material culture associated with tanning hides (lithic, animal bones, metal refuse, etc.) was recovered archaeologically. Despite this, it is a function to consider for circular and oval dry stone rock features on Gilboa Hill.

This function, like animal husbandry, reflect the possible evidence of a taskscape, or taskscapes, much like Ingold (1993) defined. Enslaved Africans working in these areas worked together to procure stones from the immediate area for specific purposes. Their communal efforts were further evident by an indication they attempted to pile rocks together in consistently shaped and of relatively the same size at each given site. It is possible enslaved Africans working in the area initiated this taskscape for their own gain on land their owners secured for them for provisioning or other related labor activities including animal husbandry and tanning hides.

\section{Provisioning Grounds}

Provision grounds originated with plantation production to provide sustenance for enslaved labor, first in use in the Caribbean region by the Portuguese, then the Dutch as early as the sixteenth century (Berlin and Morgan 1993). The Dutch clearly had a long established preference for their use for almost 300 years. Given this, I think it would have been a staple on most if not all Dutch islands despite its lack of depiction on historical maps. By the nineteenth century, however, provision grounds were widely used and noted as the main subsistence strategy used in the Caribbean (Armstrong 1999, 2001, 2009; Bates and Galle 2012; Delle 1998; Heath and Bennett 2000; Higman 2001; McKee 
1992; Mintz 1974; Pulsipher 1994; Ruppel et al. 2003). While there were exceptions, for instance, some British planters opted to feed slaves exclusively with imported provisions to avoid the loss of labor for sugar production when enslaved Africans worked their own land (Berlin and Morgan 1993). But by emancipation, 3/4 of all enslaved Africans fed themselves through the cultivation of their own provision grounds; these lands used in cultivation were often located in "hilly or mountainous land - known as gutsides in the Leeward Islands that bordered great estates" (Berlin and Morgan 1993:25). They contributed greatly to the slave economy through the sale of excess crops at either markets or within nearby municipalities. Physician George Pinkard claimed Barbadian markets in the nineteenth century, at least, "depended almost entirely" on slave enterprise with thousands of enslaved Africans piling into the market place on the weekend; he later added this enterprise kept whites from starving (Berlin and Morgan 1993:30).

Sidney Mintz (1974:236) noted enslaved Africans in the Caribbean grew "their own subsistence on plantation uplands, using lands unsuitable for major plant crops," while "the huts of slaves, unlike provision grounds, were regularly located near the center of the plantation itself." While this is not a set pattern for every plantation in the Caribbean, it was certainly one established pattern to consider. Studies in the Caribbean revealed enslaved African communities grew the following crops in their provision grounds either in flat plots or terraces: guinea yams, okra, corn, sweet potatoes, potatoes, tomatoes, cabbage, carrots, breadfruit, yucca, as well as citrus, avocado, papaya, soursop, mango, coconut, and akee trees (Mintz 1974:236). 
Crumley and Marquardt (1990:73) suggested the decisions enslaved Africans made, as well as the energy they extended, to develop community settlements was to adhere to set preferences, needs, or even experiences of the community. I think the construction of terracing and the cultivation in provision grounds illustrates this perfectly. Bates and Galle (2012) studied the provision grounds on the British Caribbean islands of Jamaica and Nevis using a detailed landscape analysis, initially, and then systematic test pits to consider spatial organization and the level of economic advantages slaves experienced using excess produce as commodities. Their investigation revealed that Jamaicans utilized more of their provision grounds to achieve economic gain and this was evident in the increased amount and variability of European ceramics in the material culture (Bates and Galle 2012).

Slaves on mountainous islands like Jamaica were initially allotted the land next to their slave quarters to cultivate large gardens for domestic consumption, but over time the need to expand land used for cash crops on plantations forced slaves to utilize provision grounds that were assigned to them (Heath and Bennett 2000). These provision grounds were often in less desirable locations further up the mountains and slaves would have travelled great distances to cultivate this land (set in plots with unique size and shape) in order to have a surplus to sell at local markets (Armstrong 1999, 2001, 2009; Bates and Galle 2012; Delle 1998; Heath and Bennett 2000; Higman 2001; McKee 1992; Pulsipher 1994; Ruppel et al. 2003).

Early accounts on St. John, in the 1730s, depict provision grounds on less desirable land on the periphery of plantations as a perfect solution for plantation owners' 
to feed their slaves, they saved money when they allowed them to grow their own food (Olwig 1993). Provision grounds were important indeed, historical accounts on Nevis from 1776 to 1783 report the deaths of over 3000 plantation slaves from starvation when drought plagued the island (Olwig 1993). Similarly, on the island of St. Eustatius slaves were allowed to carry this surplus of produce to the center of Oranjestad to sell at the local market for blue beads (Gilmore 2009).

Ruppel et al. (2003:4) suggested while garden spaces, like those in provision grounds, were dominated and overseen through surveillance, the "garden could conceal a hidden transcript, one that spoke of desires to preserve cultural and religious values, to maintain family stability, and to achieve freedom”. Further, these transcripts would be laden with embedded meaning, allowing gardeners to engage in cultivation activities in an environment rich in personal symbolism while the planters were seemingly unaware; this allowed their resistance to the dominating planter class and the continuation of their culture to be "hidden in plain view" (Ruppel et al. 2003:5). Another consideration is that provision grounds in containing embedded meaning, also facilitated the cultural retention of folk medicinal practices. Edwards-Ingram (2001) suggested herbal remedies were an integral part of the lives of enslaved African women and their children and the cultivation of medical plants would have acted to help shape their communal identities in new communities. Much like spiritual leaders, women's extensive knowledge of traditional botanical remedies acted to provide "solidarity among the enslaved community" as individual roles served the community as a whole (Edwards-Ingram 2001:38). Michael Curvelje's family is of special interest, then, given the probate indicated only women and 
children slaves (three women and eight children) resided at the plantation in the latter part of the nineteenth century. Given the Widow Ducas was probably around the same age as the Widow Curvelje, can we assume her enslaved population residing with her were women and children as well? Unfortunately, without further historical documentation to provide conclusive evidence of gender of the Widow Ducas' slaves, we cannot be certain whether the suspected provision grounds belonged to women, but does pose interesting questions for future research. Given Agave, more specifically Agave Virginica (not quite as large as the species found in the northern hills), was found to be used in folk medicine within enslaved African communities in the United States, it seems appropriate to consider the Agave cultivated near terracing at GH14 and GH15 as a potential intentionally planted crop (Covey 2007).

Sugar was cultivated through a slash and burn method after an extensive growth cycle of 15-16 months before cane was ready to harvest (Reeves 2011). Cane was cut, cleaned, stacked, and cooked in a timely manner to ensure none of the cane spoiled (Reeves 2011). It usually required large expanses of land for cultivation, although on some Caribbean islands it was cultivated using extensive terracing set into the mountainous landscape (Carrington 2002; Reeves 2011). These terraces share similarities with those noted downslope from sites GH9 and GH10 on Gilboa Hill's third ridge, near the second ridge, (Appendix B). The terracing at the four sites in this investigation, however, do not share similarities with terracing used for sugar cultivation given their dry stone rock wall lengths are much shorter, they have weaker integrity, and are built into a far more rugged topography. 
In addition to the steep elevation on Gilboa Hill's third ridge, the four sites in this investigation were littered with dry stone rock piles, large boulders and trees likely on the landscape during the time of enslavement; the four sites were rugged and clearly not suitable for the expansive cleared land required for the cultivation of sugar. If enslaved Africans working on St. Eustatius (like those in the northern hills) were cultivating sugar across the plantation landscape, given the length of time to harvest sugar cane it is possible they were engaged in other labor activities including cultivating their own crops for self-sustenance.

\section{Terracing}

If we are to rethink what tradition means, more so the bond that unifies men, women, and the materials they use, or even choices they make, then it can be seen as a perpetuation of a knowledge or an ethnic worldview. Renfrew and Bahn (2000:203) offered, "Terracing involves cooperative effort on the part of a whole community," rather than the activity of a few select workers. The terracing observed on Gilboa's third ridge, then, becomes a clear indication of planned and cooperative labor. This would extend to enslaved African labor environments. St. Eustatius notably has irregular rainfall and this

discouraged agricultural pursuits, even though sugar was "extensively cultivated well into the nineteenth century (Dethlefson 1982:73). To mediate this lack of consistent rainfall, terracing was used in the northern hills. Terracing by definition is an intervention strategy for methods of cultivation where erosion, or the loss of soil and water, downslope is eminent and has been extensively studied throughout the world from South America to Asia (Atha 2012; Benfer and Enriquez 1987; Kelly 2008; Treacy and Denevan1994). 
General typologies includes: weir, sloping dry field, bench, valley floor, wet field, and barrage (Benfer and Enriquez1987; Enfari et al. 1982; Treacy and Denevan 1994). It is this last type of terracing on Gilboa Hill shared the most similarities with sloping platforms, stone walls, filled by erosion and segmented in rows (Treacy and Denevan 1994). This type was first identified by Spencer and Haley in 1961 in Southern Israel (Enfari et al. 1982). Their purpose is to harvest water from occasional heavy rains like those in the Caribbean during the rainy season and enslaved Africans working at these four site locations would have found them to be incredibly useful in the prevention of erosion given the slopes on Gilboa Hill's third ridge are quite steep. More directly, this terracing is extensive and required exhaustive labor on the part of enslaved Africans to build and maintain them. I think the terracing is the most conclusive of all the evidence I have found of traditional continuity as it attests the enslaved Africans in this region working closing together in cultivating provisions for their community members.

\section{Agave}

As no historical documentation to date notes Agave's use in provision grounds and no archaeological investigations have considered it in the plantation landscape in the Caribbean, the large Agave groves at GH14 and GH15 appear to be anomalies. Agave, I argue, however, is a native species and has possible been overlooked until now. Since most investigations into the provision grounds of enslaved Africans has focused on cash crops either for consumption or to sell at local markets, this is likely the case (Armstrong 1999, 2001, 2009 Bates and Galle 2012; Delle 1998; Heath and Bennett 2000; Higman 2001; McKee 1992; Pulsipher 1994; Ruppel et al. 2003). 
Agave once initially planted from offshoots (not seeds) self-propagates for centuries and is quite hardy (Thurston and Fisher 2006). To harvest Agave a spade is used to cut the heart from the center of one of the mature stalks shortly after it flowers, which can take up to nine years and after the plant dies leaving new offshoots (Thurston and Fisher 2006). The water from where the heart is harvested is cooked and left to ferment for to two days to cook a beverage called pulque (Thurston and Fisher 2006). Once fermented, it must be used quickly within three to five days (Thurston and Fisher 2006). The heart is also cooked in a large vat and ground into a paste (Thurston and Fisher 2006). It has a similar rate of spoilage, but provides vitamin C, iron, protein, and carbohydrates to indigenous diets (Thurston and Fisher 2006). This process suggests Agave was not regularly harvested, probably on an as needed basis, or more opportunistic when flowers bloomed, given its short shelf life. No evidence at GH14 or GH15 was recovered archaeologically to support the Agave groves at these locations was intentionally planted, harvested, or processed (vats, fire pits, or spades). Then again, it is possible I did not find it at this time.

Agave is important to consider for this investigation for several reasons. First, it was not located anywhere else on the third ridge which suggests the groves at GH14 and GH15 were likely intentionally planted near the terracing as part of provision grounds used by enslaved Africans living and/or working in the area. Second, sugar was not given to slaves in provisioning on most Caribbean islands, they had to use molasses or agave (Armstrong 1999, 2001, 2009 Bates and Galle 2012; Berlin and Morgan 1993; Delle 1998; Heath and Bennett 2000; Higman 2001; McKee 1992; Pulsipher 1994; Ruppel et 
al. 2003). Third, enslaved Africans cultivated ginger, arrowroot, gums, and oil nuts to sell at local markets in addition to their regular subsistence crops, not sugar (Berlin and Morgan 1993). Fourth, Agave fibers were used by enslaved Africans and indigenous populations to make shoes, clothing, rope, baskets, and hammocks (Thurston and Fisher 2006). And finally, Agave might have been used in folk medicinal remedies within the enslaved African communities (Covey 2007). For these reasons, Agave is important to keep in mind for this study.

\section{Enslaved African Domestic Environments}

This comparative analysis attempted to investigate the extent to which the architecture and spatial orientation on Gilboa Hill reflected traditional African architectural and spatial patterning practices. Much like those designed using a communal Ubuntu principle because I think enslaved communities on Statia experienced a higher level of ideological freedom that allowed them to negotiate their built environments, even if they did not, they would have resisted complete control in a myriad of ways that are discernable from the archaeological record. Through the comparison of the spatial organization in the proposed slave villages on Gilboa Hill to other spatial patterning analyses in historical archaeology, both on and off the island, as well as ethnographic studies, similarities and differences were noted. For instance, while dry stone rock features did not conform to shape and size dimensions of other dwellings in the study the spatial patterning (nucleation and dispersion) was consistent with slave village environments. Through analysis of these similarities or differences it is possible to assess the varying levels of ideological freedom slaves experienced in their environments. 
I assert, more ideological freedom might have led to the retention of African traditional spatial patterning practices and village organization, or at the very least, a stronger presence of an Ubuntu-like principle in the blending of traditions.

Delle (1998) suggested that the daily labor regime for slaves was less severe on sugar plantations than on coffee, tobacco, and other plantations and extensive resources would have been put toward the construction of productive sugar cultivation spaces. This would have allowed slaves the freedom to design their village settlements in whatever way they wanted or could (Delle 1998). Contrary to his argument that the rugged terrain of the Blue Mountains on the island of Jamaica would have "inhibited the construction of symmetrically ordered villages," I argue that the physical landscape was not the only factor that contributed to the lack of symmetrical ordered villages. The heightened freedom given to slaves to design and construct their own village settlements offered the ability to choose their spatial pattern. This investigation of the landscape on Gilboa Hill assessed spatial orientation and evaluated if increased levels of freedom were at work in the construction of their domestic and work environments.

Archaeologists have become increasingly interested in the levels of freedom slaves experienced in designing their village settlements and constructing their cabins or slave quarters (Armstrong 2011, 2009, 2001; Beswick 2010; Deetz 2006; Delle 1998,1999, 2008; Denyer 1978; Ferguson 1992; Fesler 2004; Heath and Bennett 2009; Heath 1999; Higman 1988; Kelly 2004; Leone and Marie Fry 1999; MacDonald and Morgan 2012; Mullin 1992; Orser 1998, 1996; Ruppel et al 2003; Vlach 1993, 1993; Voss 2010). Edwards (1994: 155) noted "In comparing the plans and other architectural 
features in colonial houses of the Spanish Caribbean, their French and English derivatives in the Antilles, and the Creole cottages of the Gulf Coast and Chesapeake Tidewater, one cannot help but be impressed with the similarities," and I think this is impressive; it attests to a pervasive thread that unifies their construction. Is it possible this unifying thread has underlying elements that are a part of cultural continuity? I think so. MacDonald and Morgan (2012) shared my view when excavation at the Coincoin plantation revealed earthen architecture from 1781 - 1816 had "wooden posts...placed at the margin of walls, or embedded within them, rather than transversing them," which is strikingly similar to some West African rectilinear, rammed earth traditions where timber supports are widely spaced just as dwellings are among the Igbo, Yoruba, Benin, Togo and Ghana of Africa (Denyer 1978). Analysis of Spanish colonial military settlements determined the Reglamento in 1772 specified presidio settlement patterns including shape or form (quadrangle), wall construction specifications, and defensive characteristics (single row housing lining the edge of the rectangular plaza) (Voss 2010). This is not surprising as it is similar to the Code Noir used by the French and amelioration efforts used by the British to standardize slave housing and village environments from 1798 on (Carrington 2002). What is interesting is despite this standardization, slaves would have found subtle ways to resist.

Teresa Singleton (2001) documented slave quarters' spatial organization on Cuban plantations in prison like quarters called barracones, and the level of control exerted by planters in an attempt to organize the spatial arrangements to maximize the enslaved labor force's productivity. She determined that slaves living in these highly 
controlled prison-like compounds still exercised some level of control over their living conditions overtly (ran away, planned rebellions, and took their or their owner's life) and covertly (in everyday life activities, material culture, refusal to work) (Singleton 2001). While she did not look at the landscape of labor in the light that I am studying it in a sugar plantation setting, her study was beneficial in not only understanding the relationship of control and resistance between planters and slaves, but documented how Spanish planters often took measures to quell slave rebellions by improving living condition. This is an important contrast because for the Dutch, this was standard practice from the beginning. On plantations in the Caribbean it appears there was variation in the level of control asserted by the planter class, leaving slaves the choice to incorporate traditional or renegotiated traditional design elements in their village settlement. Traditional African design elements would have included scattered patterns of dwellings around a centralized yard space for communal activities (Armstrong 2011, 2009, 2001; Delle 1999, 1998; Ferguson 1992; Vlach 1995, 1993).

Lenik (2012) examined the spatial patterning on mission plantations that used slave labor in seventeenth-century French Martinique, Dominica, and Guyana and determined that the importance placed on surveillance varied in the Caribbean. While measures were taken to guide the construction of slave villages by missionaries they did not focus on maximizing productivity or overly controlling their enslaved labor force (Lenik 2012). This suggests that varying levels of ideological freedom would impact slave settlement patterns, both from within the slave communities and from the planter class. 
On typical antebellum plantations in the United States plantation owners or overseers designated areas of land on the plantation for slaves to use for settlements and had specific size, methods, or even restrictions for them to follow during their construction (Heath 1999; Vlach 1993; Delle 1998; Ferguson 1992; Fesler 2004; Ruppel et al. 2003; Young 2003). The yardspaces, or enclosed outside areas, were extensions of their living space and were used for daily activities including cooking, laundering, gardening, worshipping, and socializing (Heath 1999). Evidence from the construction of slave quarters, their spatial arrangement, and evidence of daily activity are found in the artifact concentrations, cooking pits, and remnants of physical features and fences on plantations sites (Heath 1999). My research weighed heavily on identifying whether the four sites on Gilboa Hill were either domestic or labor related, therefore, I focused the bulk of my fieldwork to try and gather as much information about the settings, artifact concentrations, and remnants of physical features (including spatial patterning) as possible. When it became apparent the sites were likely a part of a enslave labor environment rather than domestic in nature, I decided to concentrate more effort in broadening my search to include the peripheries of the sites, vegetation, terracing, and to determine if cultural practices like yard-sweeping were detectable.

\section{Domestic Structures}

My understanding of the dry stone rock features on Gilboa Hill and their placement in the landscape hinged on identifying whether they were a part of a domestic or labor environment and it was necessary to use established models of domestic space for comparison. Traditional dwelling... “embody a society's collective perception of the 
role men and women play in the universe and the relationship they maintain with their physical, sociological, and spiritual surroundings" (Bourdier and Minh-ha 2011: 7). This suggests domestic dwellings, given the opportunity, become as much a part of the community as the population that resides within them. I believe the increased ideological freedom experienced by slaves living on the Dutch occupied island of St. Eustatius gave them the opportunity to practice some level of traditional continuity in the construction of their domestic structures with building principles that would have acted to unify them within the confines of enslavement, like the ideological philosophy of Ubuntu. The discovery of the Schoenshoek slave village on the island in 2012 acted to substantiate this hypothesis (Stelten 2012). Unlike slave communities living in the Caribbean and Latin America living often in barrack-style living quarters, enslaved Africans on Statia chose the construction of their dwellings, which favored traditional African village architecture, and adhered to traditional village orientation in their placement (White 2000).

Bridenbaugh and Bridenbaugh (1972) and Carrington (2002) found through extensive research in the Caribbean that vernacular architecture in enslaved communities consisted mostly of wattle and stick huts with thatched roofs and slaves slept atop wooden planks on dirt floors. Research on St. Eustatius and neighboring islands found similar dwelling construction (Gilmore 2012, 2013; Higman 1998, 2001). Dwellings were all rectangular shape with less than $6 \mathrm{ft}$. in length until Amelioration effort began after 1798 to standardize enslaved African village housing (Bridenbaugh and Bridenbaugh 1972; Carrington 2002; Higman 1998, 2001). Then, efforts shifted, but dwellings were still constructed of wood, rectangular, and about the same size 
(Carrington 2002; Higman 1998, 2001). This was of interest to this investigation given all of the structures recovered archaeologically at the SSV conformed to this pattern, all were rectangular and constructed of wood. Similarly, each of the structures at the FBV were also rectangular in shape, however, they had stone foundations. If the dry stone rock features on Gilboa Hill were rectangular and shared similar construction and size dimensions of known enslaved African dwellings, their function on the landscape might be determined. This was not the case; only four dry stone rock features out of the 199 compared that were not half constructed walls or terracing walls were archaeological features from Gilboa Hill. The dry stone rock features on Statia are unique.

Deetz (1996) carefully documented many traditional African architectural elements evident in slave quarter construction in North America. He asserted that in North America African Americans were not permitted to construct their houses "that might show clear connections to prior African forms" given the level of control plantation owners held over their construction (Deetz 1996:218). However, he did note that despite restrictions slaves used creolized forms of architecture, reverting to traditional African wattle-and-daub postin-groundconstruction, other forms of earthfast construction, traditional room positioning and size, and the use of root cellars (Deetz 1996).

Whereas on most other Caribbean islands the slave dwellings were in sight of the plantation owner's house, on Statia this was not the case, as indicated on multiple historical maps. This suggests that surveillance of the slaves' activities while at home was limited and the owners may have felt no need to constantly watch their slaves. 
As a result, slaves probably enjoyed a much different physical and social environment that those living on other islands. On Statia, slaves moved between the plantations and throughout the trading district with relative ease. This lack of supervision and relative freedom in mobility most likely influenced both domestic and labor activities in the northern hills as well.

James Delle's (1998:144) research in Jamaica showed that African slaves lived in "nucleated villages clustered in areas on the plantation defined by the planters as marginal;" this appears to be the case with the village sites in the northern hills on St. Eustatius, as all historical maps show no sugar cultivation fields in these elevated regions. He admits that heavy soil erosion and the absence of any archaeological record of slave village settlements has inhibited more thorough research, but cartographic and historical documents indicated that, from 1790 to 1859 , slave villages appeared to be 2.7 acres in size and slaves traveled from slave quarters to work fields between 139yds and 366yds (Delle 1998). He further noted that there have been few archaeological investigations of the internal arrangements of slave village sites on Jamaica and on the island of St. Eustatius (Delle 1998, 1989). His work on the island of St. Eustatius was a detailed spatial analysis of all existing sugar plantations, but he was unsuccessful in locating slave villages, sugarcane fields, or provision grounds in the field and were not a part of his investigation at the time (Delle 1989).

Douglas Armstrong (2011, 2009, 2001, 1999), however, was able to locate two slave villages in Jamaica using cartographic maps and conducted an intensive spatial analysis of their construction. What he found was the evidence of traditional African 
architectural construction, that of wattle and daub (Armstrong 2011, 2009, 2001, 1999; Delle 1999, 1998). Upon initial investigation, when he compared traditional wattle and daub houses from east, west, and central Africa to the reconstructed model he created from archaeological evidence in Jamaica, the resemblance was strikingly similar. Could this mean the slaves living on the island of Jamaica consciously chose to emulate traditional African architecture and spatial patterning?

John Michael Vlach's $(1995,1993)$ extensive 30 year research dedicated to vernacular architecture in Africa, the Caribbean and the southern United States has revealed that slave housing and the seemingly improved conditions in some villages or increased freedom evident in traditional spatial patterning was not necessarily indicative of a better environment for slaves. In fact, he insists that these conditions reflect the owner's desire to use what he terms "benign techniques of coercion" to subdue slaves, lessen their resistance to slavery, and increase their productivity (Vlach 1995:118). He defined and described variations in slave housing with at least nine distinguishable types, including single room or two room cabins, with plans that included hall and parlour, dogtrot log house, I-house style two story buildings (typically for four families), and multiple tenant houses (Vlach 1993). Vlach (1993) noted these variations in plan forms, construction techniques, and decorative elements were an indication that planters began to have an increased concern for the physical welfare of slaves during the 1830s; this was partly fueled by amelioration (or standardization) efforts on plantations after the Amelioration Act passed in 1798 (Carrington 2002). These improvements empowered slaves and allowed for greater autonomy within slave communities (especially on larger 
plantations) as well. The strongest measure of ideological freedom, however, was in the complete and overt resistance to the planter ideal. Despite the ongoing repressive conditions of slavery and the planter's improvement efforts to secure productivity, slaves continually reworked and negotiated conditions within their slave village to foster selfworth and a "sense of place" (Vlach 1993:236).

\section{Material Culture}

The focus on material assemblages recovered from each site on Gilboa Hill held the potential to reveal different activities, through concentrations of particular types of wares that can perhaps identify activity areas, or what Tim Ingold (1993) refers to as “taskscapes." In my research, I noticed plotted artifact concentrations in the Schoesenhoek slave village were consistent with other archaeologically recovered domestic environments. Ceramics associated with cooking (Afrocaribbean wares, plates, knives, etc.) were scattered outside buildings within a central yard space. This was telling, it starkly contrasted with the lack of artifacts at the four sites on Gilboa Hill. This was beneficial in determining whether the sites were a part of a domestic or labor environment.

\section{Ceramics}

Afro-Caribbean wares are distinct creolized locally made low-fired eathernwares that have been affiliated with Caribbean slave communities. Barabara Heath (1999) carefully documented the available examples on the island of St. Eustatius by paste attributes, type, and diagnostic vessel attributes (rims, feet, handles, lids and knobs). It was a firm belief that this project's surface collection would yield examples of 
Afro-Caribbean wares like the ones Heath catalogued. However, given that St. Eustatius was a thriving Dutch port the question will be whether there will be a great diversity of ceramics evident in the material culture on Gilboa Hill. Unfortunately, as later chapters will discuss in detail, no Afro-Caribbean wares were recovered. Had they been found, this too would have been definitive evidence to support enslaved Africans were preparing food in a domestic environment in the northern hills.

Leland Ferguson (1991) examined locally produced coarse redware ceramics in South Carolina and determined that slaves living on plantations used pottery to reinforce their common cultural heritages and to separate them from whites living on the plantation. Similarly, Peterson et al. (1999) determined that Afro-Caribbean ceramics were used in the northern lesser Antilles on the islands of Anguilla, Antigua, Barbuda, and Montserrat over a period of 300 years to denote historic and ethnic traditions among slaves living on plantations in the Caribbean. Other historical archaeological investigations have shown that slaves used decorated redwares to express cultural and social differences (Torres de Souza and Symanski 2009). The presence of Afrocaribbean wares among the assemblages on Gilboa Hill and those in both the Schoenhoek slave village and the FBV (Free Black Village) would provide insight into the ethnic traditions and chronological placement of these different archaeological contexts.

Alison Bell (2002) considered the material culture of planters from what she considered middling social positions and their use of refined earthenwares to emulate higher social classes during the eighteenth to nineteenth centuries in Virginia. What she discovered is that while there were advantages in emulating higher social classes, planters 
shared these trends across the region in unison (Bell 2002). This suggested that the use and purchase of refined earthenwares by planters empowered residents in rural communities in the shaping of their identities (Bell 2002). If residents on Gilboa Hill were acquiring higher levels of refined earthenwares, were they attempting to emulate the higher classes on St. Eustatius to negotiate their identities as well? Is this emulation evident in other material assemblages in the investigation? Ceramic assemblages on slave sites in the Caribbean offer insight into the economic decisions slaves made during their time of enslavement to increase their quality of life.

\section{Networks}

Charles E. Orser, Jr. (1996) stressed that artifacts should be viewed as commodities to exchange along relational networks. "Network," he defined as, "interconnected systems of material and nonmaterial elements tied together in some fashion" (Orser 1996:240). He viewed groups of people as being linked together in a variety of complex ways both culturally and physically (Orser 1996:241), including "kinship, power relations, class loyalties, and economic strategies." He asserted that slave plantations are ideal locations to examine the relationships between material culture and people (Orser 1996, 1992, 1988). This was important to my study because slaves would have traded with one another within social networks to emulate the planter class (Bell 2002). I had hoped to discern if enslaved Africans living or working on the sites on Gilboa Hill were doing so, but unfortunately the material culture assemblage doesn't support these sites were even part of a domestic environment. I did, however, find evidence to suggest enslaved communities living at the SSV and the FBV might have utilized social networks to emulate the planter class. 
Even though it is typical to find more bowls than plates among the material culture on slave sites, a study conducted by Adams and Boling (1989) revealed that actually the slaves had more expensive wares when compared to the plantation owners (Orser 1996). I agree when he notes this "contradicts the logic of master-slave relations" (Orser 1996:246). It is important to determine, then, where slaves acquired their ceramics and other material culture. Given that St. Eustatius' port had a diverse and variable ceramic availability for residents on the island and slaves were permitted to sell their surplus commodities at the local market in Oranjestad, would this be reflected in the material culture among the slave village assemblages on Gilboa Hill? Orser (1996) proposes the consideration of various networks in order to determine this including: networks within the slave communities, between slave communities on Gilboa Hill and other plantations on the island, other larger networks, or even the possibility of clandestine networks. He reasons that the presence of great variability among slave material culture assemblages is due in part to these networks and sub-network activities (Orser 1996). I was not able to assess this at this juncture of my research, again because of the lack of artifacts at the sites on Gilboa Hill.

Amy Young (2003) also looked at archaeological assemblages at the Locust Grove Plantation in Kentucky (matched sets) and uncovered the existence of kinship networks or the practice of "gift giving" as an explanation of ceramic variability among slave material culture assemblages. This is another possibility to consider: would the slaves on the island who had the access to greater variability have shared these commodities with their fellow village residents in keeping with the philosophical ideal of 
ubuntu that viewed possessions as community owned rather than individually owned? The lack of material assemblages on Gilboa Hill left the inability to determine if social trade, economic, or commercial networks affected the diversity of the ceramic assemblages. However, this research was incredibly helpful to keep in mind when comparing the seven artifacts to both the Schoenhoek slave village and FBV assemblages. The material culture associated with the Schoenhoek slave village indicated a clear attempt by slaves to emulate the planter class. This was evident from the mixmatched wares that all shared similar blue lines at their rims. The ceramics were clearly not of the same set, yet the blue line was similar enough to suffice as one most like their owner.

\section{Summary}

As mentioned at the beginning of this chapter, this project warranted multiple scales of analysis to determine whether an increased level of ideological freedom experienced by enslaved Africans resulted in their active participation in the construction of their domestic and labor environments. Given the massive area under investigation, I approached my research under the patronage of landscape archaeology to detect whether the lack of Dutch colonial power's dominance over the daily lives of enslaved Africans living and working on St. Eustatius reflected cultural continuity in the creation of their built environment. A built environment created using an Ubuntu-like principle; an African worldview that possibly helped shape new communities in the New World. This was possible given the slaves on St. Eustatius were likely from West Africa and ethnographic studies were important to determine if settlement patterns and vernacular 
construction could share similarities to those in this region of Africa. Given labor related activities governed the daily lives of slaves, assessing their labor environments is a worthy endeavor. Additionally, in order to determine whether the four sites under investigation were domestic or labor related it was also essential to consider the large body of work that previously looked at the domestic environments of slaves through their material culture and understand possible patterns. As patterns emerged, it became evident through my analysis that the lack of artifact concentrations and absence of characteristics of a domestic environment present at each of the sites indicated the likelihood of the dry stone rock features at each of the sites being part of a landscape of labor. This study will add to the growing research in understanding the labor environments of enslaved Africans in the Dutch Caribbean. The following chapters will outline the results of my extensive analyses and provide conclusions for consideration. 


\section{CHAPTER III}

\section{METHODOLOGY}

The discussion in the previous chapter of the theoretical underpinnings of my research and the work of previous archaeological, historical, and ethnographic investigations built a framework for this study in order to understand enslaved domestic and labor environments on St. Eustatius. The dry stone rock features discovered on Gilboa Hill required multiple lines of investigation. Historical maps offered the potential to associate the four sites to a documented plantation during the time of enslavement. This affiliation helped to discern whether slaves living and working in the area were a part of the sugar industry and shed light on the potential function of the dry stone rock features at the four sites.

Increasingly, archaeologists use survey at sites in addition to, or instead of, excavation, and regional survey has become a major part of archaeological fieldwork; coupled with extensive mapping, this too comprised the bulk of my archaeological work (Renfrew and Bahn 2000). Barbara Purdy (1996:76) describes survey as the "noninvasive, non-destructive means to assess past human activities in an area... with the ultimate goal being to produce a reliable prediction about what is under ground." With this, Renfrew and Bahn (2000) suggest the most effective way to survey is systematic, whereby equally spaced transects are walked systematically rather than a simple walk over. In this way, no one area under investigation is under or over represented. 
As I chose in my fieldwork and discuss in detail in the next chapter, each area is then subdivided into transects to examine a particular area more closely; this, they suggested is simply more effective (Renfrew and Bahn 2000). Further, Godja (1997) supports the use of survey in landscape archaeological investigations because surface testing, test pitting, and small scale excavation is both non-destructive and preserves the integrity of the sites for future research.

Therefore, to determine whether the function of dry stone rock features in the mountainous landscape was domestic in nature, the setting and respective characteristics at each of the four sites were documented using pedestrian survey, extensive mapping, surface collection, and sub-surface testing. This, along with their spatial organization and dry stone rock feature attributes, provided a rich database for comparison to known domestic village environments to identify similarities in shape, size, as well as nucleation and dispersion associated with domestic villages. Upon comparison, structural and broader architectural analyses revealed unique deviations on the island that could reflect the direct, shaping of an environment by active participants that experienced higher degrees of ideological freedom under the Dutch colonial rule. If so, I think, enslaved African communities on St. Eustatius experienced a level of cultural continuity as they worked to build their environment. Artifact assemblages from previously excavated villages on the island offered a comparison to the assemblage collected in the upland region, this helped understand the differences in labor and domestic environments on the island, as well the differences in the material culture of enslaved populations as they transitioned from slave life to emancipation. 
Several factors of the cultural and natural setting, however, had the potential to make the identification of structures and features difficult. The survey research methodology presented in this chapter directly dealt with these issues. Likewise, artifact analysis followed standard methodologies adapted to the time constraints and special conditions of archaeology on St. Eustatius. Plan maps of ethnographic studies of villages in West Africa, coupled with archaeological data of structures in the Caribbean and in the United States, provided extensive comparative datasets for use in this investigation. In the end, the use of regional comparisons, structural, spatial, and artifact analyses facilitated a comprehensive assessment of the four sites located on Gilboa Hill. In the next chapters, I discuss these comparisons in detail.

\section{Historical Maps}

Initially, the examination of historical maps laid the groundwork for further investigation for this research by providing further information about the spatial and historical context of the archaeological features under study. Primary sources (historical maps from the seventeenth to twentieth centuries and Google Earth images) and secondary sources (archaeological survey reports) were examined to determine which plantation the four sites on Gilboa Hill might be associated with. These sources indicated that ownership of the sites under investigation likely had one owner for nearly forty-five years, the Widow Ducas, but depictions of property boundaries shifted over time and needed further scrutiny, especially since by the year 1829 there was only one plantation depicted on historical maps. Three maps were relevant for this research (Fahlberg, Samuel 1829; Martin, P.F 1781, 1791). The historical map from 1781 when compared to 
the 1791 and 1829 historical maps of the northern hills revealed differences. As one might expect, a shift in boundaries from one map to the next depicts the transition of the land from one owner to another. However, spatial analysis revealed slight erroneous deviations in boundaries on maps attributed to historic cartographer's preferences and not actual physical boundaries.

Fortunately, these differences in plantation space on the island provided a basis for understanding the changing landscape in the northern hills, much like James Delle's (1989) master's research on plantations and their change in distribution across the island did. In general, these maps determined that one of two owners was likely affiliated with the four sites on Gilboa Hill's third ridge: Michael Cuvilljes or the Widow Ducas. Fellow graduate student, Sean Stretton, using ARCmap software, created an overlay of two historical maps, topographic maps, and GPS coordinates for the Gilboa Hill sites in an effort to help contextualize the variance in spatial data for these two owners (Figure 2). This depiction served to provide the basis for further inquiry into plantation ownership because GPS coordinates of the four sites on Gilboa Hill align with one plantation, but discrepancies in historical boundaries of the island affiliate the sites with another.

Contrary to previous analysis of cartographic and documentary sources of the Northern Hills, evidence revealed ownership of the sites under investigation most likely belonged to the Widow Ducas and not Michael Cuvilljes. Dry stone rock walls at the top of the third ridge played an important role in this determination as historic maps clearly indicate these walls on the Widow Ducas' property. This was later corroborated in the field with the discovery of dry stone rock walls at the top of the third ridge; they align 
with the walls that are depicted on the Widow Ducas' property on all historic maps. Further, GPS coordinates also confirmed the location of the dry stone rock walls to be closer associated with Widow Ducas' property as well. This is particularly curious given that the Schotsenhoek slave village used for comparative analysis in this investigation also belongs to the Widow Ducas, making the comparison all that more pertinent. The dry stone rock walls at the top of the third ridge of Gilboa Hill depicted on the Widow Ducas' property on all historical maps provides an important element of a timeline for this analysis given their construction dates at least to their depiction on historic maps. This terminus ante quim, then, while not definitive of when the walls were constructed does offer their placement on the landscape during the eighteenth century. 


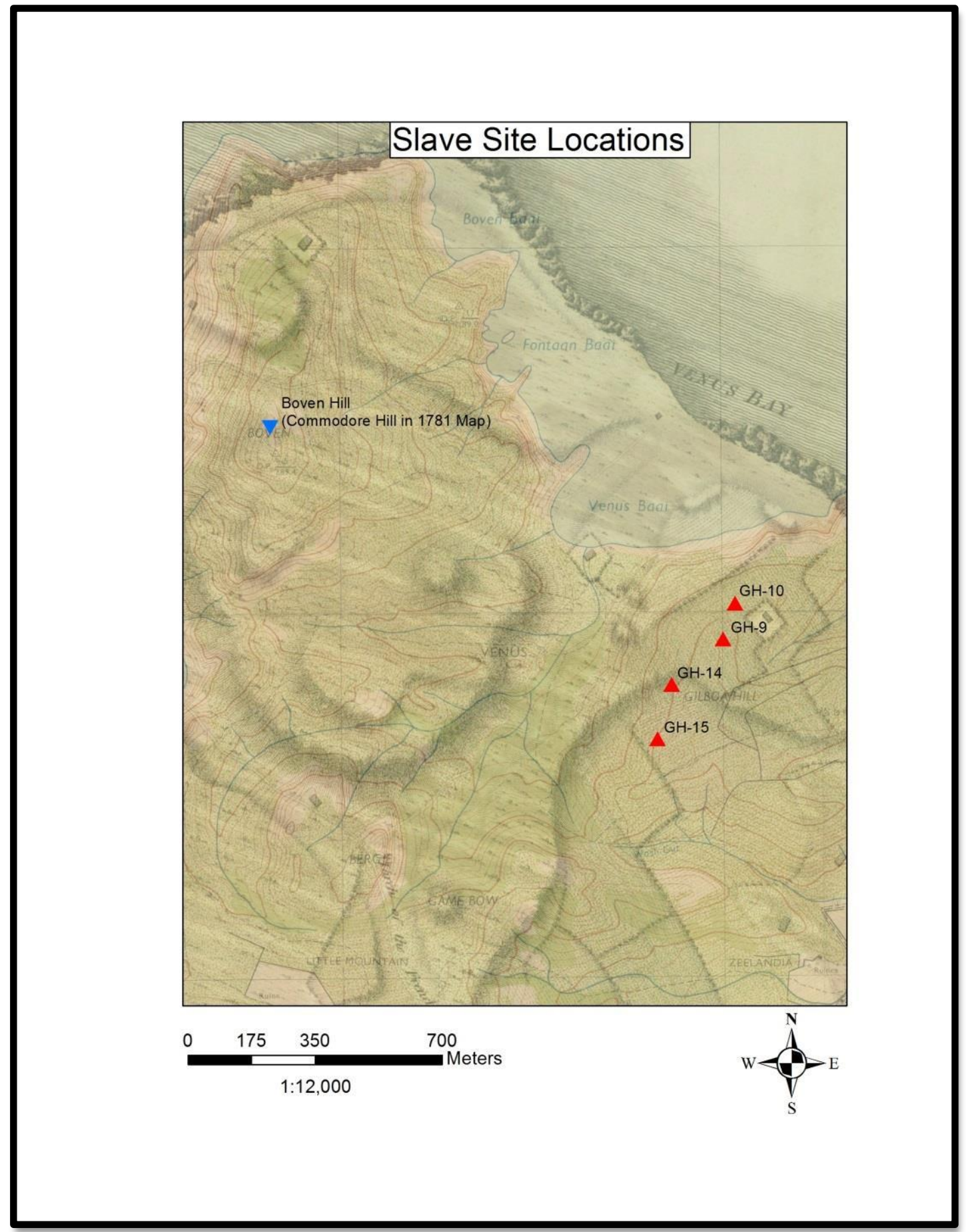

Figure 2. Overlay of Historical and Topographic Maps of the Northern Hills with GPS Coordinates of the Sites on Gilboa Hill 


\section{Fieldwork on Gilboa Hill}

In order to determine whether the dry stone rock features on Gilboa Hill were associated with either domestic or labor environments on the island and if characteristics from these sites shared similarities to other African environments, it was important to conduct extensive fieldwork at the four sites located at the highest elevation, on the third ridge. Fieldwork began July 22012 and lasted for six weeks. I conducted a systematic pedestrian survey of the entire third ridge, with special emphasis at each of the four sites in the investigation; a total of 9,094m. I defined site limits based on the extent of human construction and extended this approximately $10 \mathrm{~m}$ to $20 \mathrm{~m}$ in each direction for the best probability of artifact recovery. Once mapped, I used the location of dry stone rock features to concentrate sub-surface testing. I place shovel test pits, $1 \mathrm{~m}$ x $1 \mathrm{~m}$ brechas cut into the surface every $4 \mathrm{~m}$, and additional $50 \mathrm{~cm}$ x $5 \mathrm{~cm}$ test units around dry stone rock features, downslope from their location, and along the periphery of the site.

\section{Field Investigation Summary and Goals}

After analyzing historic maps and documentation, and discovering a potential owner of the sites under investigation, it became important to conduct an extensive survey of the entire third ridge in order to assess whether the potential slave villages could be located. Armstrong (2001) cited two main problems with locating slave villages in the Caribbean: most slave housing was of earthfast construction leaving few to no visible clues of their placement in the landscape, and constant reworking or reallocating of slave village land further erased visible signs of them. Further, as other investigations in the Caribbean have noted, not all slave villages placement follow a distinct, predictable 
pattern. With this in mind, an exhaustive pedestrian survey appeared to the best method to approach the challenge of locating the slave villages on Gilboa Hill's third ridge.

My archaeological fieldwork, conducted over the summer months of 2012 on Gilboa Hill's third ridge, added to the existing rich database of pre and post-emancipation village environments already under investigation in the lowland region on the island. In order to assess the spatial patterning of places where enslaved people lived and worked in the northern hills, it was important to understand the setting of each of the sites located on Gilboa Hill. I gained permission from the St. Eustatius Center for Archaeological Research director and island archaeologist to begin a six-week investigation on the island up in the northern hills. I organized research assistants, planned initial fieldwork, and purchased equipment for use in the northern hills. This equipment was later donated to the research center along with a considerable donation to cover utility costs and dorm use.

\section{Pedestrian Survey and Surface Collection}

Over the course of six weeks, four sites on the third ridge of Gilboa Hill were investigated to determine if the dry stone rock features were part of a domestic occupation of slaves living or working in the mountains during the time of enslavement. Within each located site, measurements of the entire site as well as terracing and identifiable rock features were recorded. From July 2, 2012 to August 16, 2012, I conducted a pedestrian survey and subsequent testing on Gilboa Hill's third ridge with the assistance of two paid graduate students, three volunteers, and graduate students from Leiden University. Volunteers, graduate students, and I walked the pedestrian survey 
transects in $2 \mathrm{~m}$ to $4 \mathrm{~m}$ intervals across each site. We measured each site (GH15, GH14, GH9, and GH10) and set perimeters using pink flagging tape. Each archaeological dry stone rock feature was meticulously measured as well. These measurements were later used to recreate the site boundaries and archaeological features on hand drawn maps (drawn to scale) back in the lab (Appendix A and B). Noted terracing from previous archaeological survey at GH7 and GH8 was added to the hand drawn map of sites GH9 and GH10 using GPS coordinates, field notes, and pedestrian survey. I used a tape and compass to obtain all measurements in the field and an engineer rule to measure archaeological and ethnographic maps using the corresponding scales provided. At each site, a handheld GPS unit helped obtain directional north, used for measurements and subsequent mapping. All maps provided in the following chapters are to scale. Rock Features discussed in this thesis refer to circular and oval dry stone rock piles ranging in size $1 \mathrm{~m}$ to $6.5 \mathrm{~m}$ (circular) and $0.5 \mathrm{~m} \times 0.75 \mathrm{~m}$ to $5.5 \mathrm{~m} \times 4.5 \mathrm{~m}$ (oval). Two small walls are also noted as well as multiple terracing walls; all identified as dry stone rock construction.

St. Eustatius is noted for its expansive surface collections across the entire island; it is commonplace to find pottery sherds, glass, metal, or even the notorious, although occasional, blue bead. It was this assumption that led the investigation to concentrate on the identification of potential slave villages on Gilboa Hill from surface collection alone. Unfortunately, this was not the case in the Northern Hills. 


\section{Observations and Subsurface Testing}

Subsurface testing included the use of standard archaeological investigative techniques (shovel test pits, test units, and brechas). Gilboa Hill's poor surface collection led to the use of shovel test pits at each site, because it offered an alternative methodology to increase the chance of artifact recovery.

Surface collections were bagged and labeled for processing, then later photographed at the research center. Observations of site location, vegetation, terrain, vistas, and setting were recorded for each of the four sites in my field journal and soil samples were collected for later classification using the Munsell (2000) soil color chart back in the lab.

Brechas are $1 \mathrm{~m} \times 1 \mathrm{~m}$ areas of complete removal of vegetation and surface debris. They were judgmentally placed to search for artifacts beneath the ground cover and were spaced approximately $3 \mathrm{~m}$ to $4 \mathrm{~m}$ apart at each site. This served as an effective methodology as the ground cover at each of the four sites on the third ridge, both under the canopy and in semi-arid areas, was extensive. Total removal of ground cover would have taken weeks or months. The use of brechas allowed for the successful completion of the survey within the time constraints for this project.

Over the course of the six-week fieldwork on the island of St. Eustatius, various testing methods helped gather additional data from the four sites on Gilboa Hill. Shovel Test Pits (STPs) consisted of a standard garden shovel dug to a depth of approximately $10 \mathrm{~cm}$ to $30 \mathrm{~cm}$ to sterile soil with soil sifted for artifacts in a $1 / 8$ mesh screen and deposited back in the hole. Additional testing included $50 \mathrm{~cm} \times 50 \mathrm{~cm}$ test units to bedrock at $40 \mathrm{~cm}$ to $50 \mathrm{~cm}$ (Appendix C) with soil sifted for artifacts and placed back in to the unit 
(Appendix $\mathrm{C}$ depicts profile depths for these test units). Subsurface testing proved to be ineffective, however, as no new artifacts were recovered.

\section{Summary}

Extensive survey of 9,094 m on Gilboa Hill, or $5.6 \mathrm{~km}$, and subsequent testing only yielded seven artifacts. Upon the conclusion of the fieldwork during the summer of 2012, it became apparent that the four sites under investigation were different from other known domestic sites on the island. Previously excavated sites yielded large material assemblages and definitive evidence of domestic occupation. It was important to examine two of these previously excavated slave villages more closely to understand why these differences emerged.

\section{Excavation Methodology}

Surface collection, pedestrian survey, GIS mapping, and excavations have been ongoing important archaeological endeavors on the island of St. Eustatius in documenting the planter's life from the mid-seventeenth century to twentieth century. Fortunately, opportunities to conduct excavations at two sites thought to be associated with both enslaved and emancipated life were presented to lead archaeologists working with SECAR in 2007, and again in 2012. These sites, both located near the central uptown of Oranjestad, offered the potential to increase our understanding of the differences between domestic environments among the slave and planter classes, as well as how emancipation might have affected these environments. These excavations will be discussed in detail below. 


\section{Schotsenhoek Slave Village}

In June 2012, Ruud Stelten, lead island archaeologist at SECAR, commenced excavation at a potential domestic site that was located using historic maps and pedestrian survey. Mechanical stripping pulled back the top soil to remove the plow zone, approximately $2 \mathrm{~m}$ deep, opening a section measuring $45 \times 15 \mathrm{~m}$. One $5 \mathrm{~m}$ trench was cut along the NW/SE axis along the southern end of the site and another $14 \mathrm{~m}$ trench was dug along the NE/SW axis directly off center. Thirty postholes were identified, profiled, and then mapped (Appendix E). Mapping identified seven distinct, possible structures within the central region of the site and a smaller line of shallow postholes revealed a possible wooden fence along the far NW corner of the site. Artifacts were screened, washed, dried, and photographed. Careful recording of provenience throughout this process included bagging and labeling each separate context. Fellow graduate students and I prepare d a catalog in July 2012. The catalog and maps provided comparative data for later analysis when I returned to the United States.

\section{Free Black Village}

On October 26 2007, Grant Gilmore, former director at SECAR, commenced excavation at a possible Free Black Village site located using historic maps after ethnographic investigations and survey revealed the potential location on the outer edge of the Congo Preserve campground. The Preserve located on the northern edge of Oranjestad spans approximately $2400 \mathrm{~m}$, of those $137 \mathrm{~m}$ were surveyed and excavated. Four stone foundations were uncovered (Appendix D). Artifacts were screened, washed, dried, and catalogued to include 257 proveniences. 


\section{West African Ethnographic Examples}

Over the duration of 30 years, Professors Dr. Jean Paul Bourdier and Dr. Trinh T. Minh-ha have conducted ethnographic fieldwork in West Africa, concentrating on rural communities, their culture, and spatial organizations. Remote communities were located and they established relationships with community members. They collected ethnographic data on kin relationships, which led to a better understanding of each village's spatial organization. They prepared detailed to scale drawings of each village and compiled them into three separate publications in 1988, 1996, and 2011. For this study, I chose four of those villages for their vernacular architectural construction features and close proximity to the region Dutch slave traders would have obtained slaves.

\section{Methods of Analysis}

\section{Regional}

Crumley and Marquardt (1987:74) defined a region as "a certain scale in its distinctiveness from and interactions with other such unites, both spatially and temporally." This definition was helpful in defining boundaries between the upland and lowland areas on the island and establishing characteristics for further comparison. Upland regions were defined initially by their physical characteristics, with two sites under heavy canopy and extensive organic surface debris as upland region one (GH14 and GH15) and two sites in a semi-arid environment with dry brush and grasses as upland region two (GH9 and GH10), (Figure 2). These upland regions were then compared to the two settlement sites in the lowlands (the Schotsenhoek slave village and the 
Free Black Village). In addition to the observed noticeable differences between upland regions (physical characteristics of the landscape, the presence of dry stone rock terracing, dry stone rock features composition and placement, vegetation), stark differences in the lowland settlement sites were also observed (possible dwelling features, distinct spatial patterning, artifact concentrations, vegetation).

\section{Structural}

\section{Feature Comparisons}

Historical accounts of sugar cane production zones support the idea that slaves working in areas of agricultural production never stayed longer than a few weeks at a time, rotated in and out, and did not sustain long term domestic settlements in upland regions (Dunn 2000; Gilmore 2012). Gilmore (2012) suggested that laborers constructed temporary dwellings near their work area. These villages of temporary shelters would have consisted of clustered of groupings of rock piled together, covered by a daub-like substance for sealing the floor, and a crude lean-to constructed rood erected to protect slaves from the elements (Gilmore 2013). Taking these ideas into consideration, the initial premise for this investigation included recording and evaluating rock features as temporary housing for the seasonal sugar cane labor force working in the area during the eighteenth century. The analysis of spatial patterning of these features, then, provided a way to look at the way enslaved people organized their lives. What stood in contrast to expectations was that these constructions are clearly different from any kind of domestic space either recovered archaeologically or attested ethnographically. They do, 
nevertheless, directly address the question of the degree of self-determination in laborer's lives, as they document the staging and organization of their work.

While comparative analysis was not an attempt to draw direct parallels from ethnographic examples to archaeological structures and features, it did offer an established framework to consider potential function based on similar shape and size. Upon comparison, these correlates helped establish general patterns in domestic environments. For instance, the smaller a structure was in the ethnographic examples, the more likely it was used for storage. With this in mind, in order to understand whether similarities existed between ethnographically documented structures in West African villages and archaeological features on Gilboa Hill, I compiled a database with all of the 199 structures and features' dimensions under consideration. Plan maps of the Schotsenhoek slave village, Free Black Village, and ethnographic examples were measured using a standard engineer rule using the scale provided by the illustrator. The dimensions of dry stone rock features at each of the four proposed sites on Gilboa Hill's third ridge, structural dimensions at two known village archaeological sites on St. Eustatius (the Schotsenhoek slave village and Free Black Village) and ethnographic examples from West Africa were used. When available, ethnographic information (including function, type and name) for each of the structures in the four West African villages was noted. Site information for each of the structures and dry stone rock features recovered archaeologically on St. Eustatius was also included. This database was used to categorize structures and features using simple typology of shape and size. These 
measurements were then included in a broader architectural comparative analysis of 29 structures in the United States and throughout the Caribbean, to understand spatial arrangement such as dispersion and nucleation, and in further analysis of isolated dry stone rock features to determine if their dimensions could support a reclining human being.

Once compiled, 199 structures and features were first sorted by shape and then by size. Each shape category was then transferred to a separate spreadsheet to generate a comparative table. Then, this table was further sorted by size, from smallest to largest. Circular structures and features were sorted by their diameter, oval, square and irregular shape structures and features were sorted by their area, and rectangular shape structures and features were sorted by their area (once converted to a ratio of length to width). This generated subcategories within each shape category that were subdivided by $.5 \mathrm{~m}$ increments. These increments were carefully chosen to detect correlates between size and function. For circular shaped structures and features, six subcategories with ratios ranging from $1 \mathrm{~m}$ to $6.5 \mathrm{~m}$ were noted. For oval shape structures and features, twelve subcategories with total areas between $0.375 \mathrm{~m}$ to $2.75 \mathrm{~m}$ were noted. Square and irregular shape structures and features were all noted to be from ethnographic examples and were grouped into small and large subcategories with an area range of $1.6 \mathrm{~m}$ to $6.5 \mathrm{~m}$. Rectangular shape structures and features had seven subcategories with ratios ranging from $1.1 \mathrm{~m}$ to $33 \mathrm{~m}$. Of interest, within the rectangular shape structures and features comparison it quickly became apparent that terrace walls at sites GH14 and GH15 on Gilboa Hill had the largest area ratios of length to width; subcategory seven consisted 
only of these walls. Once subcategories were established, I made observations using typology like those of the terrace walls on Gilboa Hill and generated further inferences drawn between shape and size and respective correlates in each subcategory.

\section{Dry Stone Rock Feature Dimensions}

Once structures and spatial organization revealed eight of the fifty-three archaeological features on Gilboa Hill appeared to conform to attributes of ethnographic examples, I evaluated how they would accommodate a person, or more specifically, whether each feature had suitable dimensions to support a reclining or sleeping individual if it was used as a sleeping quarter, even crude temporary one. Human heights of $1.5 \mathrm{~m}$ and $1.8 \mathrm{~m}(5 \mathrm{ft}$ and $6 \mathrm{ft})$ individuals and an approximate shoulder width of $0.46 \mathrm{~m}$ to $0.51 \mathrm{~m}$ (18in to 20in) were used to create representative individual figures with similar dimensions. These figures were laid on the figures of the eight dry stone rock features under question (also drawn to scale) to visualize what individuals would have experienced while sleeping on the supposed platforms. Even with Berlin and Morgan's (1993:40) suggestion that over time subsequent generations of imported slaves in the Caribbean were shorter than North American slaves, the range of height I used was incredibly helpful in determining how realistic given dimensions of dry stone rock features were in accommodating human height. Unfortunately, the inconsistency and variability between features at the four sites under investigation, when compared to human height and shoulder width, raised more questions during the investigation regarding their intended purpose. If they were indeed sleeping platforms, one would assume there would be uniformity or at least a minimum length; however, this was not 
the case. This analysis was part of a multi-faceted approach to determine if the dry stone rock features served a domestic function in the landscape on Gilboa Hill.

\section{Broader Architectural Comparisons}

Amelioration efforts on slave plantations included attempts to standardize slave villages with housing aligned in rows, uniform structural dimensions, and adherence to specific construction materials and/or methods. Because village dimensions noted in the Caribbean conformed only moderately after 1790 to efforts to ameliorate, or standardize, slave housing, it was important to compare architectural structures to known plantations sites to determine if spatial orientation and slave quarter dimensions in domestic environments held to a specific pattern. I compiled a database of the dimensions of architectural structures of enslaved communities from the United States as well as in the Caribbean and conducted an exhaustive comparison. As expected, each community was unique in their spatial orientation and construction in domestic environments, yet, patterns in similar shape and size did emerge.

The artifact distributions recovered at archaeological sites reflect patterns in spatial orientation and provide a general guideline for identifying slave village environments in the field. Therefore, it was important to compare structures at each of the sites recovered archaeologically, both in the upland Gilboa Hill region and in the lower village sites, on the island of St. Eustatius with documented structures at coffee, sugar, cotton, and rice plantations in the Caribbean as well as in the United States to determine if notable correlates existed. 
Slave quarter dimensions in the Caribbean were compared from the following nine plantations: William Chapman (St. Croix), Alexander Barclay (Jamaica), John Stewart ( Jamaica), Roehampton (Jamaica), El Padre (Cuba), Bryan Edwards (Jamaica), Montpelier (Jamaica), Rev R. Bichell (Jamaica), R C Dall ( Jamaica). Additionally, dimensions were compared from the following 8 plantations in the United States: Rosemount (Alabama), Thornhill (Alabama), Kingsley (Florida), Cannon's Point (Georgia), Hampton (Maryland), Hermitage (Tennessee), Bell City (Texas), Cavitt (Texas). These dimensions were recorded in the investigations conducted by Higman (1998, 2001) and John Michael Vlachs' (1995) extensive investigations of plantation architecture and spatial orientation.

The dimensions were compared by size and shape to the archaeological structures and dry stone rock features on the island of St. Eustatius. Most structures in the comparative sample appeared to be rectangular and divided between three distinct categories: small, medium, and large. Dry stone rock features on Gilboa Hill did not correlate to any structures in the comparison.

\section{Post Hole Analysis}

An even finer scale of architectural analysis was to determine the possible building sequence within domestic settlements. The postholes at the slave village were evaluated using detailed profiles drawn by archaeologist Ruud Stelten (2012) to determine if their depths and size indicated a function in the excavated features, clues as to the structures shape and size, or whether the posts were part of first or secondary construction. If phases of construction could be determined, this would provide evidence 
of ongoing construction in the village environment either as a sign of multi-generational occupation or reworking the slave community environment over time. Additionally, post hole placement provides evidence of vernacular house construction methods. If evidence of construction at one location built by slaves supports the use of communal Ubuntu-like principles of orientation, then perhaps others on the island such as features in the upland regions on Gilboa Hill might invoke these principles as well. This analysis provided identifiable construction techniques for comparison. Using the plan map of the slave village and scaled profile drawings of the post holes, depths and location were recorded and then compiled into a database. An examination of these depths helped determine that in fact some posts were set deeper, while other more shallow postholes may have been roofed areas exterior to structures.

\section{Spatial}

\section{Spatial Orientation}

The planter class under English, French, and Spanish colonial rule regimented the standardization of their slave's villages. What is interesting, despite this documented attempt to standardize enslaved African environments, is investigations like Higman's (1998, 2001), conducted on two hundred and eighty six Jamaican plantations revealed this was not always the case (78\% were not regularly dispersed across the landscape as expected). In keeping with Okeefe's (2000) argument of not merely calculating the nucleation and dispersion (isolated and clustered spacing) of structures across the landscape, this investigation attempted to deduce correlates between nucleation and dispersion rates as direct, clear cut patterns within each site rather than use a blanketed 
approach for their entire study. For this, I compiled, as Okeefe (2000) suggested, a comparative index of the minimum and maximum distances between each of the dry stone rock features for each of the four sites on Gilboa Hill, the Schotsenhoek slave village and the Free Black Village. From these site comparisons, I deduced set patterns unique to that specific site then used this information in a broader comparison to one another. If standardization occurred under Dutch colonial power, then the spatial orientation of these dry stone rock features and the features of possible dwellings from the Schotsenhoek slave village and Free Black Village would reflect this. Minimum and maximum distances would be carefully nucleated and dispersion within the village, or relatively uniform placing features at set intervals as they adhered to this standard. None of the examples held to a set pattern associated with standardization and this analysis helped raise inquiries into other factors that influences the spatial organization, or nucleation and dispersion rates, of features in the investigation.

\section{Artifact}

\section{Material Culture Analysis}

Material assemblages are traces of human activity. Two hundred years of soil erosion and persistent run off on Gilboa Hill could have deposited artifacts against dry stone rock walls downslope from the dry stone rock features associated with the alleged temporary dwellings. Further soil deposition along those dry stone rock walls had the potential to average between $1 \mathrm{~m}$ to $2 \mathrm{~m}$ in depth and testing could have yielded high concentrations of artifacts if people had been eating, drinking and living in the area. I recovered seven artifacts from the survey region during surface collection, not from sub- 
surface testing. This was a strong indication that the sites on Gilboa Hill were not domestic environments.

The few artifacts I recovered during surface collection were compiled into a database along with the Schotsenhoek slave village material assemblage I catalogued over the summer months. During the month of November in 2012, I returned to St. Eustatius to catalog the first 100 provienances of the Free Black Village material assemblage and added this to the existing database. This was important in considering the vast differences in quantity and variability between the upland and lowland regions. If material assemblages from times of enslavement were small (for obvious and understandable economic reasons) then an even smaller material assemblage recovered at a temporary labor site might be plausible. However, given that most archaeological sites on St. Eustatius (the Schotsenhoek slave village and Free Black Village included) have very large material assemblages, this analysis was benficial in confirming the sites on Gilboa Hill were very different from any archaeological site found to date.

Observations included notable differences between the material assemblages from the Schotsenhoek slave village and Free Black Village; namely differences between the availability and frequency of items indicative of the transition from slavery to emancipation. Identification of eighteenth century ceramics, Afrocaribbean wares, glass, and pipestems were identified using research references including: Noel Hume (2001) A Guide to the Artifacts of Colonial America's images of pearlware, whiteware, tin-glazed and other ceramic types, Olive Jones' (1985) Parks Canada Glass Glossary’s images of glass and other ceramics (http://www.sha.org/bottle/pdffiles/GlassGlossary.pdf), images of redwares and coarse earthenware on the DAAC's website using the downloaded GLC 
player software, Gerard Gusset's (1980) images of stoneware, Haviser (1999) description of Dutch artifacts recovered on Curacao, Schiffer's (1975) images of export porcelain patterns, and Canadian guides to Spode and other transfer prints (1979). Artifacts in each assemblage were measured, photographed, and recorded in a site specific database.

Minimum number of vessel counts was also calculated for each site in the investigation.

Analysis for these collections included calculations of the Mean Ceramic Date using Stanley South's (1977) formula. Using spreadsheets to organize data, assemblages were also calculated for frequency and variability in vessel waretype and decoration. The frequency and variability of vessel form was not recorded.

\section{Taskscapes}

Concentrations of artifacts often follow depositional patterns associated with activity and accumulate over time in long-term occupation sites (i.e. refuse disposal, etc.). Even though the sites on Gilboa Hill were not proposed to be long term domestic sites, they were evidence of labor practices that could be closely compared to domestic occupation deposition. In addition to the structures themselves, this labor activity could have left traces around structures, in the case of the sites on Gilboa Hill this would have translated into concentrations, or zones of concentrated artifact deposition, around the dry stone rock features potentially, or if yard sweeping was practiced, at least down in the ravines downslope from these features.

In order to determine if the sites on Gilboa Hill had these activity areas, or taskscapes, a control had to be established. In this case, the artifact patterning of a known village was characterized. Artifacts were mapped onto the Schotsenhoek slave village plan map using the following denotations: pipe stems and bowls (P), Afrocaribbeanware 
(A), grinding stone $(\mathrm{Gs})$, colander $(\mathrm{C})$, knife handle $(\mathrm{K})$, utensil handle $(\mathrm{U})$. This created observable concentrations of activity around structures when plotted on the map and in turn raised questions about the absence of these deposits in the upland regions for comparison. If the slave village had activity areas associated with domestic occupation, or site-specific taskscapes, then it was most likely that other village environments on the island would as well. This meant the observable terraces and constructed dry stone rock features in the upland region on Gilboa Hill were related to an entirely different taskscape altogether.

\section{Limitations of the Study}

As mentioned previously, over the course of my fieldwork during the summer of 2012, my methodology needed to be adjusted to not only increase the potential to recover artifacts, but also to fit within the limited time for research, consider the dangerous locations of the nine proposed sites, and to address particular research questions (both original and new). Despite my best efforts, several shortcomings are still present, however, and these gaps need to be taken into consideration when considering the results. Fieldwork concentrated on only the four sites located on the third ridge of Gilboa Hill. The proposed project would have included other documented sites on the first and second ridge, nine in total, as they are similar in nature to these four sites, but unfortunately, their location on an extreme slope near the edge of the second ridge proved too dangerous to continue survey after initial attempts. Instead, and in part due to time constraints, efforts to compile more data from the four sites under investigation on the third ridge seemed more appropriate. 
Investigation of the slave village is ongoing, so only the initial data and analysis of materials from the first phase of excavation is included in this analysis. To provide a comparative data sample, only the first 137 (exactly half of) proveniences of the FBV material assemblage are included in this analysis along with the surface collection and plow zone materials dating from October 262009 to July 62009 .

Whether domestic spatial arrangement of slaves living on the island reflected elements of African origin was evaluated by comparing archaeological remains with carefully selected ethnographic examples from regions in West Africa. As posed in the previous chapter, similarities do exist and are detectable to a degree in the archaeological record. For this, plan drawings of only four West African Villages, the Schotsenhoek slave village, and the Free Black Village were used during an extensive comparative analysis. This small sample holds the potential to be problematic as it is limited in scope. However, while previous historical investigations of American slaves' origin has determined West and Central Africa as likely regions, Caribbean slaves, especially Dutch slaves might have mostly come from one region in West Africa near the Gold Coast (Rawick 1972: 8). This would have included a stretch of land along the coast as far south as Bakongo and to the north to Senegambia (Rawick 1972: 8). For this reason, the four villages chosen for this analysis are in this limited region. The shortcoming is that these four villages do not reflect the entire spectrum of villages or tribal communities in West Africa or account for the influence of colonial and postcolonial changes that affected these villages, but they do provide quality examples of the variety of spatial organization in this region. With this in mind, it is not the assumption that these village communities represent pristine examples of pre-contact environments, but with consistent village 
alignment characteristics, patterns emerge. These patterns are potential elements of West African groups that remain despite different political, economic, and social conditions that influenced their communities over time. Observations from these four villages have served well in identifying patterns in domestic settlements and categorizing archaeological structural elements; if nothing else, they were an essential point of departure for this investigation.

\section{Summary}

In order to determine whether dry stone rock features at the four sites on Gilboa Hill had evidence of patterns consistent with village environments indicative of occupation, either domestic or temporary, this project required multiple lines of investigation. Research of historical maps helped determine potential plantation affiliation, as wells as dates of construction and use of the sites in the investigation. Fieldwork, mapping and testing provided a substantial database for further analysis. The sites in the study were defined by regional characteristics to help recognize patterns and differences between them. Structural comparisons of those at archaeological sites on the island to ethnographic examples were enlightening with regard to prevalent shapes and sizes of structures. This was supported by broader comparisons of slave quarter dimensions in the Caribbean and in the United States. Nucleation and dispersion patterns were evident among the comparative sample. This led to eight features being reanalyzed. Using illustrations of human beings placed on to images of dry stone rock features to drawn to scale dimensions were considered to determine if their function could have served as sleeping quarters. Material assemblages (once catalogued, analyzed and mapped) helped understand differences between not only the upland and lowland regions, 
but between the two lowland regions as well. These components were all very important in understanding the four sites under investigation on Gilboa Hill. The next chapter will explore the results of these analyses in depth. 


\section{CHAPTER IV REGIONAL COMPARISONS AND ARCHITECTURAL ANALYSIS}

In order to investigate the landscape on Gilboa Hill, I used multiple lines of evidence during several analyses. Historical maps of St. Eustatius held the potential to determine if the four sites on Gilboa Hill were associated with the Michael Curvelje's plantation and understand their function in the landscape. Analysis of historical maps not only answered this research question, but also offered something more: a terminus ante quim between the late eighteenth to early nineteenth centuries and depict the area where dry stone rock features are located as being near the far boundary of the Widow Ducas' property, behind a large structure, and in an uncultivated area in the landscape. This was important as it reflects their use at the plantation may have been for a purpose other than domestic and slaves were afforded privacy given they were located behind a large structure. This might have allowed enslaved Africans working at this location an increased level of freedom to choose the construction of their domestic or labor environments. Fieldwork including mapping and testing, provided a rich data source to support comparative analyses in this investigation. By establishing regions, comparing data from the four sites to documented village environments on the island, in the Caribbean, in the United States and from ethnographic sources in West Africa, 
identifiable pattern emerged, revealing that the landscape on Gilboa Hill was unique not only to the island but to the New World as well. This was helpful in determining if the four sites on Gilboa Hill were consistent with known domestic or labor environments recovered archaeologically or in ethnographic examples from West Africa. In this chapter, I will discuss in detail the results of the findings from using the methodology outlined in the previous chapter. The next chapter will review the results of the material assemblage analysis.

\section{Historical Maps}

The lack of historical documentation describing labor activities in the Northern Hills presented a challenge in determining the nature of the four sites located on the third ridge; however, it was the assumption that if an affiliation to a specific plantation were made, then the type of plantation would potentially offer additional clues to help diagnose the dry stone rock features' intended purpose. In addition, since the initial premise for this investigation included the association of sites located on the third ridge of Gilboa Hill to the Michael Cuvilljes plantation located on the first and second ridge, it was important to consider whether historical records substantiated this claim. Using aerial photographs, satellite images and historic maps of St. Eustatius from 1774 to 1989, the four sites on Gilboa Hill were located and then compared between earlier and later maps to determine if an affiliation to a specific plantation was possible and if plantation boundaries changed over time. Examining these maps and images proved only to raise more questions.

In Figure 3, a magnified sample from the 1781 map of Gilboa Hill depicts two plantations in close proximity to the four sites. Historical records listed the sizes of only 
one of the two plantations: Michael Cuvilljes's plantation was 158 acres with three roads running through his property, and Widow Ducas' plantation of an undetermined acreage with only one road. Again, without historical records of direct ownership of the sites located on the third ridge, it is impossible to know for sure which plantation affiliation these sites have, but visual observations seemed to indicate that Widow Ducas' plantation would have been more likely associated with the sites on the third ridge, not Michael Cuvilljes's plantation as originally suspected. This was determined by the physical location of two dry stone rock walls (observed during fieldwork) and the four sites in relation to these walls. In Figure 3, blue X's denote the four sites on Gilboa Hill and the red lines are the dry stone rock walls that run along the third ridge.

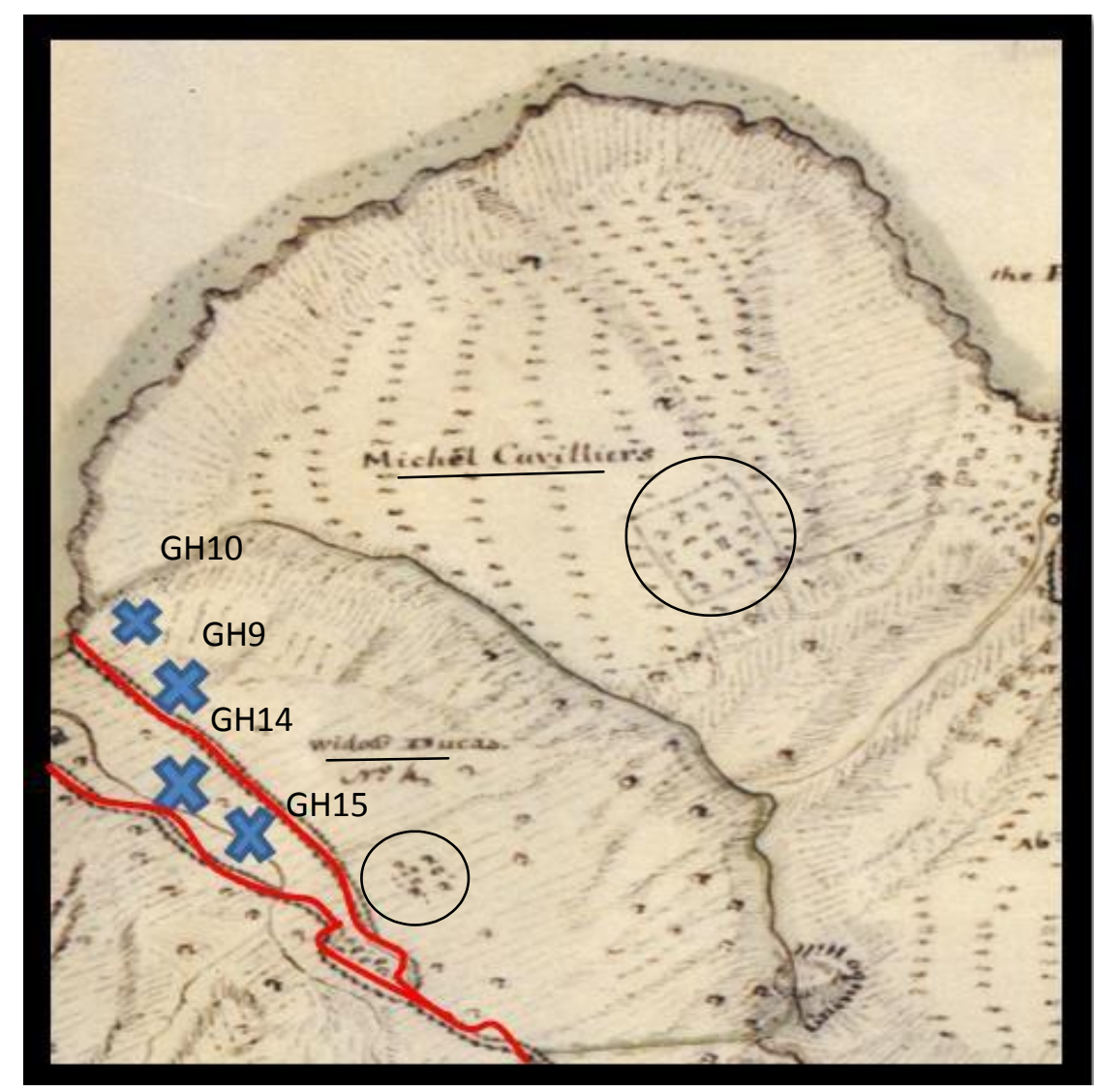

Figure 3. Historical Map of St. Eustatius, 1781 
Originally, my first impression was that Widow Ducas' property was misrepresented on historic maps of Gilboa Hill given that historical documents account for the ownership of 473 acres, however, upon further investigation I realized that the property where the four sites are located was actually the smallest of the properties she owned. The majority of her property was in the lowland region of the island, including the land of the Schotsenhoek slave village, discussed in greater detail later in this chapter. This was a surprising discovery as most plantations on St. Eustatius with less than 300 acres in total cultivated land were not used for sugar cultivation, but were documented as such so the owner could participate in the illicit processing of sugar cane arriving from the port. This suggests both properties, owned by the Widow Ducas and Michael Cuvilljes, might have had another purpose given their small size. This could have included a number of other labor purposes including the cultivation of other crops, slave provision grounds, the care of livestock, or even the construction of additional facilities. With the loss of most historical accounts in a fire near the late nineteenth century, an archaeological investigation in this region of the northern hills held the potential to answer many questions.

Another concern included the potential for erroneous affiliations of plantation boundaries in previous archaeological investigations with the lack of depiction of identifiable structures further making this problematic. Using Figure 3 again as an example, Michael Cuvilljes' bustling plantation is clearly the largest on the 1781 map and his direct connection to the sugar industry in historical accounts offers a potential purpose for the dry stone rock features on Gilboa Hill. Yet the location of the dry stone rock walls 
during fieldwork clearly indicates, once again, the four sites under investigation quite possibly belonged to the Widow Ducas. Given that she was not directly affiliated with the sugar industry, it is highly probable that these sites were related to other labor activities in the mountainous landscape.

To support this I reviewed historic maps from 1781 to 1795 of the island. In Figure 3, the 1781 map does not depict a clear plantation complex (small circle) on the Widow Ducas' property nor does it have clearly defined boundaries, which might indicate that there was less activity at this location, however, what is telling is the map of 1795, (Figure 4). This map does depict a large, well-defined plantation complex and delineates the boundaries of the property; this could indicate a clear change in the level of activity over time. Archaeological interpretations of the historical record warrant caution to avoid misrepresenting a property, by its boundaries or structures depicted on historical maps. Archaeologists must acknowledge subtle changes in possible activity or function over time as well. Even though Michael Cuvilljes' plantation on all historical maps attests to the consistent level of activity, his property was not the only active plantation in the area it would seem.

Additionally, the location of the four sites in this investigation are not depicted in the 1795 map of Widow Ducas' property in association with the area for cultivation (the cleared, flat area with obvious plowed rows) but rather behind a structure in what appears to have more natural topography. Given the location of the four sites in this investigation are not directly depicted with plantation activities, were located in what appears to be a less favorable location, and are near the outer boundaries of the plantation, I think it is 
possible two of the four sites (GH14 and GH15 with terracing) were provision grounds. Unfortunately, by 1829 the historical record became elusive and one only plantation is depicted on Gilboa Hill with no information of ownership. Our window for this investigation appears to be between the late eighteenth to early nineteenth centuries based on the maps I reviewed. Historical property boundaries can be ambiguous from one map to the next and make it incredibly difficult to determine ownership. Further, specific structures depicted on historic maps have to be examined carefully to determine their possible function in the plantation landscape.

Similarly, two-dimensional maps are a 2D rendering of 3D space and lack the ability to depict the accurate terrain on Gilboa Hill. In the 1795 historical map of the island, (Figure 4 with both Widow Ducas and Michael Cuvilljes' properties labeled), the depiction of the plantations on Gilboa hill are deceiving. The natural topography of this mountainous landscape is far from flat; without accurate scale and elevation, houses become inappropriately set on the landscape. Widow Ducas' house, for instance, appears to be located in the valley on the north side of the mountain, in actuality the house at this location would be dangling off the side of the mountain. Another example is in the 1829 map of the island (Figure 5) that depicts only one plantation on Gilboa Hill. Not surprisingly, many sugar plantations by the mid-eighteenth to nineteenth century were in decline, but this offers little help in determining the dry stone rock features potential location in the plantation landscape or providing a date of construction for the dry stone rock features on Gilboa Hill. However, they do identify the property boundaries in the current natural landscape that can be used as a guide in the field. If the four sites on 
Gilboa Hill were part of other labor activities unrelated to sugar production (as part of a wider landscape of labor in the mountains) then the lack of clearly defined boundaries on historic maps with relation to the natural terrain is problematic for another reason as well. It makes it difficult to find the location of these activity areas and their intended purpose.

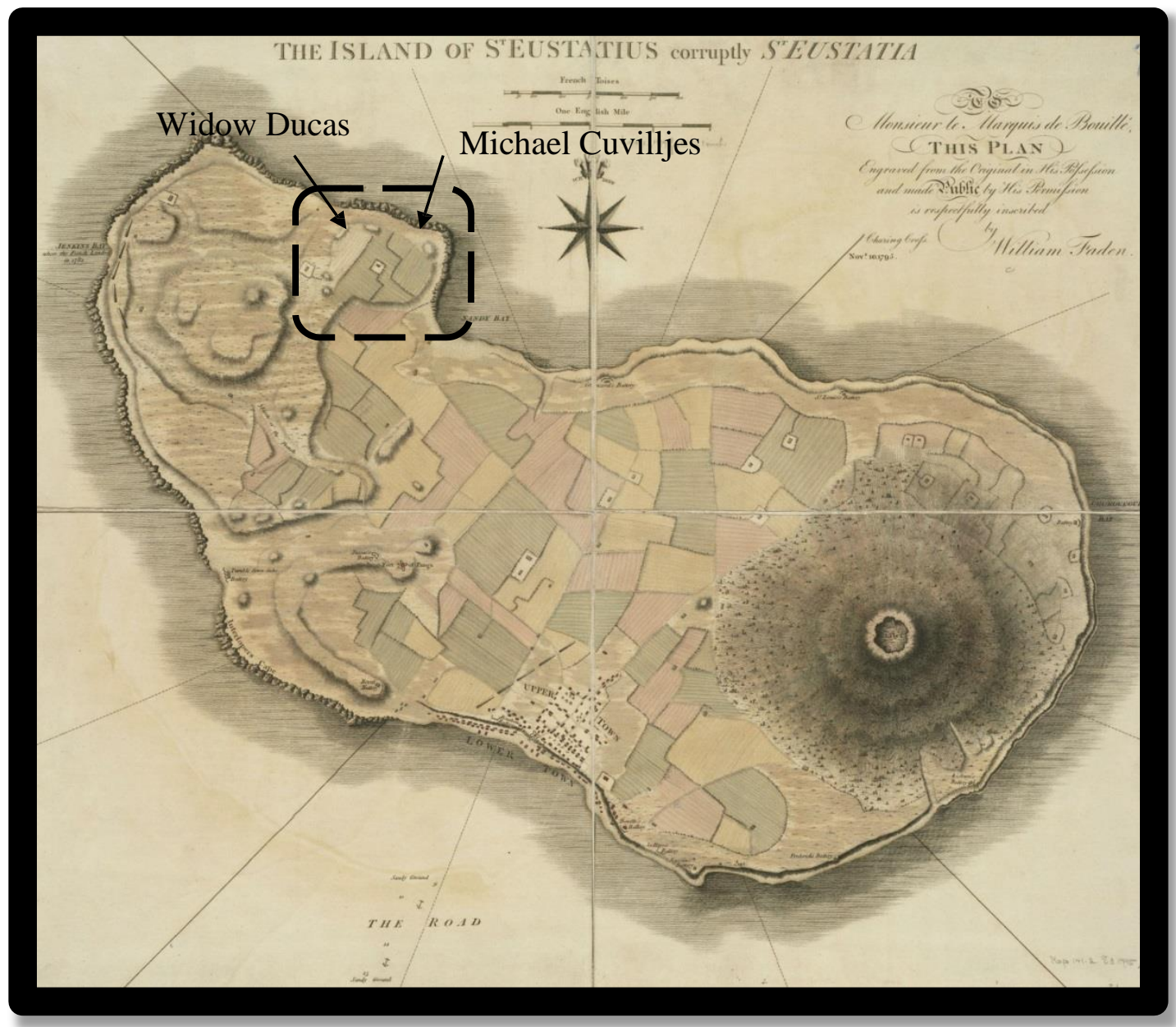

Figure 4. Historical Map of St. Eustatius, 1795 (Survey area noted in black) 


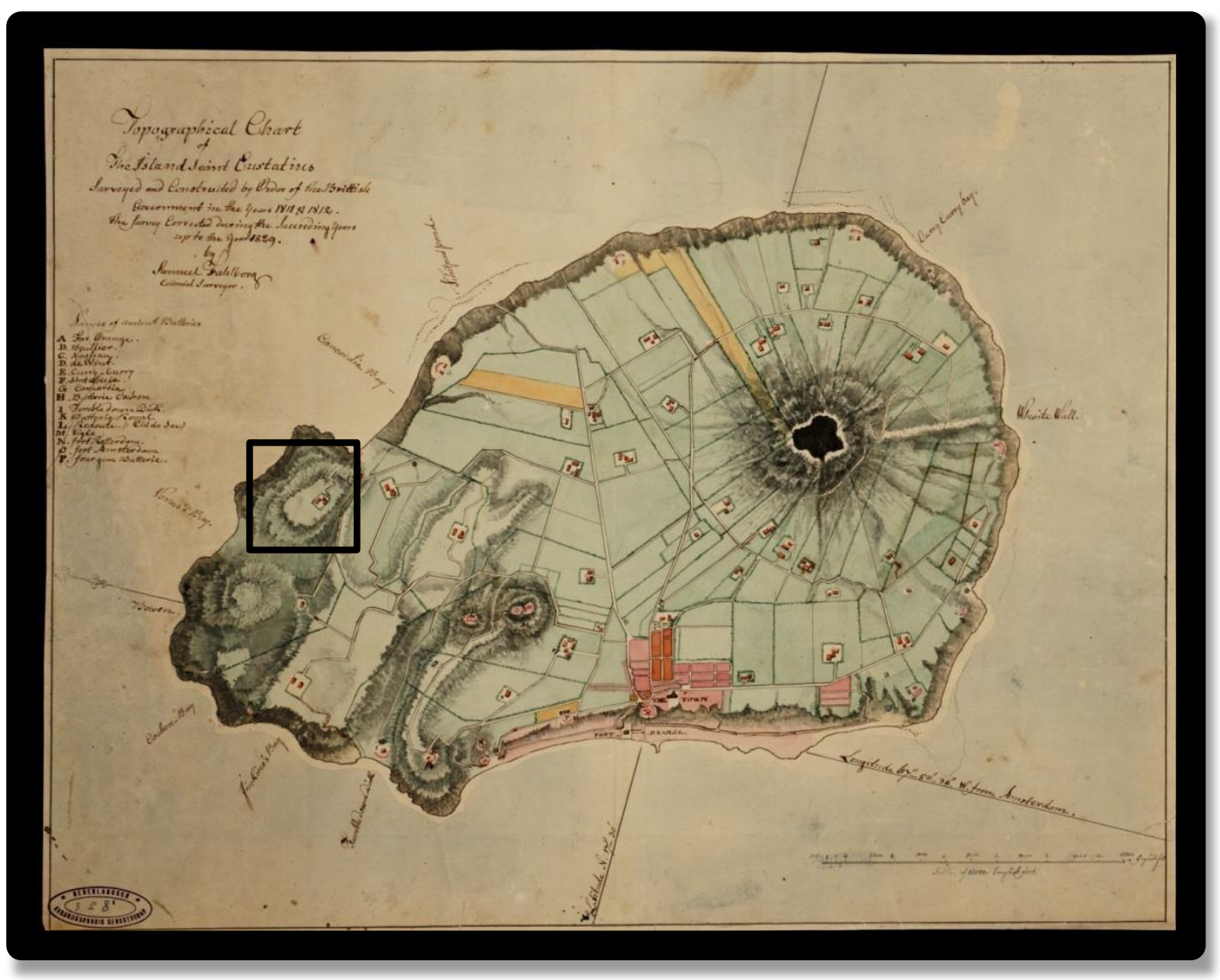

Figure 5. Historical Map of St. Eustatius, 1829

(Survey area noted in black) 
Determining the boundaries of both Widow Ducas and Michael Cuvilljes plantations, with the available depictions of boundaries for the plantations, are vague at best. The 1963 aerial photograph (Figure 6) illuminates the possibility that plantation boundaries might have been based on natural physiography, with two of the three ridges acting to separate plantations across the landscape. For example, the Widow Ducas' property might have been on the third ridge and Michael Cuvilljes' property might have been on the second or first. The white arrows depict both the Widow Ducas and Michael Cuvilljes' properties indicating where the natural landscape acted as possible boundaries. Without further historical documents to identify boundaries, though, the origin and purpose of the four sites on the third ridge remains ambiguous.

\section{Summary}

After examining historic maps of St. Eustatius from 1774 to 1989, the plantation belonging to the Widow Ducas appeared to be in closer proximity to these sites; a significant find that was later substantiated during fieldwork. Since sugar plantations were organized into tightly nucleated arrangements, the location of the sites on the third ridge of Gilboa Hill appear to conflict with efficient spatial orientations noted on sugar plantations in the Caribbean, that is, if they were truly associated with the Michael Cuvilljes plantation. Unfortunately, the historical record is silent. It is unclear whether Michael Cuvilljes sold parcels on Gilboa Hill, or if these parcels were used for other purposes besides sugar cane cultivation and processing, or if the sites on Gilboa Hill were even associated with his plantation. If Widow Ducas did indeed own the land on the third ridge, it raises the important question of what purpose they served since the majority of 
her property was located in the center of the island and the small, narrow parcel of land on the third ridge was not entirely used for the cultivation of sugar. With sites in this investigation depicted on land not suitable for sugar cultivation and their remote location behind a larger structure at the Widow Ducas' plantation, the land shares similarities of documented provision grounds on other islands: remote and on undesirable land like those recorded on Antigua, St. Kitts, St. John, Nevis, Dominica, Martinique, Barbados and Jamaica (Armstrong 1999, 2001, 2009; Bates and Galle 2012; Delle 1998; Heath and Bennett 2000; Higman 2001; Lenik 2012; McKee 1992; Mintz 1974; Pulsipher 1994; Ruppel et al. 2003). 


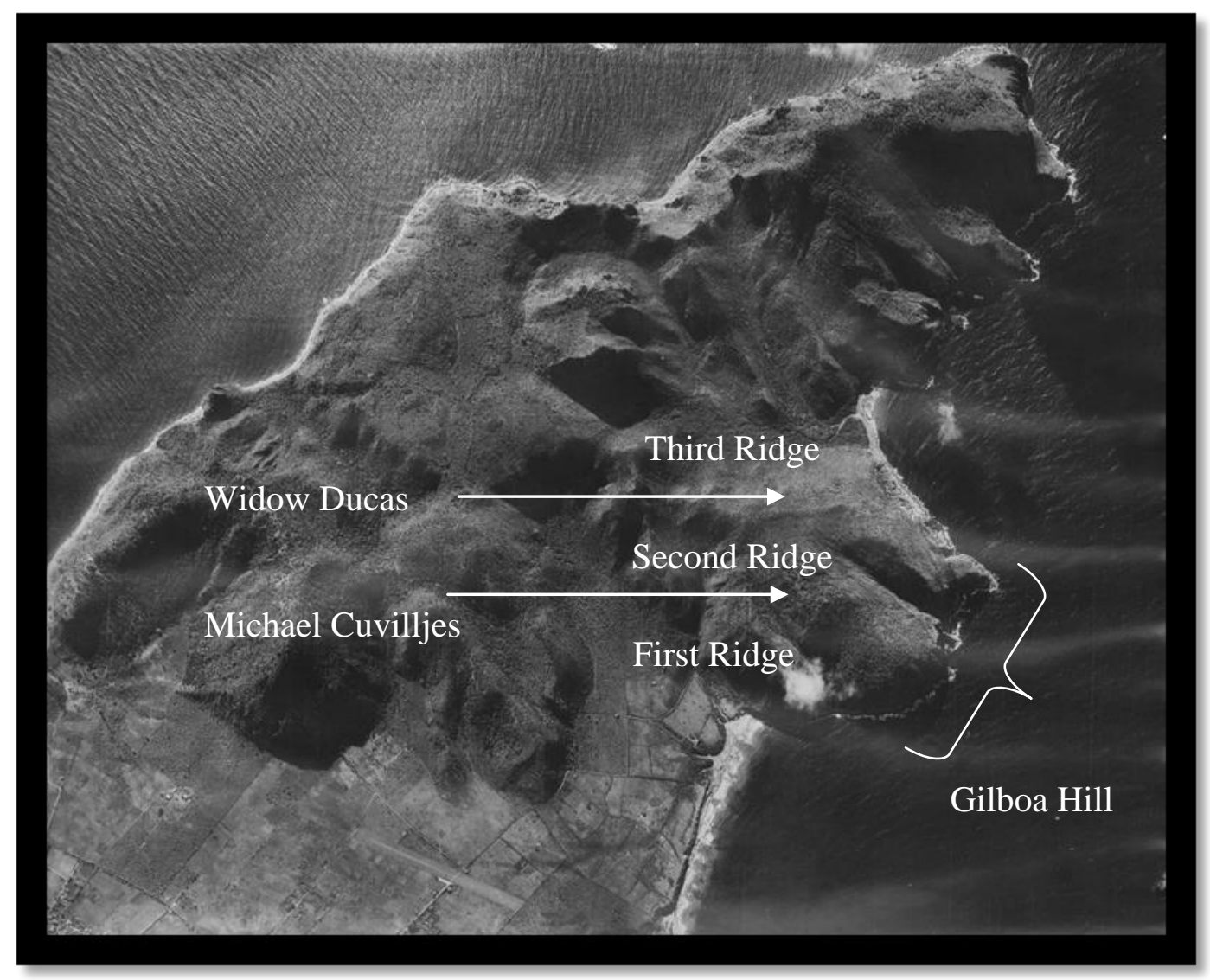

Figure 6. Aerocarto KLM Composite Image of the Northern Hills, 1963

\section{Regional Comparisons}

\section{Upland Regions}

Each of the four sites on Gilboa Hill do appear to be unique in their specific

location, quantity of dry stone rock features and their placement across the landscape, however, observations during fieldwork of the physical environments accompanied with site specific data collection easily separated the four sites into two distinct upland region along the third ridge. The lack of recognizable structural features, posthole presence, and 
distinguishable uniformity in dry stone rock features coupled with the paucity of artifacts expected in domestic occupation environments brought into question the nature of the sites on Gilboa Hill.

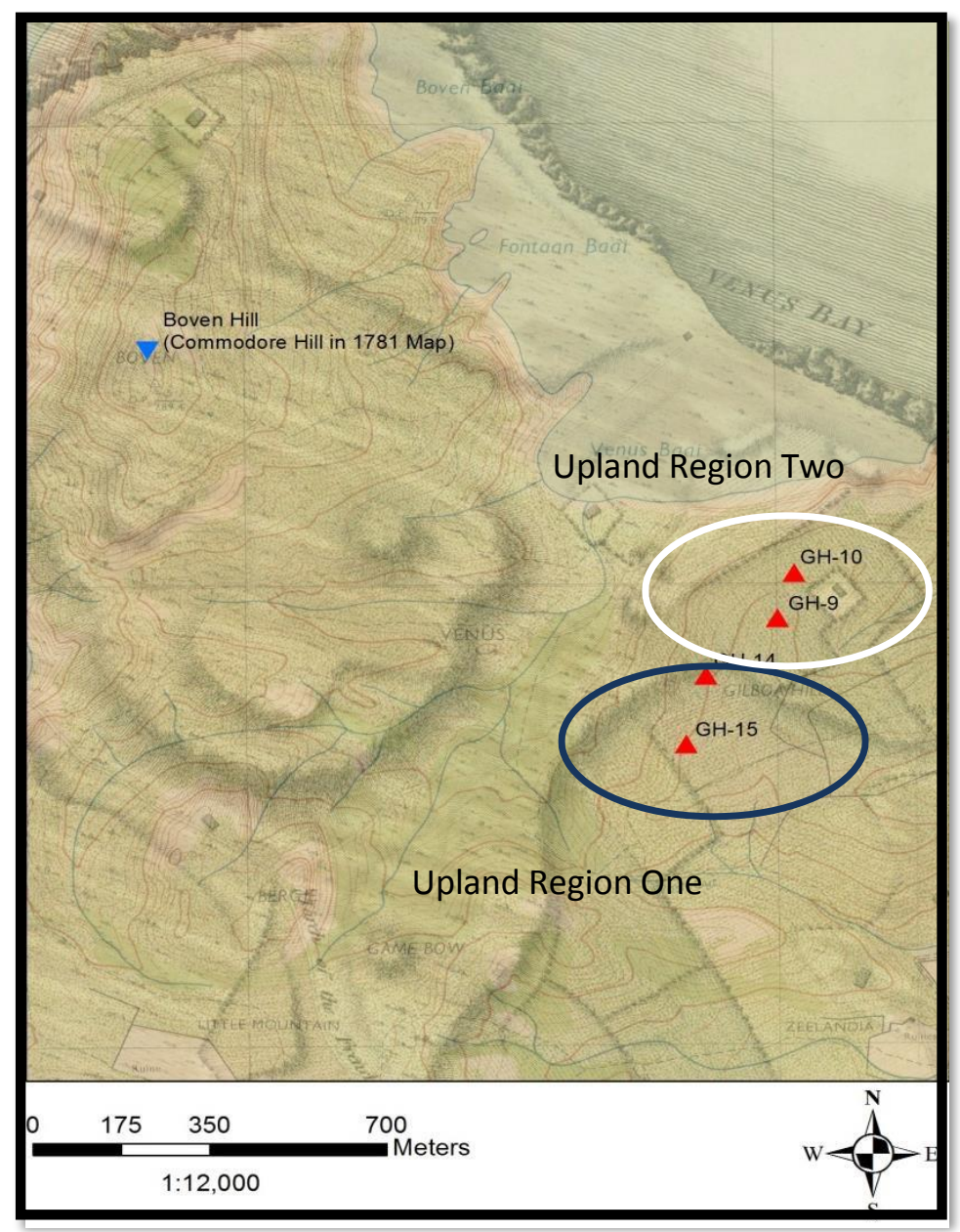

Figure 7. Overlay of Maps from 1795 and 1963 of Gilboa Hill of Upland Regions 
Upland Region One. This region consists of two archaeological sites on Gilboa Hill on the southern end of the third ridge, GH15 and GH14, (Figure 7 noted with a dark blue oval). This upland region, characterized by thick, new growth forested canopy, extensive fallen foliage ground cover, abundant bromeliads and other tropical plant life, has limited sun exposure. The two sites in this region, situated along the western edge of the third ridge, benefit from the lack of trade wind exposure being on the windward side and have noticeable well-constructed dry stone rock features. Five dry stone rock features discovered in the far west corner of GH15 were adjacent to a dry stone wall at the cliff's edge extending to the northeast for approximately $39 \mathrm{~m}$. The rock features located at GH15 ranged in size from $2.1 \mathrm{~m}^{2}$ to $4.185 \mathrm{~m}^{2}$ in total area and were oval in shape. Rock features at GH14, were more numerous, 19 in total. These rock features included three circular dry stone features ranging from from $3 \mathrm{~m}$ to $3.4 \mathrm{~m}$ in diameter, 12 oval dry stone features ranging from $3.57 \mathrm{~m}^{2}$ to $11.6 \mathrm{~m}^{2}$ in total area, and two rectangular dry stone walls; one $4 \mathrm{~m}$ in length, the other $10.2 \mathrm{~m}$ in length.

Most vistas from these two sites were obstructed by a large canopy of trees, creating a sense of seclusion at the sites, but trees at these location are new growth and were likely not part of the landscape during the time of enslavement. Even still, GH14 and GH15 are located on a steep incline and likely afforded enslaved Africans moderate seclusion upslope from the large structure depicted in the historical map from 1795. Only one vista, from GH14's far western dry stone cliff wall, facing west, revealed a clear view of Boven Hill, (Figure 8). The only other clear vista was directly south of both 
GH14 and GH15 just before the bend to continue north along the trail, (Figure 9). These vistas were an important consideration when defining Region One as they indicated a possible higher level of seclusion or privacy, upslope from the plantation complex, for laborers working at these two sites. This increased privacy might have translated into a higher degree of ideological freedom in the construction of their domestic and labor environments.

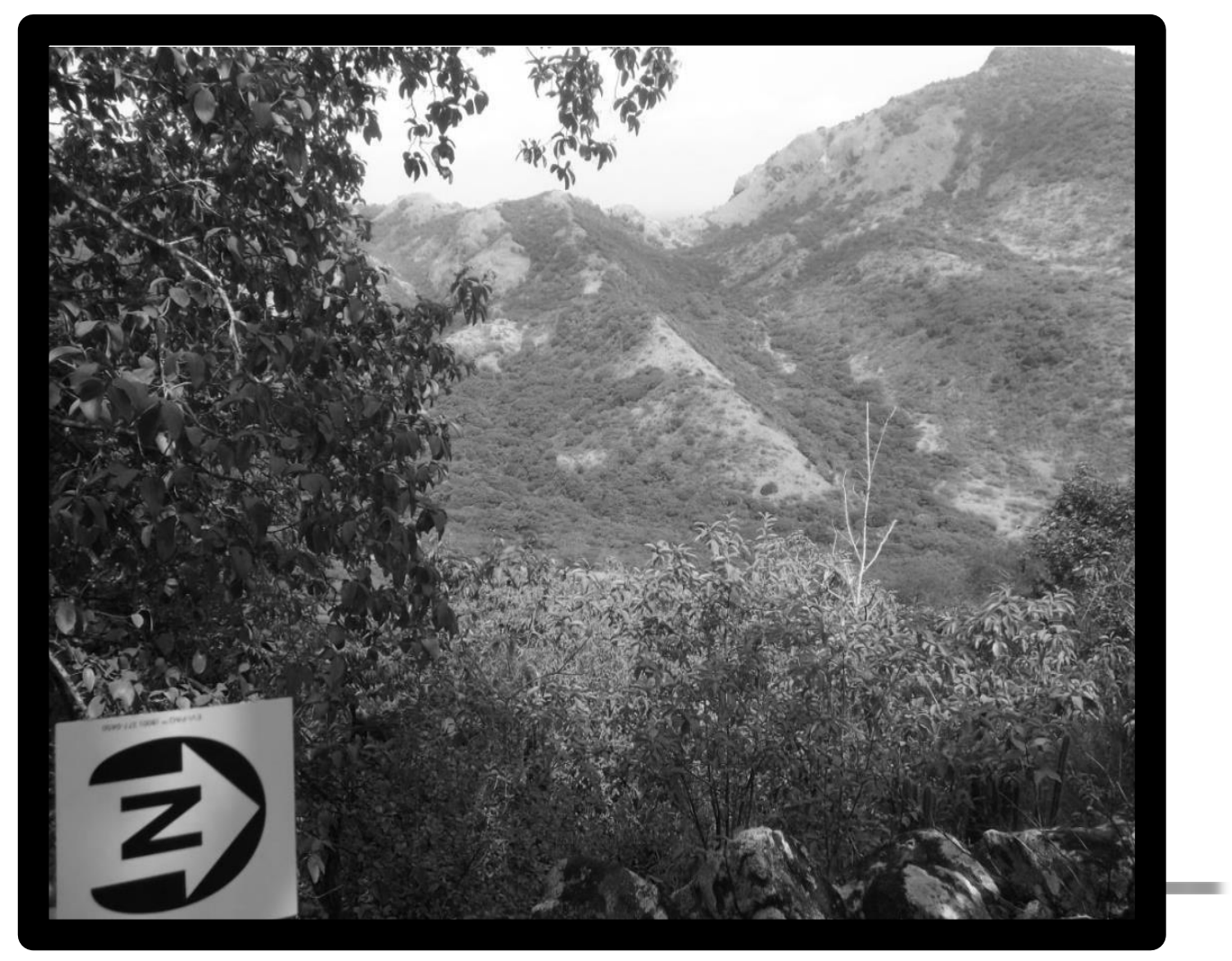

Figure 8: Vista Looking to Boven Hill 


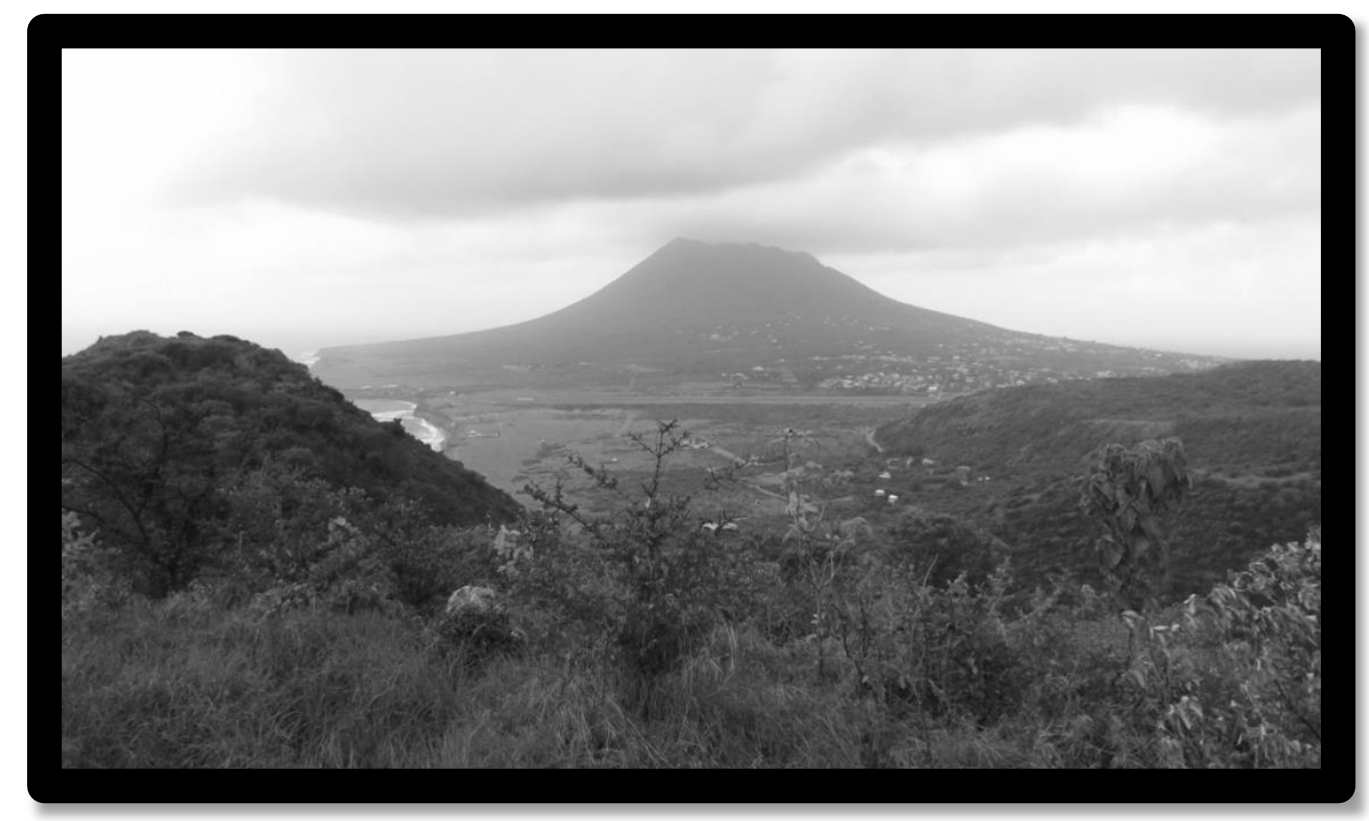

Figure 9. Third Ridge Vista Facing South

One table discovery during the regional comparison was distinctive dry stone terracing walls running along a northern axis only in the first Upland Region on Gilboa Hill. It is not only unique to Gilboa Hill, but is the only terracing documented on the island to date. Of these, five dry stone terracing walls were located at GH15; they ranged in length from $11 \mathrm{~m}$ to $16 \mathrm{~m}$, with only the top wall fully intact, (Figure 10 depicts terracing at GH15). Seven dry stone terracing walls were identified in the upper eastern portion of GH14 as well, ranging in length from $23 \mathrm{~m}$ to $33 \mathrm{~m}$, Figure 11 depicts the the top dry stone terracing wall located at GH14. This dry stone wall construction at GH14 is indicative of the prevelant construction method used to construct walls across the island. 


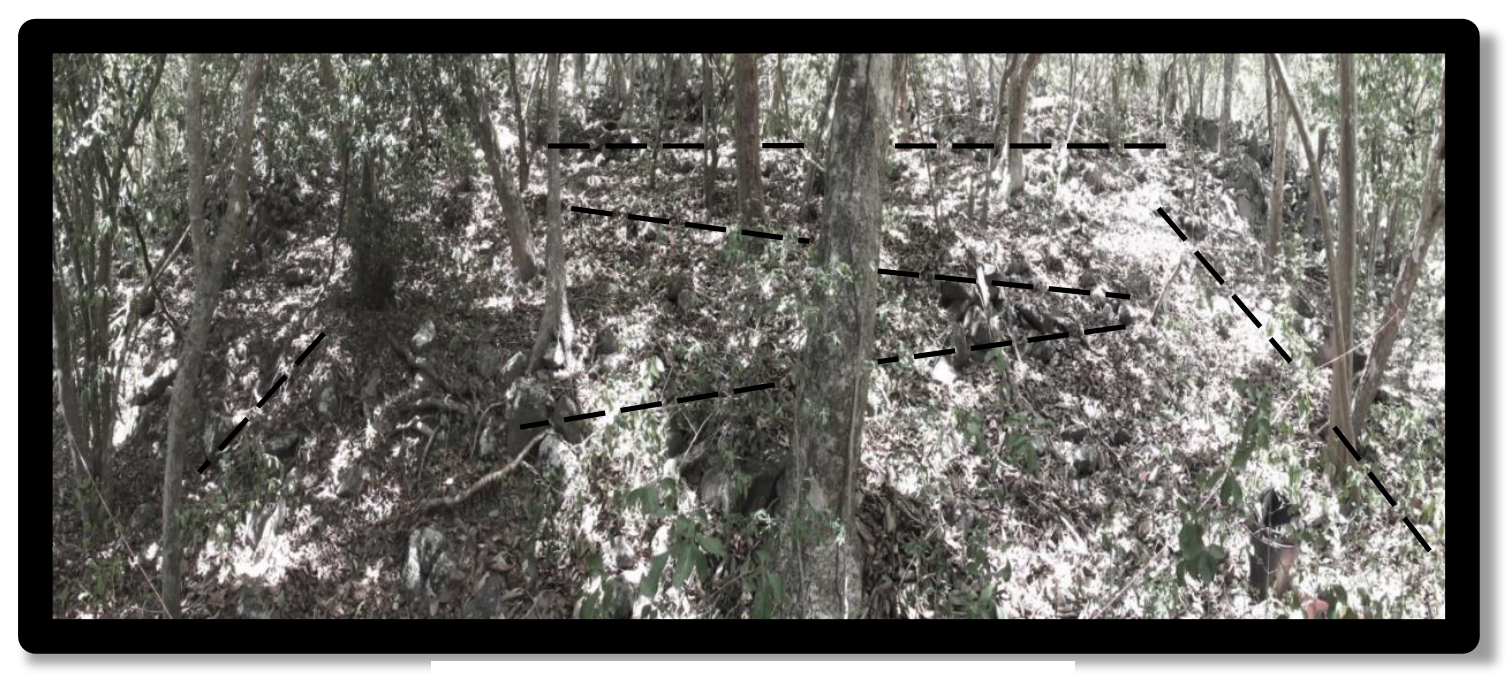

Figure 10. Terracing at GH15

While sites GH14 and GH15 shared observable terracing, terracing at these locations constrasted in not only in wall length but in their dry stone rock construction as well. Terracing walls at GH15 were shorter, ranged in length from $11 \mathrm{~m}$ to $16 \mathrm{~m}$, and were not tightly constucted; only the top wall was fully intact. They were orientated slightly at an angle as they desending downslope in a Z like pattern. At GH14, terracing walls were much longer, again ranging in length from $23 \mathrm{~m}$ to $33 \mathrm{~m}$ and well constructed in linear rows much like stair steps. These differences in design and construction of terracing walls at both GH14 and GH15 might indicate the difference in types of crops grown at each location. Roots crops like carrots, potatoes, sweet potatoes, and guinea yams would rot if planted in walled terraces like those observed at GH14; the high moisture would have been too much. However, the cascading terraces at GH15 would have stopped erosion and held enough moisture for their successful cultivation. Other crops like tomaotoes, okra, corn, cabbage, as well as fruit trees like avocado, mango, papaya, soursop, coconut and citrus would likely thrive in soil with higher moisture levels that the linear walls 
afforded at GH14. Additonally, with the identification of Agave groves alongside terracing at these two locations it is likely enslaved Africans carefully planned their provision grounds for efficiency. Unforutnately, not enough archaeological research in the Caribbean has focused on the cultivation strategies used by enslaved Africans in their provision grounds or the use of Agave as a cultivated crop; without a comparative sample, this cannot be confirmed at this time. 


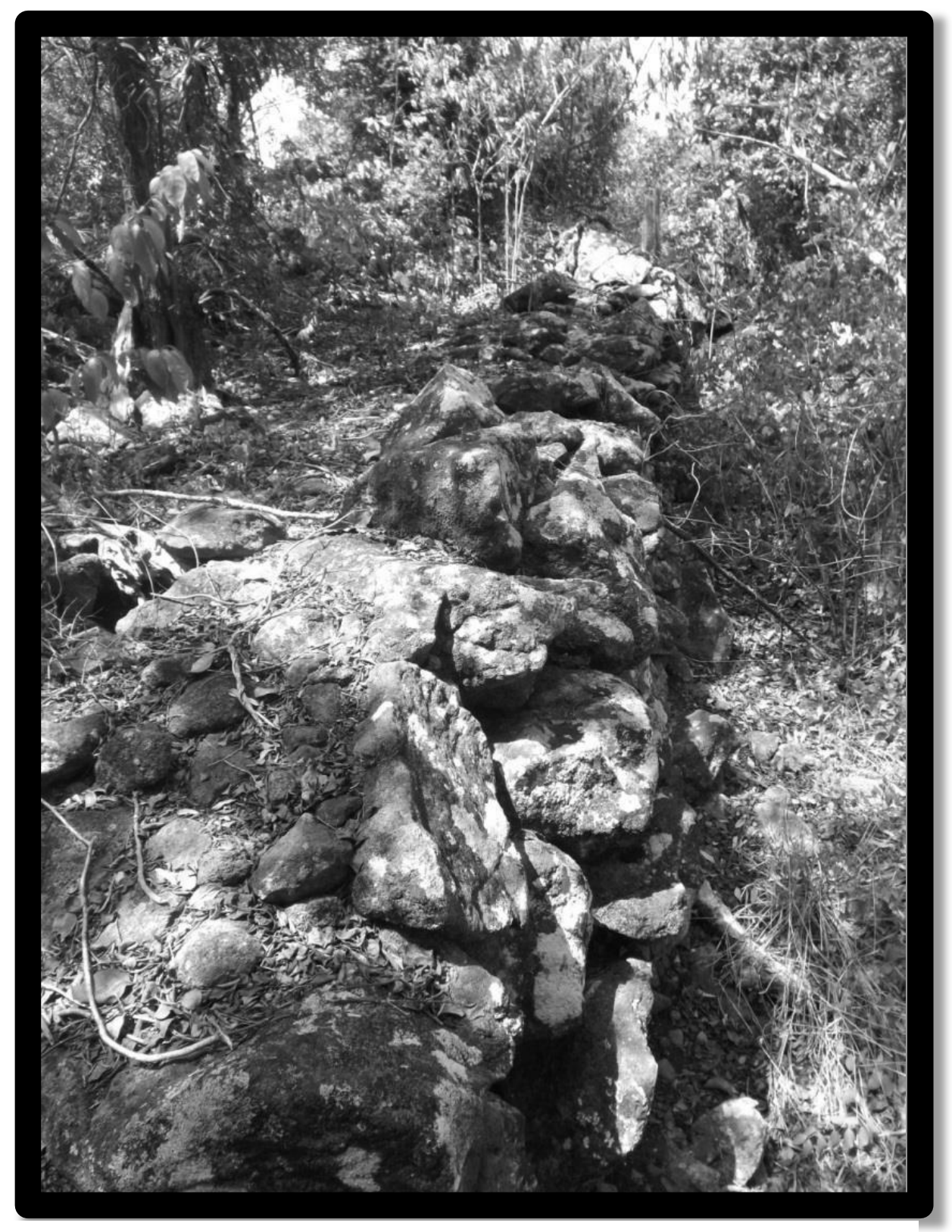

Figure 11. Top of Dry Stone Terracing Wall at GH14 
Upland Region Two. This region is characterized by a semi-arid landscape with thick, dry, tall, grassy groundcover and three small groves of trees substantially shorter than other trees on the island; possibilities for their short stature include greater sun exposure, less moisture, or new growth. Two sites, GH9 and GH10, located east of a large boulder field are at the far northern end of the third ridge; GH10 is right at the edge of the mountain, (Figure 7 marked with a white oval). The two sites sit along the eastern side of the third ridge and are exposed to fierce leeward trade winds and the sun. Dry stone terracing walls are absent at these two sites; instead only dry stone rock features dot the landscape, (Figure 12).

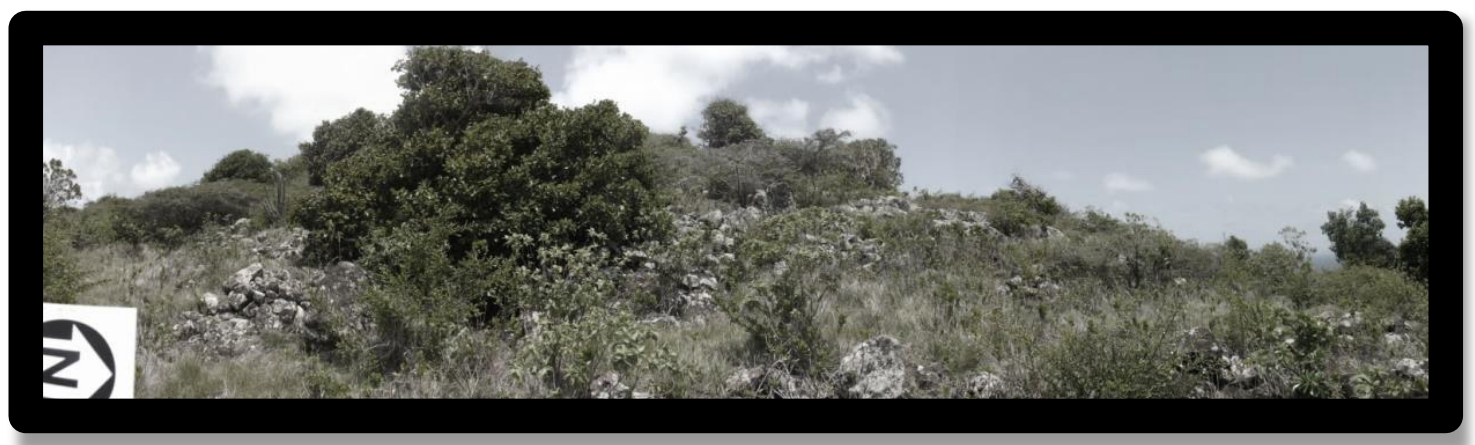

Figure 12. Dry Stone Rock Features at GH9

Dry stone rock features at GH9 include: one circular dry stone rock feature $2 \mathrm{~m}$ in diameter and six oval shaped dry stone rock features ranging from $3 \mathrm{~m}$ to $24.75 \mathrm{~m}$ in total area. GH10's dry stone rock features include: eight circular dry stone features ranging in size from $2 \mathrm{~m}$ to $3 \mathrm{~m}$ in diameter, oval shaped dry stone rock features ranging in size from $4.8 \mathrm{~m}$ to $10.5 \mathrm{~m}$ in total area, and two additional oval shaped rock features measuring 
$0.375 \mathrm{~m}^{2}$ in total area that were possible natural features utilized for water procurement. Dry stone rock features 20,21 , and 22 were rectangular in shape and located directly north of the boulder field at the top eastern portion of GH9. These rock features were spaced in a radiating pattern and had fairly uniform dimenstions, $1 \mathrm{~m}$ in width and $2 . \mathrm{m}$ to $3.5 \mathrm{~m}$ long, (Figure 13). Their unique shape and placement at the top of site GH9 represented one example of the inconsistant nature of the rock features at each of the sites investigated. Vistas for this region included the unobstructed view of the ocean to the east and northeast (Figures 14 and 15) and the view of the first and second ridges to the south (Figure 16).

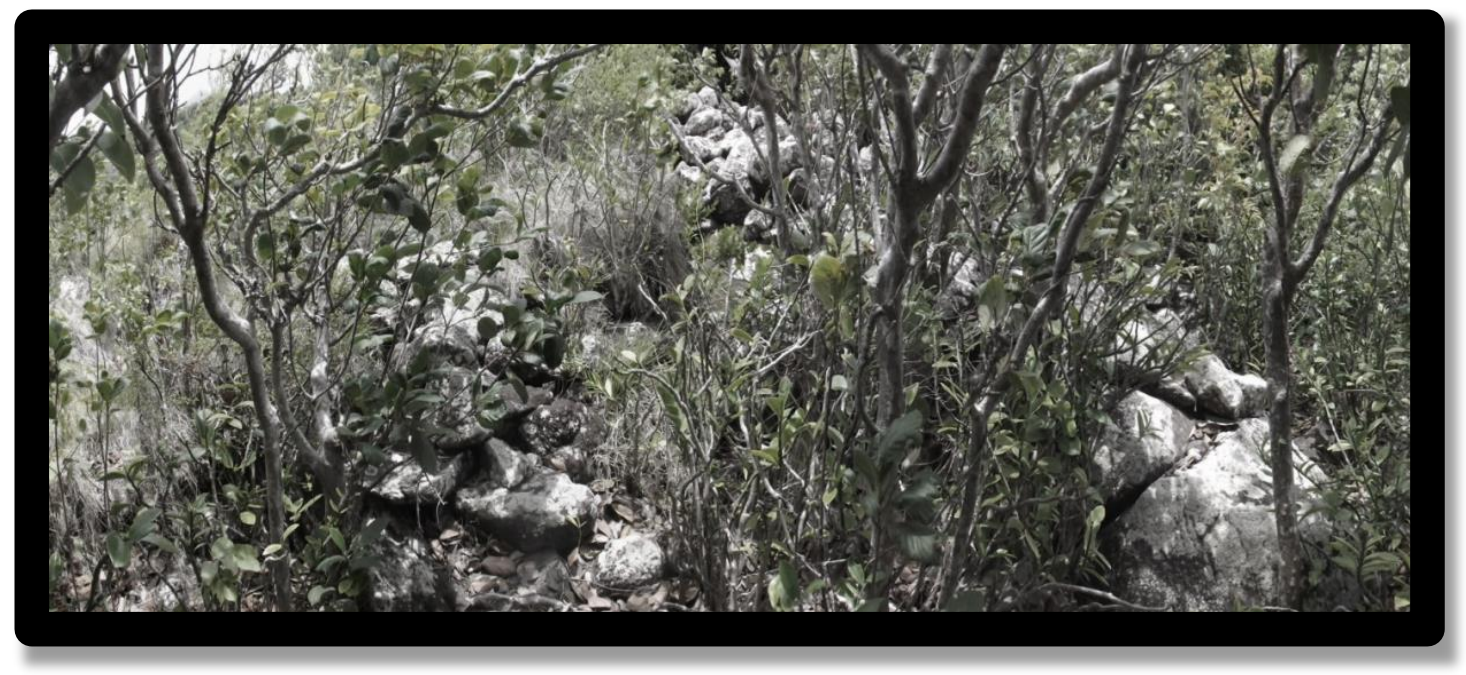

Figure 13. Rectangular Dry Stone Rock Features in Radial Pattern at GH9 


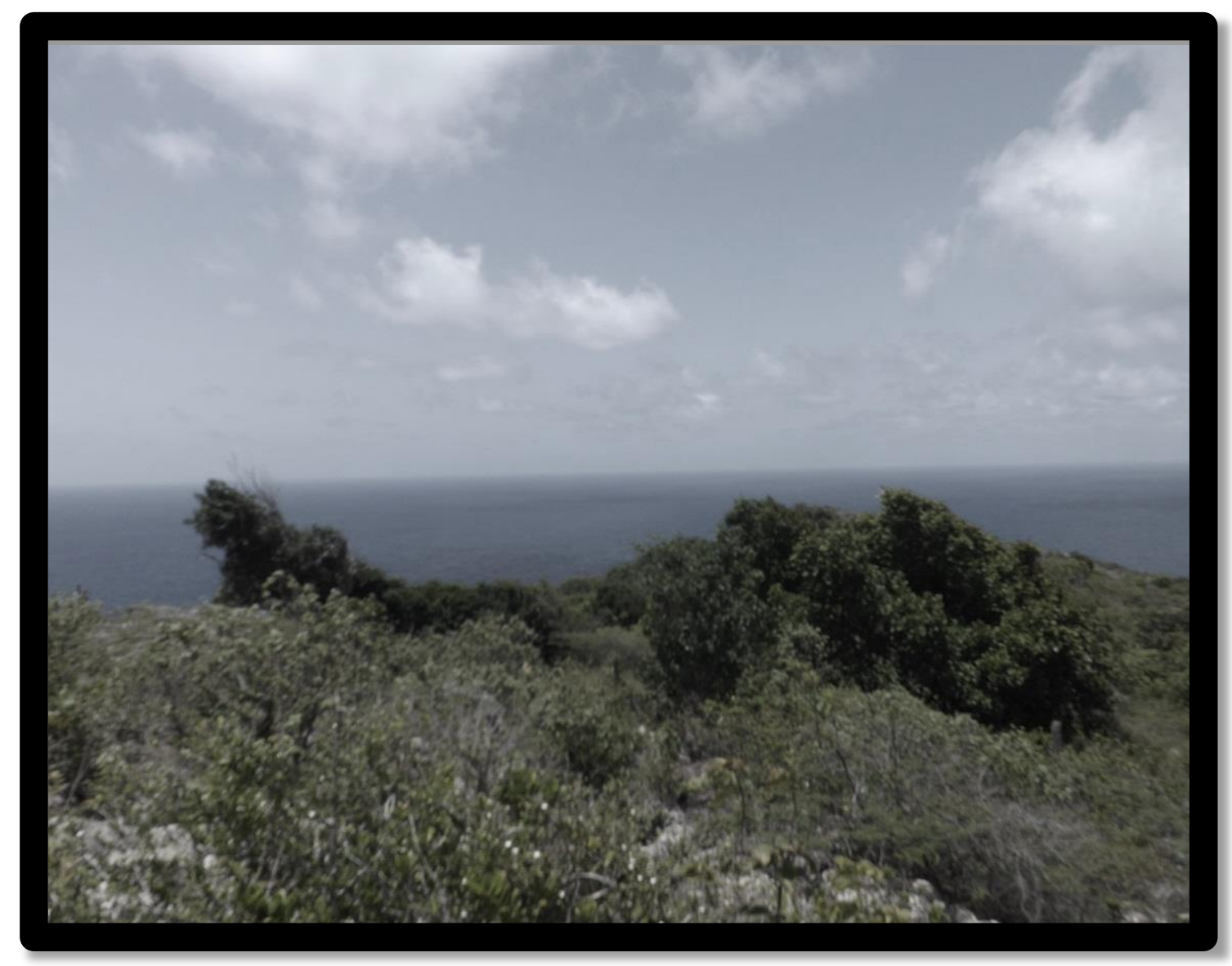

Figure 14. Vista Looking East to the Ocean from GH9 


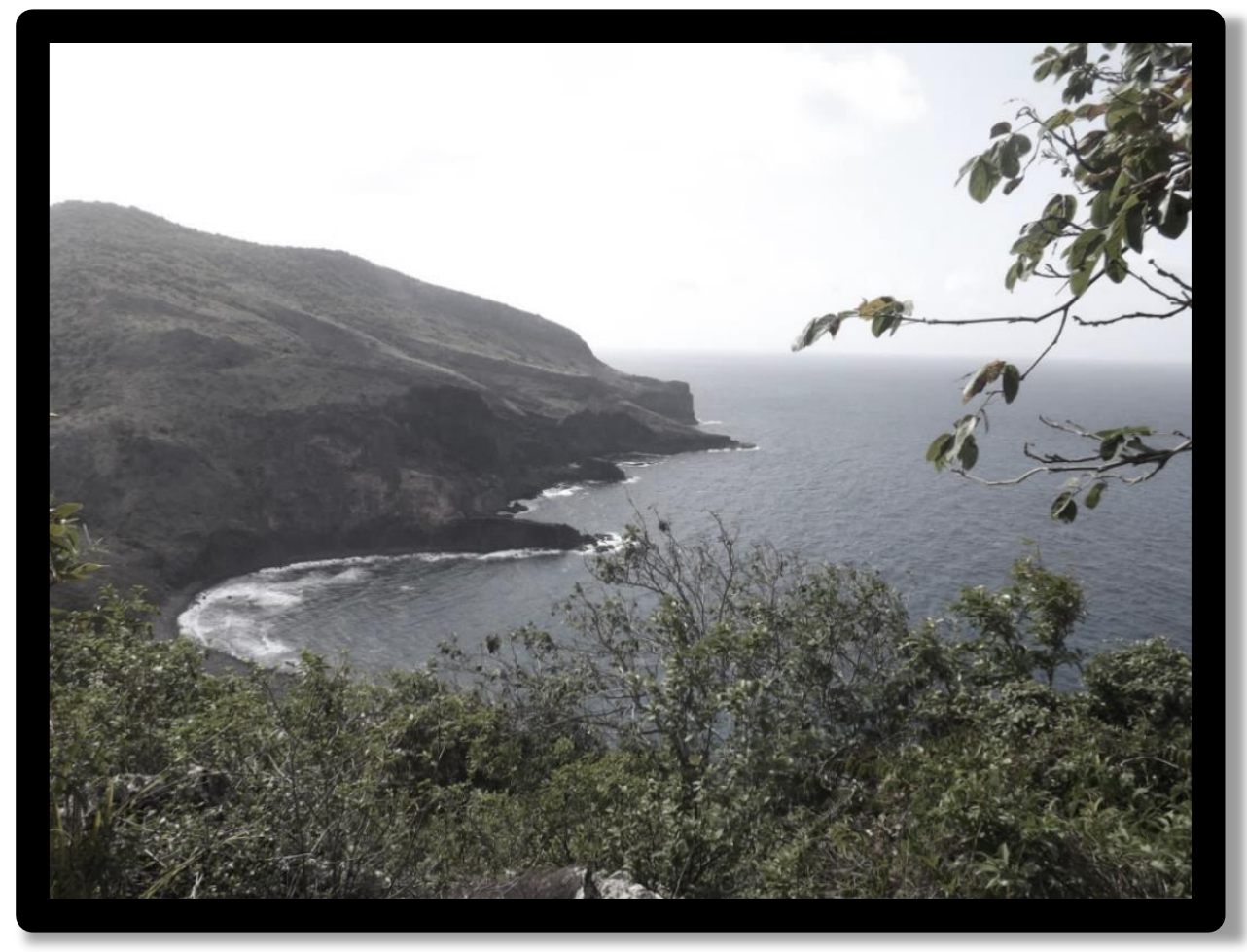

Figure 15. Vista Looking to Northeast from GH10 


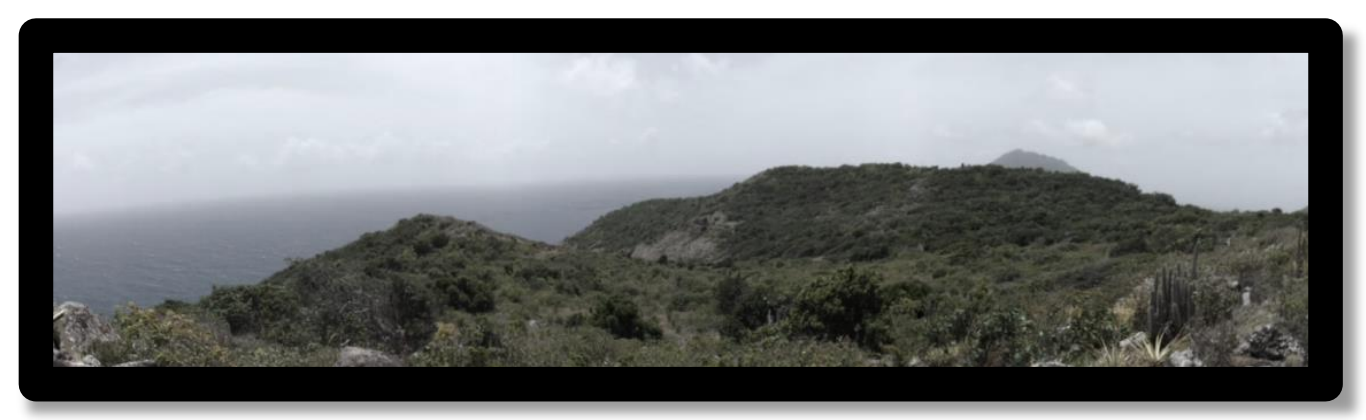

Figure 16. Vista Looking South to First and Second Ridges from GH9

\section{Gilboa Hill}

Over the course of six weeks, fieldwork (survey, mapping, and archaeological testing) conducted at each of the four sites under investigation on Gilboa Hill documented archaeological features; this provided not only a rich database, but also raised intriguing questions. To begin, the recorded archaeological features lacked evidence to support their use as dwellings; postholes were not present, associated construction debris was absent, and their size appeared to be too small for humans to either reside in or recline on. If these archaeological features were not dwellings, what were they? Additionally, an extensive survey of $9094 \mathrm{~m}$ on Gilboa Hill, or 5.6km, and subsequent testing only yielded seven artifacts. This was surprising, as one of the initial premises of this research was that the sites on Gilboa Hill, abandoned after emancipation and virtually undisturbed, would have large material assemblages. Since this was not the case, it raised questions of why not and what other purposes the sites could have had. In order to answer these questions, each site was meticulously investigated using the methodology outlined in the previous chapter; the findings are detailed below. 


\section{Potential Activity Area and GH15}

The trail up the mountain forks between Gilboa Hill's second and third ridges and following the trail up to the top of the third ridge winds through thick canopy, opens into a small overlook with tall grass and a spectacular vista before curving back into thick canopy and running the full length of the top of Gilboa Hill. It was along this winding trail, near the entrance back into the thick canopy, that GPS coordinates helped locate the general site location of GH15 as well as surface scatter located to the east of the third ridge trail against the western edge of a dry stone rock wall $2.4 \mathrm{~m}$ wide and ranging in height from $8 \mathrm{~cm}$ to $65 \mathrm{~cm}$. This wall extended $14 \mathrm{~m}$ to the south and $46 \mathrm{~m}$ to the north and continued out of sight. Surface collection consisted of scattered bones: a humerus, 3 large foot bones, molars, 6 ribs, thoracic vertebrae, cervical vertebrae, sacrum, phalange, astragulus, complete mandible, head of a tibia, skull, femur, and two unidentified bones all belonging to a large mammal. The scatter had what looked like a haphazard placement pattern across the entire $22 \mathrm{~m}^{2}$ area. This placement coupled with clear cut marks on the bones strongly indicated this was likely an activity area, where an animal died or was killed and scavenged or processed, but it was uncertain how long ago the activity had taken place. Ten STPs systematically spaced ever $1 \mathrm{~m}$ across a $20 \mathrm{~m}^{2}$ area yielded bone fragments, seeds, and small mortar chunks, but no other artifacts, and were no deeper than $30-40 \mathrm{~cm}$ before a soil change was noted. 


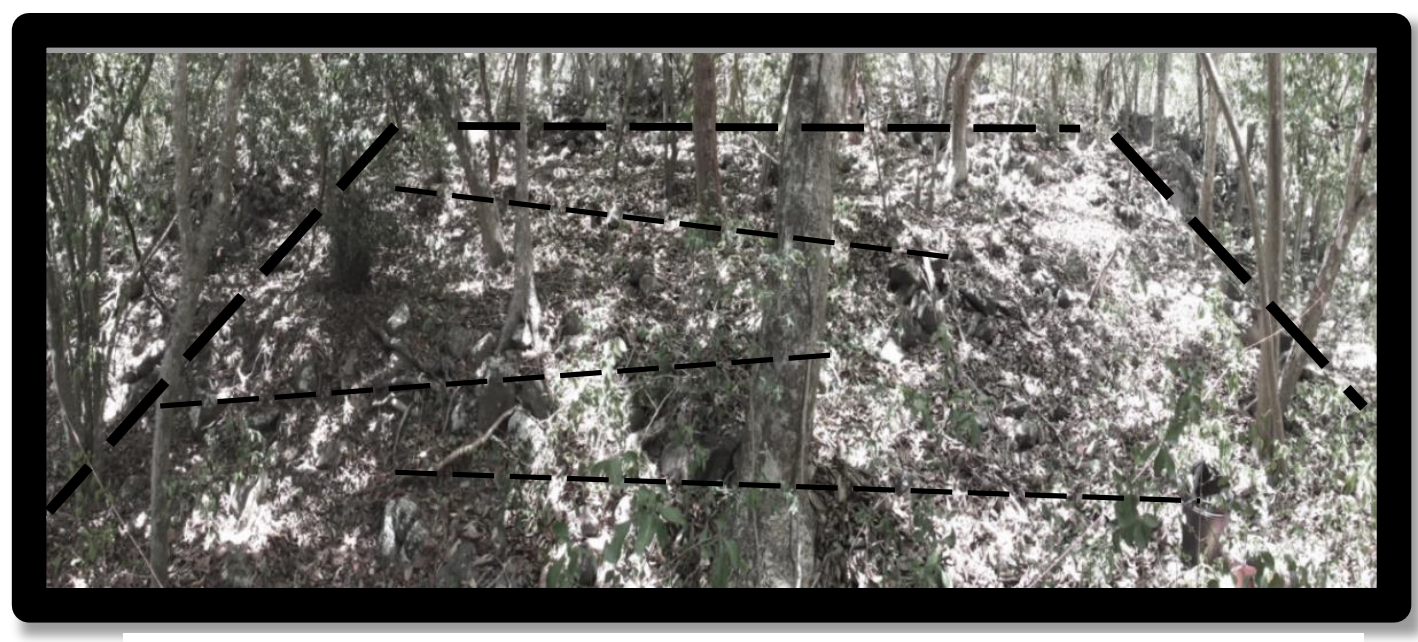

Figure 17. Terracing at GH15

(Approximate location of terracing walls depicted in black)

The upper dry stone terracing wall, was located $12 \mathrm{~m}$ to the northwest of the trail extending $63 \mathrm{~m}$ along the NE/SE axis of the top portion of site GH15. Four additional dry stone terracing walls descending downslope from the upper dry stone terracing wall were inside a walled perimeter with scattered dry stones and larger boulders to both the left and right of the terracing area, running east to west, in what appeared to be a $\mathrm{Z}$ like pattern descending downslope, (Figure 17). Following the natural terrain downslope, relatively flat $2 \mathrm{~m} \times 2 \mathrm{~m}$ areas, were sampled as likely locations for artifact recovery, and 15 randomly spaced STPs were placed throughout the slope leading to the dry stone rock features; all STPs were sterile in the terracing area. After STPs were conducted, four pedestrian survey transects, through the terracing area and lush vegetation including tropical dry forested trees, bromeliads, cacti, and thorny bushes, totaling $540 \mathrm{~m}^{2}(3 \mathrm{~m}$ wide, $2 \mathrm{~m}$ apart, and $45 \mathrm{~m}$ in length) also yielded no artifacts.

Five rock features were discovered in the far west corner of the site near a dry stone wall at the cliff's edge that extended to the northeast for approximately $39 \mathrm{~m}$ before 
continuing out of sight, (Figure 18). Upon pedestrian survey, three fragments of a stoneware vessel were located on $\mathrm{RF} 3$, in a crevice $22 \mathrm{~cm} \times 20 \mathrm{~cm}$. This find warranted the placement of seven carefully spaced STPs between RF1, RF2, and RF3 as well as along their perimeter; each STP was sterile. With the idea that a material assemblage might be located in deeper deposition at this site, in between RF1 and RF2, I dug three $50 \mathrm{~cm} x$ $50 \mathrm{~cm}$ test units, and an additional three $50 \mathrm{~cm} \times 50 \mathrm{~cm}$ test units between RF2 and RF3, with careful attention to arbitrary levels of $10 \mathrm{~cm}$ increments. Unfortunately, all testing was negative for artifacts or features before reaching bedrock at $40 \mathrm{~cm}$ to $50 \mathrm{~cm}$. Near the perimeter of the dry stone rock features, four $1 \mathrm{~m}$ brechas were cleared in the surrounding fallen debris, as before, all tests were negative. An additional activity area was encountered adjacent to the dry stone rock features to the north, in a $6 \mathrm{~m} \times 3 \mathrm{~m}$ flattened area that lacked an abundance dry stone rocks; an unusual location given that the landscape was dotted with dry stone rocks and boulders that had fallen from the slope above. Five STPs in this $6 \mathrm{~m} \times 3 \mathrm{~m}$ flattened area at the far northern corner of the site recovered fragments of burnt bark and brick, (Figure 19). 


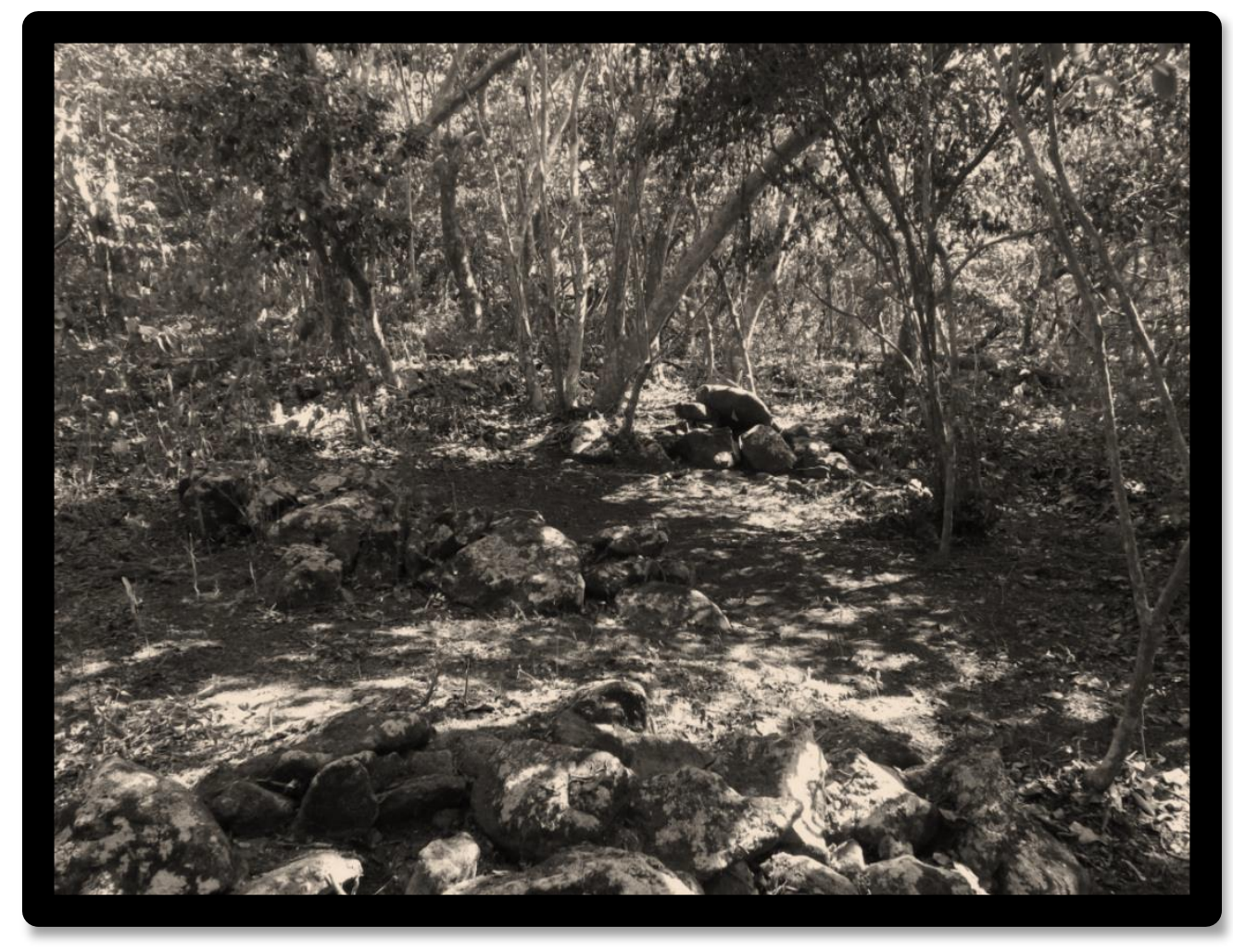

Figure 18. Activity Area at GH15 


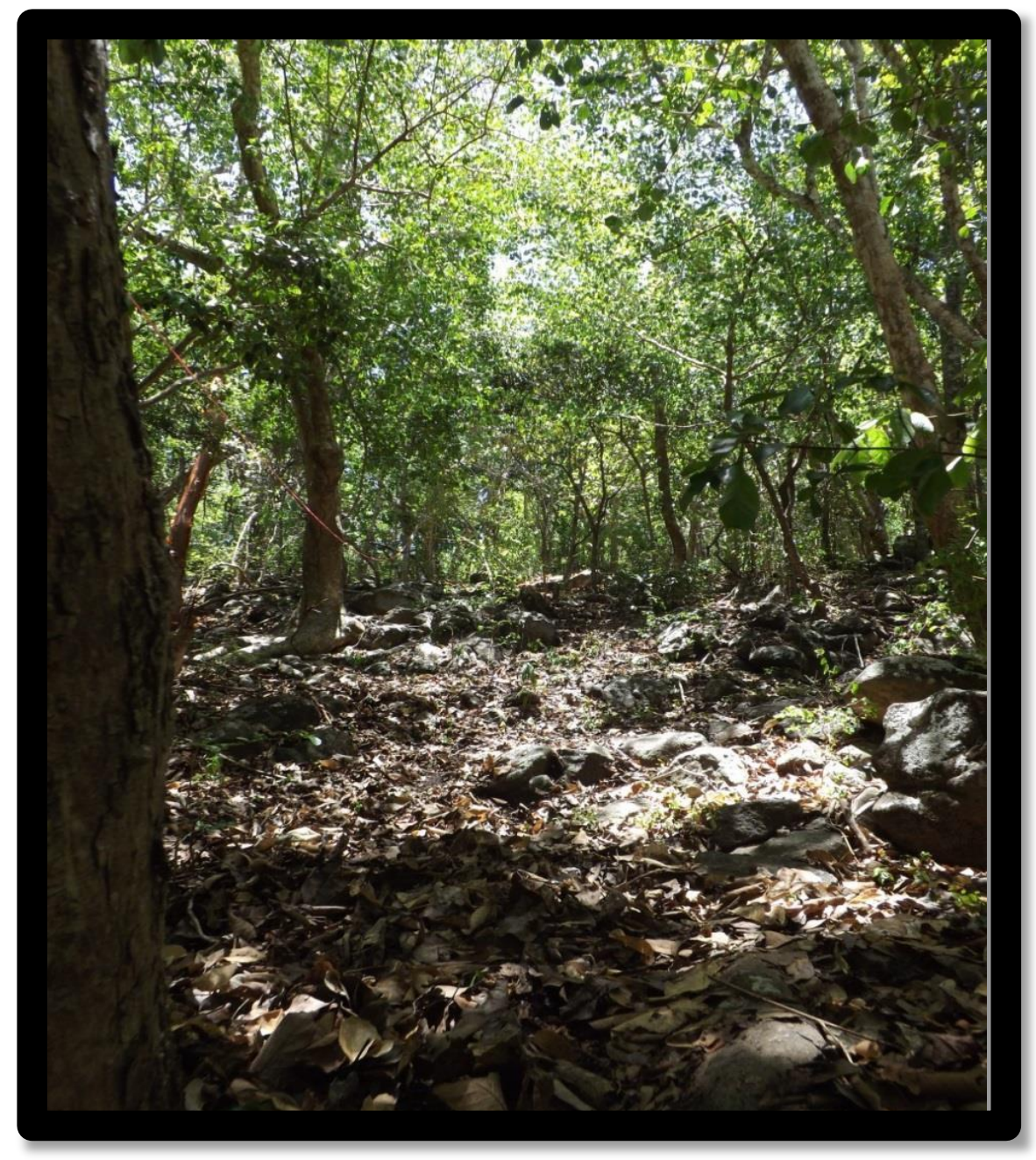

Figure 19. Three of the Five Dry Stone Rock Features at GH15 
In addition to the five dry stone rock features, a large agave grove measuring $4 \mathrm{~m}$ $\mathrm{x} 6 \mathrm{~m}$ was located along the northeast edge of the site. This was a significant find as the type of agave identified in the northern hills has a cyclical regeneration pattern whereby offshoots or suckers at the bottom of the plant extend the life of the original plant; as the flowers die, the new shoots continue to grow. This plant is commonly referred to as the century plant because it can survive multiple generations, is quite hardy, and given the size of the grove it is possible that occupants of the island would have seen or perhaps planted this grove. It raised the question whether slaves working in the area tending these potential provision grounds purposely planted this grove and the other grove later noted at GH14; it would have been a deliciously sweet addition to any recipe or used for medicinal purposes. As previously mentioned, no historical documentation to date notes the intentional cultivation or harvesting of Agave at provision grounds in the Caribbean, but I think given the species is found on most Caribbean islands, it is possible enslaved Africans exploited this hardy, native plant. Surface and subsurface testing did not recover any associated material culture associated with Agave cultivation or harvesting at this time. Their location near terracing walls at both locations warranted consideration.

In a last attempt to recover artifacts, I conducted additional testing. Three additional $50 \mathrm{~cm} \times 50 \mathrm{~cm}$ units were judgmentally placed with arbitrary levels of $10 \mathrm{~cm}$ increments along a far northeastern dry stone retaining wall directly northeast of the five dry stone rock features. These test units were also sterile and consistent with the other profiles of test units at GH15 that revealed the depth before reaching bedrock was only $20 \mathrm{~cm}$ to $40 \mathrm{~cm}$; this was not expected. This was an important discovery, albeit a disappointing one, as the original premise for this research included the possibility of 
recovering large material assemblages against retaining walls far downslope from the documented sites. These sterile units starkly contrasted with what I expected to find. If the soil deposition at this site was shallow, the probability of locating artifacts in these and subsequent units was low. Further, five additional STPs along this retaining wall were also conducted and 19 brechas were cleared to recover any surface collection both along the retaining wall and back to the top of the slope; this additional testing was negative. This was telling as surface scatter, if any existed, likely washed away rather than accumulating over time as originally assumed. At the onset of the investigation, GH15 proved to set the standard for expected finds at each of the remaining sites investigated with $3003 \mathrm{~m}$ surveyed and only three artifacts recovered.

\section{GH14}

Following the curves of third ridge trail, site GH14 was located $144 \mathrm{~m}$ north of GH15. The first visible indication of the site was the top of the dry stone terracing wall, $64 \mathrm{~m}$ in length, extending to the north, and parallel to an adjacent dry stone wall to the east. Survey of the adjacent wall extending to the north on the east of the trail found no terracing downslope from this location or dry stone rock features. Given the lack of terracing and dry stone rock walls to the east, efforts were concentrated downslope to the west of the identified terrace wall. Initial observations of the terracing at GH14 that continued to the west, indicated considerable differences in length and integrity from the terracing observed at GH15, with almost $25 \mathrm{~m}$ in consistent length comprising individual dry stone walls, without breaks. Subsequent measurements of seven additional dry stone terracing walls descending downslope in an organized, horizontal pattern $28 \mathrm{~m}$ directly to the west, indicated terracing at GH14 was extensive and well planned. Once the 
perimeter was established, 19 dry stone rock features were recorded, to the east of the terracing walls. Two of these dry stone rock features included substantial, unfinished dry stone walls (Figure 20). The wall depicted was unlike any of the other dry stone rock features documented at the four sites on the third ridge. The construction was solid, $10.2 \mathrm{~m}$ in length, and dropped off on its north end in what appeared to be a slight collapse of the construction after its abandonment.

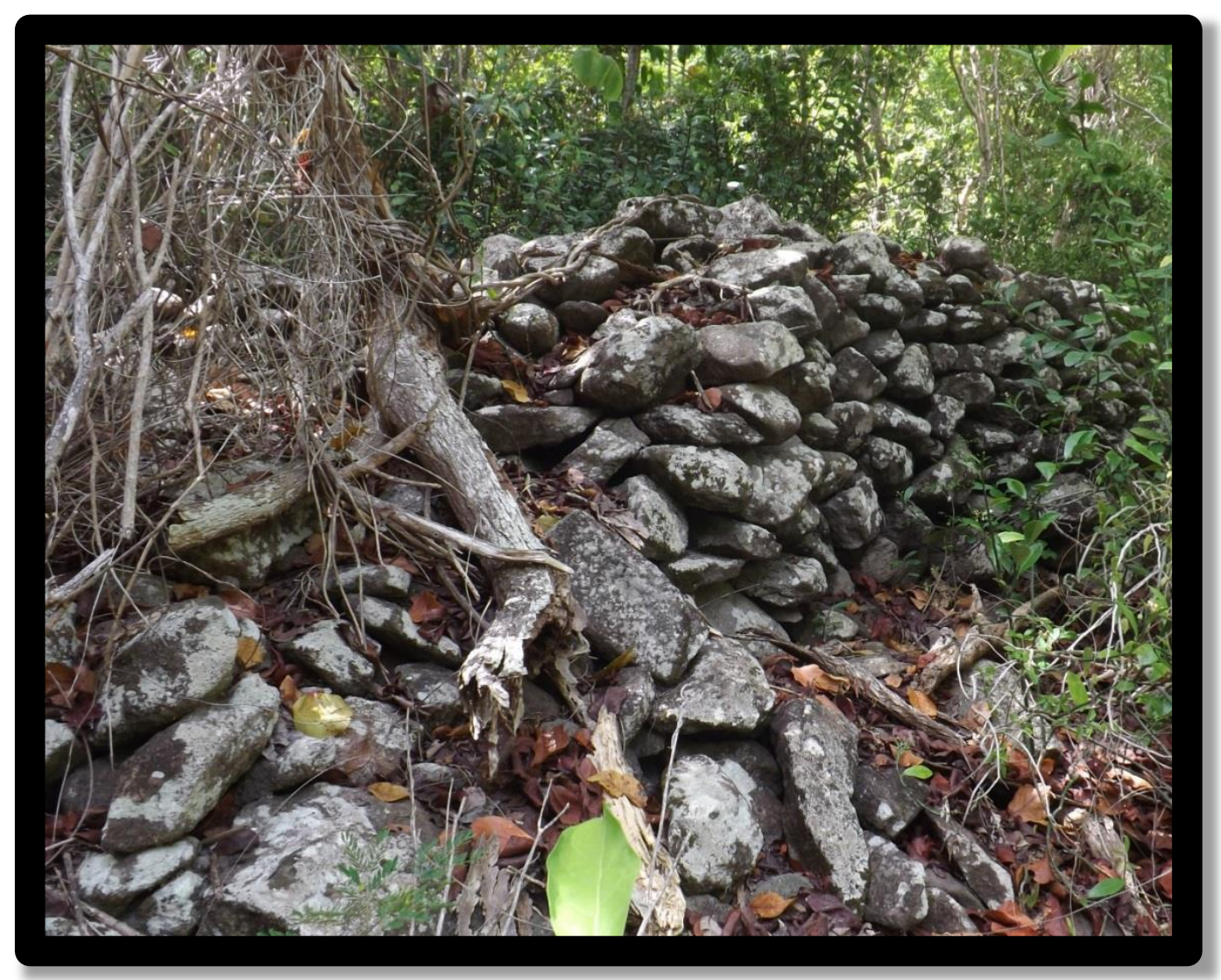

Figure 20. Unfinished Dry Stone Rock Wall at GH14

The dry stone rock features were concentrated directly south of the large wall

(Figure 20) and to the west of the documented terracing walls adhering to the natural slope of the landscape. Downslope from all dry stone rock features, I dug nine judgmentally placed $50 \mathrm{~cm}$ x $50 \mathrm{~cm}$ test units, with careful arbitrary levels of $10 \mathrm{~cm}$ 
increments, with focused attention of placement along a retaining wall running along the western cliff edge. My intention was to locate large material assemblages that had washed downslope and been deposited against the dry stone wall. Unfortunately, like drawn profiles indicated shallow soil deposition at GH15, profiles depths at GH14 were similar, only $20 \mathrm{~cm}$ to $40 \mathrm{~cm}$ before reaching bedrock (Appendix C). This became a real concern in the field and warranted additional testing. This additional testing included 10 judgmentally placed STPs throughout the site and $481 \mathrm{~m}$ brechas spaced $5 \mathrm{~m}$ apart, starting $17 \mathrm{~m}$ from the edge of the site from the east to the west and then back from the east to the west end of the site in a zig-zag pattern. All additional testing was negative for artifacts or features. Three survey transects measuring $944^{2} \mathrm{~m}$ ( $7 \mathrm{~m}$ wide, $4 \mathrm{~m}$ to $5 \mathrm{~m}$ apart, and $45 \mathrm{~m}$ in length) from west to east recovered only one artifact at the far eastern edge at the top of the dry stone terracing wall: a dark green piece of flat glass.

Two additional large agave groves similar to the one at GH15 were located at the boundary edges of the site. The first measured $8 \mathrm{~m} \times 9 \mathrm{~m}$ and was located at the southwest edge of the bottom terracing wall and the second was located at the northwest end of a clearing, not far downslope from the northern edge of the bottom terracing wall (making them nearly parallel), and was approximately $5 \mathrm{~m}$ x 8m, (Figure 21). Both agave groves extended downslope and were visual markers of site boundaries in the natural landscape. Again, this was a significant find as the plants' longevity brought into question whether the occupants of the plantation intentionally planted the agave. Given that the terracing was well constructed at this location, it is highly likely that this is the case, but no comparative studies in the Caribbean to date have considered Agave's use at provision grounds. Subsequent research on other ridges and along the trail down the mountain were 
unsuccessful in locating other agave groves; this might mean their unique placement on the landscape was deliberate. Yet is unclear if this is the case. They might have been planted in the twentieth century.

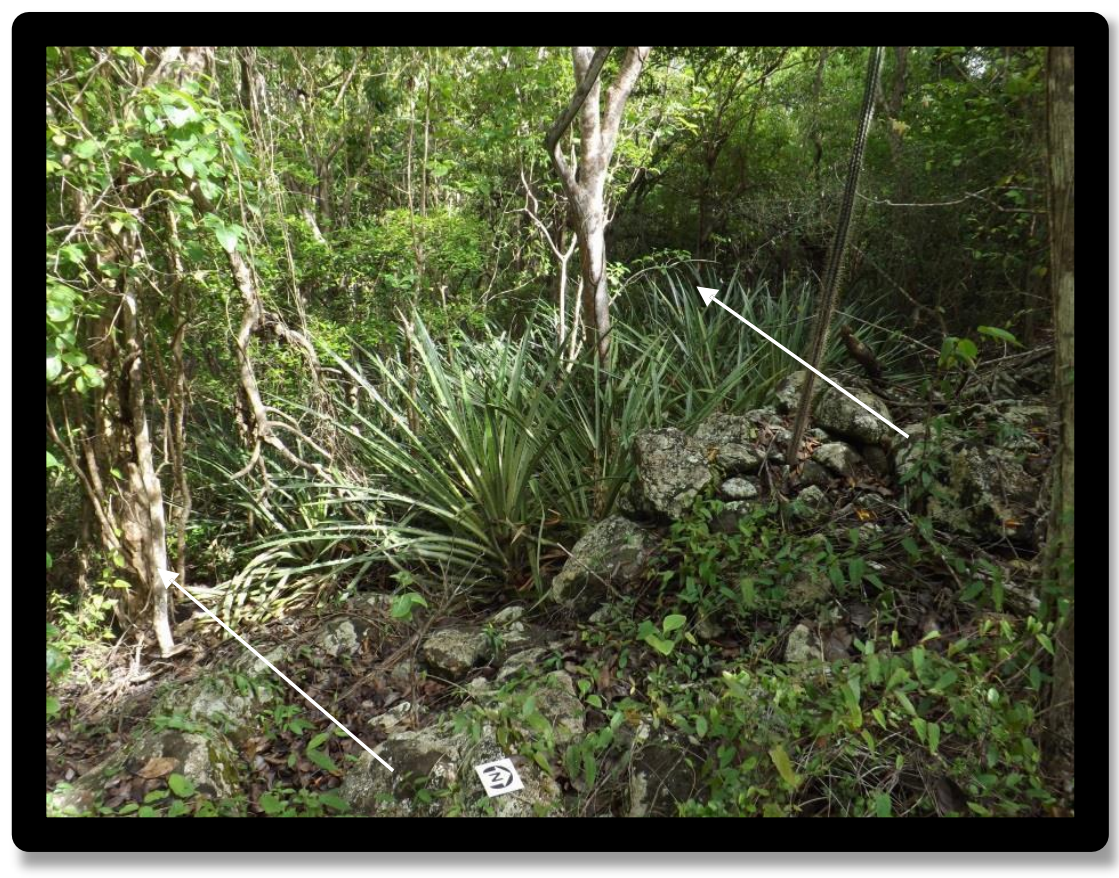

Figure 21. Large Agave Grove at GH14

All dry stone rock features at both GH14 and GH15 were down slope from the observable terracing and it is unclear how dry stone rock features were associated with the terracing walls at this time. It is possible they might have added to these existent walls or had another purpose at these two site locations including use in constructing animal enclosures for animal husbandry and/or used for tanning hides. Comparative analysis did not provide defintive answers at this time. 
After consideration of the lack of artifacts and potential causes, it was possible that artifacts washed downslope into the ravine to the west of the site either by natural causes (rain, wind, erosion) or removal from occupants living in the area (yard sweeping, pitching trash over the side of the wall). Ethnographic observation of current residents living on the island yard sweeping and pitching trash over the side of property walls confirmed the ravine was indeed a possible location to explore. If artifacts were in the ravine, it would certainly explain the lack of artifacts within the site boundaries. After survey continued into the ravine for the span of $520 \mathrm{~m}^{2}$ and no artifacts were found, I needed to consider other explanations for the lack of artifacts. In total, $4,729 \mathrm{~m}^{2}$ were surveyed and only one artifact was recovered.

\section{GH9}

Survey continued along the third ridge trail to the north for approximately $170 \mathrm{~m}$. After navigating through the large boulder field that physically separates the northern and southern sites on the third ridge (upland region one and upland region two) for $12 \mathrm{~m}$ to the east, immediate terrain and physical characteristics were noted. Unlike sites GH14 and GH15, GH9 and later GH10 were noticeably more arid and devoid of lush vegetation except for an occasional grove of clustered young trees. It was near one of these groves, $6 \mathrm{~m} \times 6 \mathrm{~m}$ in size, that the only two artifacts were recovered from GH9, two Dutch delft tin glazed pottery sherds with probable dating to c1640 to c1800. At this location I dug two $50 \mathrm{~cm} \times 50 \mathrm{~cm}$ test units, with careful arbitrary levels of $10 \mathrm{~cm}$ increments, with the hope of recovering more artifacts; unfortunately, much like the two previous sites, testing revealed shallow deposition and no new artifacts or features. This confirmed the soil deposition on Gilboa Hill's third ridge was not as deep as originally thought. 
Pedestrian survey was far easier in this location, without the intense canopy and dried leaf scatter, however, two survey transects ( $8 \mathrm{~m} \times 44 \mathrm{~m}$ and $2 \mathrm{~m} \times 63 \mathrm{~m})$ yielded no artifacts or features other than dry stone constructions. With the additional visibility, this site offered a stark contrast to the previous sites observed to the south, but given the intermittent ground cover of tall, dry grass, I decided to clear $221 \mathrm{~m}$ brechas, spaced $4 \mathrm{~m}$ to $6 \mathrm{~m}$ apart, across the entire site; each brecha was sterile.

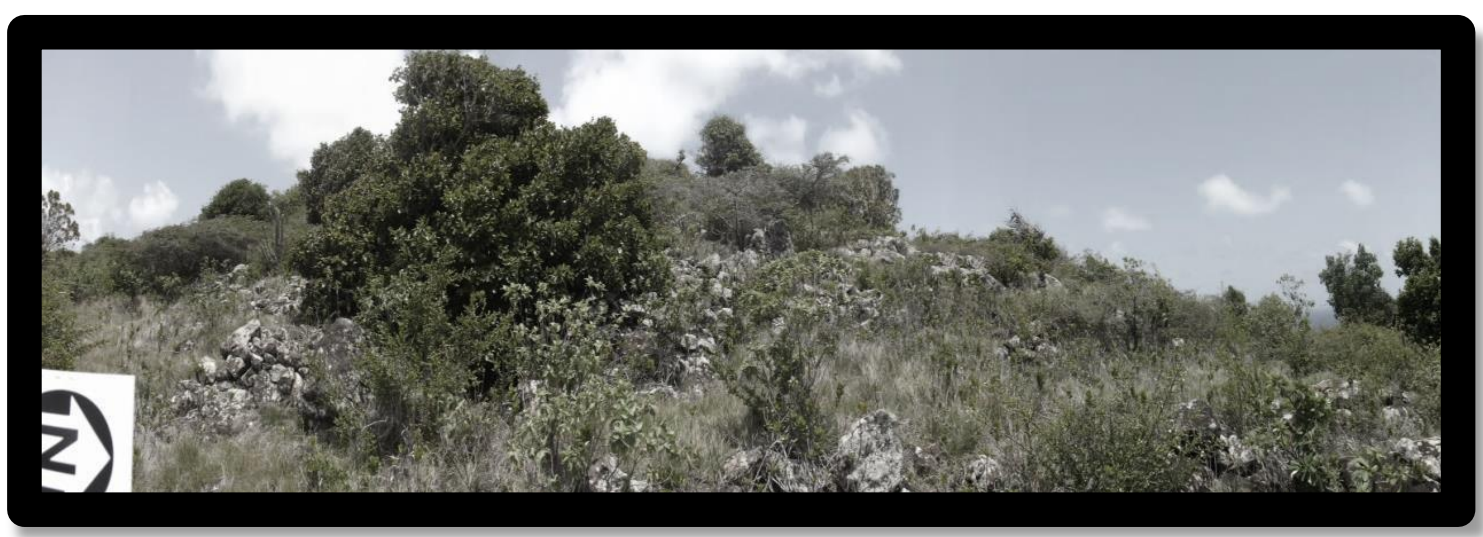

Figures 22. Dry Stone Rock Features Placement on the Landscape

At GH9 there was a notable lack of terracing or other constructed walls; instead, rock features appeared haphazardly placed across the landscape with little discernible organization, (Figure 22). Additionally, a potential activity area was located in the far southern portion of the site, which was unlike the other features noted during fieldwork. A flat depression in the boulders, measuring approximately $14 \mathrm{~m} \times 14 \mathrm{~m}$, had natural water catches on either side, one with a lid, (Figures 23, 24, and 25). Did the occupants of 
the plantation use this area while they worked in the area? Given that this particular area had large wild seagrape plants, Coccoloba uvifera, surrounding each of its edges, and not in other areas, it is a possibility, (Figure 26). People grow seagrapes in the Caribbean as hardy ornamental plants, they are harvested for their sweet fruit, and in the West Indies, the fruit is used as a dye in tanning hides (Haviser 2013). Jay Haviser (2013) later commented some of the dry stone rock features scattered across the island reminded him of similar features used by enslaved workers on other Dutch islands for tanning hides. If these dry stone rock features were used for a similar purpose, there are no traces that were observed at the time of fieldwork. Occupants of the plantation could have used the plants for many purposes including tanning hides then placed them on the dry stone rock features like those observed on the island of Curacao to dry (Haviser 2013).

Unfortunately, the plant use, like purpose of the dry stone rock features, remains enigmatic.
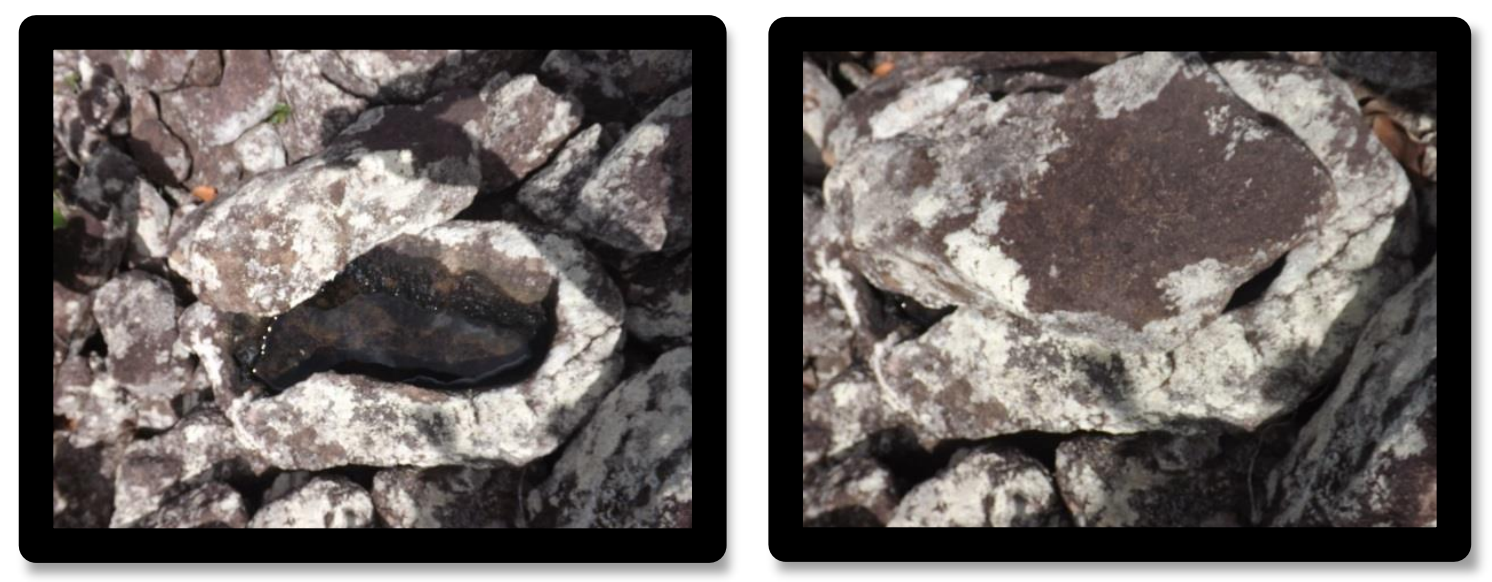

Figures 23 and 24. Natural Water Catch with Lid at GH9 


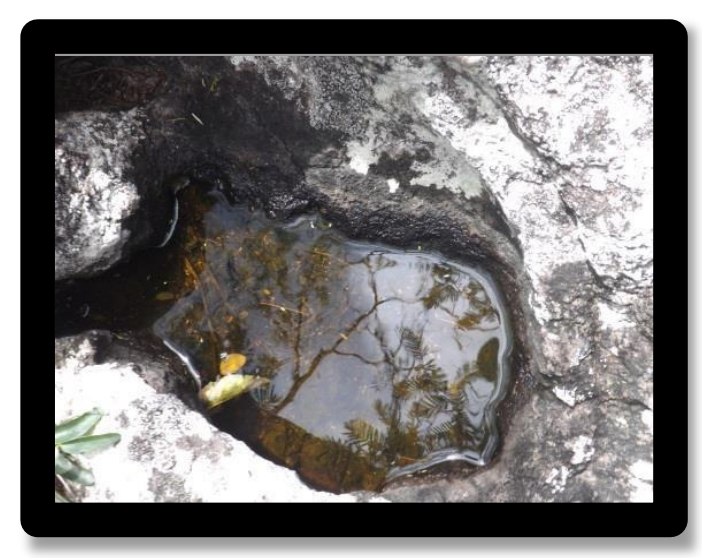

Figure 25. Natural Water Catch Without Lid at GH9

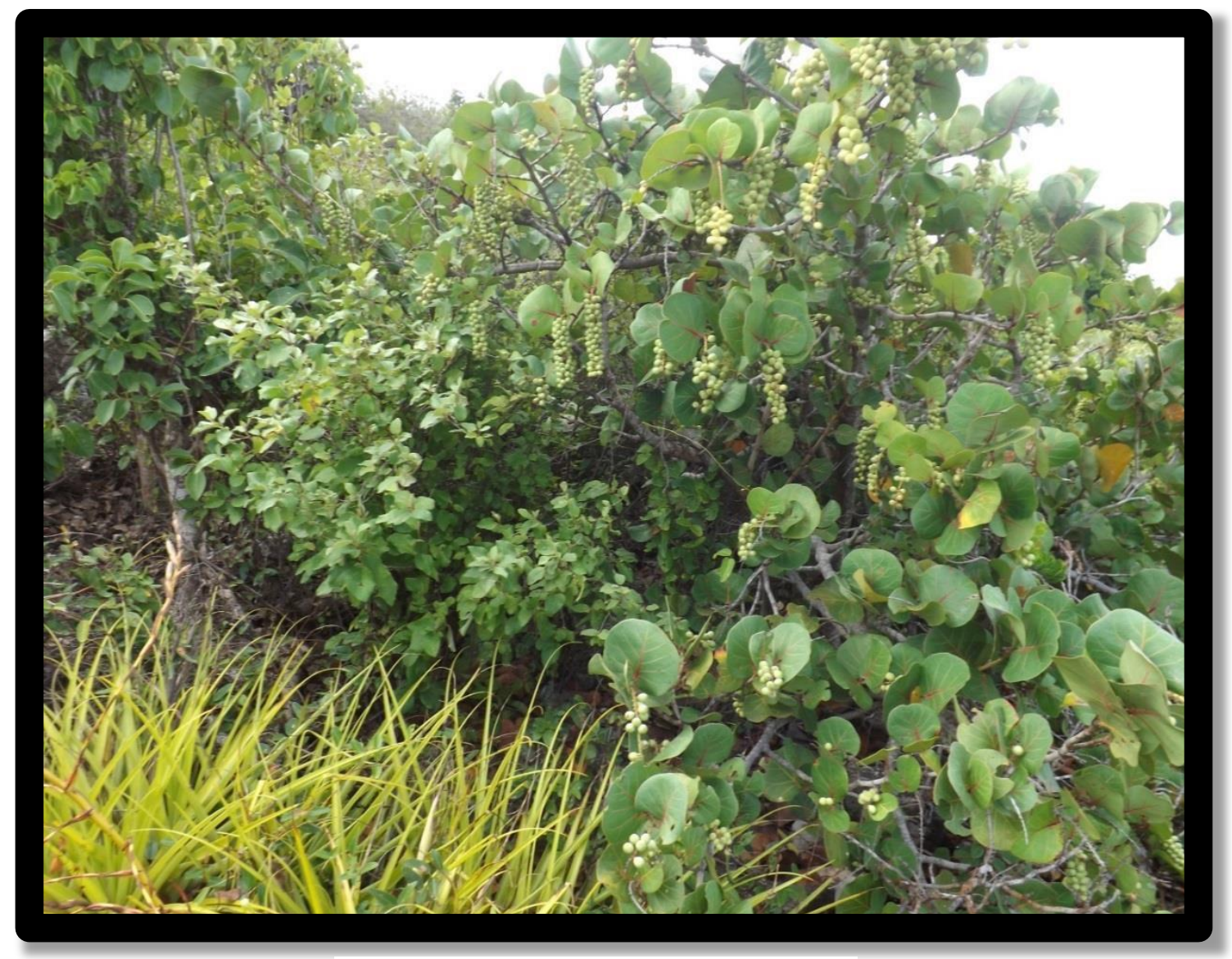

Figure 26. Seagrapes at GH9 


\section{GH10}

North of site GH9, nestled in thick brush, was an isolated dry stone rock feature of site GH10 (Figure 27) which was observably different from other dry stone rock features in the investigation because it appeared to be platform. The rest of the dry stone rock features were at the far northern edge of the ridge approximately $15 \mathrm{~m}$ to $20 \mathrm{~m}$ from the cliff edge and took the longest to locate in part because of this close proximity to the cliff edge. Most of the rock features were similar to those at GH9, but two features were noticeably different from other dry stone rock features in the entire investigation because they more closely resembled the construction used in the fort started in 1687 on the second ridge, (Figures 28 and 29). As before, I conducted four survey transects $(3.5 \mathrm{~m}$ wide, $3 \mathrm{~m}$ wide, and $11 \mathrm{~m}$ to $20 \mathrm{~m}$ long) across the entire site, but this survey yielded no artifacts. The pattern continued of undoubted human constructions, but no detritus of daily living.

The visibility at site GH10 was comparable to that of GH9, however, ground cover of tall, dry grass still warranted the placement of $201 \mathrm{~m}$ brechas, spaced every 5m; each of these were sterile. I included five judgmentally placed STPs with this additional testing; these too were negative for new artifacts or features. I also conducted nine $50 \mathrm{~cm}$ x $50 \mathrm{~cm}$ test units, again with careful arbitrary levels of $10 \mathrm{~cm}$ increments, throughout the site, yet decided to concentrate near the three structures that most resembled platforms as they seemed most likely to yield material assemblages. True to the pattern established at the previous three sites on the third ridge, soil depth was shallow and no artifacts were recovered. I did find an artifact along a path leading to the dry stone rock features. It was a small shard of an aqua blue glass body; this was the only artifact recovered at this site. 
This site had fewer features, was closer to the ridge edge, exposed to trade winds and had the most spectacular vistas of any place in the investigation, (Figure 30). Because of this, it is worth reiterating that this site did not resemble the other three sites previously investigated and might have been an ideal location to construct domestic structures of some kind. Two of the three dry stone rock features were similar to the fort construction on the second ridge and appeared to be long and wide enough to support a reclining individual. This site quickly became one of interest to evaluate during further analysis of dry stone rock features recorded during fieldwork.

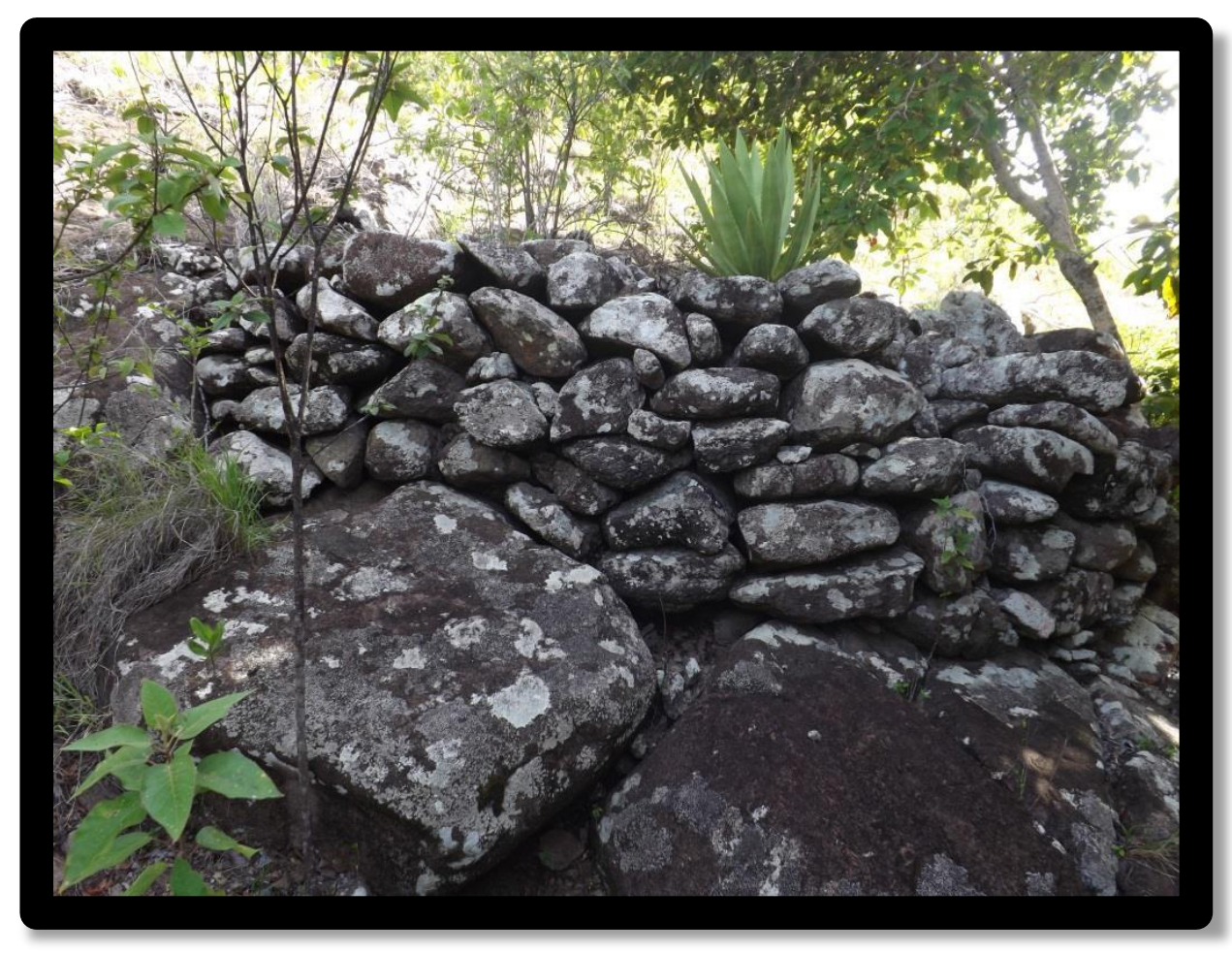

Figure 27. Isolated Dry Stone Rock Feature at GH10 


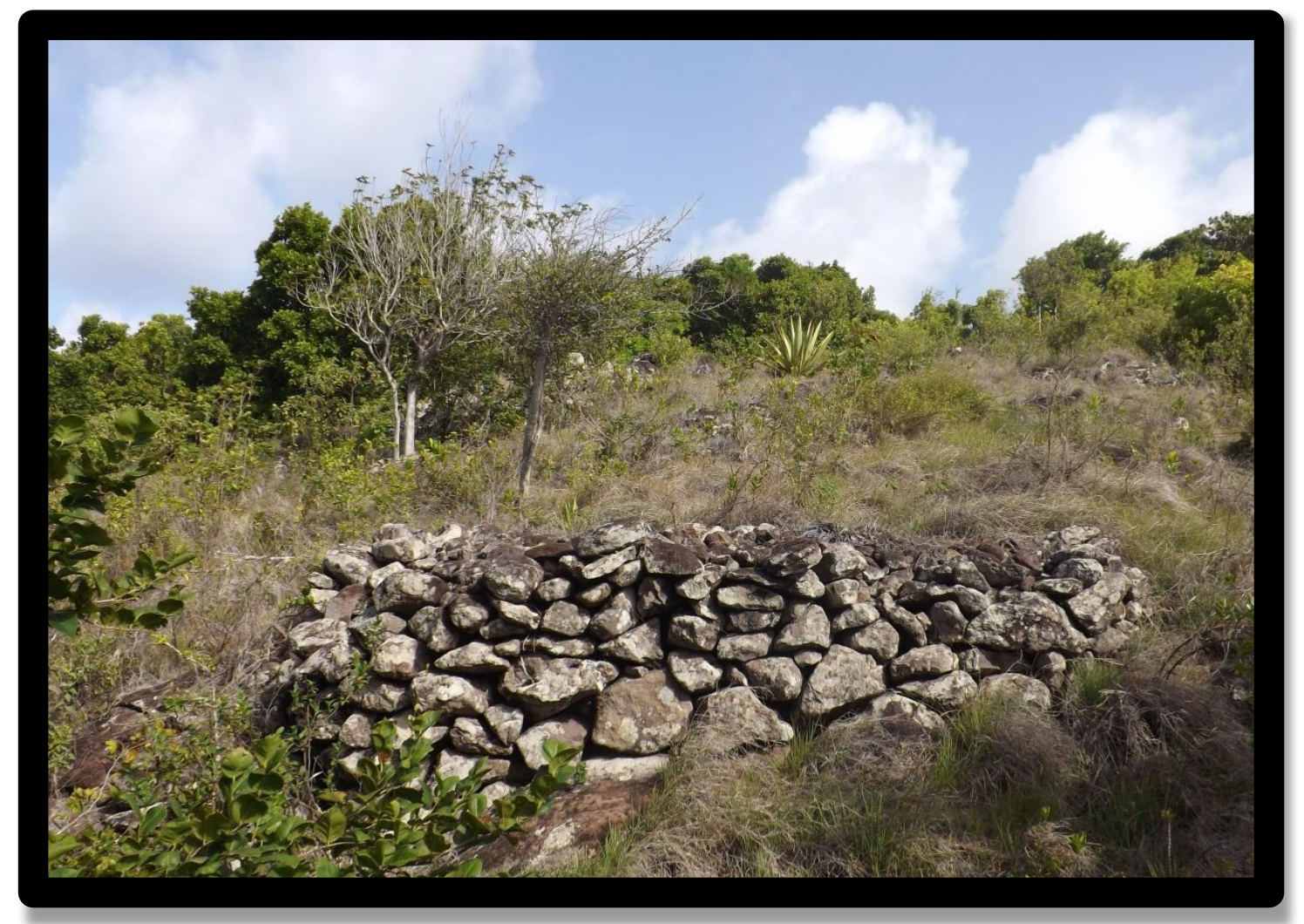

Figure 28. Dry Stone Rock Feature at GH10 Similar to Fort on Second Ridge

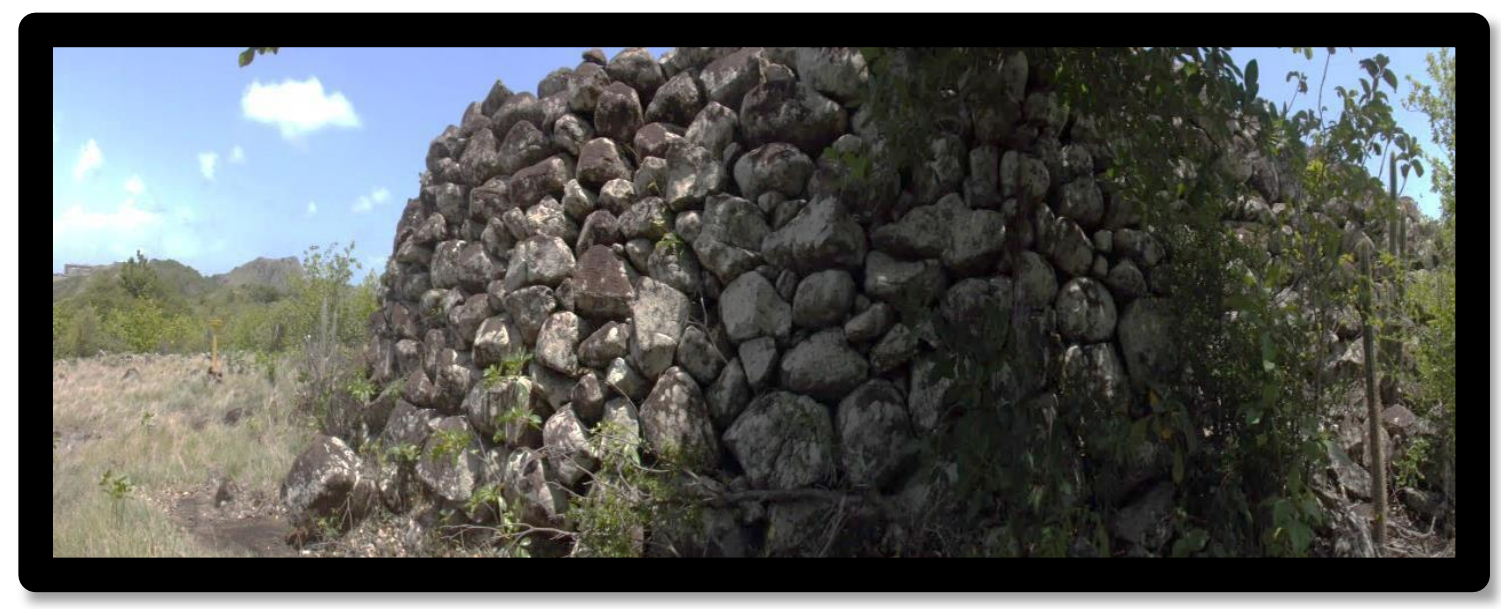

Figure 29. Fort Started in 1687 on the Second Ridge 


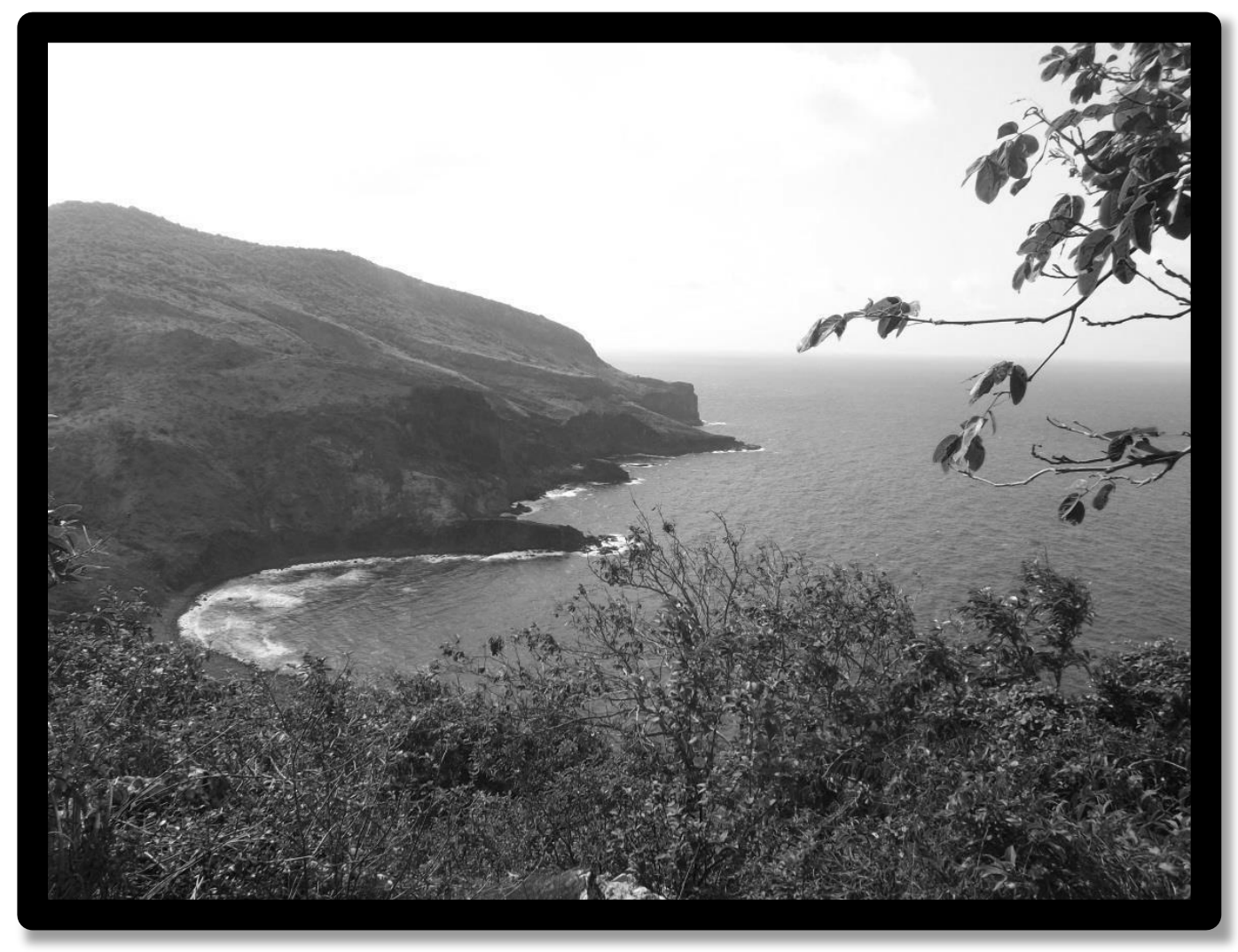

Figure 30. Vista from the Far Western Edge of the Third Ridge at GH10

After fieldwork, I placed each of the four sites on Gilboa Hill into two distinct upland regions using their distinguishing characteristics. While each site was unique, their differences in terrain, vegetation, exposure, dry stone rock features, the presence or absence of terracing, as well as their spatial orientation shared similarities. For instance, in upland region one GH14 and GH15 were located downslope from the trail, were shaded by a thick canopy of trees, had abundant organic groundcover, had little exposure to sun or trade winds, all dry stone rock features were well constructed, terracing was present, and dry stone rock features shared close nucleation and dispersion across the landscape. In contrast, GH9 and GH10 in upland region two were located down a steeper slope at the far edge of the mountain, lacked trees, had lush dry grass groundcover, were exposed to fierce trade winds, while the dry stone rock features lacked the integrity and 
closely nucleated spatial orientation observed at the other two sites. I think the locations of each of the four sites on Gilboa Hill (in both upland region one and upland region two) on the historical map of 1795 away from land used for sugar cultivation and behind a large plantation structure suggest the labor activities conducted by enslaved Africans at these sites were unrelated to sugar production. These regions offered a scale to compare each of the sites, their features, and differences in the landscape and as a result I found both upland regions shared similar indications of taskscapes with multiple labor activities likely performed at each of the sites. Potential activities include the use of dry stone rocks to construct walls for use in the noted terracing as part of provision grounds owned by enslaved African communities, possible animal enclosures, the tanning of hides, or another unknown purpose. Evidence of the dry stone rock features with terracing, large agave groves, seagrapes, and possible water catches all raised interesting questions about the landscape of labor in the northern hills.

Dry stone rock construction used in terracing walls observed at GH14 and GH15 might have been used to cultivate crops in provision grounds owned and worked by the enslaved African community living and working on the island. These terraces would have allowed enslaved Africans to grow provisions for subsistence and to sell their surplus in the market in Oranjestad. Broad Caribbean studies of provision grounds include crops of guineas yams, okra, corn, sweet potatoes, potatoes, tomatoes, cabbage, carrots and breadfruit, with some grown in terraces like those observed on Gilboa Hill (Lenik 2012; Mintz 1974). These observed differences in design and construction of terracing walls at both GH14 and GH15 might indicate the difference in types of crops grown at each location. Carrots, potatoes, sweet potatoes, and guinea yams are root crops and would 
likely rot if planted in walled terraces like those at GH14 where soil would retain a larger amount of moisture. In contrast, the cascading terraces at GH15 would have held enough moisture, but also would have stopped erosion of crops with above ground stalks or runners like tomaotoes, okra, corn, cabbage, in addition to fruit trees like avocado, mango, papaya, soursop, coconut and citrus would likely have thrived in soil with higher moisture levels that the linear walls afforded at GH14. It is possible dry stone rock features observed on Gilboa Hill were to add to exsistent terracing walls or construct new ones.

Dry stone rock features could have been intentionally set across the landscape for use in the construction of animal enclosures as well. Extensive attention in archaeological investigations has been given to the efforts enslaved communities used in animal husbandry within provision grounds, gardens and yardspaces to raise chickens, goats, cattle, etc. (Armstrong 1999, 2001, 2009; Bates and Galle 2012; Delle 1998; Heath and Bennett 2000; Higman 2001; McKee 1992; Mintz 1974; Pulsipher 1994; Ruppel et al. 2003). The half constructed walls at GH14 might have been used in a related activity.

With the identification of Agave groves alongside terracing at these two locations it is likely enslaved Africans intentionally planted it given that it is was not located anywhere else on the third ridge (in the survery area or along the third ridge trail). Agave was not harvested often and had a very short shelf life, only a few days, but the adddition to dishes, its use as a valuable ingredient in folk remedies, its fibers use in shoes and clothing, and/or other purposes likely made it an important addition to provision grounds. Eventhough previous research in the Caribbean of provision grounds and historical 
documentation do not list its use by enslaved Africans, it is still highly suspected as being intentionally planted at the potential provision grounds at GH14 and GH15.

Keeping in mind, dry stones cleared from the plantation landscape likely served two functions: to build dry stone walls or for drying hides during the process of tanning it is likely the seagrapes located near the dry stone rock features at GH9 also reflect the potential function of dry stone rock features directly adjacent to it (Mintz 1974). Seagrapes have not been studied in archaeological investigations in the Caribbean, but they are noted as being used to tan hides. The dry stone rock features at GH9 correlate with those identified by Jay Haviser (2012) on the Dutch island of Curacao that were used to tan hides; they are the same size and shape (small, circular and oval).

Additionally, other dry stone rock features at GH10, GH14 and GH15 (downslope from observed terracing) also share the same correlation. The dry stone rock features use as platforms to dry hides is a possibility, but I did not recover any material culture (animal bones, lithic, or metal refuse) that could determine this at this time.

The features at GH9 that appear to be water catches I think attest to labor activities as well given their placement next to the dry stone rock features in the immediate area. The discovery of sherds from a Dutch gin stoneware bottle at GH15 (potentially used as a water canteen) is a similar find. If the dry stone rock features were associated with labor activities on the third ridge, artifact and features associated with water procurement for laborers is expected.

Upland region one clearly had evidence of various labor activities across the four sites in this investigation. Terracing at GH14 and GH15 were for one labor activity while the dry stone rock features downslope were likely part of another. Dry stone rock 
features could have been used to add to terracing walls at GH14 and GH15, to construct new ones at each of the four sites, construct animal enclosures, part of the process of tanning hides, or another unknown purpose. Additionally, the large Agave groves, seagrapes, and water catches noted next to archaeologically recovered dry stone rock features have been undocumented to date in the Caribbean. It is unclear whether they were associated with labor activities at this time.

\section{Lowland Regions}

Archaeological investigations of the Schotsenhoek slave village (SSV) and the Free Black Village (FBV), revealed a stark contrast to the upland regions in location, setting, features recovered, and artifact volume and concentrations. The slave village had over 1000 artifacts and the FBV had over 17000 artifacts; an obvious difference between the upland and lowland region. Observations of the setting, feature composition and orientation, and artifact concentrations in the upland regions when compared to the archaeological evidence from the lowland regions indicated the lowland regions had clearly identifiable characteristics to catergorize these sites as having long-term domestic occupations. The two lowland regions are depicted here with an $\mathrm{X}$ with the four sites in the upland regions to the far left in the map, (Figure 31). 


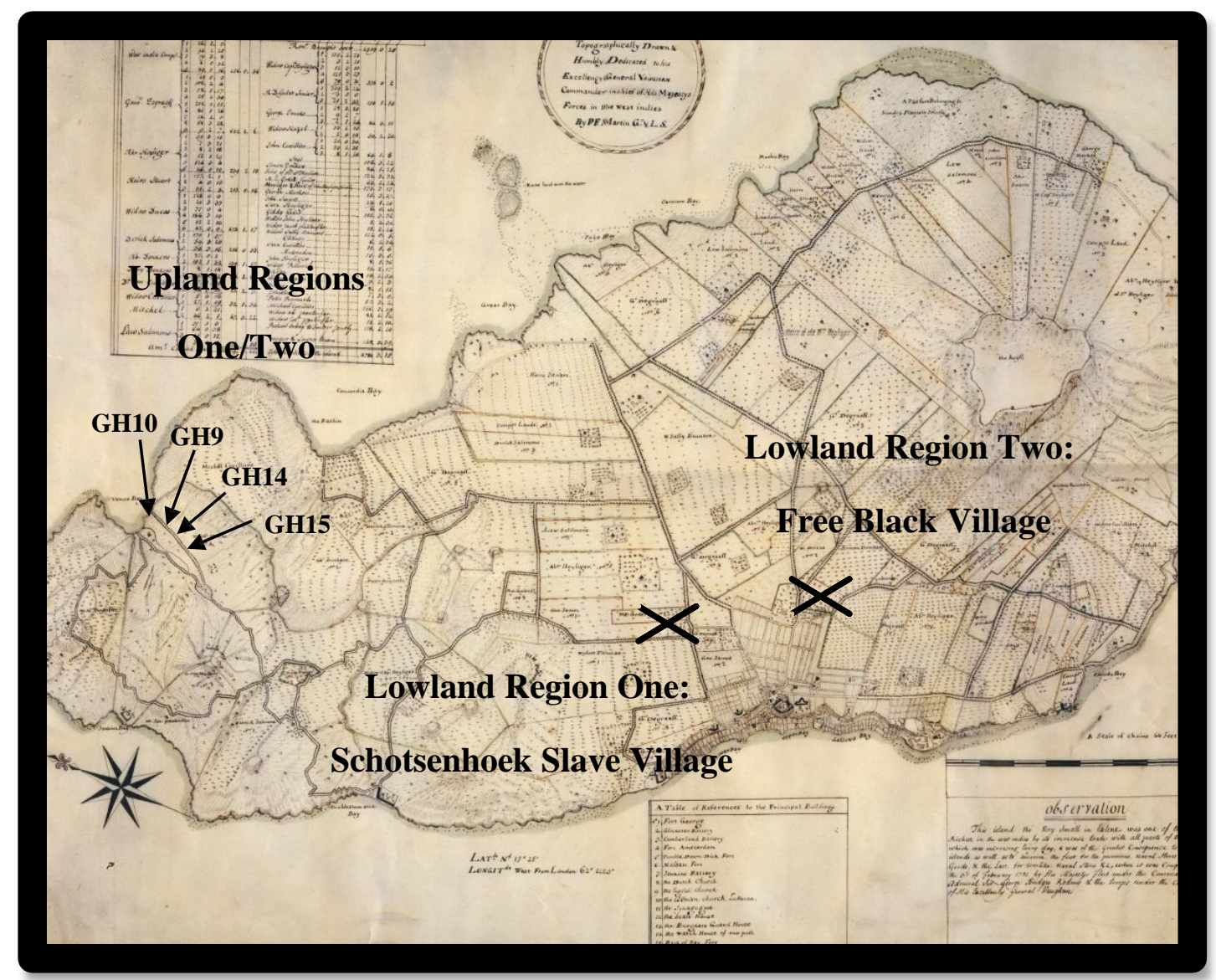

Figure 31. 1781 Map of St. Eustatius, Lowland Regions

\section{Lowland Region One: Schotsenhoek Slave Village}

The Schotsenhoek Slave Village is located northwest of the town center of Oranjestad, in a small area known today as Golden Rock. Characterized by flat terrain and similar semi-arid vegetation of upland region two, the plantation had ample sun exposure. Initial archaeological excavations revealed postholes/postmolds associated with ten potential rectangular structures ranging $1.5 \mathrm{~m} \times 2 \mathrm{~m}$ to $9.5 \mathrm{~m} \times 5.5 \mathrm{~m}$ in size. Subsequent excavations have recovered additional features associated with potential structures; however, for this analysis only the first of these potential structures were considered. Of 
the 26 posthole/postmolds recovered, ten were shallow and ranged in depth between $12.5 \mathrm{~cm}$ to $22.5 \mathrm{~cm}$; others were set deeper to $40 \mathrm{~cm}$. These potential structures were spaced close together and relatively uniform in size. Vistas from this lowland region were obstructed by vegetation and topography as the slave village sat in a small depression on the plantation. Figure 32 depicts the location and setting of the first phase of excavation.

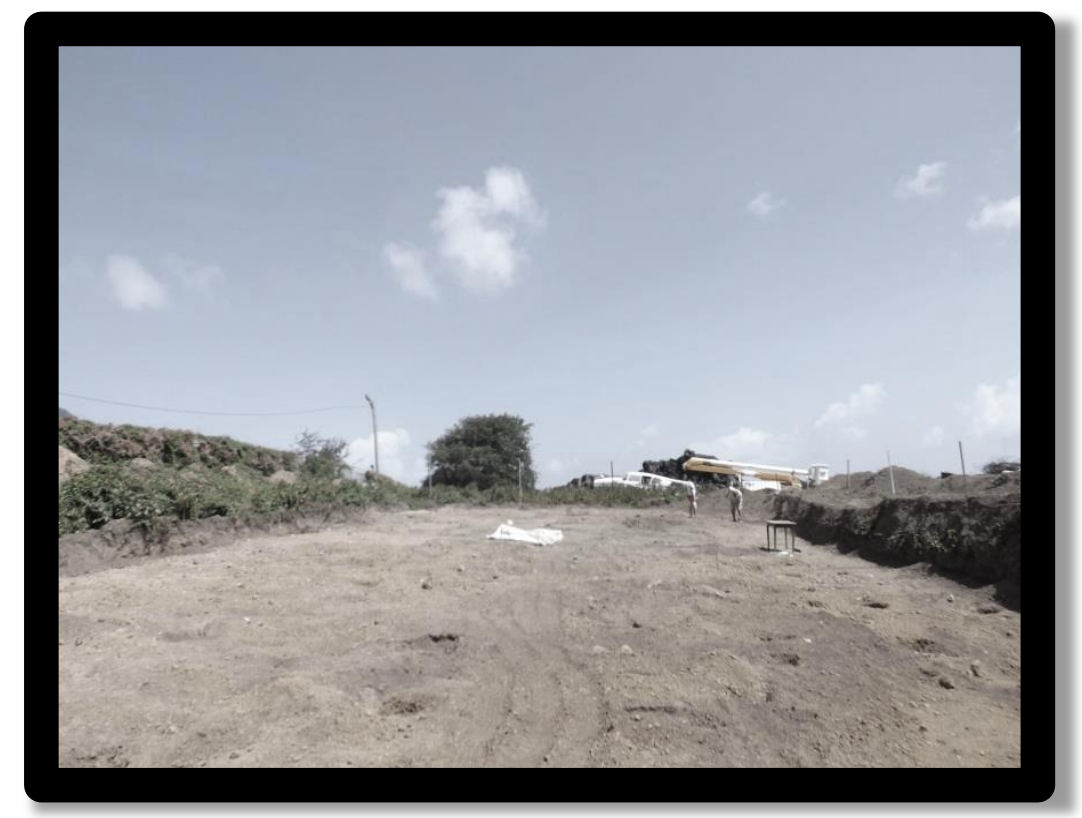

Figure 32. Schotsenhoek Slave Village Excavation 


\section{Lowland Region Two: Free Black Village}

This lowland region was characterized by similar vegetation observed at both the slave village and upland region two, however, it was slightly elevated, on a rise overlooking the city of Oranjestad to the south. The site is associated with multiple phases of construction and a wide variety of vernacular architecture, including the three stone foundations. Each of the structures and the 17,000 artifacts recovered during archaeological investigations, are consistent with characteristics of domestic occupation spanning the eighteenth to nineteenth century. The expansive site, encompassing approximately 1 ha, is a rare glimpse into the choices of freed slaves in both spatial orientation and construction of domestic structures. Structures were in close proximity and had obvious alignment associated with a village environment, with only slight variation in dimensions.

\section{Summary}

Regional comparisons between sites located in the upland regions revealed each of the two upland regions both lacked substantial material assemblages, but shared similar components. Each of the four sites on Gilboa Hill had dry stone rock features that consisted of clustered groupings of rocks piled atop of one another. While their variation in size, shape, and quantity varied from site to site, all dry stone rock features appear to have been constructed using rocks from the immediate area rather than brought in from another location. Due to the lack of significant material assemblages, this raised a troubling question. If a labor force were gathering rocks at these site locations to construct dry stone rock features for dwellings, where is the evidence to support their 
presence on the landscape? Even if the artifacts were not associated with domestic occupation, one would assume that there would be more to indicate laborers working in the area. Understanding the landscape of labor offers insight into ways the world of enslaved African work activities stood in stark contrast to those in daily domestic life.

Stark differences in dry stone rock features and the physical settings of the two upland regions were also observed. While the four sites on Gilboa Hill had similar dry stone rock features, features at GH14 and GH15 were more organized in composition, including those used for unfinished walls and terracing, and were relatively concentrated in the lower portion of the site. Dry stone rock features at sites GH9 and GH10, in contrast, were distributed across the entire site and lacked the integrity of the rock features at the other two sites in upland region one, (see Figures 33 and 34 for contrasts).

It is unclear after this comparison why dry stone rock features vary. Dry stone rock features have been located all across the island, so their variation could be attributed to different practices in the labor force that constructed them rather than functional differences. But different functions at each of the sites on Gilboa Hill is also a possibility. At GH14 and GH15, dry stone rock features varied in their size, shape and integrity as they were Another recognizable difference between the two upland regions was their physical environments. Upland Region One was located on the leeward side of the mountain under a thick canopy of vegetation while upland region two was located on thesemi-arid windward side with tall dry grasses and shrubs. This difference, while not indicative of specific function of the sites, does bring into question whether these sites were all part of the same plantation activity. If they were not, it might account for the differences in their features and spatial arrangement. 
These similarities and differences, are significant as they indicate characteristics that differentiate the two upland regions from the two lowland regions. Possible structures identified during archaeological investigations at the Schotsenhoek slave village using postholes and the three identified stone foundations at the FBV are clearly associated with the extensive material assemblages. The presence of large material assemblages, as they are consistent with previously established patterns, while not always an indication of domestic occupation, do easily distinguish the two sites in lowland region as domestic village environments on the island, while the sites on Gilboa Hill in the two upland regions remain ambiguous. The only striking difference between the two lowland regions observed was that the slave village had fewer artifacts and less

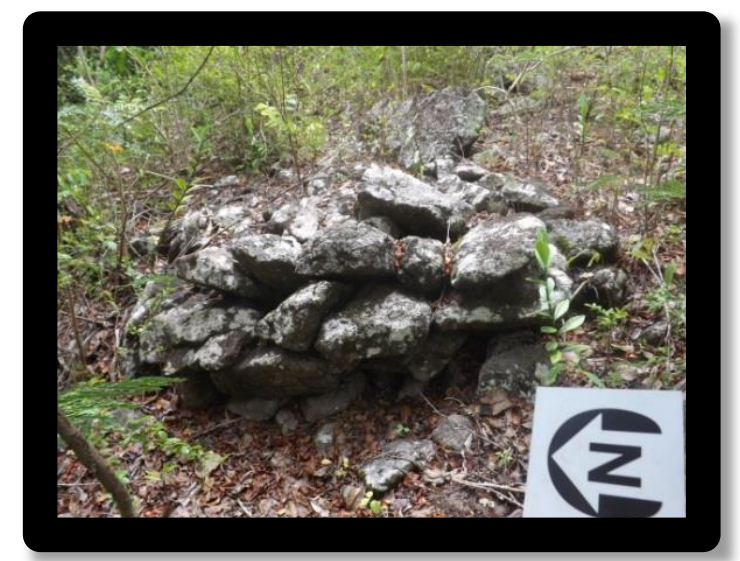

Figure 33. Dry Stone Rock Feature at GH14

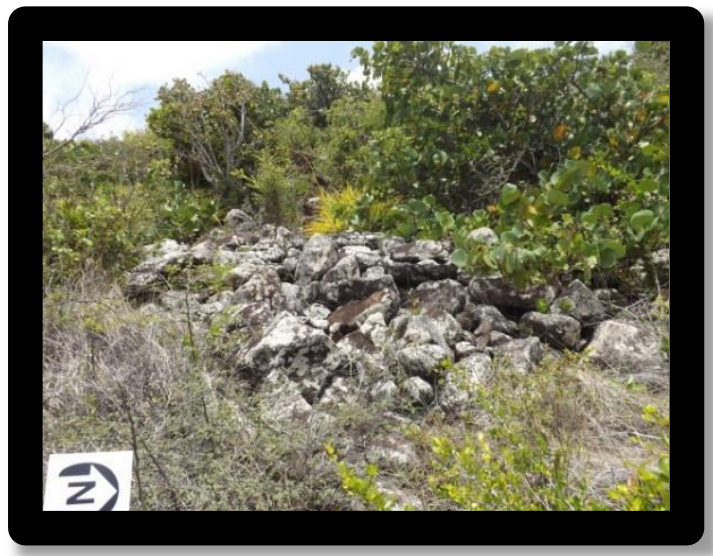

Figure 34. Dry Stone Rock Feature at GH9

material assemblage recovered from the FBV. Based on these differences between the upland and lowland regions, what is important to take away from this regional comparison, then, is that structural evidence and the volume of artifacts recovered at the sites in both lowland regions implies that the upland region sites were not domestic sites, but certainly areas where people worked. 


\section{Structural Analysis}

After regional comparisons indicated a strong likelihood that the four sites located on Gilboa Hill were not domestic in nature, it was important to analyze each structure under investigation more thoroughly. After comparing dry stone rock features in the upland regions to the potential structures and stone foundations in the lowland regions, correlations might exist. Further, these correlations might compare to ethnographic examples. If so, this will determine if a pattern of village structural dimensions is recognizable on the island. For this research, 52 dry stone rock features, 12 terracing walls, and two small partial dry stone rock walls located at GH9, GH10, GH14, and GH15 were analyzed using data from field work conducted on Gilboa Hill. Using the methods summarized in the previous chapter, these features were compared to four stone foundations at the Free Black Village, 10 potential structures at the Schotsenhoek Slave Village, and 119 ethnographic examples from West Africa in order to identify correlates on the basis of size, shape and location within village settings. A posthole analysis using potential features recorded during excavation at the Schotsenhoek slave village offered the opportunity to assess significant patterns of structural dimensions, including shape, used in a slave village environment on St. Eustatius as well as possible construction methods for vernacular architecture. This was important to determine if correlates to the features on Gilboa Hill existed. Further comparison to structural examples from the United States and the Caribbean provided additional insight into potential patterns of uniform structural dimensions within village environments. This was important to determine if similarities to domestic environments indicate a correlation to domestic environments rather than on the premise of the lack of artifacts alone. 


\section{Typological Attributes: Shape and Size}

A comparison of a total of 199 features, potential structures, and stone

foundations identified typological attributes used to categorize examples. This

comparative sample not only represented the variety of archaeologically recovered examples on the island of St. Eustatius to date, but included potential correlates to traditional African examples as well. 


\section{Circular}

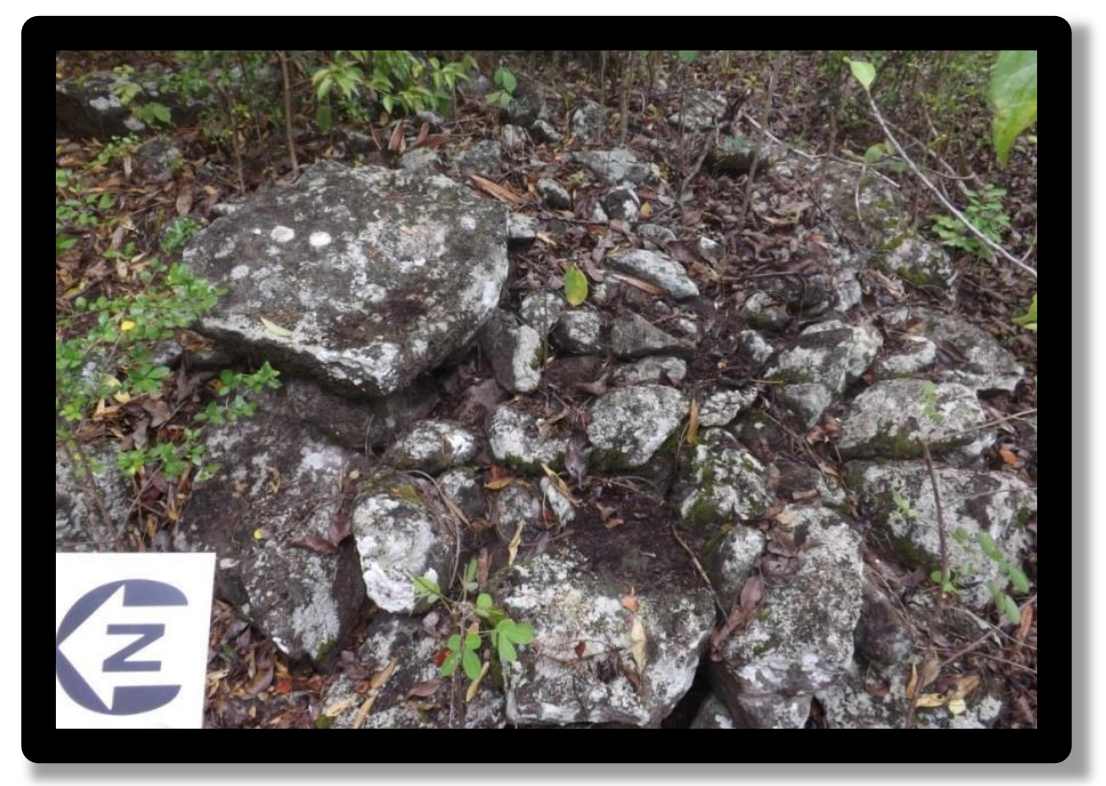

Figure 35. Circular Rock Feature 8 at GH14 on Gilboa Hill

All circular dry stone rock features on Gilboa Hill were constructed in the same way with dry stones piled atop one another forming solid piles with not spaces in the middle next to boulders already present in the landscape. Variation in the integrity of their construction from site to site (some were more loosely piled) was noted. In contrast, circular structures in ethnographic examples had open spaces in the center and shared consistent integrity in construction. The main difference between circular structures and rock features was their variability in size; they ranged in size from $1 \mathrm{~m}$ to $6.5 \mathrm{~m}$ in diameter. Identified in this shape category were archaeological examples from sites located on Gilboa Hill at GH9, GH10, and GH14 (for example Figure 35 and one stone foundation from the FBV). Ethnographic examples from African Villages A, B, C, and D were also included. Considerable differences in scale are associated with specific structural function among the ethnographic examples analyzed and were recognizable in 
six subcategories (Table 1). Upon comparison of these differences in scale with archaeological examples, marked patterns emerged. 
Table 1: Circular Typology Dimensions

\begin{tabular}{|c|c|c|c|c|}
\hline site & Type & Function & name & Diameter \\
\hline Village $\mathrm{C}$ & Livestock & Chickens & kunmuno 1 & 1 \\
\hline Village B & Storage & grains/food & buntun diun 3 & 1.25 \\
\hline Village B & Storage & grains/food & buntun diun 4 & 1.25 \\
\hline Village B & Storage & grains/food & buntun diun 5 & 1.5 \\
\hline Village B & Storage & grains/food & buntun diun 6 & 1.5 \\
\hline Village B & Storage & grains/food & buntun diun 10 & 1.5 \\
\hline Village B & Storage & grains/food & buntun diun 11 & 1.5 \\
\hline Village B & Storage & grains/food & buntun diun 1 & 1.75 \\
\hline Village B & Storage & grains/food & buntun diun 2 & 1.75 \\
\hline Village B & Storage & grains/food & buntun diun 7 & 1.75 \\
\hline Village B & Storage & grains/food & buntun diun 8 & 1.75 \\
\hline Village B & Storage & grains/food & buntun diun 9 & 1.75 \\
\hline GH9 & rock feature 8 & & & 2 \\
\hline GH9 & rock feature 9 & & & 2 \\
\hline GH9 & rock feature 15 & & & 2 \\
\hline GH10 & rock feature 6 & & & 2 \\
\hline FBV & stone foundations & & & 2 \\
\hline Village $\mathrm{C}$ & Storage & Granary & kukro 1 & 2 \\
\hline Village $\mathbf{C}$ & Storage & Granary & kukro 5 & 2 \\
\hline GH14 & rock feature 14 & & & 2.4 \\
\hline GH9 & rock feature 2 & & & 2.5 \\
\hline GH14 & rock feature 4 & & & 3 \\
\hline GH14 & rock feature 5 & & & 3 \\
\hline GH9 & rock feature 4 & & & 3 \\
\hline GH9 & rock feature 16 & & & 3 \\
\hline GH9 & rock feature 17 & & & 3 \\
\hline GH9 & rock feature 19 & & & 3 \\
\hline Village A & domestic structure 1 & Dwelling & suudu & 3 \\
\hline
\end{tabular}


Table 1: Circular Typology Dimensions Continued

\begin{tabular}{|c|c|c|c|c|}
\hline site & Type & Function & name & diameter \\
\hline Village B & domestic structure & Cooking & koba 6 & 3 \\
\hline Village B & domestic structure & Cooking & koba 8 & 3 \\
\hline GH14 & rock feature 8 & & & 3.4 \\
\hline Village B & domestic structure & Cooking & koba 7 & 3.5 \\
\hline Village C & domestic structure & instruction/grp discuss & bugo & 3.5 \\
\hline Village A & livestock & goat pen & Suudu Bey & 4 \\
\hline Village D & domestic structure & older circular dwelling & ndokkron & 4 \\
\hline Village A & domestic structure 2 & Dwelling & suudu & 4 \\
\hline Village B & domestic structure & Cooking & koba 5 & 4 \\
\hline Village C & domestic structure & Kitchen & ga & 4 \\
\hline Village C & domestic structure & man's dwelling & buńo 1 & 4.5 \\
\hline Village C & domestic structure & man's dwelling & buńo 2 & 4.5 \\
\hline Village C & domestic structure & women mt entrance & buluno & 4.5 \\
\hline Village C & domestic structure & woman's room & muso buno 1 & 4.5 \\
\hline Village C & domestic structure & woman's room & muso buno 2 & 4.5 \\
\hline Village C & domestic structure & woman's room & muso labuno 1 & 5 \\
\hline Village C & domestic structure & woman's room & muso labuno 2 & 5 \\
\hline Village $\mathrm{C}$ & domestic structure & senior man's room & kiebuno & 5 \\
\hline Village B & domestic structure & Dwelling & bumba2 & 6 \\
\hline Village B & domestic structure & Dwelling & bumba3 & 6 \\
\hline Village B & domestic structure & Dwelling & bumba1 & 6.5 \\
\hline Village B & domestic structure & Dwelling & bumba4 & 6.5 \\
\hline
\end{tabular}


Subcategory 1. This category consisted of two structures in ethnographical examples from African Villages B and C, and ranged in size from $1 \mathrm{~m}$ to $1.75 \mathrm{~m}$ in diameter. The smallest of these structures was identified as a chicken coop from African Village A, while the remaining eleven structures were used for grain storage in African Village B. There were no archaeological examples noted. This suggests very small circular structures served a specific function in the domestic environment, making the size of a structure an important consideration.

Subcategory 2. This category had nine examples ranging in size from $2 \mathrm{~m}$ to $2.5 \mathrm{~m}$ in diameter. Of these, one was from the FBV (stone foundation 4) and two structures from ethnographic examples in African Village C; both used for grain storage. The remaining six examples were from archaeological sites on Gilboa Hill (GH9, GH10, and GH14) and fell between the ranges of $2 \mathrm{~m}$ to $2.4 \mathrm{~m}$ in diameter. A noteworthy correlation between grain storage and size is evident in this circular subcategory; this might indicate a consistent correlation of size, shape, and function. The stone foundation at the FBV was noted as being some sort of erected shrine, however, this analysis shows correlation with structures in ethnographic examples used for storage.

Subcategory 3. Examples in this category clearly correlated to cooking and small domestic structures in ethnographic examples in West African Villages. Subcategory 3 had thirteen examples ranging in size from $3 \mathrm{~m}$ to $3.5 \mathrm{~m}$ in diameter. Archaeological examples included those $3 \mathrm{~m}$ in diameter from Gilboa Hill at GH9 and GH14. Small dwellings from African Village A and cooking structures from African Village B were examples represented as well. Larger examples in this subcategory included one archaeological example from Gilboa Hill, rock feature 8 from GH14, and two domestic 
structures from African Villages B and C. Interesting to note are the archaeological examples correlated to ethnographic examples used for cooking and small domestic structures; yet, no evidence of cooking was recovered during fieldwork. Does this provide insight into structural function based on size? I think it does. Smaller size clearly in ethnographic examples thus far indicate a pattern of smaller size and functional structures of storage, cooking, etc. No archaeological evidence was recovered that indicated circular rock features were used for cooking, however.

Subcategory 4. This category included only structures from ethnographic examples in West African Villages and these examples are considerably larger with diameter ranges from $4 \mathrm{~m}$ to $4.5 \mathrm{~m}$. These structures are associated with livestock pens and domestic structures used as dwellings. These structures were constructed with circular walls with empty spaces in the middle for use as living quarters.

Subcategory 5. This category had only three structures from ethnographic examples from West Africa; all are associated with use as dwellings, more specifically those of women and older men. These too, were larger than structures used for grain storage and had diameters of $5 \mathrm{~m}$. These structures were constructed with circular walls with empty spaces in the middle for use as living quarters as well.

Subcategory 6. The structures in subcategory 6 were all associated with dwellings from West African Village B with similar construction of those in category 4 and structures were the largest of the circular structures with diameters between $6 \mathrm{~m}$ to $6.5 \mathrm{~m}$. The absence of archaeological examples in this subcategory and the previous subcategories is significant. If dimensions from archaeological examples on the island fall within the smaller, circular shape category and closely correlate to ethnographic 
examples used for storage and cooking, then an affiliation between small size and function for the archaeological examples on St. Eustatius is plausible. Additionally, this analysis suggests, as indicative of subcategory 6 , that consistent size relative to one specific location (in this case to West African village B) provides a possible pattern of site-specific dimensions. Each village environment may have structural dimensions specific to that village, constructed by the same individuals who preferred similar dimensions for structures that served an intended purpose. For instance, structures used for grain storage may share similar size dimensions because these structures all have the same purpose in the village environment. Likewise, the archaeological features on Gilboa Hill might have been constructed with site-specific dimensions in mind because of shared preferences that were consistent among builders in one area.

\section{Summary}

Considerable differences in scale could be associated with specific structural function among the examples analyzed. Smaller circular structures ranging in size from $1 \mathrm{~m}$ to $1.75 \mathrm{~m}$ in diameter were primarily from ethnographic examples from African Villages and served as grain storage, cooking, and a chicken coop. Large structures, $3 \mathrm{~m}$ to $6.5 \mathrm{~m}$ in diameter, were all domestic structures used as dwellings. Of all the 51 structures in the circular category, archaeological examples from Gilboa Hill, 14 in total, fell within the mid-range and ranged between $2 \mathrm{~m}$ and $3.4 \mathrm{~m}$ in diameter. It is apparent that the rock features on Gilboa Hill share similarities with structures used for storage, cooking, chicken coops, and not with those used as domestic dwellings. Despite being unique and having no correlates to domestic dwellings, as subcategory 6 indicated it is possible that site-specific dimensions of structures plays as role in the function the dry 
stone rock features served on the mountainous landscape. 


\section{Oval}

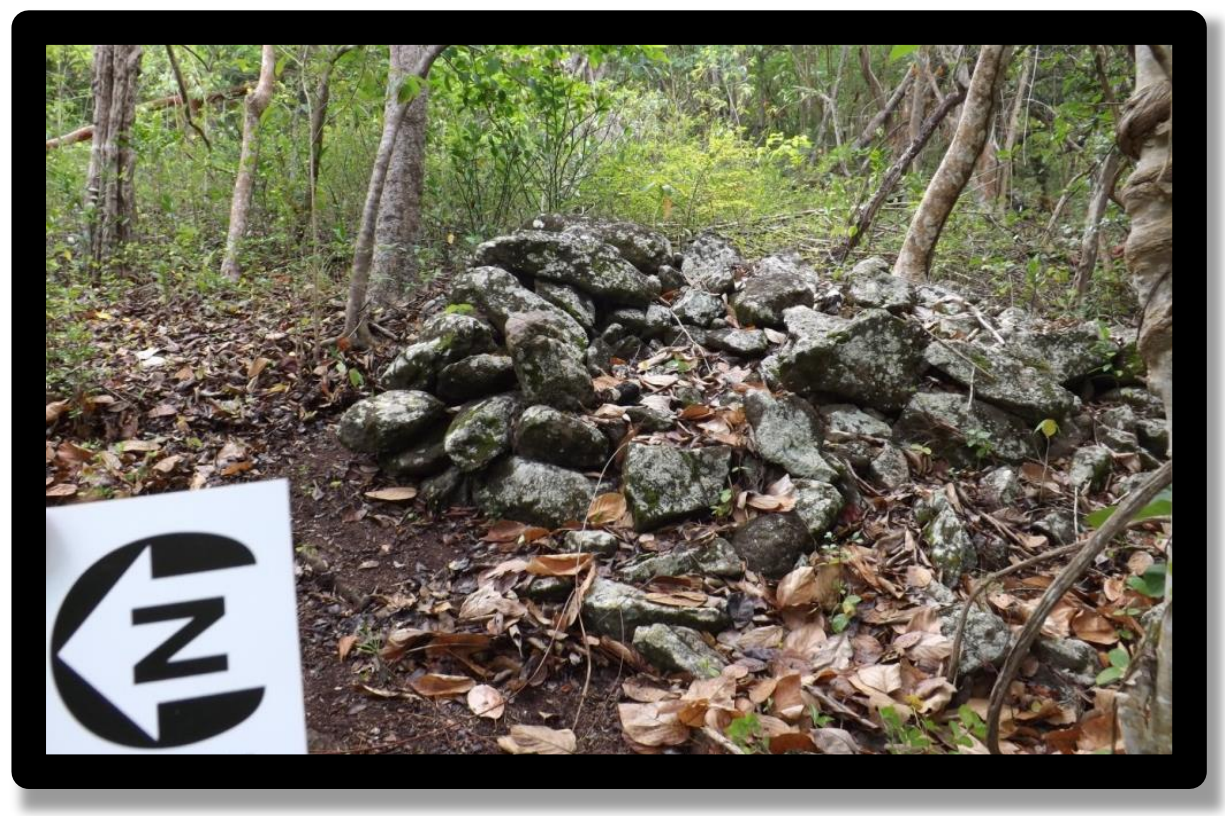

Figure 36. Oval Dry Stone RF4 at GH14

The majority of archaeological examples documented on Gilboa Hill were oval

and all had shared similar solid construction of dry stones piled atop one another with no empty spaces in the middle, (Figure 36 for an example). These oval dry stone rock features ranged in size from $0.375 \mathrm{~m}$ to $27.75 \mathrm{~m}$ in total area and notable concentrations of archaeological examples from all four sites on Gilboa Hill comprised the majority of this category with only two ethnographic examples from African Village C evident, (Table 2). These two examples from the African Village $\mathrm{C}$ were fire pits. To reiterate, there were no identifiable traces of hearths or other evidence the oval dry stone rock features on Gilboa Hill were used as fire pits. A discussion of the twelve subcategories for oval archaeological examples (with two examples from Village C) follows. 
Table 2: Oval Typology Dimensions

\begin{tabular}{|c|c|c|c|c|c|}
\hline Site & type & function & length & width & area \\
\hline GH9 & rock feature $12 \mathrm{a} / \mathrm{b}$ & water-catch & 0.5 & 0.75 & 0.375 \\
\hline \multicolumn{6}{|c|}{ Village C: Fire } \\
\hline Pit & outdoor cooking space & fire pit - a & 2 & 1 & 2 \\
\hline \multicolumn{6}{|c|}{ Village C: Fire } \\
\hline Pit & outdoor cooking space & fire pit -b & 2 & 1 & 2 \\
\hline GH15 & rock feature 2 & & 2.1 & 1 & 2.1 \\
\hline GH15 & rock feature 4 & & 2 & 1.3 & 2.6 \\
\hline GH15 & rock feature 5 & & 2 & 1.5 & 3 \\
\hline GH10 & rock feature 7 & & 2 & 1.5 & 3 \\
\hline GH14 & rock feature 12 & & 1.7 & 2.1 & 3.57 \\
\hline GH14 & rock feature 13 & & 1.7 & 2.1 & 3.57 \\
\hline GH9 & rock feature 6 & & 1.5 & 2.4 & 3.6 \\
\hline GH15 & rock feature 1 & & 3.5 & 1.1 & 3.85 \\
\hline GH15 & rock feature 3 & & 2.75 & 1.5 & 4.125 \\
\hline GH9 & rock feature 3 & & 2 & 2.2 & 4.4 \\
\hline GH14 & rock feature 18 & & 2 & 2.4 & 4.8 \\
\hline GH9 & rock feature 7 & & 2.4 & 2 & 4.8 \\
\hline GH9 & rock feature 13 & & 2 & 2.5 & 5 \\
\hline GH9 & rock feature 14 & & 2 & 2.5 & 5 \\
\hline GH14 & rock feature 3 & & 2.3 & 2.5 & 5.75 \\
\hline GH14 & rock feature 2 & & 2.3 & 2.6 & 5.98 \\
\hline
\end{tabular}


Table 2: Oval Typology Dimensions Continued

\begin{tabular}{|c|c|c|c|c|c|}
\hline Site & type & function & length & width & area \\
\hline GH14 & rock feature 17 & & 2.6 & 2.3 & 5.98 \\
\hline GH10 & rock feature 5 & & 3 & 2.2 & 6.6 \\
\hline GH14 & rock feature 9 & & 2.5 & 2.7 & 6.75 \\
\hline GH14 & rock feature 1 & & 2.5 & 3 & 7.5 \\
\hline Gh14 & rock feature 15 & & 3 & 2.5 & 7.5 \\
\hline GH14 & rock feature 16 & & 2.5 & 3 & 7.5 \\
\hline GH9 & rock feature 1 & & 2.5 & 3 & 7.5 \\
\hline GH9 & rock feature 5 & & 3 & 2.5 & 7.5 \\
\hline GH9 & rock feature 11 & & 3.6 & 2.1 & 7.56 \\
\hline GH14 & rock feature 10 & & 2.4 & 3.3 & 7.92 \\
\hline GH10 & rock feature 1 & & 4 & 2 & 8 \\
\hline GH10 & rock feature 2 & & 4.5 & 2 & 9 \\
\hline GH9 & rock feature 10 & & 3.1 & 3 & 9.3 \\
\hline GH14 & rock feature 6 & & 3.2 & 3 & 9.6 \\
\hline GH10 & rock feature 4 & & 3 & 3.5 & 10.5 \\
\hline GH9 & rock feature 18 & & 3 & 3.5 & 10.5 \\
\hline GH14 & rock feature 7 & & 2.9 & 4 & 11.6 \\
\hline GH10 & rock feature 3 & & 5.5 & 4.5 & 24.75 \\
\hline
\end{tabular}


Subcategory 1. This category consisted of two small features, possibly natural or man-made water catches located at GH9 on Gilboa Hill. They were $0.375 \mathrm{~m}$ in total area and located in the far southern corner of the site. Not only were they unique to the island, but their size and location at GH9 suggests a possible function.

Subcategory 2. This category consisted of six structures with a range in area of $2 m$ to $3 m$. Two of these were fire pits from African Village $C$ and have areas of exactly $2 \mathrm{~m}$. The other four were rock features from archaeological sites GH10 and GH15 on Gilboa Hill. Still, they shared no similarity other than their solid construction, or so I initially thought. On closer inspection, two of the dry stone rock features at GH10 and GH15 were the same size. This was interesting because it suggested that perhaps there was uniformity among the dry stone rock features. Each of the dry stone rock features were piles or groupings of rocks, however, and not hollowed for use as hearths. With no evidence recovered during fieldwork indicating any of the dry stone rock features in this category, or others, were fire pits, the dry stone rock features in this category could not be directly correlated to ethnographic examples of smaller dimensions.

Subcategory 3. This category consisted of four archaeological examples from GH9, GH14, and GH15 on Gilboa Hill. These rock features ranged in size from 3.57m to $3.85 \mathrm{~m}$ in total area. Of interest are the two dry stone rock features at GH14 (RF12 and RF13), as they were the exact same size and were located close to one another. As the previous shape typological category suggested, this reflects an emerging pattern that dry stone rock features at the same site might have had the same function, and/or legacy of construction method, making their similar size dimensions an integral part of their purpose, or the way people managed their work. If enslaved Africans were using the 
dry stone rock piles to add to the terracing already set in the landscape, this suggests they managed this hard work in to small manageable piles.

Subcategory 4. In this category, with not much difference in size and construction, features consisted of four archaeological rock features ranging in size from $4.125 \mathrm{~m}^{2}$ to $4.8 \mathrm{~m}^{2}$ in total area; these included features from sites: GH9, GH14, and GH15. Again, as with the previous subcategory, two dry stone rock features from GH9 (RF3 and RF7) have very similar construction, size and location. This again, supports the emerging pattern that size dimensions at a particular site might be a clue to their specific function or management of work in the landscape.

Subcategory 5. Similarly, subcategory 5 consisted of five archaeological rock features ranging in size from $5 \mathrm{~m}^{2}$ to $5.98 \mathrm{~m}^{2}$ in total area. These features held to the same pattern as the previous two subcategories. Two dry stone rock features (RF13 and RF14) located at GH9 had the exact dimensions and were located right next to one another. Equally, three dry stone rock features at GH14 (RF2, RF3, and RF17) all had the same dimensions. RF17 was in fact in closer proximity to RF2 an RF3 than its name suggests. Again, this is telling; it appears that all subcategories thus far have the same pattern.

Subcategory 6. This category consisted of two archaeological rock features ranging in size from $6 \mathrm{~m}$ to $6.75 \mathrm{~m}$ in total area. One rock feature was from GH10 and the other was from GH14. An important observation is that all archaeological features from Gilboa Hill, only two fell within this range. More than half of oval shape dry stone rock features on Gilboa Hill were smaller than $6 \mathrm{~m}$ in total area; only 15 were larger. While the same pattern of similar size dimensions for dry stone rock features 
and their placement in close proximity to one another did not appear in this subcategory, it appears this might be the midrange of size for the archaeological examples investigated.

Subcategory 7. This category consisted of seven archaeological rock features ranging in size from $7.5 \mathrm{~m}^{2}$ to $7.92 \mathrm{~m}^{2}$ in total area, all from sites GH14 and GH9. This subcategory is by far the most exciting of the oval subcategories because it confirms, without a doubt, that a pattern has emerged during this analysis. In subcategory 7 , this pattern is demonstrated not with two separate dry stone rock features at a particular site, but with three dry stone rock features. GH14 had three dry stone rock features (RF1, RF15 and RF16) with the exact same dimensions. Like RF17 in subcategory 5, given the nature of the way the dry stone rock features were numbered during fieldwork, both RF15 and RF16 are closer in proximity to RF1 than their names suggest. Similarly, three dry stone rock features (RF1, RF5, and RF11) at GH9 were the exact same size. While they were not closely nucleated, the site itself is smaller than GH14 and all dry stone rock features seem to be closer in proximity given the smaller area of the actual site. These indeed confirms dry stone rock features on Gilboa Hill share similar size dimensions and are placed within close proximity of one another at a particular site.

Subcategory 8. Only slightly larger, subcategory 8 consisted of only one archaeological rock feature from GH10. It was $8 \mathrm{~m}$ in total area. What is interesting is that the $0.5 \mathrm{~m}$ difference between this dry stone rock feature from GH10 (RF1) and the dry stone rock feature from GH10 (RF2) that fell into the next subcategory. Making them more similar than not given the other dry stone rock features have more than 0.8 (almost a full meter) difference in size compared to RF2 at GH10. Both RF1 and RF2 at 
GH10, virtually the same size and obviously within close proximity, represent a consistent pattern evident in almost all of the subcategories thus far. It appears that other archaeological features measured approximately $1 \mathrm{~m}$ larger in subsequent categories. There is no clearly discernible reason for this uniform increase in size increments.

Subcategory 9. This category consisted of three archaeological rock features ranging in total area of $9 \mathrm{~m}^{2}$ to $9.6 \mathrm{~m}^{2}$. These features were located at GH9, GH10, and GH14. As discussed in the previous subcategory, one dry stone rock feature at GH10 (RF2) while technically in this subcategory can be more readily associated with RF1 at GH10 in subcategory 8 . As for the two dry stone rock features with total areas ranging between $9.3 \mathrm{~m}^{2}$ and $9.6 \mathrm{~m}^{2}$ they are similar in size dimensions as well, however, they are not from the same sites. While this does not hold to the same emergent pattern, it does suggest that all sites on Gilboa Hill are highly similar in their oval dry stone rock features.

Subcategory 10. This category consisted of two archaeological rock features at sites GH9 and GH10. Each of these rock features had a total area of $10.5 \mathrm{~m}$. As with the previous subcategory, both the dry stone rock features are the exact same size, with the same dimensions, but are from two different sites. Both of these dry stone rock features are much alike despite not being from the same site. Only three dry stone rock features at GH10 (RF1, RF2, and RF3) have the same construction, in fact, their construction more resembles the start of a fort constructed on the second ridge rather than other dry stone rock features dotted across the landscape in upland region two. For this reason, I concluded that RF4 from GH10, of the same construction as RF18 at GH9, should be considered as support for the emergent pattern despite their spatial separation. 
Subcategory 11. This category had only one archaeological rock feature from GH14; it was $11.6 \mathrm{~m}^{2}$ in total area. The lack of other archaeological rock features in this subcategory, and the next subcategory, suggests that dry stone rock features on Gilboa Hill might have a maximum range with the size of $11 \mathrm{~m}^{2}$ being an outlier in terms of dimensions.

Subcategory 12. The last subcategory, subcategory 12 consisted of one archaeological rock feature measuring $24.75 \mathrm{~m}^{2}$ in total area, RF3 from GH10. This was by the far the largest of the archaeological features considered in this portion of the analysis, yet surprisingly, despite its large size, it still confirmed the previously discussed pattern. Given that it is distinct in construction and size, and does not show the slightest uniformity with the other dry stone rock features investigated in this typological category, it is possible it was for a different purpose or stage of construction entirely. Since RF3 closely resembles the construction of the fort on the second ridge and is highly suspected of being some sort of outpost built to warn occupants of incoming fleets from the north, then it would make sense that it did not correlate with any of the other oval dry stone rock features recorded. This suggests that those dry stone rock features that closely resemble one another, both in size and nucleation, across a particular site, are likely for the same purpose or for work organized in a similar way.

\section{Summary}

The shape of these archeological rock features on Gilboa Hill is unique, making them distinctive when compared to other structures on the island. Further, a pattern emerged among the dry stone rock features in this category that is quite telling. It appears that dry stone rock features from the same site, within close proximity to one 
another, are similar in size, if not exactly the same. This suggests that while oval dry stone rock features, which again comprise the majority of those found on Gilboa Hill's third ridge, appear to be haphazardly placed across the landscape with no real similarities, this analysis decisively proves this wrong. The majority of oval dry stone rock features at each site on Gilboa Hill had correlates at that particular site, in similar shape and size.

While no evidence has been presented to suggest these dry stone rock features were used as dwellings and correlation to ethnographic examples used as dwellings was not noted, this is telling evidence to support that in fact each site on Gilboa Hill did have a level of uniformity. Whether this translates into village environment is unclear, what it does answer is it that whoever constructed the dry stone rock piles had specific dimensions in mind when constructing them and could very well relate to their purpose in the plantation landscape. If enslaved workers cleared the land or piled rocks for sleeping platforms, either because being instructed to do so or on their own accord, this pattern demonstrates they intentionally grouped the dry stone rocks into similar sized piles. This spatial analysis documented no other structures that were oval shaped among the archaeological and ethnographic examples compared, except two structures from the African Village C used as fire pits. However, no archaeological evidence was recovered that indicated any of the oval shape dry stone rock features were used as fire pits.

The majority of the 35 oval rock features did have a total feature area larger than $3 \mathrm{~m}^{2}$, or $9 \mathrm{ft}^{2}$, only 14 of these rock features had lengths longer than $2.5 \mathrm{~m}$, or $7.5 \mathrm{ft}$. Over half, 21 rock features, fell below this with a range from $1.5 \mathrm{~m}$ to $2.5 \mathrm{~m}$ in length, or $4.5 \mathrm{ft}$ to $7.5 \mathrm{ft}$. Given the average human being today ranges in height from $1.5 \mathrm{~m}$ to $1.8 \mathrm{~m}$, or 
$5 \mathrm{ft}$ to $6 \mathrm{ft}$. If these were dwellings, the oval shaped platforms that were less than $2.5 \mathrm{~m}$, or 7.5ft, in length (which again comprised the majority of these features) would have allowed only approximately $0.5 \mathrm{~m}$ to $0.65 \mathrm{~m}$, or $1.5 \mathrm{ft}$ to $2 \mathrm{ft}$, in additional space at either end of an individual. In most cases, given a few inches were taken by constructed walls the individual would not have been able to recline on the platform. Even taking in to consideration that human height has changed over time, with men and women on average closer to the $1.5 \mathrm{~m}$, or $5 \mathrm{ft}$ or perhaps shorter in the past, this still seems improbable dwellings were this small. It would have only required a small amount of rocks and/or labor to construct a dwelling that accommodated an individual more adequately.

Of the 14 rock features that did have lengths longer than $2.5 \mathrm{~m}$, these features ranged in length from $2.6 \mathrm{~m}$ to $5.5 \mathrm{~m}$, or $7.75 \mathrm{ft}$ to $17.5 \mathrm{ft}$. This is an important discovery as these rock features could provide dimensions suitable for supporting a reclining individual. On closer inspection three of these, the longest with lengths of $4 \mathrm{~m}$ to $5.5 \mathrm{~m}$, or 13ft to $17.5 \mathrm{ft}$ were RF1, RF2, and RF3 located at GH10. These rock features were noticeably different in construction and composition than any other rock feature investigated and closely resembled the unfinished fort constructed on the second ridge. These features all faced north, were near the edge of the cliff, and had an unobstructed view of the ocean. If incoming threatening fleets were coming from the north, these potential dwellings would have made ideal candidates for posts to help warn island inhabitants as part of a watchtower construction. Two additional rock features at GH10 also had similar lengths suitable for a dwelling: RF4 and RF5. These rock features were located directly to the southeast of rock RF1, RF2, and RF3. For reasons noted earlier, these two additional rock features bring the total to five rock features that were potential 
candidates for dwellings, despite their obvious difference in construction. This warranted further scrutiny and is discussed in the next chapter.

Other rock features, longer in length, $2.6 \mathrm{~m}$ to $3.6 \mathrm{~m}$, or approximately $8 \mathrm{ft}$ to $12 \mathrm{ft}$, did not have as clear distinguishable characteristics, location or orientation in common, however. Of these, two were from GH15, three from GH14 and four from GH9. Although the two rock features from GH15 had substantial length to accommodate a sleeping individual, $2.75 \mathrm{~m}$ and $3.5 \mathrm{~m}$ in length, or roughly $8 \mathrm{ft}$ to $11.5 \mathrm{ft}$, their width would have made for considerably cramped quarters $-1.1 \mathrm{~m}$ to $1.5 \mathrm{~m}$, or $3 \mathrm{ft}$ to $4.5 \mathrm{ft}$ across. If these structures were only used for sleeping, this is entirely plausible, but then why was the adjacent rock feature smaller with dimensions of $2.1 \mathrm{~m} \times 1 \mathrm{~m}$, or $6.5 \mathrm{ft} \times 3 \mathrm{ft}$ ? This suggests a great variability between the three rock features with dimensions suitable for an individual dwelling. It would then appear that each individual constructed a dwelling specific to one's individual dimensions. This is highly unlikely when laborers supposedly rotated in and out of the area. It would make more sense to construct uniform dwellings in size like other domestic structure environments. Perhaps the pattern that emerged during this portion of the analysis becomes all that more relevant, with similar size and dimensions of dry stone rock features at a particular site more adequately associated with their function in the plantation landscape.

Three rock features located at GH14 also had the length to accommodate a sleeping individual, but on closer inspection, they are proportionally unique to the six rock features directly adjacent to them that were shorter. This would suggest that only three rock features in a cluster of nine were structures used for sleeping while the adjacent rock features were not. This is certainly a consideration, but if they were 
occupied by individual laborers, would all the rock features used for sleeping be more uniform in size to accommodate all of the laborers rather than only three?

The four rock features (RF5, RF10, RF11, and RF18) located at GH9 also had similar lengths. The first of these, rock feature 5 on closer inspection revealed its length was actually due in part to scattering of rocks rather than intentional grouping. Its middle width calculated as $2.5 \mathrm{~m}$ in length, is misleading. This width was not uniform across the entire structure; RF5 narrowed at both ends and at its western edge ran almost continuously into the adjacent RF3. This was not conducive to a dwelling as it narrowed considerably at both ends. Rock RF10 and RF11 had dimensions suitable for dwellings as well, but were the only two that were located directly under the large boulder field. While it is plausible that these were potential dwellings, the choice of location is questionable. RF 18 was located off to the east close to the site boundary. A dwelling here is quite plausible, but raises the question as to why the adjacent rock feature, RF19, was not a candidate. Why have two rock features far away from the others, with only one with the dimensions to be an adequate dwelling?

The question remains regarding the longer rock features; could rock features on Gilboa Hill be evidence of initial construction efforts where laborers intended to round out these rock features to be uniform in size for use as dwellings to sleep in? I think the evidence in this portion of the analysis suggests that a comparison of known dimensions of archaeological examples from plantations in the Caribbean and the United States might provide more answers to understand how the dimensions of these archaeological structures correspond. As a pattern is established, the dimensions of the oval structures on Gilboa Hill will certainly be unique, but further analysis might eliminate the 
possibility of their use as dwellings in the plantation landscape. Additionally, a closer inspection of spatial orientation in both archaeological and ethnographic examples might be helpful in understanding how size dimensions correspond to village environments. Even if slaves living in the northern hills had a higher level of ideological freedom, would their dwellings reflect a village environment with relatively uniform dwelling dimensions or dwelling dimensions as variable as those documented thus far? I think if a village environment existed on Gilboa Hill, then the dwellings would reflect uniformity across the entire site. The oval dry stone rock features do exhibit a pattern of uniformity, but the length of the individual dry stone rock features are not long enough to support a reclining individual. The next chapter explores this further. 


\section{Rectangular}

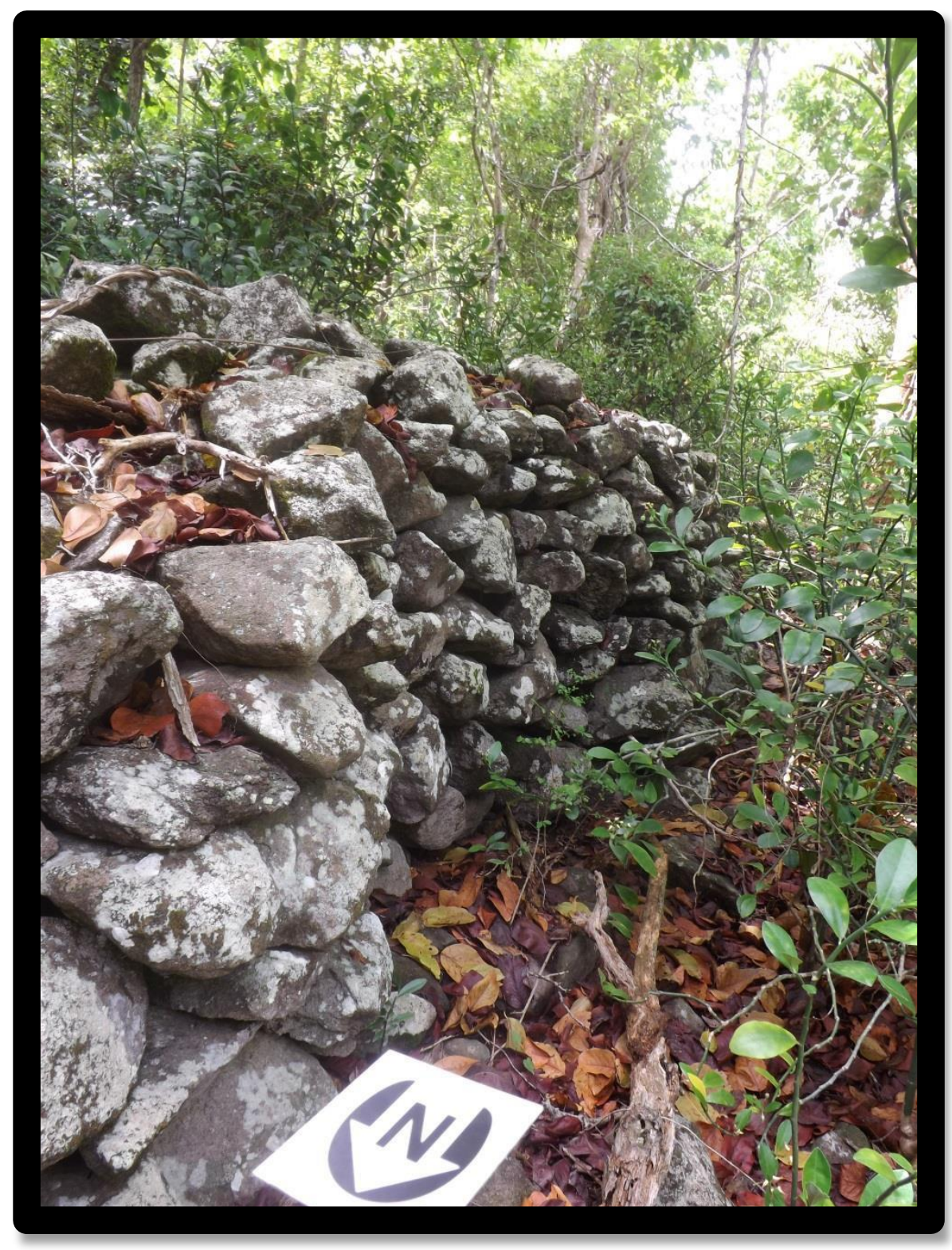

Figure 37. Rectangular Dry Stone Rock Feature 11 at GH14 
Table 3: Rectangular Typology Dimensions

\begin{tabular}{|c|c|c|c|c|c|}
\hline$\underline{\text { site }}$ & tvpe & possible/function & length & width & $\underline{\text { Ratio }}$ \\
\hline GH14 & terrace wall & terrace & 29 & 1 & 0.03 \\
\hline GH14 & terrace wall & terrace & 33 & 1 & 0.03 \\
\hline GH14 & terrace wall & terrace & 23 & 1 & 0.04 \\
\hline GH14 & terrace wall & terrace & 24 & 1 & 0.04 \\
\hline GH14 & terrace wall & terrace & 28 & 1 & 0.04 \\
\hline GH14 & terrace wall & terrace & 32 & 1.5 & 0.05 \\
\hline GH14 & terrace wall & terrace & 26 & 1.5 & 0.06 \\
\hline GH15 & terrace wall & terracing & 16 & 2 & 0.13 \\
\hline GH15 & terrace wall & terracing & 16 & 2 & 0.13 \\
\hline GH15 & terrace wall & terracing & 16 & 3 & 0.19 \\
\hline GH15 & terrace wall & terracing & 11 & 2.25 & 0.2 \\
\hline GH15 & terrace wall & terracing & 12 & 2.6 & 0.22 \\
\hline Village $\mathrm{C}$ & enclosed areas & yard or pen space & 27.5 & 7.5 & 0.27 \\
\hline GH9 & rock feature 21 & & 3.5 & 1 & 0.29 \\
\hline GH14 & rock feature 11 & wall & 10.2 & 3 & 0.29 \\
\hline Village $\mathrm{C}$ & standalone structure & resting platform & 2.25 & 1 & 0.33 \\
\hline Village $\mathrm{C}$ & standalone structure & dwelling & 2.25 & 1 & 0.33 \\
\hline GH9 & rock feature 20 & & 3 & 1 & 0.33 \\
\hline GH14 & rock feature 19 & wall & 4 & 1.5 & 0.38 \\
\hline FBV & structure & dwelling & 8 & 3 & 0.38 \\
\hline GH9 & rock feature 22 & & 2.5 & 1 & 0.4 \\
\hline Village C & standalone structure & dwelling & 2 & 1 & 0.5 \\
\hline Village C & standalone structure & dwelling & 2 & 1 & 0.5 \\
\hline Village $\mathrm{C}$ & standalone structure & dwelling & 2 & 1 & 0.5 \\
\hline Village $\mathrm{C}$ & standalone structure & dwelling & 2 & 1 & 0.5 \\
\hline Village A & Arbor & resting & 2 & 1 & 0.5 \\
\hline
\end{tabular}


Table 3: Rectangular Typology Dimensions Continued

\begin{tabular}{|c|c|c|c|c|c|}
\hline site & type & possible / function & length & width & ratio \\
\hline SE92 & potential structure 3 & dwelling & 3.2 & 1.75 & 0.55 \\
\hline Village B & raised platform & resting & 3.5 & 2 & 0.57 \\
\hline FBV & potential structure & dwelling & 7 & 4.5 & 0.64 \\
\hline Village A & standalone structure & dwelling & 4.5 & 3 & 0.67 \\
\hline Village B & raised platform & resting & 2 & 1.5 & 0.75 \\
\hline Village $\mathrm{C}$ & firewood storage & storage & 2 & 1.5 & 0.75 \\
\hline Village A & standalone structure & dwelling & 4 & 3 & 0.75 \\
\hline SE92 & potential structure 8 & dwelling & 5 & 4 & 0.8 \\
\hline SE92 & potential structure 7 & dwelling & 3 & 2.5 & 0.83 \\
\hline Village A & wooden platform & resting & 3 & 2.5 & 0.83 \\
\hline Village B & raised platform & resting & 3 & 2.5 & 0.83 \\
\hline Village A & standalone structure & dwelling & 3 & 2.5 & 0.83 \\
\hline Village A & standalone structure & dwelling & 3 & 2.5 & 0.83 \\
\hline FBV & stone foundations & & 3 & 2.5 & 0.83 \\
\hline SE92 & potential structure 2 & dwelling & 3.5 & 3 & 0.86 \\
\hline SE92 & potential structure 5 & dwelling & 1.5 & 2 & 1.3 \\
\hline Village B & raised platform & resting & 1.5 & 2 & 1.33 \\
\hline SE92 & potential structure 10 & dwelling & 3.5 & 2.5 & 1.4 \\
\hline SE92 & trapezoid structure & & 2 & 3 & 1.5 \\
\hline SE92 & potential structure 6 & dwelling & 1.5 & 2.5 & 1.67 \\
\hline SE92 & potential structure 11 & dwelling & 1 & 2.5 & 2.5 \\
\hline SE92 & potential structure 12 & dwelling & 1 & 2.5 & 2.5 \\
\hline
\end{tabular}


Fifty-one rectangular structures, grouped into 10 subcategorizes according to size ratios between $0.6 \mathrm{~m}$ and $33 \mathrm{~m}$, were helpful in identifying a pattern of correlation between West African ethnographic examples and archaeological examples on the island, (Table 3). Of the 51 structures considered, 13 structures consisted of examples from both the slave village and FBV; the slave village represented ten domestic structures and the FBV represented three domestic structures. In addition, almost a third of the rectangular category was comprised of fourteen rock wall features, including terracing walls, from two archaeological examples on Gilboa Hill, GH14 and GH15; all had similar solid construction of dry stones with no empty spaces in the middle. These terracing walls immediately separated from the remaining structures at the start of the analysis. These categories, as well as four notable subcategories in size are discussed in the following paragraphs.

Subcategory 1. As mentioned in the introduction, walls used for terracing immediately grouped together. Subcategory 1 consisted of seven dry stone rock structures from site GH14 with ratios between $0.03 \mathrm{~m}$ and $0.06 \mathrm{~m}$; the largest of all of the dry stone rock structures, and were identified as terracing walls located at GH14. This is significant because it suggests, as did dry stone rock feature dimensions in the oval category, that similar size dimensions at the same site reflect a direct relationship to their function at the site. In this case, all of the terracing walls with ratios in this size range were part of a carefully constructed terrace system used for agricultural purposes in upland region one. 
Subcategory 2. Just as the previous subcategory had only terracing walls from site GH14, this subcategory had only terracing walls, all five, from site GH15 with size ratios between $0.13 \mathrm{~m}$ and $0.23 \mathrm{~m}$. This further supports the previously established pattern of similar structural dimensions or size and site-specific function. For two distinct sites to both have their rectangular shape dry stone rock structures group into singular size categories is quite remarkable, but the fact they were used for terracing is even more so. Unfortunately, the remaining rectangular structures did not have such a clearly discernable pattern.

Subcategory 3. This category had three structures with ratios between $0.27 \mathrm{~m}$ to $0.29 \mathrm{~m}$. Of these, one was an enclosed area from West African village C, RF21 from GH9, and RF11 from GH14. An interesting find included the correlation between a structure in an established village environment in West Africa used for yard or pen spaces to house animals and the structures in this subcategory. In addition, and more important, RF11 at GH14 was a half- constructed wall! While not definitive, it is telling to correlate a half-constructed wall to a structure that was used to house animals. This wall at GH14 was quite tall, when finished, was it meant to hold cattle at this location? This cannot be confirmed, but the possibility is significant. In addition, RF21, grouped with two other rectangular features at GH9, shared similar size as the examples in this subcategory as well. Does this suggest the rock features at GH9 had a similar function? 
Subcategory 4. This category had six structures with size ratios between $0.33 \mathrm{~m}$ to $0.38 \mathrm{~m}$. Two of these were of the same size, noted as resting platforms, at West African village $\mathrm{C}$. Two structures, RF20 and RF22, were from GH9, another structure was from the FBV, quite possibly a dwelling, and the remaining structure was a wall at GH14, RF19. Given the correlation to two features in Village $\mathrm{C}$ used as resting platforms as well as to a structure most likely used as a dwelling at the FBV, site GH9 was a candidate to determine whether its three structures (RF20, RF21 and RF23) may have been dwellings. It would make sense, if so; these rectangular-shaped dry stone rock features were set apart on the landscape and oriented much differently from the other dry stone features noted at the site. Their size, shape, and location appear to distinguish them in the landscape. The correlation to RF19, a wall at GH14, further suggests RF20, RF21, and RF22 at GH9 had a different function at the site.

Subcategories 5-10. These categories, grouped together for their lack of archaeological rock features from Gilboa Hill, had 27 structures with ratios between $0.5 \mathrm{~m}$ and $2 \mathrm{~m}$. These subcategories included the remaining 12 archaeological examples from the slave village and FBV, as well as the remaining 15 structures from ethnographic examples. Differences in size dimensions were not remarkable except that those structures at the slave village were the smallest of all the structures in the analysis. What is telling about all of the structures in this subcategory is their function in the village environment was noted as either dwellings or resting platforms. 
This is important as it indicates, as previously discussed, that there is yet again a clear connection between size and function at a specific site. In these subcategories it appears that size in general might relate to function, perhaps the broader comparison of structures used as dwellings would be useful.

\section{Summary}

In this portion of the spatial analysis, rectangular subcategories provided the soundest evidence thus far for clearly differentiating archaeological structures in the slave village and the FBV from the dry stone rock features from Gilboa Hill. Upon comparison, structures from both the slave village and FBV were closer to the dimensions evident in the ethnographic examples from African Villages A, B, C, and D rather than those from sites on Gilboa Hill, except for RF20, RF21 and RF22 at GH9. Clear divisions between domestic structures and rock terracing walls were noted. Those archaeological rock features from Gilboa Hill that were rectangular and not identified as rock terracing walls or unfinished walls were still noticeably different in construction than domestic structures by comparison. From this data, it is apparent that domestic structures used as dwellings in the slave village, the FBV, and ethnographic examples from African Villages, A, B, C, and D were often rectangular and all of relatively the same size. This is consistent with the pattern that surfaced in the previous discussion of oval shape dry stone rock features; size is relative to function or staging of work/task within a specific locale. Only four of the 51 structural features in this category that could not be associated with unfinished walls or terracing were archaeological rock features located on Gilboa Hill; this is an important finding. If the vast majority of domestic structures on the island were 
rectangular, rock features that were another shape on Gilboa Hill could be associated with another function other than domestic occupation dwellings. If they were dwellings, then their shape and dimensions would be unique to the island. With this in mind, rock features at GH9 warrant a closer look.

\section{Square and Irregular}

All structures within the square shaped category were from African Village ethnographic examples found in Villages A, B, C and D. These structures ranged from $1 \mathrm{~m}^{2}$ to $6.5 \mathrm{~m}^{2}$ in total area. On the smaller end of this range from $1 \mathrm{~m}^{2}$ to $3 \mathrm{~m}^{2}$ in total area consisted of structures used for grain storage, chicken pens, wooden raised platforms, bathing enclosures, two cooking areas, a kitchen and food prep area, and two small dwellings. The larger structures ranging in size from $3.5 \mathrm{~m}^{2}$ to $6.5 \mathrm{~m}^{2}$ in total area were associated 15 structures noted as being dwellings, a kitchen, two millet storage structures, and large open courtyards.

Irregular shaped archaeological structures were not among the analyzed examples. Irregular examples consisted of cooking, activity areas, yard spaces, animal pens, and bathing enclosures and were only associated with ethnographic examples from African Villages A, B, and C.

\section{Summary}

Despite the lack of archaeological examples in these categories it is important to note that structures in this analysis have followed a pattern that is easily identifiable among the ethnographic examples. Smaller sized structures served as potential storage, livestock pens, and cooking areas. Only small dwellings are in this smaller category. Larger structures are easily identifiable as domestic structures used as large kitchens and 
dwellings. Without certainty of the exact function of each of the archaeological features on Gilboa Hill, ethnographic range of function by size then becomes a useful tool to understand the potential of archaeological examples in comparison. More importantly, the fact that no square or irregular archaeological examples were documented on the island is a key finding and more analysis becomes useful in determining whether the oval structures were dwellings at all.

\section{Broader Comparative Analysis: Structural Dimensions}

A comparison of archaeological examples on the island of St. Eustatius and ethnographic examples from West Africa determined that the archaeological features under investigation on Gilboa Hill, suspected of being dwellings, were unique; especially the oval features. They did not correlate to archaeological examples on the island and comparisons revealed only a minute parallel to structures within the same size in ethnographic examples. Additionally, examples from West Africa and structures in both the SSV and FBV were constructed mainly of wood with variances in type of wood, construction design, and building techniques; none of these structures were constructed using dry stones like those recorded on Gilboa Hill. Structures at the FBV and one ethnographic village did have stone foundations, but differences in shape, size, and construction were immediate in comparison to the dry stone rock features in the study. With this in mind, a broader comparison of known archaeological slave dwellings and their dimensions from plantations in the Caribbean and the United States seemed likely to provide insight into whether these archaeological examples correlated with structures associated within the plantation landscape at all, and if so, which ones? If correlations to other known slave dwelling dimensions are established, perhaps the archaeological 
features on Gilboa Hill can be definitively identified as dwellings. If they were unique, which might indicate higher ideological freedom in choice of construction, perhaps a close correlate on another plantation might be observed. If not, what does this suggest about the archaeological examples on Gilboa Hill? Surely, if they were unique both on the island and in a broader comparison, this does not rule out the possibility of their function as dwellings. However, if no known correlates exist and features are far too small to accommodate a reclining human being, other uses or purposes need to be made; this includes the possibility of their use not as domestic dwellings at all, but as part of labor activities.

Investigation of 29 structures in the United States and the Caribbean from 1751 to 1863 revealed a strong prevalence of rectangular and square shaped slave quarters. This generated great interest for further comparison of structural dimensions from known plantations and structures or features recovered archaeologically on St. Eustatius. The rectangular slave quarters from fourteen plantations when compared to rectangular structures both in the slave village and FBV, as well as to three rectangular dry stone rock features documented at site GH9, divided well into three distinct subcategories: small, medium, and large with ratios between $0.2 \mathrm{~m}$ and $3.5 \mathrm{~m}$ (small, medium, and large) (Table $4)$. 
Table 4: Comparison of Slave Quarter Dimensions: United States and Caribbean

\begin{tabular}{|c|c|c|c|c|c|c|}
\hline Location & Plantation & Year & Shape & Length & Width & Ratio \\
\hline Texas & Bell City & 1835 & $\mathrm{R}$ & 5.5 & 30.4 & 0.2 \\
\hline Alabama & Thornhill & 1833 & $\mathrm{R}$ & 5.1 & 13 & 0.4 \\
\hline Jamaica & Coffee Plantation & $1751 / 1830$ & $\mathrm{R}$ & 6 & 15.2 & 0.4 \\
\hline Maryland & Hampton & 1850 & $\mathrm{R}$ & 6 & 12 & 0.5 \\
\hline SE92 & potential structure 6 & & $\mathrm{R}$ & 1.5 & 2.5 & 0.6 \\
\hline St Croix & William Chapman & 1790 & $\mathrm{R}$ & 4.9 & 8 & 0.6 \\
\hline Jamaica & Alexander Barclay & & $\mathrm{R}$ & 5.2 & 8.5 & 0.6 \\
\hline Alabama & Rosemount & & $\mathrm{R}$ & 6 & 9.1 & 0.6 \\
\hline Jamaica & John Stewart & 1820 & $\mathrm{R}$ & 3 & 4.6 & 0.7 \\
\hline Jamaica & Roehampton & $1791 / 1830$ & $\mathrm{R}$ & 4.8 & 7.3 & 0.7 \\
\hline Cuba & El Padre & $1790 / 1853$ & $\mathrm{R}$ & 5 & 7 & 0.7 \\
\hline SE92 & potential structure 9 & & $\mathrm{R}$ & 5.5 & 7.5 & 0.7 \\
\hline FBV & stone foundation 1 & $1863+$ & $\mathrm{R}$ & 1.5 & 2 & 0.8 \\
\hline SE92 & potential structure 5 & & $\mathrm{R}$ & 1.5 & 2 & 0.8 \\
\hline Jamaica & Bryan Edwards & 1790 & $\mathrm{R}$ & 4.6 & 6 & 0.8 \\
\hline Jamaica & John Stewart & 1820 & $\mathrm{R}$ & 4.6 & 6 & 0.8 \\
\hline Georgia & Cannon's Point & $1793 / 1866$ & $\mathrm{R}$ & 4.9 & 6.1 & 0.8 \\
\hline SE92 & potential structure 4 & & $\mathrm{R}$ & 3.25 & 3 & 1.1 \\
\hline SE92 & potential structure 7 & & $\mathrm{R}$ & 3 & 2.5 & 1.2 \\
\hline SE92 & potential structure 2 & & $\mathrm{R}$ & 2 & 1.5 & 1.3 \\
\hline SE92 & potential structure 10 & & $\mathrm{R}$ & 4 & 3 & 1.37 \\
\hline FBV & stone foundation 2 & $1863+$ & $\mathrm{R}$ & 7 & 4.5 & 1.6 \\
\hline SE92 & potential structure 3 & & $\mathrm{R}$ & 3 & 1.75 & 1.7 \\
\hline FBV & stone foundation 3 & $1863+$ & $\mathrm{R}$ & 8 & 3 & 1.7 \\
\hline SE92 & pontential structure 8 & & $\mathrm{R}$ & 9.5 & 5.5 & 1.7 \\
\hline SE92 & potential structure 1 & & $\mathrm{R}$ & 6.25 & 3.25 & 1.9 \\
\hline Florida & Kingsley & 1830 & $\mathrm{R}$ & 5.5 & 2.4 & 2.3 \\
\hline GH9 & rock feature 22 & & $\mathrm{R}$ & 2.5 & 1 & 2.5 \\
\hline Texas & Cavitt & 1835 & $\mathrm{R}$ & 8.1 & 3.3 & $2.5]$ \\
\hline GH9 & rock feature 20 & & $\mathrm{R}$ & 3 & 1 & 3 \\
\hline GH9 & rock feature 21 & & $\mathrm{R}$ & 3.5 & 1 & 3.5 \\
\hline Jamaica & Montpelier & & $S$ & 2.7 & 2.7 & \\
\hline Georgia & Cannon's Point & $1793 / 1866$ & S & 3.7 & 3.7 & \\
\hline
\end{tabular}




\begin{tabular}{cccccc} 
Jamaica & Rev R Bichell & & $\mathrm{S}$ & 3.7 & 3.7 \\
Georgia & Cannon's Point & $1793 / 1866$ & $\mathrm{~S}$ & 5.5 & 5.5 \\
Jamaica & R C Dall & 1790 & $\mathrm{~S}$ & 6 & 6 \\
Tennessee & Hermitage & $1804 / 1845$ & $\mathrm{~S}$ & 6.1 & 6.1 \\
\hline
\end{tabular}

The smallest of the subcategories with structural ratios between $0.2 \mathrm{~m}$ and $0.8 \mathrm{~m}$ included a varied mix of structures from plantations in the Caribbean (Cuba, Jamaica, St Croix, and St. Eustatius) and in the United States (Alabama, Georgia, Maryland, and Texas). The concentration of rectangular structures into this small subcategory suggests that smaller structures might have been preferred in village environments both in the Caribbean and in the United States. To note, even four of the structures from sites located on St. Eustatius were included in this small subcategory.

The mid-range subcategory, however, included only archaeological examples from St. Eustatius from the Schotsenhoek plantation slave village and the Free Black Village with size ratios between $1.1 \mathrm{~m}$ and $1.9 \mathrm{~m}$. The lack of comparative structures from the United States and the Caribbean is significant; it is an indication that structures on the island of St. Eustatius were unique not only in the Caribbean, but in the United States as well. Further, this suggests that structures in village environments on the island of St. Eustatius could conform to Dutch standardization efforts or occupants might have had the freedom to choose uniform dimensions according to established patterns within their communities.

The largest subcategory had examples with ratios between $2.3 \mathrm{~m}$ and $3.5 \mathrm{~m}$ from the United States (Florida and Texas) and three archaeological examples from site GH9 on Gilboa Hill (rock features: 20, 21, and 22). The rock features from GH9 were unique 
to the third ridge in general and were the only rectangular features noted during the investigation aside from terracing walls. What is particularly interesting is that these features compared with structures from plantations in the United States during the midseventeenth century rather than those from the Caribbean. These comparable structures, both in Texas and Florida, were much narrower than those in the comparison from other locations in the United States. Why would narrow structural design compare to three archaeological features on Gilboa's third ridge and not to other structures recovered archaeologically? Perhaps it has more to do with their function or staging of work in the plantation landscape. Even so, this pattern indicates that rock features located on Gilboa Hill were clearly unique even on the island.

\section{Summary}

This broader comparison was helpful as it established patterns of structural dimensions in slave village environments across plantation landscapes in the Caribbean and in the United States. With dimensions from documented structures in the Caribbean and the United States closely correlating to the smallest of archaeological structures on St. Eustatius, it suggests that slave quarters in general were smaller, yet it might indicate a pattern specific to the Dutch. Additionally, since the majority of dimensions on St. Eustatius fell into their own size category, the medium category, this further supports that Dutch occupants living in enslaved village environments on the island had unique housing dimensions. Perhaps enslaved environments, whether for work or domestic settings, had a level of standardization among constructed structures in enslaved environments on St. Eustatius; this could explain why the dry stone rock features on 
Gilboa Hill have no correlates, they were not part of a domestic village environment or were site-specific.

With this in mind, another important take away from this analysis is the dominant shape of slave housing in all of the examples considered; all were either square or rectangular, not circular or oval like those in the northern hills. The rectangular features on Gilboa Hill, closely correspond with structural dimensions found in the United States, in Florida and Texas, yet it is unclear why. Without further historical documentation to consider, it is merely supposition at this point to make a direct connection to construction practices in the United States, those in the Caribbean, and those on St. Eustatius. However, for the scope of this investigation, this broader comparative analysis was helpful in confirming the uniqueness of the structures recovered archaeologically on the island.

\section{Schotsenhoek Slave Village: Post Hole Analysis}

After searching for comparable correlates between archaeological examples on the island and ethnographic examples from West Africa and determining the dry stone rock features on Gilboa Hill were unique to the island, it was important to consider other structural dimensions within village environments. This analysis determined that not only were most slave dwellings on plantation landscapes in the Caribbean and the United States square or rectangular in shape, but structural dimensions on St. Eustatius were unique even in the Caribbean. Does this reflect a pattern that can be attributed to a Dutch standard or higher level of choice in construction among the slave population? The Schotsenhoek slave village offered the perfect opportunity to examine an archaeological 
slave village specific to St. Eustatius to determine if diagnostic patterns of structural dimensions exist for enslaved Dutch communities.

Construction of vernacular architecture in village settlements often includes the use of deeper set posts along the corners of a structure, with more shallow posts set to support walls and interior support for the roof (Gilmore 2013). For this study, a close inspection of depth and placement of postholes and post molds provided an opportunity to assess the construction of vernacular architecture within a village environment on St. Eustatius directly. If consistencies to typical vernacular construction methods exist, then this analysis will confirm the possibility of an adoption of suspected construction methods used by enslaved populations.

This analysis considered 26 recorded posthole and post molds depths within potential features at the first phase of excavation of the Schotsenhoek slave village, recorded by island archaeologist, Ruud Stelten; archaeological excavations revealed postholes as well as post molds associated with ten potential rectangular structures ranging $1.5 \mathrm{~m} \times 2 \mathrm{~m}$ to $9.5 \mathrm{~m} \times 5.5 \mathrm{~m}$ in size, with concentrations along the western edge of the site. Figure 38 visually depicts the location of each of the recovered postholes and post molds; for a full list of individual depths and profiles, (see Appendix F and G) (Ruud Stelten 2012). 


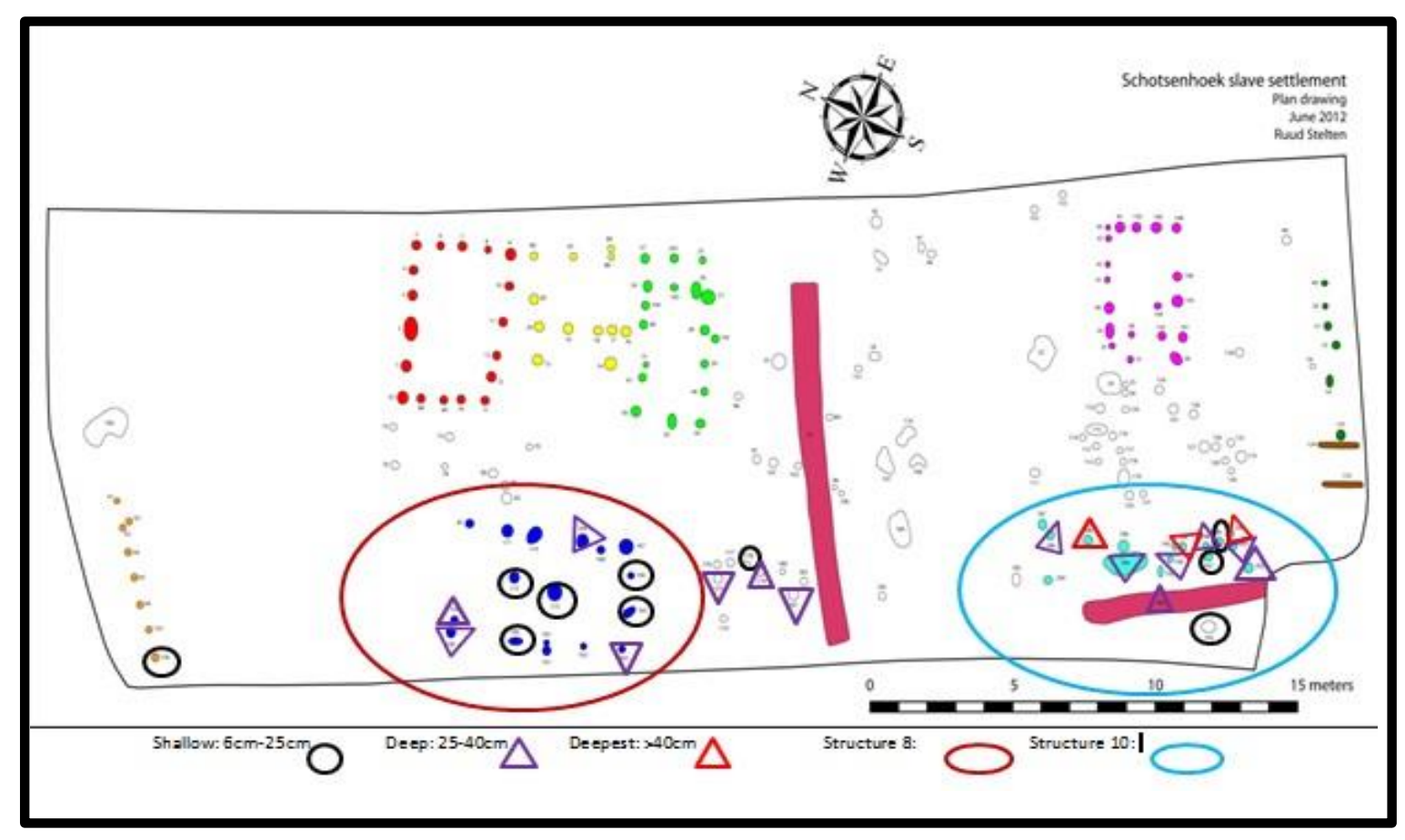

Figure 38. Schotsenhoek Slave Village Settlement Posthole and Post molds

Ten were shallow and ranged between $12.5 \mathrm{~cm}$ and $22.5 \mathrm{~cm}$, noted as black circles in figure 38. Their placement within the potential structures and their shallow depths suggest they were not used as main support posts. Structure 8 exemplifies this nicely; five of the shallow posts are visible running along the outer walls of the potential structures as well as the interior of the structure. This placement suggests they could have been support beams for the roof. Structure 10 was more ambiguous in distinguishable shape and dimensions, noted as being $4 \mathrm{~m} \times 3 \mathrm{~m}$, however, it is clear that the shallow postholes are consistent with those in structure 8 and were most likely additional support posts rather than initial posts used in the erection of this structure. One of the shallow postholes was located in the far northwest corner along the perimeter of the site; used in a suspected wooden fence. This shallow depth would be consistent with fence construction. 
Sixteen were deeper, ranging in size from $27.5 \mathrm{~cm}$ and $40 \mathrm{~cm}$, noted as purple triangles in Figure 38. Of these, five were clearly located at corners of potential structures 8 and 10; this demonstrates consistency with methods used in the construction of vernacular architecture and posts were most likely set deeper in corners for structural support posts. In structure 8, one post is set deeper along what looks like a wall, but without knowing the exact phases of construction, it is difficult to determine whether this post was part of initial or later construction. It is possible that it is a support post as well and used during the initial erection of the structure. As noted earlier, it is unclear the exact shape for potential structure 10, but two posts were noted in what appears to be the interior of the potential structure. A possibility is that these posts were set deeper to support an interior wall during the initial construction of the structure. The remaining four deeper posts were located outside the borders for structures 8 and 10, and contrary to other posts, evidence suggests these posts were not affiliated with the construction of potential structures. The three deepest posts, depicted as red triangles in Figure 38, were located along potential structure 10's eastern wall. Their placement within the potential structure is consistent with previously established patterns of vernacular construction within the Schotsenhoek slave village settlement.

\section{Summary}

While using posthole and post mold depths cannot definitively determine dates of construction for the ten potential structures identified, it is important to note that over half of the postholes and post molds were set deeper and conformed to established placement patterns used in vernacular construction. This suggests an adoption of vernacular 
construction methods and of adding on to previously erected structures within the village environment as Grant proposed (Grant 2013). More importantly, the outlines of potential structures painted from the recovered postholes suggest prevalence in one particular shape, rectangular. These rectangular structures correlate to ethnographic examples form African Villages A, B, and D with similar size and shape, but not to dry stone rock features in the upland regions on Gilboa Hill, except for the three dry stone rock features from GH9. Furthermore, while structures at the FBV had stone foundations and were notably larger, they were still rectangular and within size dimensions that were comparable to potential structures at the slave village.

This correlation with both African ethnographic examples and stone foundations from the FBV supports the possibility that these ten structures at the Schotsenhoek slave village were likely dwellings. In addition, the distinguishable rectangular shape identified here at the Schotsenhoek slave village correlates to other documented slave dwelling shapes in the Caribbean and United States. Given this established pattern of structural dimensions on St. Eustatius, it would appear that the archaeological examples on Gilboa Hill are distinctive to say the least. In the next chapter, the spatial orientation of domestic village environments and material assemblages will offer additional insight into understanding archaeological sites on Gilboa Hill. 


\section{CHAPTER V \\ SPATIAL ORIENTATION, FEATURE, AND ARTIFACT ANALYSIS}

When structural location, setting, shape, size, and construction were compared, the only pattern firmly established through the analysis discussed in the previous chapter was that the dry stone rock features on Gilboa Hill had no correlates to any of the examples in the comparison, revealing that the archaeological features in the Northern Hills were unique. The possibility of the dry stone rock features once functioning as dwellings in a former slave village, either temporary or permanent, is still plausible, but additional analysis might offer definitive conclusions. While the features had no known correlates, if the spatial organization at each of the four sites reflects a communal environment similar to a West African Ubuntu community building principle (close nucleation near a central or adjacent yardspace) then the Northern Hills were potentially the location of a unique labor village. Further, if comparisons of the material assemblages from the upland and lowland regions reveal similar patterns in quantity and distribution, then this too supports domestic occupation in the Northern Hills. 


\section{Spatial Organization}

For this analysis, the previously established typological categories (circular, oval, and rectangular) served as the foundation to measure and compare minimum and maximum distances between archaeological features on Gilboa Hill to measurements recorded from both the villages in the lowlands and ethnographic examples from West Africa. To note, only categories with a mixture of archaeological examples and ethnographic examples or just archaeological examples were used in the comparison, as the aim of this spatial analysis was to understand if archaeological features on Gilboa Hill adhered to a spatial alignment typical of village environments rather than reanalyze already established patterns in African village spatial orientation. This resulted in the exclusion of square structures entirely since there were no archaeological structures or features in this shape category.

The previous analysis identified subcategories within shape categories; however, the following discussion of minimum and maximum distances between structures across the landscape will concentrate on small, medium, and large structures rather than discuss each individual subcategory. These broad groupings were not only adequate for comparative purposes but visually display patterns in distancing between the structures under investigation well in the tables provided. Tables, compiled with descending size dimensions (from large to small) reveal striking patterns of close nucleation patterns in larger structures used as dwellings. This was expected given they were part of a domestic village settlement. These patterns are evident not only in the previously established villages in the lowland region on the island of St. Eustatius, but also in two sites on Gilboa Hill (GH9 and GH15). The following discussion will include measurements and 
discussions from small, medium, and large subcategories as well as noted patterns of nucleation and dispersal; the results of rigorous scrutiny of archaeological features at sites GH9 and GH15 will also be discussed.

\section{Circular}

Again, circular structures ranged in size from $1 \mathrm{~m}$ to $6.5 \mathrm{~m}$ in diameter.

Archaeological and ethnographic examples were sorted by size and then by minimum and maximum distances. With larger structures and features at the top of the table, one can quickly see that structures were very close together in village environments. Even the one foundation in this category (foundation 4) from the FBV is depicted close in relation to the other foundations in the village setting of which it was a part. Maximum distances indicated a similar pattern of limited dispersion indicative of village environments as well. 
Table 5: Minimum Distances of Circular Structures and Features

\section{Structures}

Village C: livestock Village A: domestic structure 3 Village A: domestic structure 1 Village A: domestic structure 2 Village D: domestic structure Village C: domestic structure Village C: domestic structure Village C: domestic structure Village $\mathrm{C}$ : domestic structure Village $\mathrm{C}$ : domestic structure Village C: domestic structure Village $\mathrm{B}$ : domestic structure Village B: domestic structure FBV: stone foundation 4 Village C: domestic structure Village C: domestic structure Village C: domestic structure Village B: storage Village B: storage Village B: storage Village B: storage Village B: storage Village B: storage Village B: storage Village B: storage Village B: storage Village C: storage Village C: storage GH9: rock feature 8 GH9: rock feature 9 GH9: rock feature 2 Village B: domestic structure Village B: domestic structure Village B: domestic structure Village B: domestic structure Village B: domestic structure Village B: storage GH14: rock feature 14 Village B: storage GH10: rock feature 6 GH9: rock feature 15 GH9: rock feature 4 GH14: rock feature 5 GH9: rock feature 19 GH14: rock feature 4 GH9: rock feature 16 GH14: rock feature 8 Village B: domestic structure Village A: livestock GH9: rock feature 17

Meters:

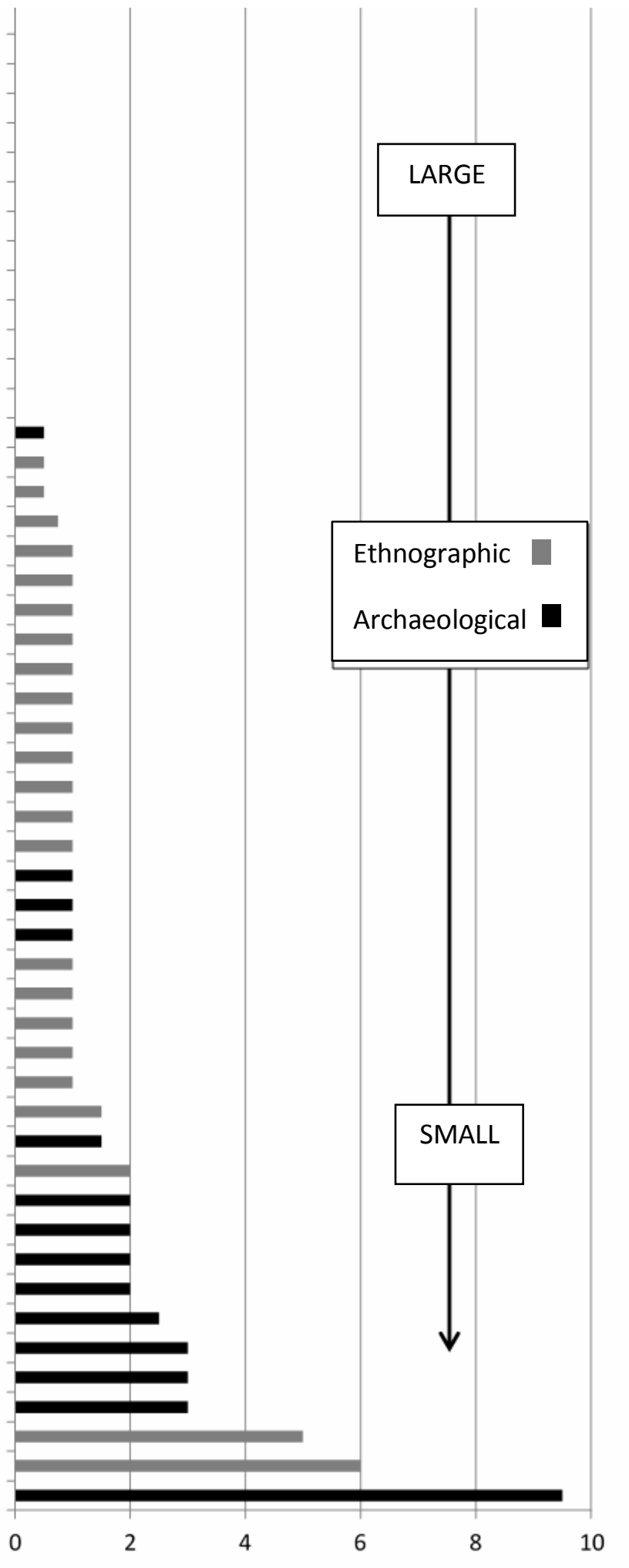


The minimum distances calculated in Table 5 indicate that structures were uniformly nucleated, at least those in the medium and large categories; structures under examination that fell into the medium and large categories all had minimum distances up to $1 \mathrm{~m}$; everything was very close together! In the medium size range only three archaeological dry stone rock features from $\operatorname{GH} 9(2,8,9)$ correlated with ethnographic examples in terms of nucleation distance. The smallest structures and archaeological features, however, were at least $1 \mathrm{~m}$ apart and nearly 10 times farther apart from one another than domestic archaeological and ethnographic structures. The majority of archaeological features on Gilboa Hill fell into this small category and clustered separately because their minimum distances were far apart compared to most ethnographic examples 
Table 6: Maximum Distances of Circular Structures and Features

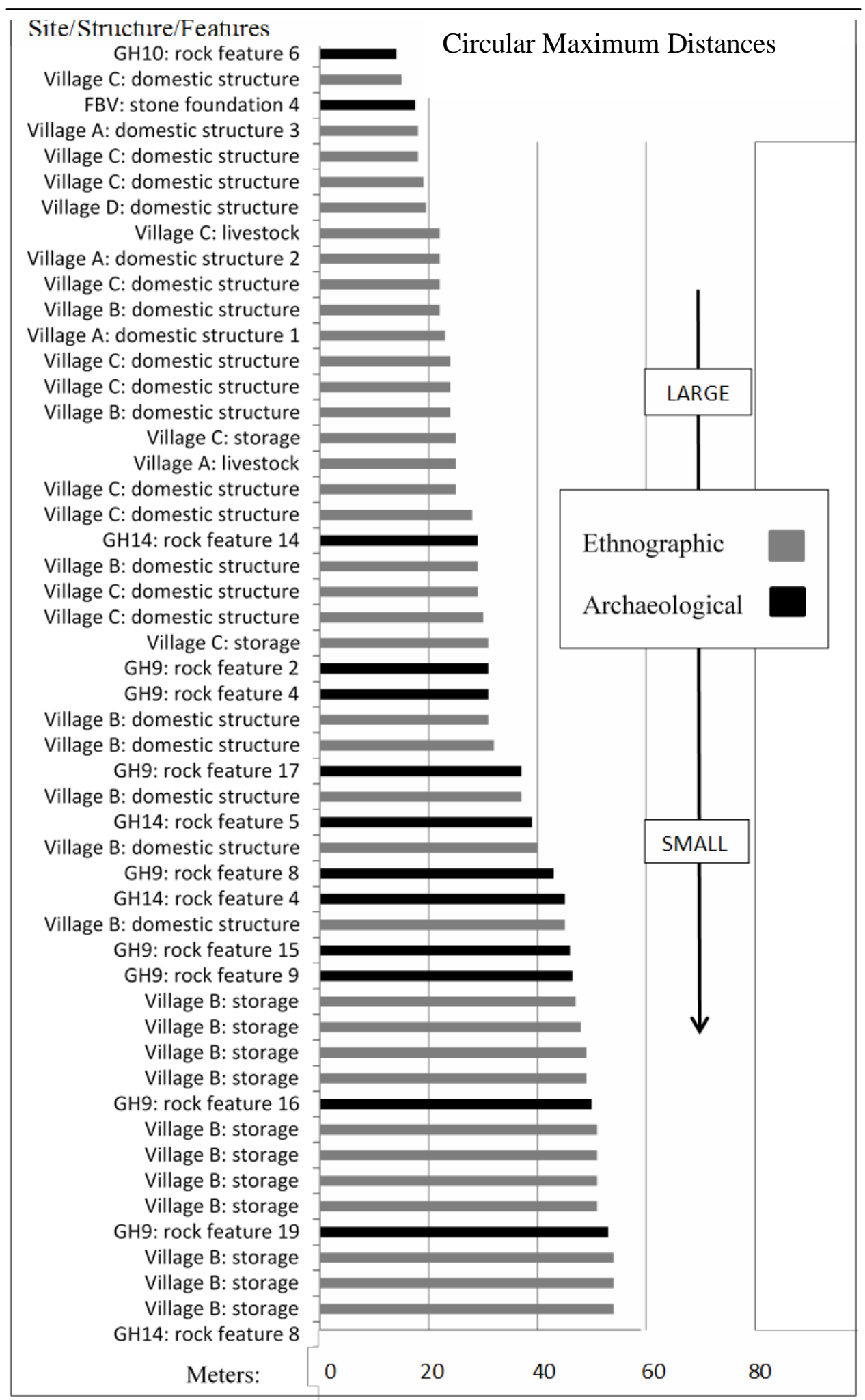


Like the minimum distances in the circular shape category, the maximum distances of village habitations tended to be located close to each other, while storage and Gilboa Hill features were located some distance from the next feature (Table 6). These patterns show that village domestic space and rock features on Gilboa Hill were fairly evenly distributed. The largest of the structures were $18 \mathrm{~m}$ to $23 \mathrm{~m}$ apart and the vast majority, 7 in total, were from village settings, one being from the FBV. The only archaeological example in the large category was rock feature 6 from GH10. This suggests a pattern of limited dispersal between structures used as dwellings in village environments in African Villages A, B, C, and D.

The maximum distances from the medium size range measured $28 \mathrm{~m}$ to $40 \mathrm{~m}$ apart. Of these, there was a mix of ethnographic and archaeological features and structures. Two were from GH9 (2 and 17), and one from GH14 (5). This indicated a higher probability of features at GH9 and GH14 having a clumped, even distribution similar to known village patterns. The small category included a few archaeological features, but it is important to note that while these features co-occurred with ethnographic examples, these structures were all used for storage and placed across the village landscape in wider intervals. Is it possible to correlate function with dispersal patterns that required placement farther from one another? Perhaps because the storage areas are work rather than habitation structures, the work spacing of the Gilboa Hill features makes sense. 


\section{Summary}

Most of the archaeological dry stone rock features in this shape category do not have patterns of even, close nucleation. Rock features at GH10 and GH14 had a close nucleation pattern. This analysis of the circular dry stone rock features' minimum and maximum distances did indicate a consistent co-occurrence with ethnographic examples. Dry stone rock features $4,8,9$, and 17 had either small or large distances apart; dry stone rock feature 2 had both which is consistent with domestic structures. Rock features at this site are indicative of a recurrent spatial pattern than at any other site under consideration.

\section{Oval}

The oval shape category was divided into three subcategories as well: small, medium, and large, (Tables 7 and 8). Similar to the circular category, the analysis of minimum and maximum distances of oval shaped archaeological dry stone rock features and two ethnographic examples indicated a clear correlation between large size and close nucleation across the landscape. Oval shape dry stone rock features closely correlated to cooking features in the ethnographic examples, but no evidence of cooking activity was recovered on Gilboa Hill. Circular structures in ethnographic examples and from the FBV had the same pattern, perhaps a similarity exists because people have to cooperate in the work, whether to build a fire pit, hearth, etc. and attests to the labor activity involved rather than the finished product of that labor. Given that the majority of archaeological features on Gilboa Hill were oval shaped, this is an important find. 
Table 7: Minimum Distances of Oval Structures and Features

Oval: Minimum Distances

$\underline{\text { Site/ Structures/ }}$

GH9: rock feature 3 GH14: rock feature 15 GH14: rock feature 16

GH9: rock feature 5

GH15: rock feature 4

GH15: rock feature 5

GH14: rock feature 13

GH14: rock feature 12

GH15: rock feature 1

GH14: rock feature 9

GH9: rock feature 1

GH9: rock feature 10

GH15: rock feature 2

GH14: rock feature 18

Village C: outdoor cooking space

GH15: rock feature 3

GH9: rock feature 14

GH14: rock feature 3

GH14: rock feature 2

GH10: rock feature 5

$\mathrm{GH} 14$ : rock feature 1

GH14: rock feature 7

GH9: rock feature 6

GH14: rock feature 17

GH9: rock feature 11

GH9: rock feature 18

Village C: outdoor cooking space

GH9: rock feature 7

GH10: rock feature 2

GH14: rock feature 6

GH10: rock feature 3

GH9: rock feature 13

GH9: rock feature $12 \mathrm{a} / \mathrm{b}$

GH14: rock feature 10

GH10: rock feature 7

GH10: rock feature 1

GH10: rock feature 4

Meters:

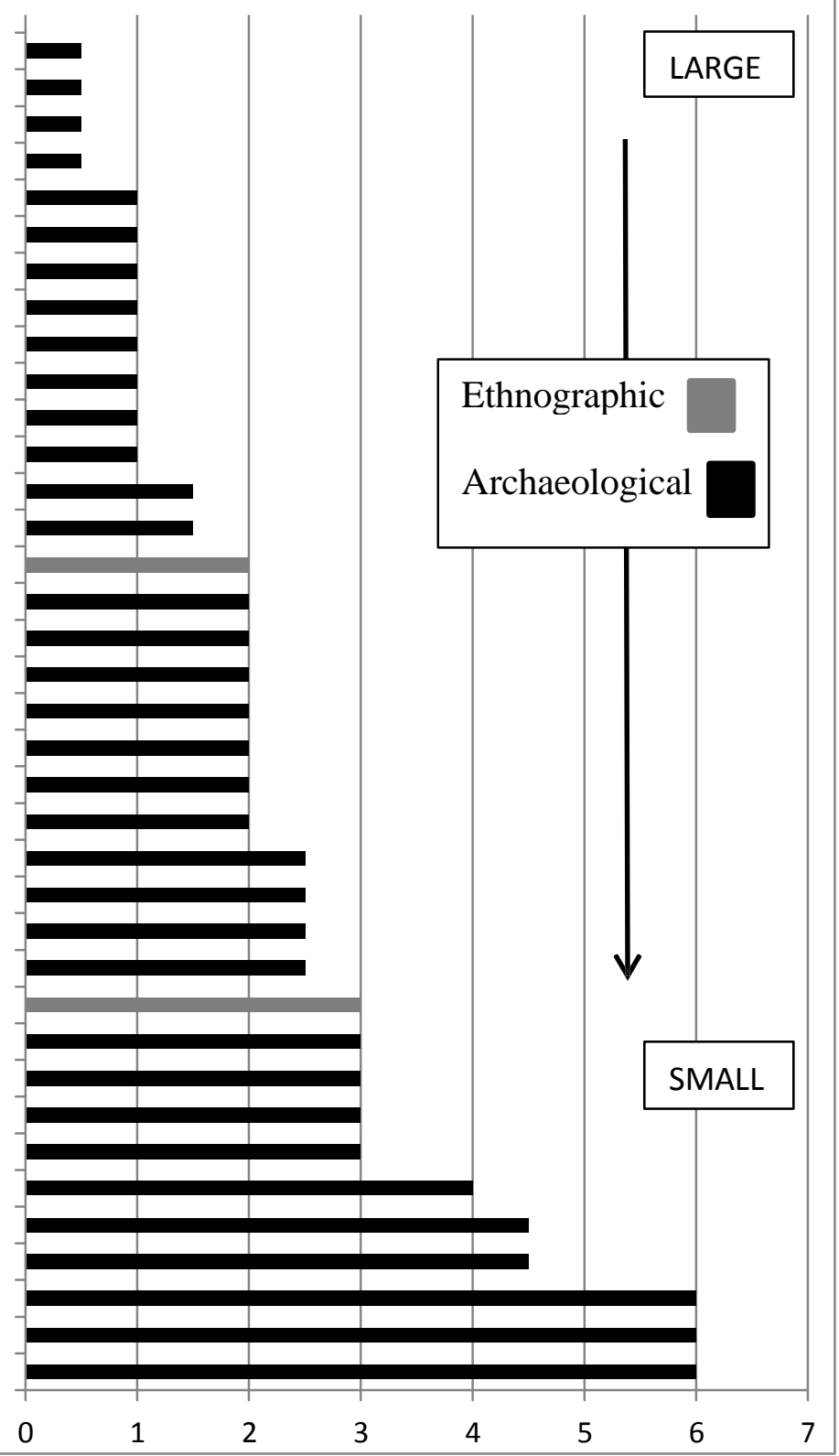


The largest of the oval archaeological dry stone rock features had distances between $0.5 \mathrm{~m}$ and $1.5 \mathrm{~m}$ from other features at the four sites under investigation. They exhibited, like other larger structures and features in the investigation thus far, a close nucleation pattern. This observation of larger features' placement in the landscape is important as it supports the previously established pattern in the circular category. Of interest, sites in the circular category that share this pattern are the same sites detected in the oval category, namely GH9 and GH14. Dry stone rock features 1, 3, 5, and 10 at GH9 brought the total features at this site to nine. Likewise, dry stone rock features 12, 13, 14, 15,16 , and 18 at GH14 brought the total of suspected conforming features to six. At GH15, four of the five dry stone rock features were associated with close nucleation in the larger archaeological structures. Given that the fifth feature was only $0.5 \mathrm{~m}$ further away, it is clear that all of the dry stone rock features at GH15 are closely spaced. The medium oval shaped dry stone rock features measured distances between $1.5 \mathrm{~m}$ and $2.5 \mathrm{~m}$ from other features and the smaller features were between $2.5 \mathrm{~m}$ and $6 \mathrm{~m}$ a part. Only two ethnographic examples were noted and expectedly, since they were used for outdoor cooking, their relatively great and variable distance across the village landscape would have been to minimize the spread of fires in the village. 
Table 8: Maximum Distances of Oval Structures and Features

$\underline{\text { Oval: Maximum Distances }}$

$\underline{\text { Site/ Structures/ Features }}$

GH15: rock feature 1

GH15: rock feature 2

GH15: rock feature 5

GH15: rock feature 4

GH15: rock feature 3

GH10: rock feature 2

GH10: rock feature 4

Village C: outdoor cooking...

Village C: outdoor cooking...

GH10: rock feature 5

GH10: rock feature 1

GH10: rock feature 7

GH10: rock feature 3

GH14: rock feature 15

GH14: rock feature 16

GH14: rock feature 13

GH14: rock feature 17

GH9: rock feature 3

GH14: rock feature 18

GH9: rock feature 1

GH14: rock feature 10

GH14: rock feature 12

GH9: rock feature 5

GH9: rock feature 6

GH14: rock feature 3

GH14: rock feature 9

GH14: rock feature 2

GH9: rock feature 7

GH14: rock feature 1

GH14: rock feature 7

GH9: rock feature 14

GH9: rock feature 10

GH9: rock feature 11

GH9: rock feature 13

GH9: rock feature 18

GH9: rock feature $12 \mathrm{a} / \mathrm{b}$

$\mathrm{GH} 14$ : rock feature 6

Meters:
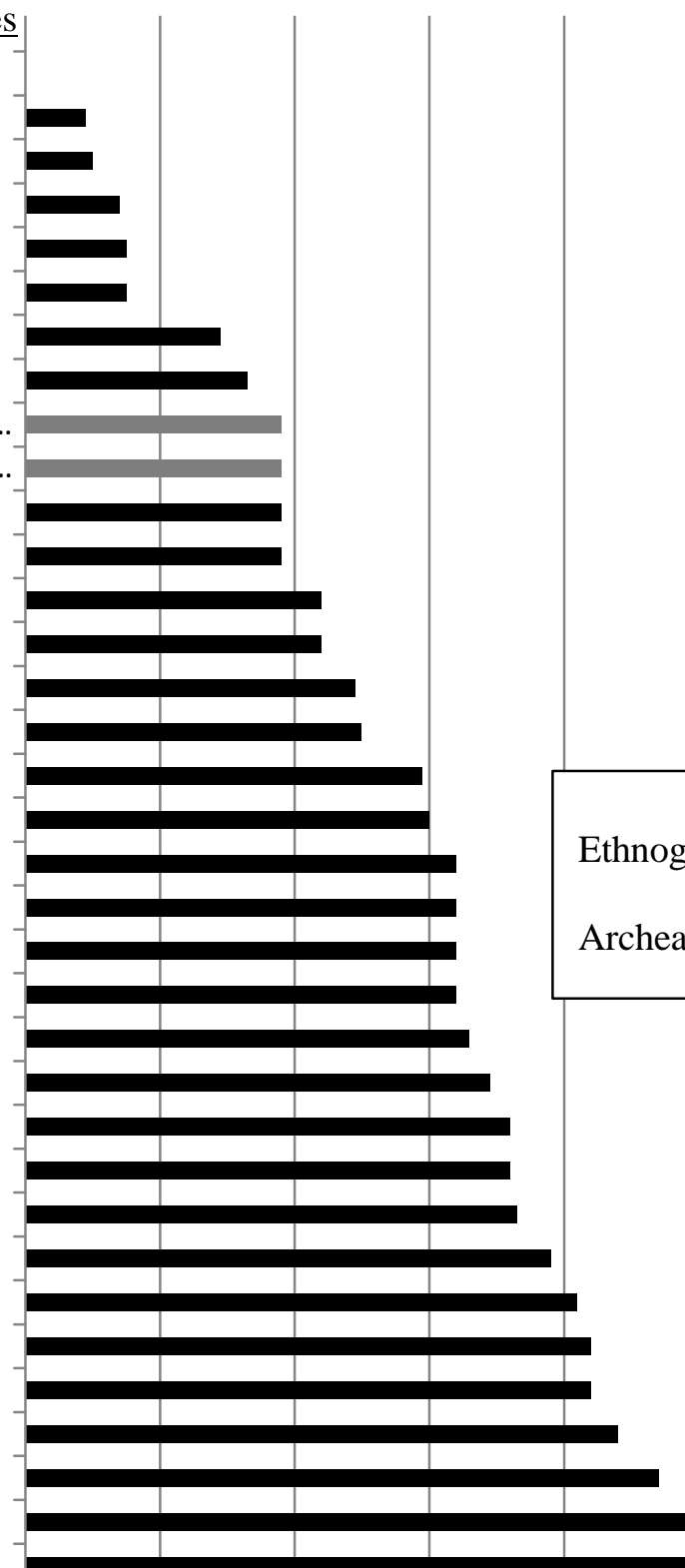

Ethnographic

Archeaological

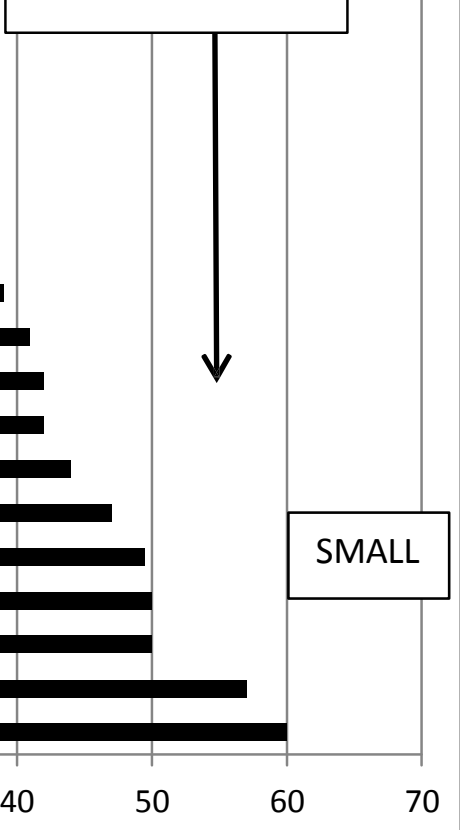


The pattern observed in the oval category's minimum distances was also observed in the maximum distances, larger features are located close to each other. It appears that features were spaced farther and farther apart the smaller the dry stone rock pile became. This means that generally dispersed features occurred in loose clumps. The noticeable difference was that all five features at GH15 had a similar level of nucleation, distinct from the other regions on Gilboa Hill. While features at GH9 appeared to have close nucleation, their distances apart were far greater; in fact, features at GH9 had spacing that is more variable across the landscape. It suggests that features were clustered close together but very much scattered over the site as if in various stages in the work being performed.

\section{Summary}

Even though close nucleation could be identified in the oval category, only $1 / 3$ of the oval dry stone rock features were closely and evenly nucleated as in the case in domestic examples, while the other $2 / 3$ did not. This suggests overall, oval shaped features, which again comprise the majority of archaeological features on Gilboa Hill, do not conform to a domestic village pattern, but most closely resemble work areas in villages, such as storage and cooking structures. Dry stone rock features were set farther apart the smaller they became, creating loose clusters. GH9 had some features with close nucleation, others with larger distances between them; only dry stone rock feature 2 was consistent in its close nucleation pattern. Each site on Gilboa Hill, then can be characterized by variability. The only exception was GH15; this site had significant nucleation among all dry stone rock features. With this is mind, the dry stone rock 
features at GH15 warranted further analysis to determine if the features could have beensleeping platforms.

\section{Rectangular}

In the rectangular category, it is important to note that only two sites were represented from Gilboa Hill, GH9 and GH14. All other archaeological structures or potential structures were from known village environments in the lowland region and closely correlated with West African village ethnographic examples. This correlation further supported the emerging pattern of larger structures having close nucleation, (Tables 9 and 10).

Minimum distances confirmed this pattern in both the large and medium categories. Smaller structures that were more widely spaced structures were resting platforms at Village $\mathrm{C}$, two standalone structures at Village $\mathrm{B}$, the partially excavated stone foundation 1 at the FBV, structure 6 at Village A, and the potential structure 10 at the SV. Of note were the three dry stone rock features $(20,21$, and 22) at GH9 as they did have close nucleation. Interestingly, these structures were far removed from other archaeological features located at GH9 on the far western edge of the site. 
Table 9: Minimum Distances of Rectangular Structures and Features

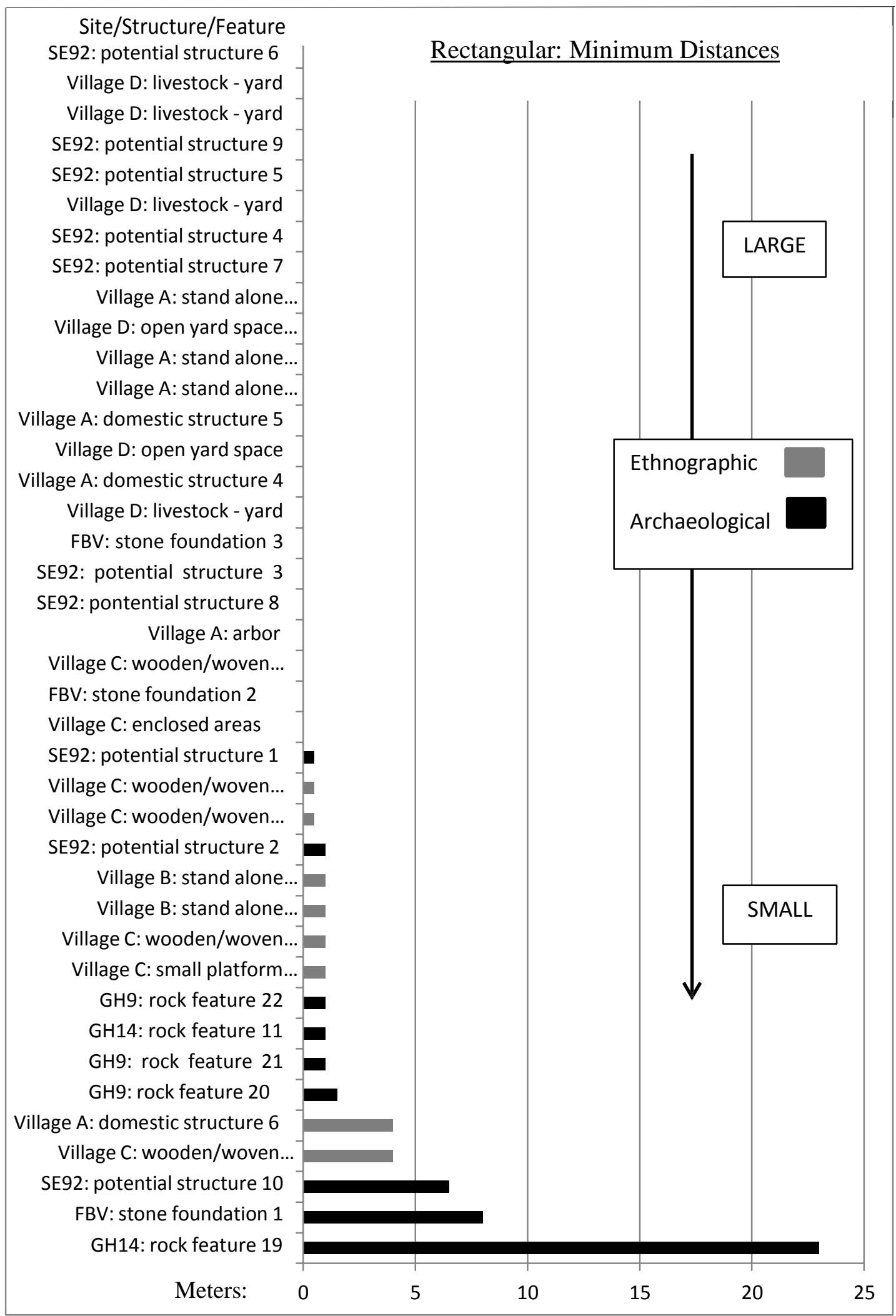


Table 10: Maximum Distances of Rectangular Structures and Features

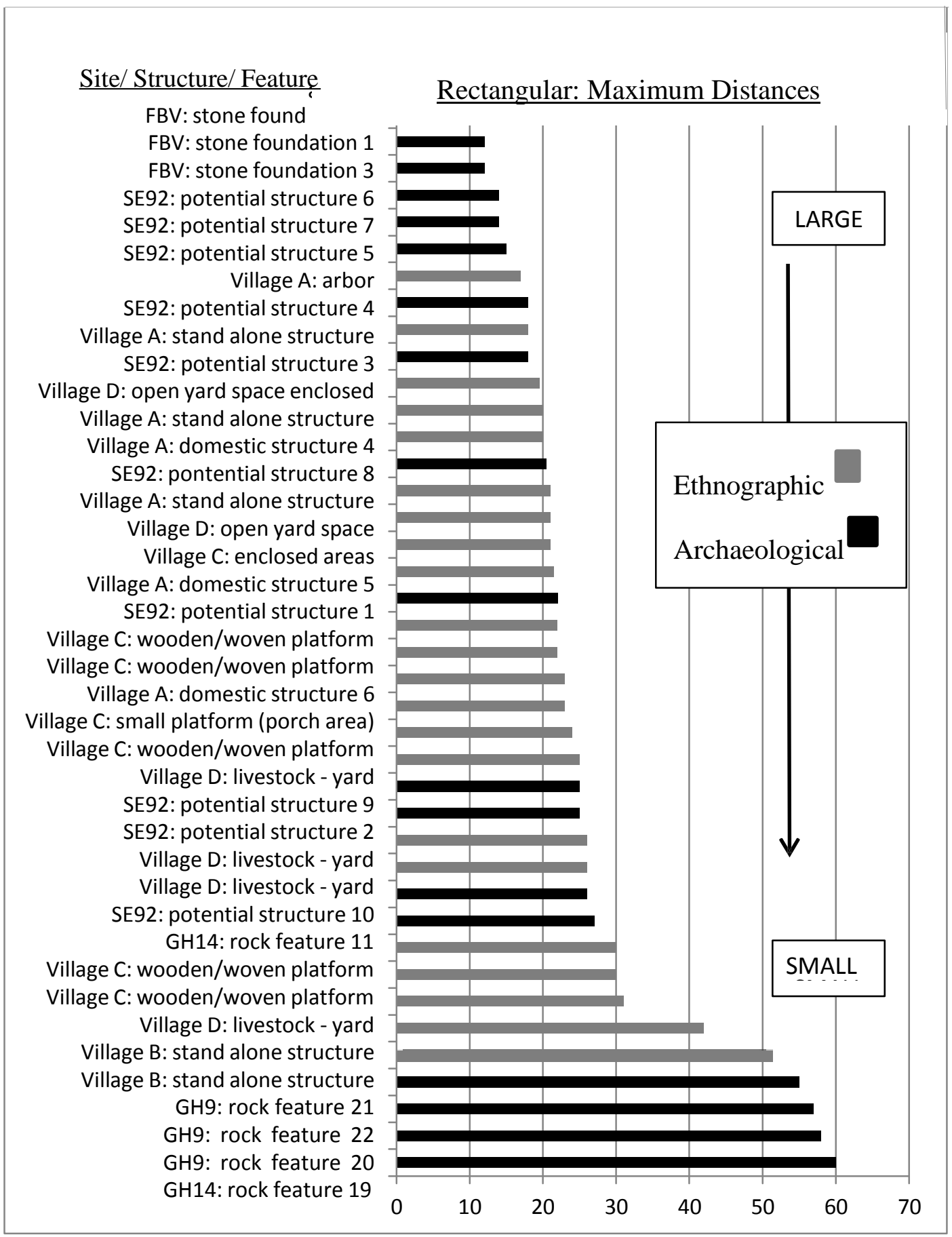


Upon comparison of the maximum distances of the rectangular structures, again larger structures were closely spaced. The medium and smaller structures were fairly close together, but separated by significant distances. In other words, medium and large rectangular structures tend to occur in clumps. The exception was the three previously identified dry stone rock features of interest at GH9 (20, 21 and 22); these features appeared to be nucleated.

\section{Summary}

The villages on St. Eustatius, the slave village more particularly, have structures with uniform clustering around a central yard space and a high degree of nucleation -these structures compare nicely with ethnographic examples from West Africa. Large rectangular, oval, and circular structures were evenly nucleated. Regardless of shape, the larger the structure or feature was, the more closely spaced it was. While this does not suggest an unequivocal pattern of West African organization practices, such as those affiliated with the ideological principle of Ubuntu, it does support that village environments, although quite different from place to place, do adhere to basic vernacular planning, even on St. Eustatius. 


\section{Feature Analysis at GH9 and GH15}

The previous analysis component revealed an observable pattern: the larger the structure or feature, the closer the nucleation across the landscape. Because sites GH9 and GH15 on the third ridge of Gilboa Hill exhibited this pattern, it was important to consider the dry stone rock features at these two sites more closely to see whether they could accommodate human heights. If so, then this might be an indication that the dry stone rock features, albeit small and physically uncomfortable, might have been as dwellings of some sort, whether short or long term.

The maximum lengths of features on Gilboa Hill were long enough to support reclining human beings, between $5 \mathrm{ft}$ and $6 \mathrm{ft}$ tall, (Table 11). Illustrations provided a visual comparison to identify exact dimensions of the possible sleeping platforms. Depictions of reclining human beings of average dimensions (approximately 18in wide and both $5 \mathrm{ft}$ and $6 \mathrm{ft}$ in length) were superimposed upon scale drawings of dry stone rock features (Figures 39 and 40). This helped visualize the space that individuals would have experienced in their accommodations and suggested whether their use as dwellings (sleeping platforms) was realistic or not. 
Table 11: GH9 and GH15 Feature Comparisons to Human Height

\begin{tabular}{|c|c|c|c|c|c|c|c|}
\hline$\underline{\text { Site }}$ & Feature & Length & Width & $\underline{\text { Human Ht }}$ & Difference & Human Ht & Difference \\
\hline GH15 & RF 4 & 2 & 1.3 & 1.5 (5 feet) & 0.5 & 1.8 (6 feet) & 0.2 \\
\hline GH15 & RF 5 & 2 & 1.5 & 1.5 (5 feet) & 0.5 & 1.8 (6 feet) & 0.2 \\
\hline GH15 & RF 2 & 2.1 & 1 & 1.5 (5 feet) & 0.6 & 1.8 (6 feet) & 0.3 \\
\hline GH15 & RF 3 & 2.75 & 1.5 & 1.5 (5 feet) & 1.25 & 1.8 (6 feet) & 1.04 \\
\hline GH15 & RF 1 & 3.5 & 1.1 & 1.5 (5 feet) & 2 & 1.8 (6 feet) & 1.7 \\
\hline GH9 & RF 22 & 2.5 & 1 & 1.5 (5 feet) & 1 & 1.8 (6 feet) & 0.7 \\
\hline GH9 & RF 20 & 3 & 1 & 1.5 (5 feet) & 1.5 & 1.8 (6 feet) & 1.2 \\
\hline GH9 & RF 21 & 3.5 & 1 & 1.5 (5 feet $)$ & 2 & 1.8 (6 feet) & 1.7 \\
\hline
\end{tabular}




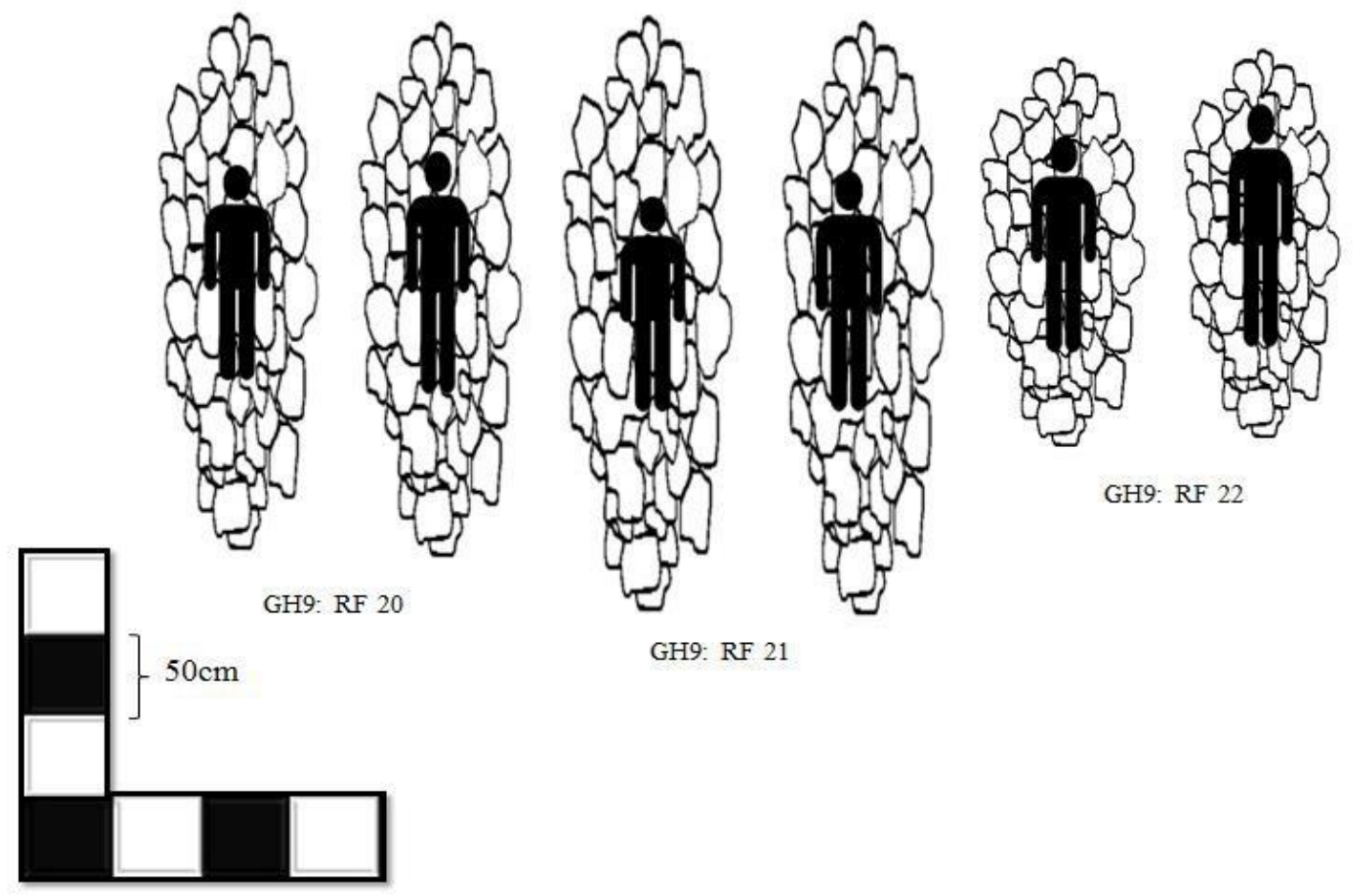

Figure 39. GH9: Dry Stone Rock Features and Human Height Comparison

What this analysis showed was the dry stone rock features at GH9 did provide adequate dimensions suitable for use as sleeping platforms. Yet while all of the features had more than adequate length, features 20 and 21 were just wide enough to accommodate a reclining human being easily. This still does not answer the question, why were their dimensions not uniform? These features would have been quite cramped for an individual taller than $5 \mathrm{ft}$. It is possible that features at GH9 could have been sleeping platforms on the basis of architectural analysis. 

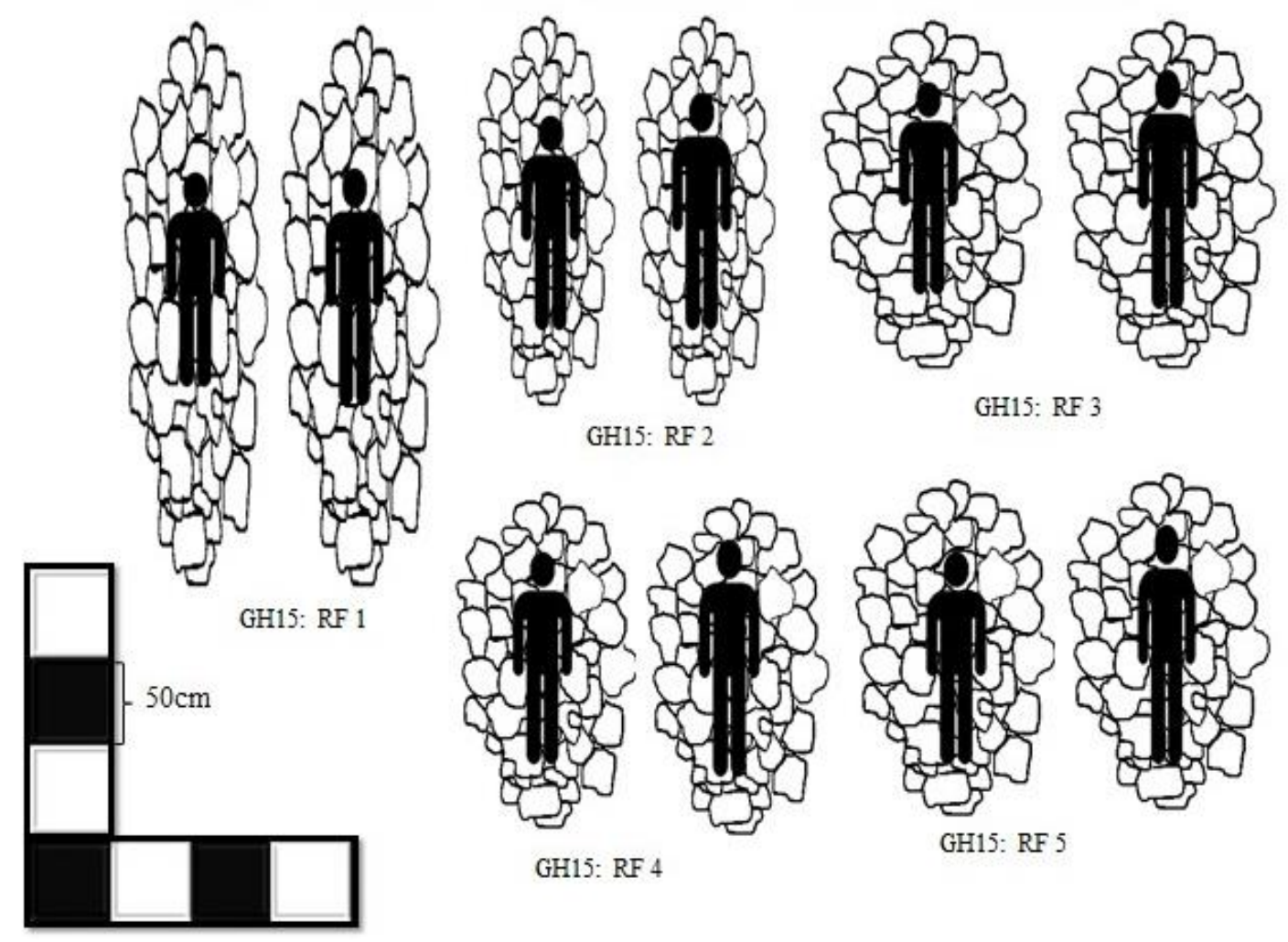

GH15: RF 2

GH15: RF 3

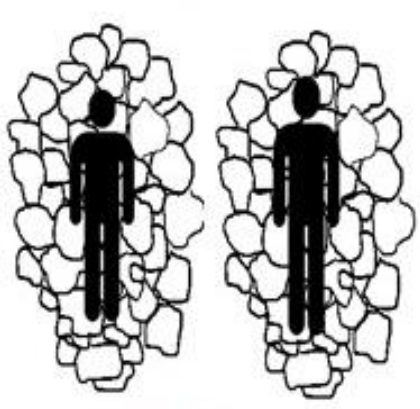

GH15: RF 4
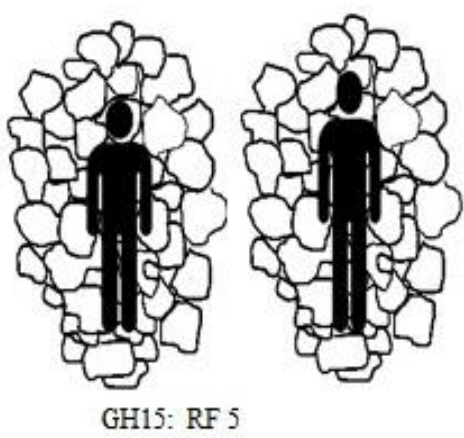

Figure 40. GH 15 Dry Stone Rock Features and Human Height Comparison

As for GH15, this analysis revealed that again all dry stone rock features had adequate length to accommodate reclining human beings, and all appear to be wide enough to accommodate a resting individual. Feature 1 like those at GH9, was long and very narrow. Feature 2 appeared to have amble room in length, more within reason, but was even narrower than rock feature 1 . Features 3,4 , and 5 appear to have both the length and width to accommodate a resting individual. Cramped at best, these dry stone rock features thus far have shown the highest potential for use as domestic sleeping platforms on Gilboa Hill. 


\section{Summary}

Given that GH9 and GH15 conformed to a pattern of close nucleation from feature to feature like village habitation structures, it was important to revisit the size dimensions of the suspected dry stone rock features at each of these sites to determine if they could accommodate the dimensions of a human being. Illustrations provided insight by visually depicting the actual dimensions individuals would have experienced if they were used as sleeping platforms. This analysis confirmed that dry stone rock features at GH9 were candidates for domestic sleeping platforms on Gilboa Hill. Likewise, all five dry stone rock features at GH15 had the appropriate dimensions suitable for resting human beings and are aligned parallel to one another. The features across the landscape appear village-like, however, the same area has great variability among all of the features, unlike ethnographic and known archaeological village samples. The key element that would let us know whether people lived anywhere on Gilboa Hill is the presence of artifacts and the next analysis will compare the quantity and kinds of artifacts between the four sites on Gilboa Hill's third ridge and known villages on the island.

\section{Artifact Analysis and Taskscapes}

The location, setting, structural dimensions, and orientation as well distinguishable nucleation patterns at the four sites on Gilboa Hill provided evidence of the features' potential function in the plantation landscape. Since the consideration of structural dimensions and spatial orientation determined archaeological features on Gilboa Hill both do and do not reflect patterning associated with known villages, the 
material assemblages from both the upland and lowland regions will be important evidence to clarify interpretations of the features.

I identified and compared the seven artifacts recovered from Gilboa Hill to the assemblage from the first phase of excavation in the SSV and the first 100 proveniences, surface collection, and postholes from the FBV. Comparing the material assemblages of the two villages in the lowland not only confirmed that large collections were the norm on the island, but also gave insight into diagnostic artifacts of village environments on the island as well. Understanding what comprised material assemblages from pre and postemancipation long-term occupation sites and the typical volume of these collections, provided a pattern to compare to the sites in the northern hills to determine if similarities existed.

The immediate difference from the upland region to the lowland region was the sheer lack of artifacts in the upland region. Across approximately 9000m, only seven artifacts were found. These included: two tin glazed Delftware sherds from GH9 dating to c1640 to c1800 and one green aqua blue bottle body glass fragment from GH10 dating between approximately to c1850 to 1880 , (Figures 5.3 and 5.4). Also, one flat olive green glass shard (most likely from a Dutch gin bottle) from GH14 dated to c1800, and three Dutch stoneware gin bottle fragments from GH15 dated from c1679 to c1900, (Figures 5.5 and 5.6). Dutch stoneware gin bottles have "a specific reputation for keeping water cool and are more durable than most other ceramics"; they have been documented at both 
domestic and labor environments of enslaved Africans in the Dutch Caribbean (Haviser 1999:256). With this small collection, a Mean Ceramic Date for the seven artifacts would be 1776, (Table 12).

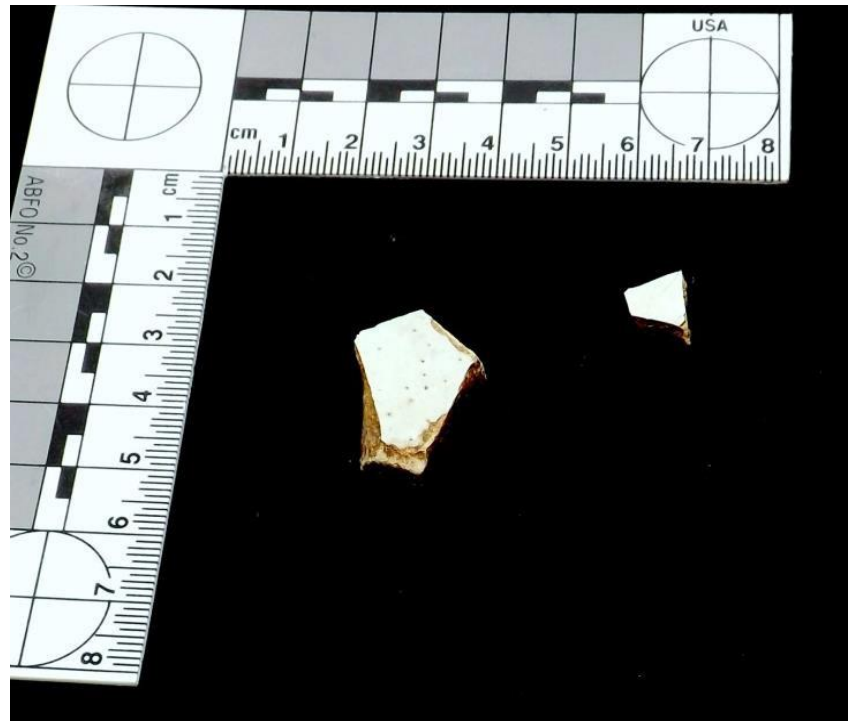

Figure 41. Tin Glazed Sherds Found at GH9

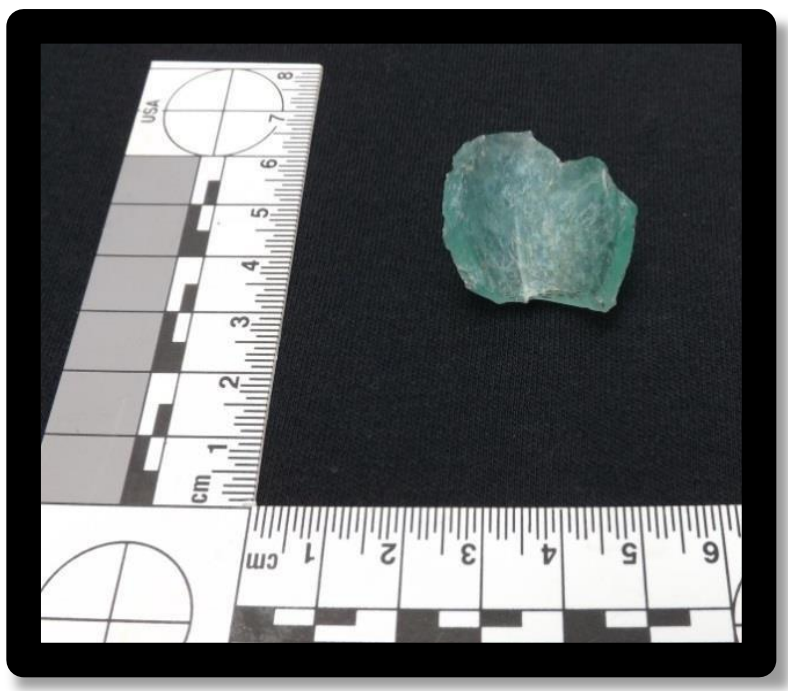

Figure 42. Aqua Blue Body Glass Found at GH10 


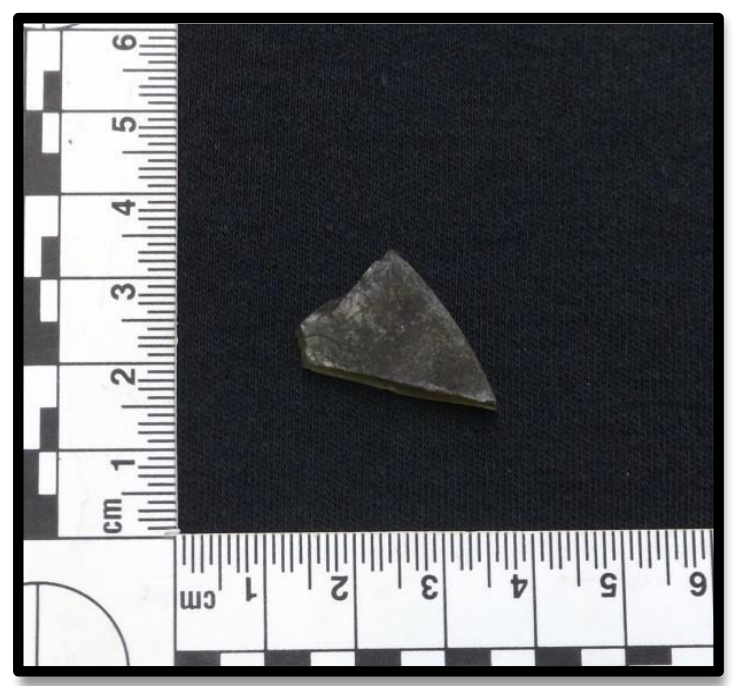

Figure 43. Olive Green Flat Body Bottle Glass Found at GH14

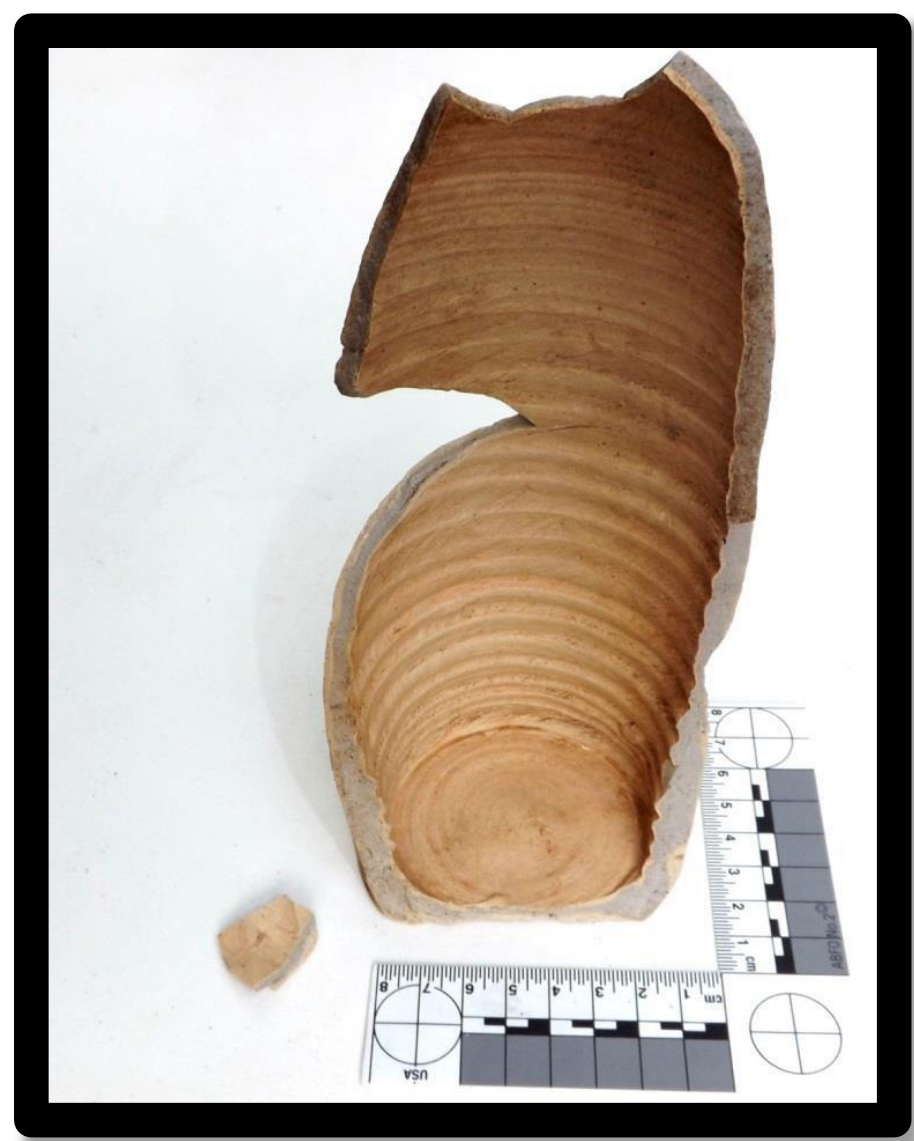

Figure 44. Stoneware Bottle Fragments from GH15 
Table 12: Mean Ceramic Date: Gilboa Hill Sites (GH9, GH10, GH14, and GH15)

\begin{tabular}{|c|c|c|c|c|c|}
\hline Site and Type & $\underline{\text { Begin date }}$ & $\frac{\text { End }}{\text { date }}$ & $\frac{\text { Median }}{\text { Date }}$ & Counts & $\underline{\text { Median Counts }}$ \\
\hline GH9 Tin Glazed & 1640 & 1800 & 1720 & 2 & 3440 \\
\hline GH10 Aqua Glass & 1850 & 1880 & 1865 & 1 & 1865 \\
\hline GH14 Flat Glass & 1800 & 1900 & 1850 & 1 & 1850 \\
\hline GH15 Stoneware & 1679 & 1900 & 1790 & 3 & 5370 \\
\hline & & & & 6 & $\begin{array}{c}10660 \\
1776.66666667 \\
\mathbf{1 7 7 6}\end{array}$ \\
\hline
\end{tabular}

The material assemblage excavated from the slave village consisted of over 2000 artifacts in the first phase of excavation in May and June 2012. The slave village assemblage was compiled into a database and the Mean Ceramic Date was calculated as 1748, (Table 13). This assemblage contained a wide variety of types including glass, ceramics, Afrocaribbeanware, nails, pipe stems, bone, and ceramics. Observations did not include matched sets except for the seven polychrome tin glazed plates, (Figure 45). Large shards of case bottle glass were in this assemblage as well as stemware and well preserved glass tableware. 


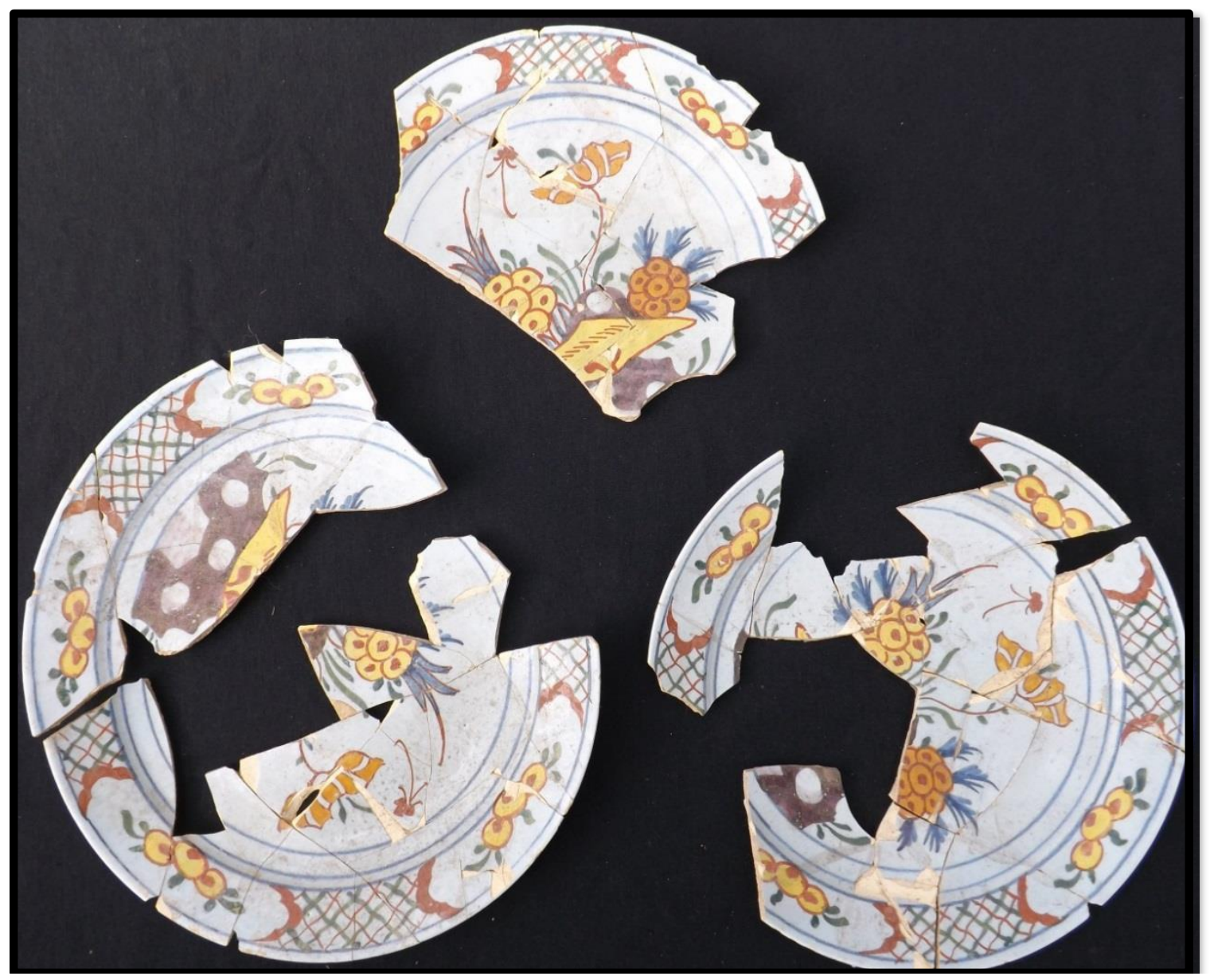

Figure 45. Delftware, Polychrome Plates, 1571-1790

The slave village assemblages consisted of a small variety of ceramics including redware (27\%), Afrocaribbeanware (15\%), and salt glazed (8\%). but the collection consisted mostly of Dutch delft tin glazed (36\%), (Table 14). Vessel forms were not recorded and I could not calculate frequency of vessel forms for this collection. The most prevalent decoration and colors appeared to be quite different from those in the FBV. Of the 35 decorated pottery sherds (only $18 \%$ of the collection) prominent decorations included floral (34\%), geometric (34\%), and hand painted (17\%) with associated colors of blue (42\%), brown (22\%), and green (13\%). (Table 15). Nearly half of the ceramics in 
the collection had some sort of color decoration or glaze (46\% of the 193 ceramic sherds).

While the assemblage of ceramics was relatively small, slaves did not have many decorated wares. This could be for a variety of reasons; cost is certainly one of them. Residents also seem to have attempted to emulate matched ceramic sets. Several vessels had blue rim patterns, however, none of the ceramics matched exactly. From a quick glance, one might assume that all of these pieces were a part of a set, but under further inspection, each piece was slightly different from one another. Most of the blue lines were hand-painted underglazed, yet each was slightly different in width, opacity, thickness, and preciseness and were painted on slightly varying body paste colors, all offwhite. Slaves living in this village seem to have emulated the higher classes living on the island by intentionally piecing together a set of ceramic wares that resembled a more expensive matched set. 
Table 13: Mean Ceramic Date: Schoesenhoek Slave Village

\begin{tabular}{|c|c|c|c|c|c|}
\hline Type & $\underline{\text { Begin date }}$ & $\frac{\text { End }}{\underline{\text { date }}}$ & $\frac{\text { Median }}{\underline{\text { Date }}}$ & Counts & $\frac{\text { Median }}{\underline{\text { Counts }}}$ \\
\hline $\begin{array}{l}\text { refined } \\
\text { earthenware }\end{array}$ & 1830 & 1900 & 1865 & 6 & 11190 \\
\hline salt glazed & 1690 & 1775 & 1733 & 16 & 27728 \\
\hline redware & 1700 & 1900 & 1800 & 53 & 95400 \\
\hline $\begin{array}{l}\text { Afrocaribbean } \\
\text { ware }\end{array}$ & 1650 & 1830 & 1740 & 29 & 50460 \\
\hline stoneware & 1720 & 1770 & 1745 & 5 & 8725 \\
\hline earthenware & 1620 & 1775 & 1698 & 1 & 1698 \\
\hline porcelain & 1660 & 1860 & 1760 & 8 & 14080 \\
\hline pearlware & 1770 & 1840 & 1805 & 5 & 9025 \\
\hline \multirow[t]{3}{*}{ tin glazed } & 1600 & 1802 & 1701 & 70 & 119070 \\
\hline & & & & 193 & 337376 \\
\hline & & & & & 1748.062176 \\
\hline
\end{tabular}


Table 14: Ceramic Concentrations at the Schoesenhoek Slave Village

$\underline{\text { Schotsenhoek Slave Village Ceramic Totals }}$

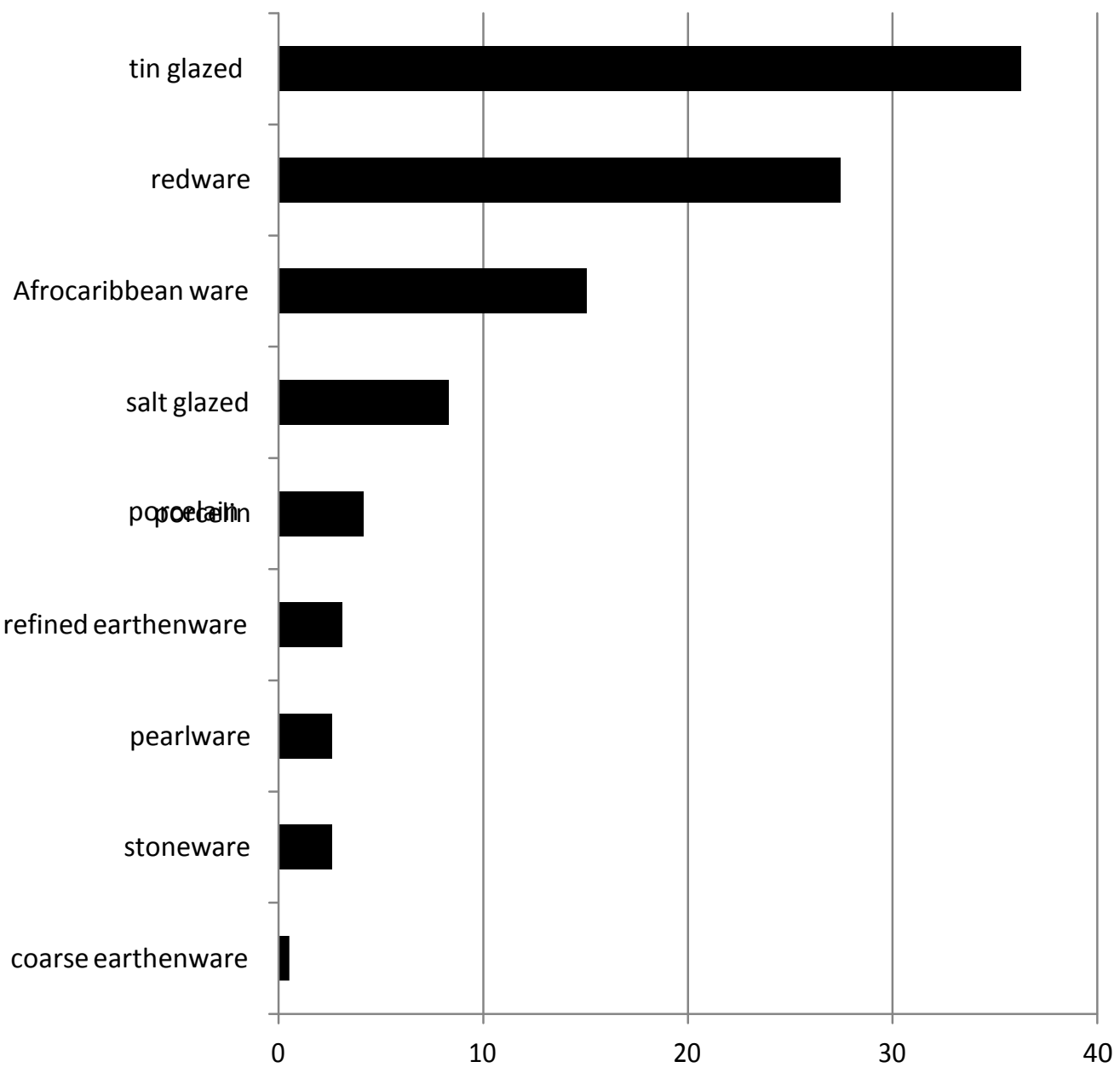


Table 15: Decoration and Color Prevalence at the Schoesenhoek Slave Village

\begin{tabular}{|c|c|c|c|c|c|c|c|}
\hline & Criss & & & Hand & & & Décor \\
\hline Decoration: & $\underline{\text { cross }}$ & $\underline{\text { Floral }}$ & $\underline{\text { Geometric }}$ & painted & $\underline{\text { Incised }}$ & $\underline{\text { Lines }}$ & $\underline{\text { Total }}$ \\
\hline Total: & 3 & 12 & 12 & 6 & 2 & 4 & 35 \\
\hline$\%:$ & 8.6 & 34 & 34 & 17 & 6 & 11 & \\
\hline Color: & $\underline{\text { Blue }}$ & Brown & Green & Gray & Orange & Yellow & $\frac{\text { Color }}{\text { Total }}$ \\
\hline Total: & 42 & 20 & 12 & 6 & 4 & 5 & 89 \\
\hline$\%:$ & 47 & 22 & 13 & 7 & 4 & 6 & \\
\hline
\end{tabular}


After analysis of the slave village assemblage, research concentrated on the comparative lowland site at the Free Black Village, which consisted of over 7000 artifacts including glass, ceramics, Afrocaribbeanware, pipe stems, gaming pieces, lead shot, textile ("Dutch Stripes” Kandle (1985)), bone, nails, textiles, flint, slate, crystals, buttons and other domestic materials. The Mean Ceramic Date for this collection was calculated as 1748, (Table 16). This is consistent with the MCD calculated by Grant Gilmore (2013) for the FBV assemblage in previous work.

The FBV ceramic assemblages comprised $40 \%$ of the collection examined (2949 ceramic sherds) and consisted mostly of tin glazed delftware (28\%) much like the slave village assemblage; other notable concentrations included pearlware (16\%), porcelain (13.3\%), creamware (12.3\%), and coarse earthenware (12\%), (Table 17). This was a stark difference in variability between the slave village and FBV assemblages. While the SSV material assemblage variability was comprised mostly of redware (27\%), Afrocaribbeanware (15\%), and salt glazed (8\%) the FBV material assemblage in contrast, had more variety: porcelain, creamware, and coarse earthenware.

Unfortunately, detecting enough vessel forms while processing the FBV ceramic assemblage to calculate percentages of vessel form frequency was not possible; estimates include several vessels for serving and cooking, but no definitive calculations. Most sherds were broken into smaller pieces and were indistinguishable from hollow or flat wares. Diagnostic foot rings, handles, and rims were only a small portion of the collection.

Decoration and color patterns proved to be less difficult to assess. Of the 438 pottery sherds that were recorded as decorated, these decorations included banded 
(49.8\%), sponged (13\%), transferprint (9.1\%), and basket weave or diaper dot $(7.8 \%)$ in the collection. Designs had a high prevalence of nature-themed transfer printed decorations (flowers, leaves, vines, animals, and landscapes) in blue, pink, green, etc. Of the $31 \%$ of the ceramic assemblage with color, most were blue $(56.7 \%)$, followed in popularity by yellow (10.2\%), orange (9.6\%), and brown (8.5\%), (Tables 18 and 19). These were similar colors to those in the slave village collection, namely blue and brown. These decorations and colors suggest a preference much like Barbara Heath $(1989,1998)$ discovered in similar ceramic assemblages of village communities on the island. 
Table 16: Mean Ceramic Date: Free Black Village

\begin{tabular}{|c|c|c|c|c|c|}
\hline & $\underline{\text { Begin }}$ & $\underline{\text { End }}$ & $\underline{\text { Median }}$ & & $\underline{\text { Median }}$ \\
\hline Type & Date & $\overline{\text { Date }}$ & $\underline{\text { Date }}$ & Counts & Counts \\
\hline dutch cooking pot & 1625 & 1775 & 1700 & 1 & 1700 \\
\hline metropolitan & 1630 & 1700 & 1665 & 1 & 1665 \\
\hline nottingham & 1683 & 1810 & 1747 & 1 & 1747 \\
\hline westerwald & 1650 & 1775 & 1713 & 1 & 1713 \\
\hline bone china & 1830 & 1900 & 1865 & 2 & 3730 \\
\hline cauliflower ware & 1740 & 1770 & 1755 & 3 & 5265 \\
\hline west midland slip & 1670 & 1795 & 1732 & 3 & 5196 \\
\hline whiteware & 1830 & 1900 & 1865 & 4 & 7460 \\
\hline Jackfield & 1740 & 1790 & 1765 & 5 & 8825 \\
\hline whieldonware & 1740 & 1770 & 1755 & 13 & 22815 \\
\hline $\begin{array}{l}\text { Mocha } \\
\text { refined }\end{array}$ & 1795 & 1895 & 1845 & 16 & 29520 \\
\hline earthenware & 1830 & 1900 & 1865 & 20 & 37300 \\
\hline faience & 1700 & 1800 & 1750 & 24 & 42000 \\
\hline salt glazed & 1690 & 1775 & 1733 & 39 & 67587 \\
\hline staffordshire & 1700 & 1800 & 1750 & 41 & 71750 \\
\hline annular & 1785 & 1840 & 1813 & 49 & 88837 \\
\hline redware & 1700 & 1900 & 1800 & 59 & 106200 \\
\hline $\begin{array}{l}\text { Afrocaribbean } \\
\text { ware }\end{array}$ & 1650 & 1830 & 1740 & 82 & 142680 \\
\hline stoneware & 1720 & 1770 & 1745 & 165 & 287925 \\
\hline $\begin{array}{l}\text { coarse } \\
\text { earthenware }\end{array}$ & 1620 & 1775 & 1698 & 354 & 601092 \\
\hline creamware & 1765 & 1820 & 1793 & 365 & 654445 \\
\hline porcelin & 1660 & 1860 & 1760 & 393 & 691680 \\
\hline pearlware & 1770 & 1840 & 1805 & 469 & 846545 \\
\hline tin glazed & 1600 & 1802 & 1701 & 839 & 1427139 \\
\hline totals: & & & & 2949 & 5154816 \\
\hline
\end{tabular}


Table 17: Ceramic Concentrations at the Free Black Village

Free Black Village Ceramic

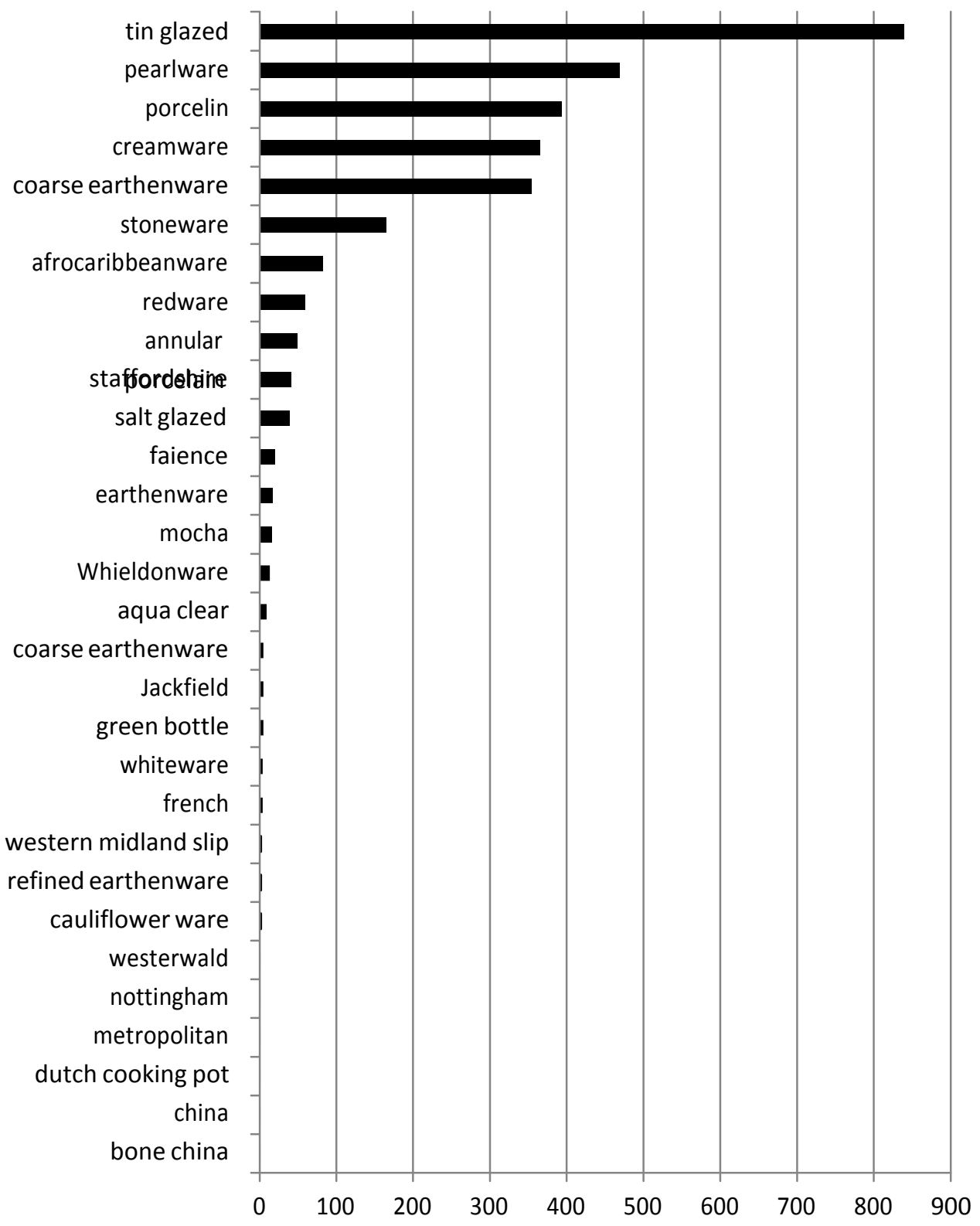


Table 18: Decoration Prevalence at the Free Black Village

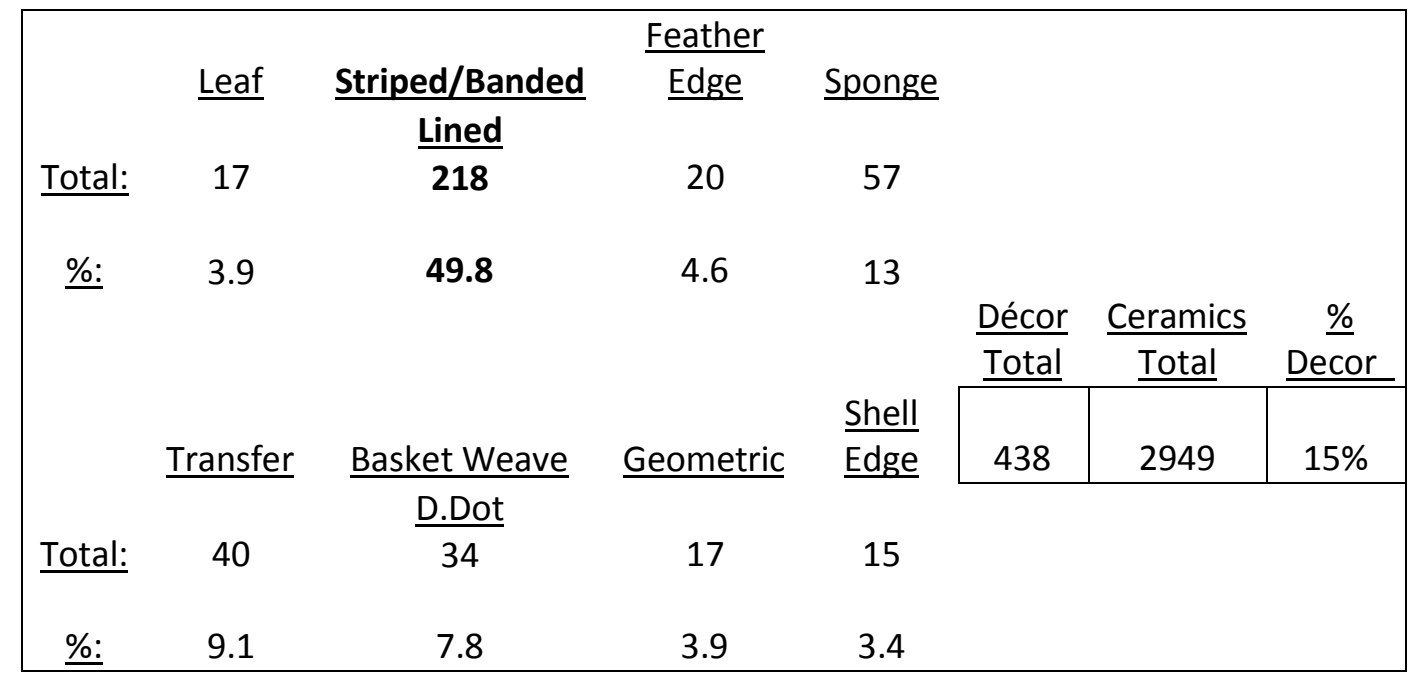

Table 19: Color Prevalence at the Free Black Village

\begin{tabular}{|c|c|c|c|c|c|c|c|}
\hline Color & Green & $\underline{\text { Red }}$ & Yellow & Peach & & & \\
\hline \multirow[t]{2}{*}{ Total: } & 72 & 15 & 94 & 12 & & & \\
\hline & & & & & Color & Ceramics & Color \\
\hline \%: & 7.8 & 1.6 & 10.2 & 1.3 & Total & Total & \\
\hline$\underline{\text { Color }}$ & $\underline{\text { Orange }}$ & Brown & Blue & Cream & 920 & 2949 & $31 \%$ \\
\hline Total: & 88 & 78 & 522 & 39 & & & \\
\hline \%: & 9.6 & 8.5 & 56.7 & 4.2 & & & \\
\hline
\end{tabular}


The percentage of Afrocaribbeanware at the FBV was $17.9 \%$, slightly more than the $15 \%$ of Afrocaribbeanware evident in the SSV ceramic assemblage perhaps indicating that emancipated enslaved Africans continued to make pottery within the village. Efforts to match both transfer and porcelain sets are evident in the assemblage. Several of the sherds of pottery on first inspection appeared to match, but a closer look revealed patterns that were slightly different from one another, (Figures 46 and 47). It appears that the pattern of emulation efforts by occupants of the slave village might have carried over into freedom at the FBV.

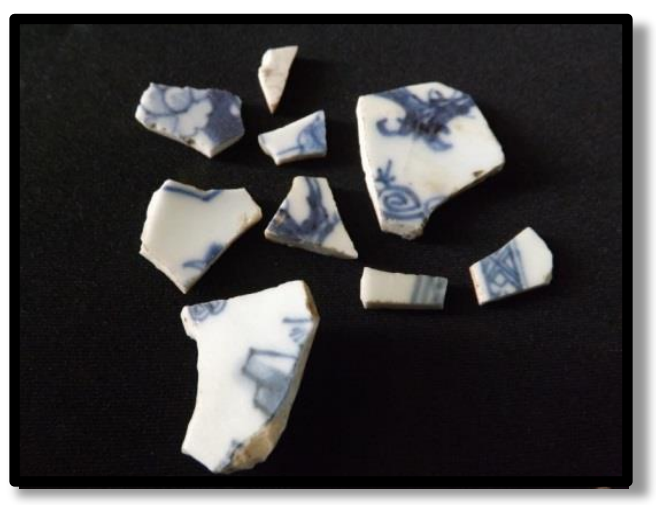

Figure 46. Chinese Export Porcelain, 1644-1912

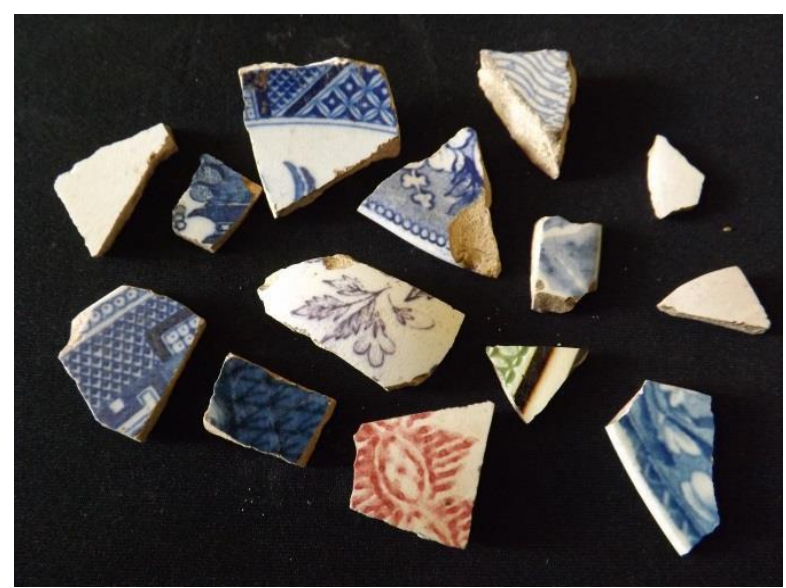

Figure 47. Transfer Print 1830-present, 1784-1840 
This analysis provides the first remarkable insights into the important transition from enslavement to freedom in the lives of the Dutch slaves on the island of St. Eustatius to date. In the slave village, relatively more Afro-Caribbean wares occurred then in the FBV, but both assemblages reveal attempts to emulate the planter or elite class. The slave village assemblage had vessels with similar rim designs despite being of different vessel. The FBV assemblage had not only an increase in porcelain but also close attempts to match similar patterns. Additionally, the FBV had artifacts that were not evident in the slave village assemblage, which included flints (evidence of firearms), slate and inkwells (evidence of efforts at literacy), (Figures 48 and 49), and crystals (evidence of open folk religious expression), (Figures 50-54). The amount of crystals was impressive, with crystals practically in every bag! The FBV residents, more than likely experienced a higher degree of ideological freedom. The absence of these items in the slave village assemblage, and the stark contrast in quantity and variability between the assemblages, are clear, noticeable differences indicative of the important transition to freedom. 

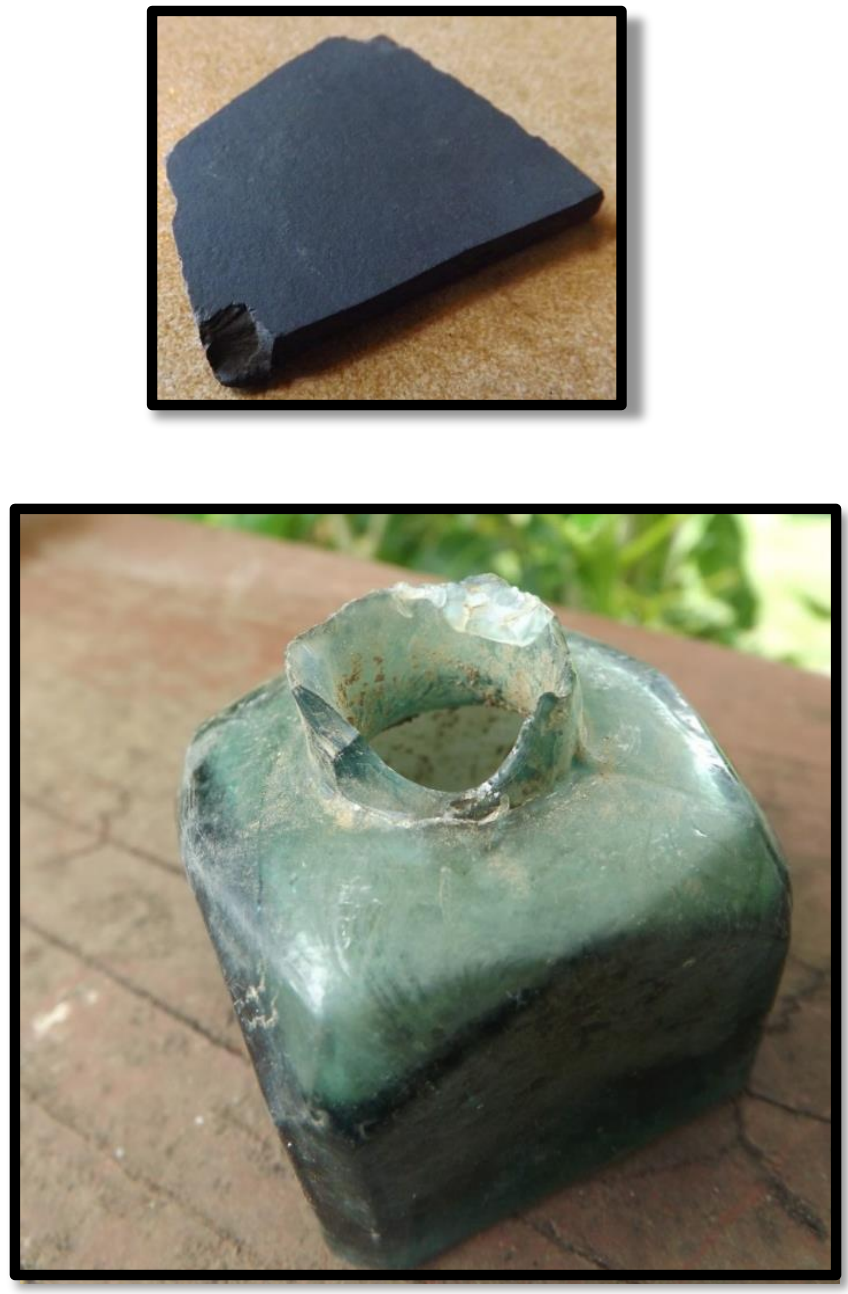

Figure 48. and 49. Ink well and Slate at the FBV 

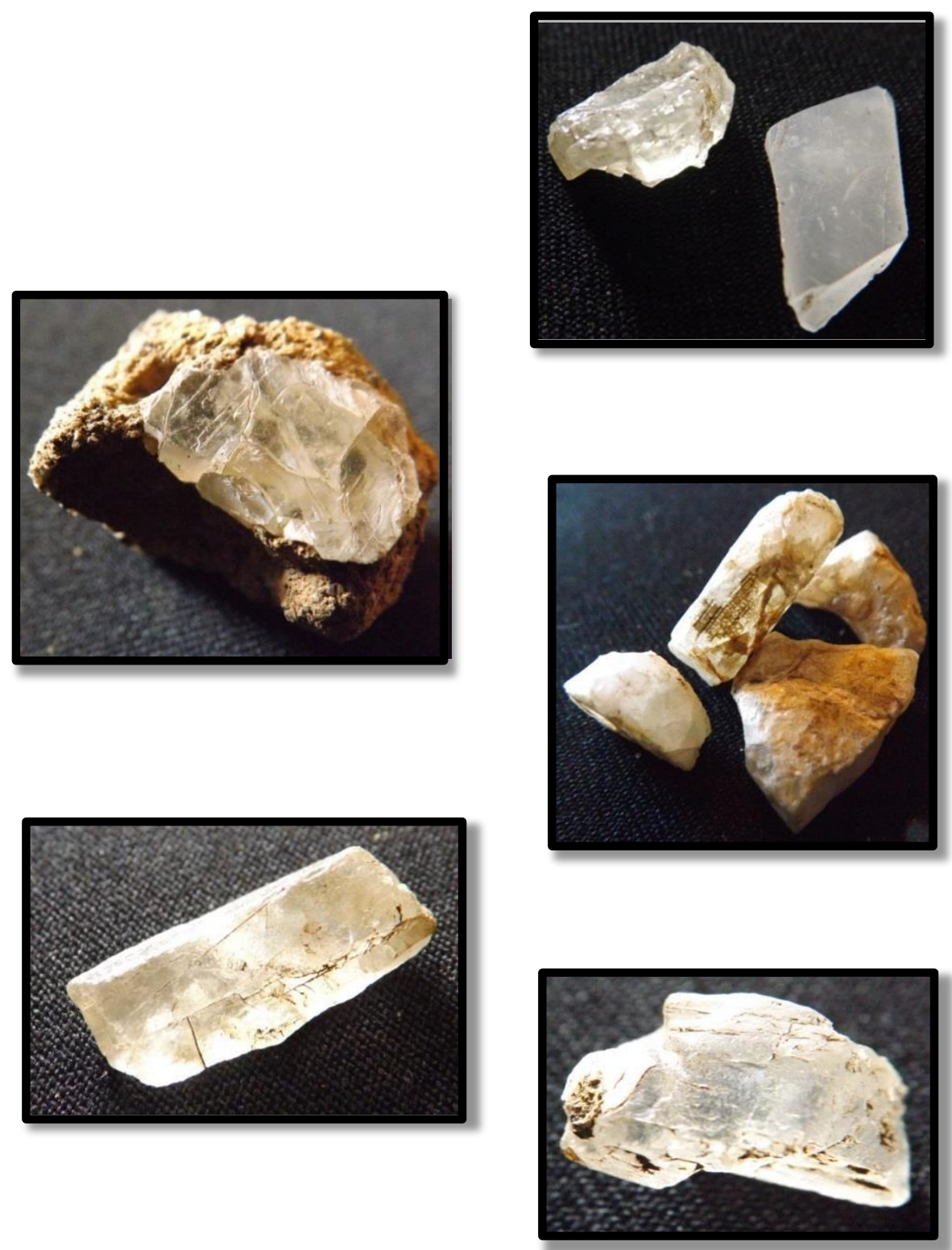

Figures 50 - 54. Crystals at the FBV 


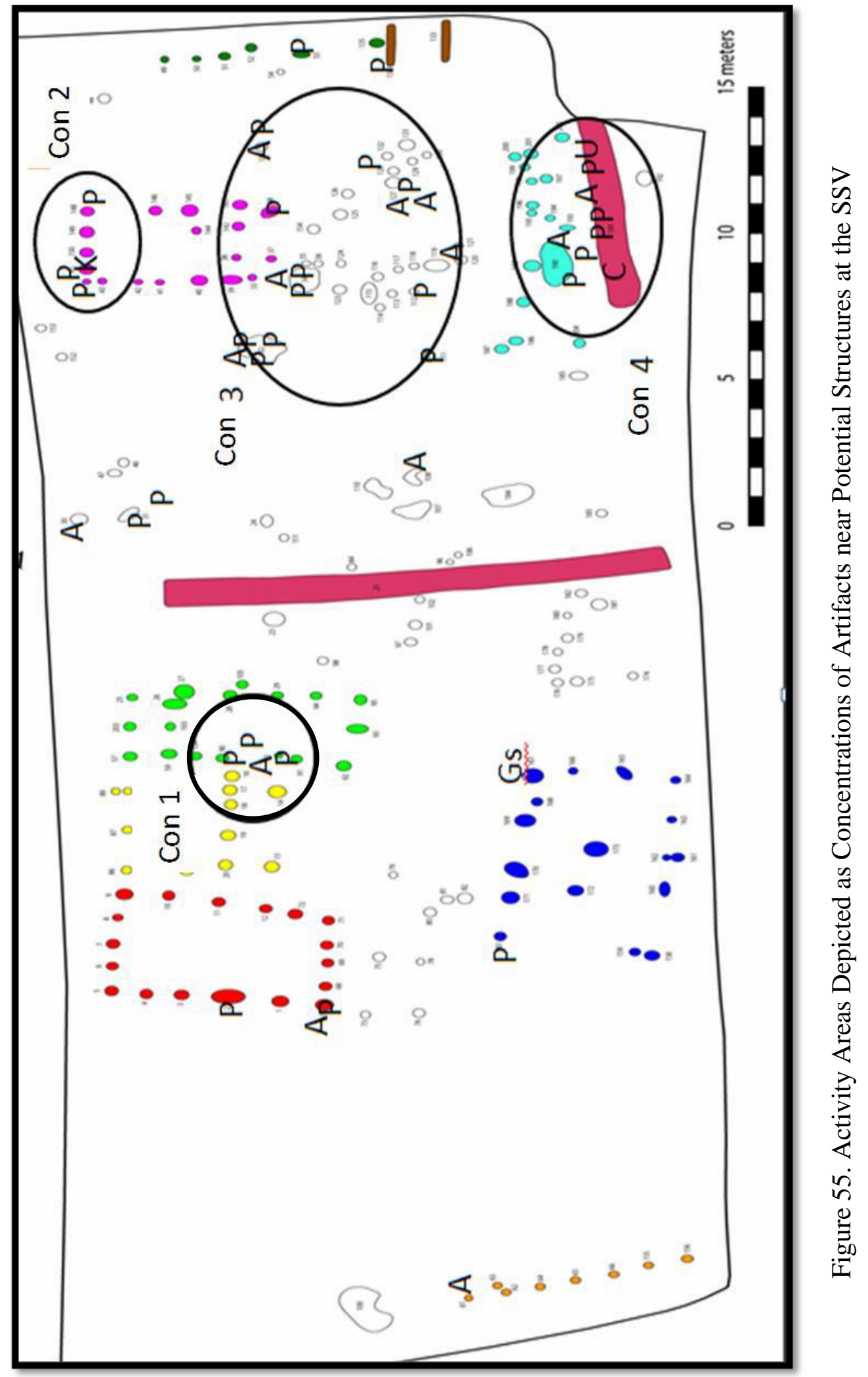


Heath (1999:33) proposed the daily activities of enslaved Africans left traces that might be recovered archaeologically because "men and women worked, worshiped, and socialized out-of-doors," and domestic chores like cooking and laundering were conducted in open yard spaces in domestic enslaved African environments. If archaeological features on Gilboa Hill were domestic in origin then artifact concentrations would be present, and not just seven, but potentially thousands of artifacts, especially if it were a long-term occupation. Even if it was a temporary situation activities create zones of material culture in most cases. For instance, in Figure 55 artifacts are designated by: pipe stems and bowls (P), Afrocaribbeanware (A), grinding stone (Gs), Colander (C), knife handle (K), utensil handle (U). These artifacts were grouped in activity zones in the vicinity of structures. These concentrations do not suggest activity occurred at the exact location of the recovered artifacts as they could have been secondary deposition. Despite erosion and various forms of ground disturbance (cultivation, human refuse disposal habits, interference of pets and children) artifacts were associated with structures. These concentrations give insight into the potential function of the associated structure. 
Concentration 1. This activity area is associated with artifacts affiliated with smoking; three pipe stems were found in this location as well as Afrocaribbeanware. This location is between two structures and appears to be where the two potential structures would have either connected or been up against one another.

Concentration 2. This activity area is associated with artifacts affiliated with smoking as well; two pipe stems were found in this location. A knife handle was also found in this location. This is either the front or back of a potential structure.

Concentration 3. This activity area had a large concentration of both pipe stems or bowls and AfroCaribbeaware suggesting cooking and smoking activities were conducted in this area. Since the artifacts were not up against a potential structure, one can assume that activity was conducted in this open courtyard. This is an important discovery, as courtyard activity is associated with many archaeological, ethnographic, and historical accounts in village environments

Concentration 4. This activity area at the far edge of the site appears to indicate somewhat similar activity as those conducted in concentration 3 with a concentration of Afrocaribbeanware and pipe stems or bowls. One difference in this area is the recovery of a stoneware colander and handle of a utensil. This suggests related activities were conducted in this area. 


\section{Summary}

The large material assemblages of the SSV and FBV revealed clear indicatios of domestic occupation and the differences in the kinds of ceramics and decorations. Grant Gilmore (2013) correlated similar activity zones during his analysis and excavations of the FBV. Ongoing archaeological investigations through SECAR hold to the same pattern as well (Stelten 2012, 2013). The sites on Gilboa Hill are obviously unlike either assemblage. Analysis of the material assemblages revealed distinct contrasts not only between the upland and lowland regions, but between the two lowland sites in this investigation as well. From the onset, the sheer lack of artifacts collected in the upland region raised queries as to whether the four sites on Gilboa Hill were domestic at all, if temporary - it appears the occupants simply did not bring many artifacts up into the upland region with them or insured their removal when they left.

The lack of artifacts from the pre-emancipation era (domesic in nature) in the northern hills regions was sobering. Why are the upland sites drastically different in artifact concentration? Artifact distribution maps from the slave village indicated distinctive concentrations of artifacts associated with daily activities surrounding structures; again, this was not an observable pattern on Gilboa Hill. These established patterns (quantity, variability, and distribution zones) should at least be represented in the northern hills to some extinct. 


\section{Discussion}

The spatial and artifactual analyses have increased our understanding of the archaeological features at the four sites located on the third ridge of Gilboa Hill in the northern hills. In an effort to determine if village spatial organization was present, minimum and maximum distances were calculated, then compared, among the ethnographic village example, known villages, and GH features. An observable pattern emerged: large structures, regardless of their shape and location, were closely and evenly spaced. At GH9 and GH15 the dry stone rock features' spacing correlated closely with a nucleated village spatial pattern, and after reexamining these features lengths and widths in comparison to average human height, it was determined that although most features would have provided cramped quarters none of the dry stone rock features had both the length and width to support a reclining human being. The lack of uniformity calls in to doubt whether they were used for sleeping platforms.

Artifacts recovered on Gilboa Hill were dated to approximately 1776, and given this timeframe, one might suggest the activity at the four sites under investigation took place during the time of enslavement, but the sample size was too small to provide definitive proof. Coupled with the lack of volume and variability of artifacts as well as the absence of artifact concentrations, no clear pattern of domestic occupation could be identified at the four sites on Gilboa Hill's third ridge, however, this does elude to the possibility of a labor environment. The next chapter will discuss the findings in this and the previous chapter in more detail. 


\section{CHAPTER VI DISCUSSION AND CONCLUSIONS}

From the beginning, my interest for this project was in assessing whether Dutch colonial rule influenced the level of ideological freedom that enslaved Africans on St. Eustatius experienced. For this, my research framework focused on two main theoretical underpinnings: cultural continuity with respect to identity and the agency enslaved populations used in shaping new communities. As the landscape is the most pervasive artifact we examine in historical archaeology, this investigation relied heavily on past research in landscape archaeology to guide this investigation.

The Dutch colonial power was quite different in the New World, with less oversight and lack of rigidity in the daily lives of enslaved Africans. It was under this premise that the island of St. Eustatius held promise for detecting ways this increased ideological freedom was stamped on to the landscape in the northern hills in either domestic or labor environments of enslaved Africans living on the island. The first three chapters have outlined in depth my research interest, theoretical underpinnings, previous research, and methodology. The previous two chapters reviewed the results of my series of extensive multi-faceted analyses including regional, structural, spatial, and artifact from the rich data set from my own fieldwork and previous research. In conclusion, this chapter will address my four main research questions, with important considerations, and suggestions for future research. 


\section{Research Questions}

Through the careful interpretation of data collected on Gilboa Hill (setting, size and shape of dry stone rock features, spatial patterning, etc.) in comparison to previous archaeological work of domestic enslaved environments on the island, in the Caribbean, in the United States, as well as to ethnographic studies conducted in West Africa, I was able to address the following points of inquiry:

1. Were the four sites on Gilboa Hill associated with the Michael Curvelje plantation?

2. Will there be variability in artifact type, quantity, and concentration at each of the four sites? And how does this compare to other sites on the island?

3. Were the four sites on Gilboa Hill consistent with known domestic or labor environments recovered archaeologically or do they share similarities with ethnographic examples?

4. Did the Dutch colonial planter class' oversight influence the levels of ideological freedom of enslaved build environments? 


\section{Historical Maps}

\section{Plantation Affiliation and Function of Dry Stone Rock Features}

Inquiry into the plantation affiliation of the four sites on Gilboa Hill's third ridge proved to be complex, with multiple lines of evidence used to differentiate between plantation boundaries, depictions of these boundaries over time, and the historical record of possible ownership. The overwhelming evidence suggests the Widow Ducas (Dijkers) and not Michael Cuvilljes (Cuvelje) was the owner of the four sites on Gilboa Hill's third ridge, simply based on location of the four sites in relation to dry stone wall boundaries recorded in the field that were later confirmed on historical maps to belong to her. This, however, is not a clear indication of ownership as the historical record is silent on familial ties with regard to kinship use of the land on Gilboa Hill.

A point to consider is whether the Widow Ducas and Michael Cuvilljes were actually relatives. I think they were. Historical documentation offered potential familial kinship ties to the Schoesenhoek plantation with accounts of the Cuvilljes (Cuvelje) and Dijkers families intermarrying in the nineteenth century. When pronounced in Dutch, Dijkers sounds exactly like Du-cas in English. While this is not definitive evidence, it raised the possibility that like many surname changes throughout history, the Dijkers name was recorded as Ducas over time. If so, the two owners on Gilboa Hill were related. Unfortunately, this cannot be confirmed at this time.

If Michael Cuvilljes (Cuvelje) was in fact her relative as documents suggest, it is quite possible that while the Widow technically owned it, his slaves may have performed tasks, or slaves worked land deemed less desirable by both parties for themselves. Suffice it to say, from the resources analyzed, the Widow Ducas (Dijkers) owned the land, but it 
is uncertain who owned the enslaved labor force. Given that both families might have owned the Schoesenhoek plantation, it is quite possible that the enslaved community at this plantation and the enslaved labor force working on Gilboa Hill were one in the same.

Despite an affiliation with either owner, slaves working for these two families at the Schosenhoek plantation would have helped with the raising of cattle, not sugar. Historical maps and records depict sugar plantations in the northern hills, and specifically for this study's interest on Gilboa Hill, but remember, most sugar plantations on the island were not for the cultivation of sugar processing but a front for the illicit processing of sugar for export. To support this, a key find included the depiction of the four sites behind a large structure in a less favorable area on the outer periphery of the Widow Ducas' property away from the plantation complex on a historical map from 1795 of the island. Since they are not depicted anywhere near the cultivation areas or near the plantation complex, this suggests they might have served another purpose in the plantation landscape including the use as provision grounds or for tanning and/or animal husbandry. Terracing at GH14 and GH15 was not suitable for the cultivation of sugar like the terracing observed downslope from GH9 near the plantation complex. Terracing at GH14 and GH15 was shorter, had shallow soil deposition, was set into the steep slope of the third ridge, and simply lacked the space to accommodate large quantities of sugar cane. With its rugged terrain and steep slope, in my opinion, these terraces were likely used to grow a variety of crops rather than utilized for only one particular crop. As previous research has confirmed, undesirable land, unsuitable for sugar cultivation, was given to slaves for use as provision grounds (Armstrong 1999, 2001, 2009; Bates and Galle 2012; Delle 1998; Heath and Bennett 2000; Higman 2001; McKee 1992; Mintz 
1974; Pulsipher 1994; Ruppel et al. 2003). With this in mind, it is completely plausible two sites under investigation (GH14 and GH15 with noted terracing), with their steep slope and high elevation, were the provision grounds given to enslaved community members because of their lack of suitability in sugar cultivation by the owners. Unfortunately, this cannot be confirmed at this time either.

The analysis of historical maps provided evidence to support the four sites on Gilboa Hills were used for provision grounds. In addition, this analysis provided a terminus ante quim between the late eighteenth to early nineteenth centuries. This terminus ante quim is helpful because even though it is uncertain when the dry stone rock features were constructed, their spatial patterning and construction clearly indicate their use/construction at the same time. 


\section{Regional}

\section{Upland and Lowland Comparisons}

The examination of the four sites in the upland region revealed stark differences between their physical environments. Two sites (GH14 and GH15) had heavily wooded canopies and thick leaf scatter with clear evidence of terracing, while the other two sites (GH9 and GH10) were exposed to intense cross winds, with a small scattering of trees, and had tall, dry grass groundcover with no evidence of terracing. Each of the dry stone rock features at the four sites on Gilboa Hill consisted of groupings of rocks piled atop on another, solid in construction with no empty spaces in the middle, and showed relative similarity in construction within upland regional comparisons, but all dry stone rock features, including those determined to be half constructed walls, varied greatly in integrity from site to site. At first glance, they appeared to be randomly spaced across the mountainous landscape, however, within each site, dry stone rock features actually shared similar spacing as well as size and shape dimensions. This suggested enslaved laborers, at individual sites, organized dry stone rock groupings with distinct size dimensions and planned spacing, most likely for an unknown intended purpose. 


\section{Structural}

\section{Broader Architectural and Feature Comparisons}

This comparison assessed whether characteristics of dry stone rock features in the upland region were similar to dwellings in two domestic village environments documented on the island. Dry stone rock features, when compared to other archaeological features in the lowland regions, both in the Schosenhoek slave village and in the Free Black Village, had limited discernable similarities among the examples reviewed because they fell into their own shape and size categories. The majority of dry stone rock features fell within the medium size category and were oval. In contrast, the structures at the two villages in the lowland region, while smaller than those in the Caribbean and United States, were still larger in comparison to the dry stone rock features found in the northern hills. Additionally, all of the structures in the lowland villages were rectangular, except a circular structure at the FBV thought to be a shrine. In broader comparisons of slave quarter dimensions in the Caribbean and in the United States, a small percentage of rectangular dry stone rock features corresponded with structural dimensions found on plantations in Florida and Texas, but it is unclear why. It appears the dry stone rock features on Gilboa Hill are unique. Only ethnographic West African examples, when compared, correlated to size and shape dimensions of dry stone rock features on Gilboa Hill in three types of structures: those used for storage, fire pits, and livestock enclosures, but no recovered archaeological material suggested any of the features were used for storage, cooking, or animal husbandry. This analysis did suggest an arbitrary correlation to size and shape as possible indications of function in the landscape. 
This was an interesting discovery, none of the dry stone rock features on Gilboa Hill closely correlated to domestic structures used as dwellings in any of the comparative examples. Their unique shape and size dimensions, mostly oval shape, after further consideration, suggested they were unique not only to the island, but in the Caribbean and in the United States as well. Village dwellings in the comparative examples were much larger in comparison, regardless of their shape, and the dry stone rock features appear to be on the opposite end of the spectrum, almost half their size or less. While the lack of correlates alone is not a direct indication that the dry stone rock features were not sleeping platforms, it seems unlikely they were given their unique shape and size. Eight dry stone rock features appeared to have size dimensions suitable to support a reclining human; but it was the closer inspection of these eight dry stone rock features that proved to be the most telling in this project. Of these, none had the length and width to support a reclining human. Analysis confirmed the dry stone rock features were simply not suitable for use as sleeping platforms.

Enslaved Africans could have utilized traditional techniques in the construction of their dwellings, even if they were temporary, and cultural continuity could potentially be detected in size, shape, and placement of structures. Because the dry stone rock features on Gilboa Hill were probably not used for domestic dwellings, either temporary or long term, levels of cultural continuity in a new domestic village environment could not be measured at this time. However, structures in both the SSV and FBV did conform to village patterning. Additionally, structures used for animal husbandry correlated with dry stone rock features at GH14. Slaves working at the Schosenhoek cattle plantation quite possibly were the same slaves working in this region of the northern hills. David 
Morgan's (2006) research at the Melrose plantation in Louisiana revealed vernacular construction at the plantation relied on African traditions. This attests to the possibility enslaved Africans used an existent knowledge base to construct dwellings and other plantation structures. I think it is possible the half-constructed dry stone walls were intended to house livestock, or had another purpose, and indicate a potential level of cultural continuity in their construction. Unfortunately, without a larger comparative sample and further historical documentation to support this claim, it is merely speculation.

Additionally, it is possible that the site boundaries I established did not allow for the exploration of the areas in between sites. Clearly, as others have noted enslaved Africans could have lived and worked in the area where their provision grounds were located, but again I found no evidence to support this at this time (Armstrong 2009, 2001; Delle 2013; Mintz 1974). I concluded that the dry stone rock features on Gilboa Hill were not former dwellings in an enslaved African domestic village environment based on the lack of similarity to known archaeologically recovered villages on the island, in the Caribbean, and in the United States. No discernable pattern of occupation could be established; dry stone rock features had no uniform dimensions consistent with accommodating human height and width at each of the sites on Gilboa Hill lacked the material culture to support domestic occupation, either temporary or long-term. 


\section{Spatial}

\section{Settlement Pattern}

Of the two domestic villages in the lowland region, the SSV compared nicely with ethnographic examples from West Africa with uniform structures clustered around a central yard space. This observable high degree of nucleation extended to the large rectangular, oval and circular structures in the comparative study. Analysis confirmed that regardless of shape, the larger the structure was the more closely spaced it was in the village environment and despite differences from place to place, most village structures do adhere to a basic vernacular village spatial plan, even on St. Eustatius.

This was important to consider when examining the dry stone rock features on Gilboa Hill because perhaps they too conformed to village spatial organization. Dry stone rock features at GH9, GH14, and GH15 had relatively even dispersion across the site, while those at GH10 appeared to be more erratic in their placement. At each site, however, all dry stone rock features shared close nucleation. While this initially correlated to domestic spatial patterning, no other evidence supported their inclusion in an enslaved African domestic environment. Instead, dry stone rock features were viewed as part of a broader landscape of labor and had the uniformity typically observed in labor activities for a specific purpose. To reiterate dry stone wall builder, Dan Snow (2001:25), “... an arbitrary mound of fieldstone can, when stone is removed, reveal the logic in its location: a blister of bedrock...because grass couldn't grow there anyway, it was a natural spot to deposit picked stone (or drift stone)." The clustering of rocks was near exposed bedrock and the result of organized efforts at each particular site to procure dry 
stones for agricultural management to use in dry stone rock construction of terracing walls, pens for animal husbandry, tanning, or other purposes.

\section{Comparative Material Culture}

Extensive survey and subsurface testing of the four sites in the upland region, across $9000 \mathrm{~m}$, yielded only seven artifacts with a mean ceramic date for the upland region of 1776 , concluding the associate features may date to the time of enslavement. Given the pattern on the island of large artifact concentrations during archaeological excavations and testing failed to recover concentrations of artifacts at the four sites on Gilboa Hill, the lack of artifacts only confirmed the improbability of dry stone rock features use as dwellings in a domestic environment. If enslaved Africans were eating, drinking, and living at these locations I would have found evidence to support this occupation; I did not.

In stark contrast, both material assemblages for the lowland regions were massive and their variability measurable. The mean ceramic dates for the Schoesenhoek slave village and Free Black Village was 1748 . This was interesting as it suggested freed slaves in fact held on to their wares from the time of enslavement rather than immediately replacing them. The noted variability between both collections was due in part to the different levels of freedom associated with the SSV and FBV; after emancipation former enslaved Africans had increased economic resources to purchase other ware types including: pearlware, porcelain, and creamware. With the transition from enslavement to emancipation distinctive artifacts marking this transition were noted as well: slate, ink wells, flint, and crystals. This suggested that slaves upon emancipation did in fact 
experience an increased level of freedom and to pursue activities that they had been prevented from doing before emancipation.

Additionally, they had the resources to continue to emulate the planter class. While several vessels in the SSV material assemblage were slightly different in width, opacity, thickness and preciseness - all had blue lines at their rims, yet none matched. They intentionally pieced together a set of ceramic wares that resembled a more expensive matched set like those owned by the planter class. In the FBV assemblage, it was clear that these efforts not only continued, but that their increase in economic resources afforded them the ability to add other ware types, patterns, and colors for an increased variety in this effort. The preference for blue ceramics in both the SSV and the FBV assemblages is consistent with documented preferences of the planter class on other islands (Haviser 1999: 272). This suggests that enslaved Africans (both enslaved and emancipated) experienced a higher degree of freedom in choosing the color and patterns of their wares to emulate the planter class. 


\section{Taskscapes}

In line with the research of Tim Ingold (1993) and how people as a community work together to complete every day activities through "taskscapes", in the end the archaeological evidence suggests I found five micro-scale taskscapes on the island. Artifact concentrations at the SSV indicated that ceramic wares associated with cooking were centrally scattered outside archaeologically recovered structures within the village environment. This revealed the presence of a communal taskscape enslaved Africans participated in during the time of enslavement much like Heath (1999:33) described.

Additionally, the dry stone rock features at each of the sites discovered on Gilboa Hill also reveal taskscapes. The piling of dry stone rocks is consistent with attempts to manage labor to increase efficiency in planning work performed and to decrease energy expenditure in dry stone wall construction efforts used in terracing, animal husbandry, tanning, and/or another purpose in the landscape. At GH14 and GH15 clear communal efforts to construct terracing walls were noted. In addition, dry stone rock piles were grouped together with close nucleation and relatively even dispersion across the landscape as well. At these two sites in particular, it is my impression that at least the observable terracing was used for provision grounds and the dry stone rock features I recorded might have been intended to add these existent terracing walls, to construct a structure (animal enclosure), or for tanning hides.

At GH9, while each of the dry stone rock features held to a similar pattern noted at GH14 and GH15, in both size and nucleation and dispersion rates, they clearly had less integrity in their construction (loosely piled). I think given this difference it is plausible that the dry stone rock features at this site were used for another purpose in the plantation 
landscape, perhaps tanning. Finally, at GH10 while, again, all dry stone rock features adhered to an established pattern found at GH14, GH15, and GH9, they were more sporadically placed; there were recognizable construction differences in the dry stone rock piles assembly as well. At least three of the dry stone rock features at GH10 shared similarities in construction to the partially constructed fort on the second ridge. This suggests that they might have been either foundations for look-out posts or had another purpose in the landscape. Unfortunately, without further historical documentation to help confirm the dry stone rock features' purpose at each of the four sites, this is merely speculative.

Snow (2001) proposed, essentially the "formula for a wall built in A.D. 2001 is recognizable in a wall built in 2001 B.C," meaning, the partially constructed walls on Gilboa Hill's third ridge do share similar attributes to others like it; the trick is in identifying those correlates rather than viewing the wall as a separate design. From this, the construction of walls (shape, size, length, etc.) becomes an important factor to consider in examining and identifying dry stone walls in archaeological research (Snow 2001:53). According to Snow (2001:32), every dry stone rock wall has four principles in its construction and can be easily identified upon further scrutiny:

1. End in, end out - run the longest dimensions of each stone into the wall so the wall's weight presses on the greatest surface area of each of the stones.

2. Cross the joints - overlaying the stones so stones are touching as many other stones as possible to ensure the tightest fit.

3. Keep the middle full - to prevent slippage or settling, each face of the wall must be built in careful, consistent unison. 
4. Taper as you go - As the wall increases in height, the waller decreases the wall width by angling the stone faces toward the center.

Terracing requires cooperative communal effort for its construction and maintenance. Snow's (2001) description of the construction of stone walls contributes to our understanding of the communal effort they require to build them effectively. Without collaboration and construction in careful, consistent unison, dry stone walls would not last. The fact that the dry stone walls at GH14 and GH15 still stand erected after almost 250 years is an indication that communal effort was involved in their construction. Not only is the terracing at the two sites on Gilboa Hill (GH14 and GH15) a clear indication of planned and cooperative labor by enslaved Africans, but the dry stone rock piles set across the landscape to construct them is as well. Terracing was hard communal work, to mediate this intense labor, enslaved Africans intentionally grouped dry stones collected in the immediate area into manageable piles. I think this communal effort speaks to a level of the cultural continuity of a community principle like Ubuntu.

\section{Provisioning Grounds}

Hauser et al. (2001: 14) asserted provision grounds were "places set apart from the industrial core of the plantation and could be spaces of their own," for enslaved Africans living on the island. Much like Scott (1990) proposed, these spaces might have held hidden transcripts whereby enslaved communities resisted the oppressive conditions of slavery. Whether the SSV and/or each of the sites on Gilboa Hill held substantial evidence of hidden transcripts was unclear at this time. However, the location of the sites on the periphery of the plantation in the northern hills on historical maps, as well as their preservation in the field, is similar to other documented land where hidden transcripts 
were identified and provides the potential to discern if enslaved Africans resisted the oppression of slavery in this way on St. Eustatius; future research might provide further insight (Ruppel et al. (2003:4).

The identified Barrage terracing at GH14 and GH15 are consistent with efforts to stop soil erosion and take advantage of infrequent hard rains for the cultivation of crops. And it is in these constructed walls I suspect enslaved Africans were growing other crops besides sugar cane. Sugar was cultivated in large expansive fields rather than in short descending terraces like those observed at sites GH14 and GH15; it is possible these terraces were used to cultivate other crops like guinea yams, okra, corn, sweet potatoes, potatoes, tomatoes, cabbage, or carrots. Provision grounds recovered in previous archaeological excavations were often in less desirable locations further up the mountains and slaves would have travelled great distances to cultivate this land (set in plots with unique size and shape) for themselves or in order to have a surplus to sell at local markets including the crops listed above (Armstrong 1999, 2001, 2009; Bates and Galle 2012; Delle 1998; Heath and Bennett 2000; Higman 2001; McKee 1992; Mintz 1974; Pulsipher 1994; Ruppel et al. 2003). Olwig (1993:2) asserted, “Although a great hardship for the already overworked slaves, the provision ground system provided certain advantages and opportunities for the slaves to develop and maintain their own culture," and field work revealed considerable efforts in the construction of terracing at both GH14 and GH15 in a remote area where I think provision grounds for enslaved communities might have been located. Early accounts on St. John, in the 1730s, as well as on the islands of Antigua, Jamaica, Barbados, Nevis and St. Kitts during the same time period depict provision grounds on less desirable land on the periphery of plantations as a perfect solution for 
plantation owners' to feed their slaves, and given their placement at the periphery of the Widow Ducas' property, this is likely the case (Armstrong 1999, 2001, 2009; Bates and Galle 2012; Berlin and Morgan 1993; Delle 1998; Hauser et al. 2011; Mintz 1974; Olwig 1993).

In addition, half-constructed walls closely correlated to West African livestock pens and it is possible enslaved communities would have used the dry stones to complete the enclosures. Notable agave groves were located at these two sites, yet no evidence to conclude if they were cultivated or harvested. Their placement at two of the site locations, and not anywhere else in the mountainous landscape, suggests they were a part of provision grounds but cannot be proven at this time. The clear lack of any significant material assemblage associated with domestic occupation at each of the four sites, only adds to the argument that these sites served another purpose entirely.

Alan Cressler (2007) stumbled upon similar dry stone rock features in the United States on a caving expedition on Baker Mountain in Tennessee and noted similar dry stone rock features in fields, historically documented as once thriving plantations that utilized slave labor, across many of the southern states. These dry stone rock features reveal a striking similarity between those in the United States and those discovered on Gilboa Hill on St. Eustatius. His find further supports dry stone rock features on Gilboa Hill were part of a broader landscape of labor whereby enslaved communities cleared the land for cultivation and construction purposes in dry stone rock wall construction used in terracing, animal husbandry and/or tanning and the cultivation and maintenance of provision grounds. While this research did not provide overwhelming evidence, it is enough in my opinion to consider that at least two of the four sites (GH14 and GH15) on 
Gilboa Hill were likely used purposes other than sugar cultivation like provision grounds. Most provision grounds were not documented on historical maps of St. Eustatius, so confirmation will have to await further archaeological research.

\section{Traditional Continuity}

Under Dutch colonial power, enslaved Africans living and working on the island of St. Eustatius were afforded liberties undocumented elsewhere in the New World. Slaves were allowed to own and benefit from animal husbandry and sell excess provisions from their gardens at the local market in Oranjestad, like other Caribbean enslaved populations, but with the lack of surveillance and restrictions in daily life enslaved Africans likely experienced a higher degree of ideological freedom in the construction of their communities. I think given the location of the sites in the outer periphery of the plantation, behind a large structure, and in more rugged terrain that enslaved Africans likely experience an increased level of freedom in the construction of their communal provision grounds.

The terracing on Gilboa Hill at GH14 and GH15 is the most conclusive of all the evidence I have found of traditional continuity as it reflects enslaved Africans' communal effort to cultivate provisions for their community members. Dry stone rock features further support this as their placement in the landscape was part of concerted efforts to minimize energy expenditure and maximize proficiency in dry stone wall construction for possible additions to existent terracing, animal enclosures used in animal husbandry, and/or tanning. While this alone is not a striking assurance that cultural continuity existed on the island of St. Eustatius, it is certainly a starting point for future research. 
Within the harsh conditions of the institution of slavery, slaves stitched a life together from various cultural traditions based in a community building principle like Ubuntu (Balcomb 2004; Gade 2011; Kurzweil 2011; Mbiti 1990; Mintz 1996; Ndaba 1994; Prinsloo 1994; Sanson 2007; Van den Heuvel 2007; Young 2007). Like Belcomb (2004) and Van den Huevel (2007) suggest, enslaved Africans shared a worldview whereby they had a deep communal relationship to their built environment and I think this helped shape not only domestic, but labor environments as well. The terracing, and communal effort it required, recovered in this investigation can certainly be viewed in this light. This terracing is evidence of the social reorganization of enslaved communities in the New World and the concerted effort to work as a community toward a communal goal. As a taskscape, it is an important discovery in historical archaeology as it is one of few documented in not only the Dutch Caribbean, but in the broader Caribbean studies of the African Diaspora. 


\section{Future Research}

This investigation of four potential slave villages in the northern hills on the island of St. Eustatius from the eighteenth century was indeed a rare opportunity in historical archeology and presented the possibility of detecting cultural continuity in established enslaved environments in the Caribbean; certainly an important endeavor. The lack of opportunity to study a new enslaved African village environment and the lack of evidence to support cultural continuity, albeit disappointing, presented the unique opportunity to examine the landscape of labor in a mountainous environment on the periphery of plantation life. An inquiry, which to date, is vastly unexplored in historical archaeology. For this reason, I propose the following future research.

\section{Geophysical and Paleoethnobotanical Analysis:}

\section{Identification of Crops in Terracing Areas at GH14 and GH15 on Gilboa Hill}

A growing number of archaeological investigations focus on the small plots of land that enslaved populations used as provision grounds and gardens within the plantation landscape either to supplement their diets or to increase economic advantages from the sale of surplus crops in local markets ((Armstrong 1999, 2001, 2009; Barickman 1994; Bates and Galle 2012; Delle 1998; Heath and Bennett 2000; Higman 2001; McKee 1992; Mintz 1974; Pulsipher 1994; Ruppel et al. 2003). Not only would slaves have benefited from their independent production and economic growth, but would have experienced a greater level of autonomy from their masters as they worked and cultivated their own resources (Barickman 1994).

The investigation on Gilboa Hill raised interest into the lives of enslaved Africans living and working on the island, but more importantly, questions remain regarding the 
exact function of dry stone rock features recorded at the four sites on Gilboa Hill. Did either the Widow Ducas (Duije) or Michael Cuvillje give this undesirable land on Gilboa Hill's third ridge to slaves for provision grounds? Did they supplement their diet and then in turn gain economic advantages through the sale of surplus? Alternatively, did the owner use this land for another purpose entirely? This remains uncertain and warrants further investigation to consider the possibility of the four sites on Gilboa Hill's third ridge use as provision grounds during the time of enslavement.

Proebsting (2007) at the Sylvester Manor found investigations based in soil micromorphology help understand the chronology of land use over time. Extracted core samples from the terracing areas at GH14 and GH15 can determine associated periods most likely used for agricultural pursuits. These soil samples with further evaluation, using floatation used in paleoethnobotanical investigations, much like Samantha Henderson (2013) used in her research into the agricultural subsistence practices used by slaves at Poplar Forest for the identification of crops, will yield information into which crops were cultivated in these terracing areas. This is incredibly helpful in determining if the terracing was indeed used for either provision or as part of the plantation economy. If samples yield higher wild edibles, medicinal, non-economic plants, and crops typically cultivated in slave community gardens or provision grounds including: guineas yams, okra, corn, sweet potatoes, potatoes, tomatoes, cabbage, carrots and breadfruit, thent the intended purpose of the dry stone rock features is clearer and at least a portion of the site's diagnosis is possible.

Additionally, Holliday and Gartner (2007) suggest geophysical analyses, like soil $\mathrm{P}$ analysis, is useful in historical archaeology to determine the level and nature of human 
activity at sites under investigation. Since terracing areas at GH14, when compared to those at GH15, are relatively flat and have less erosion, these soil samples are ideal for further testing. If soils in the terracing area at GH14 reflect more pronounced (P) distribution across the sample area, then this will indicate modifications to the soil through human behavior; most likely enslaved workers added phosphorus to the soil through fertilizer from animal husbandry. While not precise, it is an indication of their activities; when comparing plant chemical compounds to the levels of phosphorus in the soil, archaeologists will be able to understand to some degree the level and nature of activity at this particular site.

\section{Experimental Archaeology: Recreation of Enslaved African Provision Grounds}

Experimental archaeology offers the ability to reconstruct environments based on aspects of a culture or labor practices garnered through substantial research on past communities. Yentsch (1994, 1996, 1997), Beaudry (1996), and Reyonlds (1987, 1999) contribute to our understanding of past agricultural practices in their advocacy of research into historical practices in gardening and the possibility in experimental archaeology of the recreation of historic gardens. With the possible identification of specific plant species grown at Gh14 and GH15 from soil samples in paleoethnobotanical analyses, clearing the land at the two sites, and then cultivated these crops using existing terracing would be an exciting endeavor. At the very least, we can understand the level of effort required to sustain crops at this location, discover successful cultivation strategies, and possibly gain valuable insight into the daily activity of enslaved laborers. 


\section{Broader Comparisons of Landscapes of Labor: Dry Stone Rock Features}

Although more questions raised during the investigation remain unanswered and require future research, what we know is the construction of the partial walls and piling of dry stone rocks into site-specific uniform sized groupings indicated an organized effort of enslaved Africans working on Gilboa Hill. This initial landscape analysis provided the preliminary groundwork for future research in examining not only Dutch slave life in the Caribbean, but slave labor practices both in the Caribbean and in the United States in the construction of dry stone walls. Further research is necessary to investigate the process of site location, clearing the land, stone procurement, and various methods in wall construction.

Atha (2012) in his research on Chinese rice farms has shed light on the landscape of labor as heritage in agricultural cultures. By focusing on sustained practices over time, he suggested labor organization is an integral part of a community, and under further scrutiny diagnostic characteristics of familial or community labor practices can be observed. Similarly, Kolb (1997) goes so far as to suggest that labor activities, more specifically architectural efforts by a community, become markers that act to distinguish the type of labor conducted at a particular archaeological site. Most small scale building endeavors (less than $150 \mathrm{~m}$ in size and clustered together like those in dry stone rock walls) were considered familial projects, or community based, and served as architectural elements within gardens, used as animal pens, or a part of agricultural field maintenance on the island of Hawaii (Kolb 1997). According to this theory, the dry stone rock features on Gilboa Hill fall within the smallest tier in a labor management dynamic and we can speculate construction efforts were communal. Through this, we can begin to understand 
the social relationships among enslaved populations through the careful study of diagnostic characteristics of their labor environments (how and where stones were procured and choice in groupings with respect to size, shape, etc.).

This initial landscape analysis provided only the preliminary groundwork for future research and I propose an investigation of dry stone rock features at other sites on the island of St. Eustatius, as well as additional Dutch islands, in order to create a database of dry stone rock features used in similar labor practices. With an investigation in to historical documentation about their purpose across the bounded plantation landscape, both at local island historic preservation offices and at The Hague in the Netherlands, the exact function of dry stone rock features might come to light. This association to a particular activity can then provide detailed characteristics to identify the function of dry stone rock features in the Dutch enslaved community in the database. This database, once compiled, will provide the foundation for further comparisons of labor practices both in the Caribbean and in the United States on known archaeological sites associated with enslaved labor (much like those found by Alan Cressler (2007)) and holds the potential to contribute to our understanding of displaced Africans in broader studies of the African Diaspora and their landscape of labor. 


\section{REFERENCES}

Adams, Williams Hampton and Sarah Jane Boling

1989 Status and Ceramics for Planters and Slaves on Three Georgia Coastal Plantations. Historical Archaeology 23(1):69-96.

Allen, Rose Mary

2010 The Harvest Ceremony Seú as a Case Study of the Dynamics of Power in Post- Emancipation Curaçao (1863-1915). Caribbean Quarterly. 56(3). pp. 13-29.

Armstrong, Douglas, Mark Hauser, David Knight, and Stephen Lenik

2011 Out of Many, One People: The Historical Archaeology of Jamaica, edited By James Delle and Mark Hauser. The University of Alabama Press, Tuscaloosa, Alabama.

Armstrong, Douglas

2009 Variation in Venues of Slavery and Freedom: Interpreting the Late Eighteenth Cultural Landscape at St. John, Dutch West Indies using an Archaeological GIS. International Journal of Historical Archaeology 13:94-111. 2001 The Old Village and the Great House: An Archaeological and Historical Examination of Drax Hall Plantation St. Ann's Bay, Jamaica, pp.1-332. University of Illinois Press, Urbana and Chicago. 1999 Archaeology and Ethnohistory of the Caribbean Plantation. In I Too, Am America': Archaeological Studies of African-American Life, edited by Theresa Singleton, pp. 173-192. University Press of Virginia, Charlottesville, Virginia.

Ashmore, Wendy and A. Bernard Knapp 1999 Archaeologies of Landscape: Contemporary Perspectives. Blackwell Publishers, Oxford, United Kingdom.

Atha, Mick

2012 A Neglected Heritage: Towards a Fuller Appreciation of the Landscapes and Lifeways of Hong Kong's Rice Farming Past. Asian Anthropology. 11(1683478X). pp. 129-156. 
Balcomb, A. O.

2003 Human Identity and an African World-View: Some Interactions With

Science and Philosophy. Conference Proceedings at The Integrity of the Human

Person in an African Context: Perspectives From Science and Religion:

Proceedings of the Eleventh Seminar of the South African Science and Religion

Forum (SASRF) of the Research Institute for Theology and Religion Held at the

University of South Africa, Pretoria on $28 \& 29$.

Barickman, B. J.

1994 "A Bit of Land, Which They Call Roca": Slave Provision Grounds in the Bahian Reconcavo, 1780-1860. The Hispanic American Historical Review. 74(4). 649-687.

Barka, Norman E.

2001 Timelines: Changing Settlement Patterns on St. Eustatius. In Island Lives: Historical Archaeology of the Caribbean. Edited by Paul Farnsworth. University of Alabama Press.

Bates, Lynsey and Jillian E. Galle

2012 Plats and Artifacts: Comparative Analysis of Provisioning Schemes in the British Caribbean. Carbondale Visiting Scholars Conference Paper: The Archaeology of Slavery: Toward a Comparative, Global Framework. Lecture.

Bell, Alison

2002 Emulations and Empowerment: Material, Social, and Economic Dynamics in Eighteenth Century Virginia. International Journal of Historical Archaeology. 6(4): 253-298.

Benfer, R. A., G.H. weir, and B. Ojeda Enriquez

1987 Early Water Management Technology on the Peruvian Coast. In Arid Land Use Strategies and Risk Management in the Andes, edited by D.L. Browman. Westview Press, Colorado. 195-206.

Berlin, Ira, and Phillip D. Morgan

1993 Cultivation and Culture: Labor and the Shaping of Slave Life in the Americas.

Beswick, Jon

2010 Exploring Eye: West Africa's Vernacular Architecture. The Architectural Review. May pp. 1-3.

Blakely, Allison

1993 Blacks in the Dutch World: The Evolution of Racial Imagery in a Modern Society. Indiana University Press, Bloomington, Illinois. 
Bourdier, Jean Paul and Trinh T. Minh-ha 1996 Drawn From African Dwellings. Indiana University Press, Bloomington. 2011 Vernacular Architecture of West Africa: A World in Dwelling. Routledge, New York. pp 7-184.

Brown, Kenneth 2001 Interwoven Traditions: Archaeology of the Conjurer's Cabin and the African American Cemetery at the Jordan and Frogmore Plantation. Places of Cultural Memory: African Reflecions on the American Landscape. Conference Proceedings, May. U.S. Department of the Interior-National Park Service. pp. 99104.

Bridenbaugh, Carl and Roberta Bridenbaugh

1972 No Peace Beyond the Line; The English in the Caribbean, 1624-1690.

Oxford University Press.

Canadian Historic Sites

1979 Spode/Copeland Transfer-Printed Patterns. Occasional Papers in Archaeology and History (22). Quebec.

Carney, Judith A.

2001 Black Rice: The African Origin of Rice Cultivation in the Americas. Havard University Press, Cambridge.

Carrington, Selwyn H. H.

2002 The Sugar Industry and the Abolition of the Slave Trade, 1775-1810.

University Press of Florida, Gainesville. pp 362.

Cook, Mariana

2011 Stone Walls: Personal Boundaries. Damiani Press, Italy. 192 pages

Cosgrove, Denise

1984 Social Formation and Symbolic Landscape. Barnes and Noble Books,

Totowa, New York. p. 14.

Covey, Herbert C.

2007 African American Slave Medicine: Herbal and Non-herbal Treatments.

Lexington Books, United Kingdom.

Crumley, C. L., and Marquardt, W. H., 1990, Landscape: A Unifying Concept in Regional Analysis, in: Interpreting Space: GIS and Archaeology Edited by K. M. S. Allen, S. W. Green, and E. B. W. Zubrow. Taylor and Francis, London, pp. 73 79. 
David, Bruno and Julian Thomas 2008 Introduction in Landscape Archaeology. Left Coast Press, Walnut Creek, California. pp. 27-39.

Dawdy, Shannon Lee 2000 Understanding Cultural Change Through the Vernacular Creolization Louisiana. Historical Archaeology. 34(3):107-123.

Deetz, James

2006 In Small Things Forgotten: An Archaeology of Early American Life. Double Day, New York, New York. 1990 "Landscapes as Cultural Statements." In Earth Patterns: Essays in Landscape Archaeology, edited by William M. Kelso and Rachel Most, pp. 1-4. University of Virginia Press, Charlottesville, Virginia.

Delle, James

2013 Rethinking the Slave Village: Conference Abstract. Society for Historical Archaeology Annual Conference. Quebec, Canadad 2008 An Archaeology of Modernity in Colonial Jamaica. Archaeologies. 4(1): 23, 87-109.

1999 The Landscape of Class Negotiation on Coffee Plantations in the Blue Mountains of Jamaica: 1790-1850. Historical Archaeology. 33(1):136-158. 1998 An Archaeology of Social Space: Analyzing Coffee Plantations in Jamaica's Blue Mountains. New York University's Plenum Press, New York, New York.

1989 A Spatial Analysis of Sugar Plantations on St. Eustatius, N.A. MA Thesis. William and Mary Press. Williamsburg, Virginia.

Delthlefson, Edwin

1982 The Historical Archaeology of St. Eustatius. Journal of New World Archaeology 2: 73-86.

Denyer, Susan

1978 African Traditional Architecture: An Historical and Geographical

Perspetive. Pearson Education, Limited. pp 210

Dobres, Marcia-Anne and John E. Robb 2000 Agency in Archaeology. Routledge, New York, New York.

Dunn, Richard S. 2000 Sugar and Slaves: The Rise of the Planter Class in the English West Indies, 1624-1713. University of North Carolina Press

Edwards, Jay D.

1994 The Origins of Creole Architecture. Winterthur Portfolio. 29(2). 155-189 
Edwards-Ingram, $\mathrm{Y}$

2001 African American Medicine and the Social Relations of Slavery. Race and the Archaeology of Identity. Edited by Charles Orser. pp 34-53

Eltis, David and David Richardson

2010 Atlas of the Transatlantic Slave Trade. Yale University Press, New Haven, Conneticut. 336 pgs.

Enfari, M., Shanan, L., and N. Tadmor 1982 The Negev, The Challenge of a Desert. Israel Journal of Botany. (29) pp 4-21.

Epperson, T.W.

1990 Race and the Disciplines of the Plantation. In Historical Archaeology on Southern Plantations and Farms. Edited by C.E. Orser, Dr. Historical Archaeology. 24(4), 29-36.

Fahlberg, Samuel

1829 Vue de L'ile St. Eustache - Illustration used with permission from SECAR

Farnsworth, Paul

2001 Island Lives: Historical Archaeology of the Caribbean. University of Alabama Press. Tuscaloosa, Alabama.

Ferguson, Leland

2010 Cabin, Quarter, Plantation: Archecture and Landscapes of North American Slavery. Civil War Book Review. America: History Life. pp 1-3.

1992 Uncommon Ground: Archaeology of Early African America, 1650-1800.

Smithsonian Research Press, Washington D.C.

1991 Struggling with Pots in Colonial South Carolina. In Archaeology of

Inequality, edited by R. Mcguire and R. Paynter, pp. 28-39. University of Virginia Press, Charlottesville, Virginia.

Fernandez Olmos, Margarite and Lizabeth Paravisini-Gebert

2003 Creole Religions of the Caribbean: An introduction from Vodou and Santeria to Obeah and Espiritsmo. New York University Press, New York, New York. pp. 1-171.

Fennell, Christopher

2010 Carved, Inscribed, and Resurgent: Cultural and Natural Terrains as Analytic Challenges. In Perspectives from Historical Archaeology: Revealing Landscapes, The Society for Historical Archaeology. 2010 Crossroads and Cosmologies: Diasporas and Ethnogensis in the New World (Cultural Heritage Studies). University Press of Florida. 
2003 Group Identity, Individual Creativity, and Symbolic Generation in a BaKango Diaspora. International Journal of Historical Archaeology. 7(1).

Fesler, Garrett

2004 Living Arrangements Among Enslaved Women and Men at an Early Eighteenth Century Virginia Quartering Site. Engendering African American Archaeology: A Southern Perspective, edited by Julian E. Galle and Amy Young. The University of Tennessee Press.

Frazier, E. F.

1964 The Negro Church in America. Schocken, New York.

Gade, Christian B.N.

2011 The Historical Development of the Written Discourses on Ubuntu. South African Journal of Philosophy. 30(3):303.

Galle, Jillian, Fraser Neiman, Robert Philpott, and Roger Leech 2011 Site Reports for St. Kitts shovel-test-pit-surveys in 2008. Thomas Jefferson Foundation in conjunction with Digital Archaeological Archive of Comparative Slavery, Monticello Department of Archaeology, International Slavery Museum, and The University of Southhampton. (May).

Giddens, Anthony

1979 Central Problems in Social Theory: Action, Structure, and Contradictions in Social Analysis. University of California Press, Berkley, California.

Gilmore, J.K.

2009 Leprosy at the Lazaretto on St. Eustatius, Netherlands Antilles.

International Journal of Osteoarchaeology. 18(1):72-84.

Gilmore III, R. Grant

2010 Vernacular Architecture in the Caribbean. In Archaeology, Syncretism, Creolisation, edited by T. Clack, Oxford University Press, Oxford, England.

2010 Free Black Village Research and Site Report. In possession of author.

2009 Blue Beads, Afro-Caribbeanwares, and Tumblers: International Trade by enslaved Africans. In Free-Ports of Caribbean. National Archaeological Anthropological Memory Management (NAAM): Curacao, N.A. 2009 Encyclopedia of Caribbean Archaeology. Edited by Basil A. Reid and R. Grant

Gilmore, Grant

2005 The Archaeology of New World Slave Societies: A Comparative Analysis with particular reference to St. Eustatius, Netherlands Antilles. PhD dissertation. Institute of Archaeology, University College, London. 
Gilmore, J. K

2009 "Leprosy at the Lazaretto on St Eustatius, Netherlands Antilles"

International Journal of Osteoarchaeology, 18(1) 72-84.

Gilroy, Paul

1993 The Black Atlantic: Modernity and Double Consciousness. Harvard University Press.

Godja, M.

1997 The Contribution of Aerial Archaeology to European Landscape Studies: Past Achievements, Recent Developments, and Further Perspective. Journal of European Archaeology. 5(2) 91-104.

Gomez, Michael

2003 Reversing Sail: A History of the African Diaspora (New Approaches to African History) W. W. Norton \& Company.

1998 Exchanging Our Country Marks: The Transformation of African Identities in the Colonial and Antebellum South. University of North Carolina Press, Chapel Hill, North Carolina.

Goslinga, C.

1973 The Dutch in the Caribbean and on the Wild Coast, 1580-1680. University of Florida Press, Gainesville.

Gusset, Gerard

1980 Stoneware: White Salt-Glazed, Rhenish and Dry Body. History and Archaeology (38). Parks Canada, Quebec.

Hall, Edward Twitchell

1966 Anthropology of Space. Architectural Review. 140(4):163-166

Hartog, J.

1976 History of St. Eustatius. Central U.S.A. Bicentennial Committee.

Hauser, Mark W., James A. Delle and Douglas V. Armstrong

2011 Out of Many, One People: The Historical Archeology of Colonial Jamaica. University of Alabama Press.

Haviser, Jay B.

2012 Personal Communication Regarding Potential Diagnostic Assessment of Dry Stone Rock Features and Similarities to Tanning Mounds on Curacao. St. Eustatius. November.

1999 African Sites: Archaeology in the Caribbean. Markus Wiener Publishing, Princeton, New Jersey.

Heath, Barbara and Amber M. Bennett 
2009 'The little spots allow'd them': The archaeological Study of African American Yards. In Perspectives from Historical Archaeology: African Diaspora Archaeology, edited by Nicholas Honercamp. The Society of Historical Archaeology.

Heath, Barbara 1999 Hidden Lives: The Archaeology of Slave Life at Thomas Jefferson's Popular Forest. University Press of Virginia, Charlottesville, Virginia. 1999 Yabbas, Monkeys, Jugs, and Jars: An Historical Context for AfricanCaribbean Pottery on St. Eustatius. In African Sites: Archaeology in the Caribbean. Markus Wiener Publishing, Princeton, New Jersey.

Henderson, Samantha

2013 Understanding Slave Subsistence in the Context of Changing Agricultural Practices: Paleoethnobotany at Thomas Jefferson's Poplar Forest. Master's Thesis at University of Massachusetts, Boston.

Herskovits, M.J.

1958 The Myth of the Negro Past. Beacon, Boston, Massachusetts

Higman, B.W.

1988 Montpelier Jamaica: A plantation Community in Slavery and Freedom, 1739-1912. University of West Indies Press, Jamaica.

2001 Jamaica Surveyed: Plantation Map and Plans of the Eighteenth and Nineteenth Centuries. University of West Indies Press, Jamaica.

Hodder, Ian and Clive Orton

1976 Spatial Analysis in Archaeology. Cambridge University Press, London, England.

Holliday, Vance T. and William G. Gartner 2007 Methods of Soil P Analysis in Archaeology. Journal of Archaeological Science. 34(2). pp. 301-333.

Holland, Dorothy, William Jr. Lachicotte, Debra Skinner, and Carole Cain 1998 Identity and Agency in Cultural Worlds. Harvard University Press, Cambridge, Massachusetts. pp. 19-46.

Hood, J. Edward 1996 Social Relations and the Cultural Landscape. In Landscape Archaeology. The University of Tennessee Press, Knoxville, Tennessee.

Hubbard, Vincent K. 1998 Swords, Ships and Sugar: History of Nevis: 1900 to 1998. Premiere Editions International, Inc. Corvallis, Oregon. 176 pgs. 
Hume, Noel

2001 A Guide to Artifacts of Colonial America. University of Pennsylvania Press. pp 352.

Ingold, Tim

1993 The Temporality of the Landscape. World Archaeology. 25(2):24-174.

Jones, Olive

1985 Parks Canada Glass Glossary. Downloaded PDF. Society of Historical Archaeology. http://www.sha.org/bottle/pdffiles/GlassGlossary.pdf

Kahn, Aisha, Margarite Fernandez Olmos and Lizabeth Paravisini-Gebert 2003 Isms and Schisms: Interpreting Religion in the Americas, Creole Religions of the Caribbean: An introduction from Vodou and Santeria to Obeah to Espiritsmo. Anthropological Quarterly. 76(4):761-774.

Kandle, Patricia Lynn

1985 St. Eustatius: Acculturation in a Dutch Caribbean Colony. William and Mary Press, Williamsburg, Virginia. Master's Thesis. College of William and Mary Department of Antrhopology.

Karklins, K. \& Barka, N.F., 1989. The beads of St. Eustatius, Netherlands Antilles. Beads: Journal of the Society of Bead Researchers. No. 1, 1, 55-88.

Kelly, Kenneth G.

2008 Creole Cultures of the Caribbean: Historical Archaeology in the French West Indies. International Journal of Historical Archaeology. 12:388-402 2004 The African Diaspora Starts Here: Historical Archaeology of Coastal West Africa. African Historical Archaeologies. Edited by Andrew M. Reid and Paul J. Lane. pp 219-240.

Kolb, Michael J.

1997 Labor Mobilization, Ethnohistory, and the Archaeology of Community in Hawaii. Journal of Archaeological Method and Theory. 4(3/4). 265-285.

Kryder-Reid, Elizabeth 1996 The Construction of Sanctity: Landscape and Ritual in a Religious Community. In Landscape Archaeology. The University of Tennessee Press, Knoxville, Tennessee.

Lenik, Stephan

2012 Mission plantations, space, and social control: Jesuits as planters in French Caribbean Colonies and Frontiers. Journal of Social Archaeology. 12(1):51-71. 
Leone, Mark P. and Gladys-Marie Fry 1999 Conjuring in the Big House Kitchen: An Interpretation of African American Belief Systems Based on Uses of Archaeology and Folklore Sources. Journal of American Folklore. 112(445):372-403.

Lazzari, Marisa

2005 The Texture of Things: Objects, People and Landscape in Northwest Argentina (First Millennium A.D.) In Archaeologies of Materiality, edited by Lynn Meskell, Blackwell Publishing, Malden, Massachusetts. pp. 126-161.

Littlefield, Daniel

1981 Rice and Slaves: Ethnicity and the Slave Trade in Colonial South Carolina. Lousiana State University Press, Baton Rouge.

Madry, Scott L. H. and Carole L. Crumley

1990 "An Application of Remote Sensing and GIS in a Regional Archaeological Settlement Pattern Analysis: the Arroux River Valley, Burgandy, France." In Interpreting Space: GIS and Archaeology. Edited by Kathleen Allen, Santon Green, and Ezra Zu. Taylor and Francis, London. pp.364-380.

MacDonald, K.C. and D.W. Morgan

2012 African earthen structures in colonial Louisiana: architecture from the Coincoin plantation (1787-1816). Antiquity 86: 161-177.

Mann, Michael

1986 Sources of Social Power. Cambridge University Press, London.

McKee, L.

1992 Summary Report on the 1991 Field Quarter Excavaton. Nashville, Tennessee: The Hermitage

Miller, Derek Robert

2008 Breaking the Mold: Sugar Ceramics and the Political Economy of $18^{\text {th }}$ Century St. Eustatius. William and Mary Press, Williamsburg, Virginia. Master's Thesis. College of William and Mary Department of Anthropology.

Mintz, Sidney W.

1996 Enduring Substances, Trying Theories: The Caribbean Region as OIKOUMENE. The Journal of the Royal Anthropological Institute. 2(2):289-311. 1974 Caribbean Transformations. Columbia University Press, New York. pp 343.

Mintz, Sidney W. and Richard Price 1992 The Birth of African American Culture: An Anthropological Perspective. 
Beacon Press, Boston.

Mitchell, W.J.T

2002 Landscape and Power. The University of Chicago Press: Illinois.

MacDonald, K. C., Morgan, D. W., Handley, F. J. L., Lee, A. L., Morley, E. 2006 The Archaeology of Local Myths and Heritage Tourism: The Case of Cane River's Melrose Plantation. In A Future for Archaeology: The Past in the Present edited by Layton, R., Shennan, S. J., Stone, P. UCL Press, London. pp.127-142.

Mrozowski, Stephen, Maria Franklin, and Leslie Hunt 2008 Archaeobotanical Analysis and Interpretations of Enslaved Virginian Plant Use at Rich Neck Plantation (44WB52). American Antiquity. 73(4). pp. 699728.

Mullin, Michael

1992 Africa in America: Slave Acculturation and Resistance in the American South and the British Caribbean, 1736-1831. University of Illinois Press, Urbana.

Munsell

1995 X-Rite Munsell M50215B, Soil Book of Color M50215B

Norman, Neil

2012 Carbondale Visiting Scholars Conference Paper: The Archaeology of Slavery: Towards a Comparative Global Framework. Lecture. March 30, 2012. In possession of author.

2009 Powerful Pots, Humbling Holes, and Regional Processes: Toward an Archaeology of Huedan Vodun. African Archaeology. (26):187-218.

Okeefe, Tafhg

2000 Reflections on the Dispersed-Nucleated Paradigm in Medieval Settlement Archaeology. Ruralia III. Pamatky Archeologicke. 104

Okepewho, Isidore, Carol Boyce Davies, and Ali A. Mazrui

2000 The African Diaspora: African Origins and New World Identities. Indiana University Press, Indianapolis, Indiana.

Orser, Jr., Charles and Pedro P.A. Funari 2001 Archaeology of Slave Resistance and Rebellion. World Archaeology. 33(1):61-72.

1998 The Archaeology of the African Diaspora. Annual Review of Anthropology. 27:63-82.

Orser, Jr., Charles 1996 Artifacts, Networks, and Plantations: Toward a Further Understanding of 
the Social Aspects of Material Culture. Historical Archaeology and the Study of American Culture. Edited by Lu Ann De Cunzo and Bernard L. Herman. pp. 233256.

1995 Historical Archaeology. $2^{\text {nd }}$ Ed. Pearson, Upper Saddle River, New Jersey.

1994 The Archaeology of African American Slave Religion in the Antebellum

South. Cambridge Archaeological Journal. 4(1):33-45.

Ortner, Sherry

2006 Agency, Practical Politics and the Archaeology of Culture Contact. Journal of Social Archaeology. pp. 191-192.

1973 On Key Symbols. American Anthropology 1971-1995: Papers from the American Anthropologist. Edited by Regna Darnell. 75(1973) pp.1338-1346.

Painter, Nell Irvin

2007 Creating Black Americans: African-American History and Its Meanings, 1619 to the Present. Oxford University Press, New York. 464 pgs.

Palmer, Colin A.

2000 The First Passage: 1502-1619 in To Make Our World Anew: A History of African Americans. Edited by Kelley, Robin D. G. and Earl Lewis. Oxford University Press, New York. 657 pgs. (3-52) \#49

Peterson, James B., David R. Waters, and Desmond V. Nicolson

1999 Continuity and Syncretism in Afro-Caribbean Ceramics from the Northern Lesser Antilles. In African Sites: Archaeology in the Caribbean. Markus Wiener Publishing, Princeton, New Jersey.

Pons, Frank Moya

2007 History of the Caribbean. Markus Weiner Publications. Princceton. 347

Pulsipher, Lydia Mihelic

1994 The Landscape and Ideational Roles of Caribbean Slave Gardens. In The Archaeology of Garden and Field, edited by Naomi F. Miller and Kathryn L. Gleason,University of Pennsylvania Press, Philadelphia. pp. 202-221.

Purdy, Barbara A.

1996 How to Do Archaeology the Right Way. University of Florida Press, Gainsville. 76. pp192

Proebsting, Eric

2007 The Use of Soil Micromorphology at Sylvester Manor. Northeast Historical Archaeology. 36(36)1(7).

Reeves, Matthew

2011 Homeland Market Activities Among Early $19^{\text {th }}$ Century Jamaican Slaves: 
An Archaeological Case Study from Two Slave Settlements. In Out of Many, One People. Edited by James A. Delle, Mark W. Hauser, and Douglas V. Armstrong. University of Alabama Press.

Renfrew, Colin and Paul Bahn 2000 Archaeology: Theories, Methods, and Practices. Thames and Hudson, London. pp 656.

Ruppel, Timothy, Jessica Neuwirth, Mark P. Leone, and Gladys Fry 2003 Hidden in View: African Spiritual Spaces in North American Landscapes. Antiquity.

Samford, Patricia 1995 Archaeology of Slavery in North America. Annual Review of Anthropology. 24:119-140.

1994 Searching for West African Cultural Meanings in the Archaeological Record. African American Archaeology: Newsletter of the African-American Archaeology Network, 12. Online Document. Accessed 9-21-2001 http://www.diaspora.uiuc.edu/newsletter.html

Schiffer, Herbert, Peter Schiffer, and Nancy Schiffer 1975 Chinese Export Porcelain Standard Patterns and Forms, 1780 to 1880. Schiffer Publishing Ltd. Pennsylvania.

Schoenbrun, David L. 2006 Conjuring the Modern in Africa: Durability and Rupture in Histories of Public Healing between the Great Lakes of East Africa. The American Historical Review.111(5):1403-1439.

Scott, James C. 1990 Domination and the Arts of Resistance: Hidden Transcripts. Yale University Press, New Haven, Connecticut.

Silliman, Stephen 2006 Struggling With Labor, Working With Identities. In Historical Archaeology. Edited by Martin Hall and Stephen W. Silliman. Blackwell Publishing. Massachusetts. 2001 Agency, Practical Politics and the Archaeology of Culture Contact. Journal of Social Archaeology. 190-205.

Singleton, Theresa 2001 Slavery and Spatial Dialectics on Cuban Coffee Plantations. World Archaeology. (33)1:98-114. 1995 The Archaeology of Slavery in North America. Annual Review of Anthropology. (24)119-140. 
Snow, Dan

2001 In the Company of Stone: The Art of the Stone Wall. Artisan, New York. 118 pgs.

Stelton, Ruud

2013 Personal Communication SECAR: Schotsenhoek Slave Village Excavation

2012 Personal Communication SECAR: Schotsenhoek Slave Village Excavation 2010 Relics of a Forgotten Colony: The Cannon and Anchors of St. Eustatius.

Master's Thesis. Leiden University.

2012 Nustar: Schotsenhoek Slave Village Report. SECAR

Stuckey, Sterling

1987 Slave Culture: Nationalist Theory and the Foundation of Black America.

Oxford University Press, New York, New York.

Stine, Linda France, Melanie A. Cabak and Mark D. Groover

1996 Blue Beads as African-American Cultural Symbols. Historical

Archaeology 30(3):49-75.

Strang, Veronica

2008 Uncommon Ground: Landscape as Social Geography. Handbook of

Landscape Archaeology. Edited by Bruno David and Julian Thomas. Left Coast Press. Walnut Creek, CA.

Stuckey, Sterling

1987 Slave Culture: Nationalist Theory and the Foundations of Black America.

Oxford University Press, England.

Swanson, M

2005 Ubuntu: An African Contribution to a Narrative Journey of Seeking a 'Humble Togetherness'. Paper presented at the annual conference of the Comparative and International Education Society. The University of British Columbia, Vancouver, Canada. September.

Thomas, Julian

2004 Archaeology's Place in Modernity. Modernism/Modernity. 11(1):17-34.

Thurston, Tina and Christopher T. Fisher

2006 Seeking a Richer Harvest: The Archaeology of Subsistence Intensification, Innovation, and Change (Studies in Human Ecology and Adaptation). Springer. pp 269.

Tilley, Christopher 
2010 Outline of a Phenomenological Perspective. Explorations in Landscape Phenomenology, Interpreting Landscapes: Geologies, Topographies, Identities. Left Coast Press, Walnut Creek, California. pp. 25-39.

1994 Conclusions: Ideology and Place: Reconstructing the Connections in A Phenomenology of Landscape: Places, Paths and Monuments. Oxford, NewYork, 202-208

Torres de Souza, Marcos Andre and Luis Claudio Pereira Symanski 1999 Slave Communities and Pottery Variability in Western Brazil: The Plantations of Chapada dos Guimaras. International Journal of Historical Archaeology. (13):513-548.

Treacy, John M. and William M. Denevan 1994 Creation of Cultviable Land Through Terracing. In The Archeology of Garden and Field. Edited by Naomi F. Miller and Kathryn L. Gleason. University of Pennsylvania Press, Philadelphia. pp 91-110.

Upton, Dell

1985 White and Black Landscapes in $18^{\text {th }}$ Century Virginia. Places 2(2):59-72

Vlach, John Michael

1995 "Snug Li'l House with Flue and Oven": Nineteenth-Century Reforms in Plantation Slave Housing. In Perspectives in Vernacular Architecture: Gender, Class, and Shelter. (5):118-129

1993 Back of the Big House: The Architecture of Plantation Slavery. The University of North Carolina Press, Chapel Hill, North Carolina.

Voss, Barbara

2010 The Archaeology of Indigenous Heritage at Spanish-colonial Military Settlements. In Enduring Conquests: Rethinking the Archaeology of Resistance to Spanish Colonialism in the Americas. Edited by M. Liebmann and M.S.

Murphy.

School For Advanced Research Press. pp. 243-265.

Wallerstein, Immanuel

2004 World-Systems Analysis: An Introduction. Duke University Press.

Weik, Terrance

2004 Archaeology of the Africa Diaspora in Latin America. Historical Archaeology. 38(1):32-49.

White, Deborah Gray 2000 Let My People Go: 1804-1860 in To Make Our World Anew: A History of African Americans. Edited by Kelley, Robin D. G. and Earl Lewis. Oxford 
University Press, New York. 657 pgs. (169-226)

Wolf, Eric

2010 Europe and the People Without History. University of California Press. pp 536.

1971 Peoples and Cultures of the Caribbean: An Anthropological Reader. Edited by Michael Horowitz. The Natural History Press, New York.

Wood, Peter H.

2003 Strange New Land: Africans in Colonial America. Oxford University Press, Oxford. 136 pages.

Yamin, Rebecca and Karen Bescherer Metheny 1996 Landscape Archaeology. The University of Tennessee Press, Knoxville, Tennessee.

Yentsch, Anne Elizabeth 1996 Introduction: Close Attention to Place-Landscape Studies by Historical Archaeologists. In Landscape Archaeology. The University of Tennessee Press, Knoxville, Tennessee.

Young, Amy

2003 Gender and Landscape: A View from the Plantation Slave Community. In Shared Spaces and Divided Places: Exploring the Material and Spatial Dimensions of Gender Relations and the American Historical Landscape, edited by Deborah L. Rotman and Ellen-Rose Savulis. University of Tennessee Press, Knoxville.

Young, Jason

2007 Rituals of Resistance: African Atlantic Religion in Kongo and the Lowcountry South in the Era of Slavery. Louisiana State University Press, Baton Rouge, Louisiana. 
APPENDIX A

FIELD MAP GILBOA HILL: SITES GH14 AND GH15

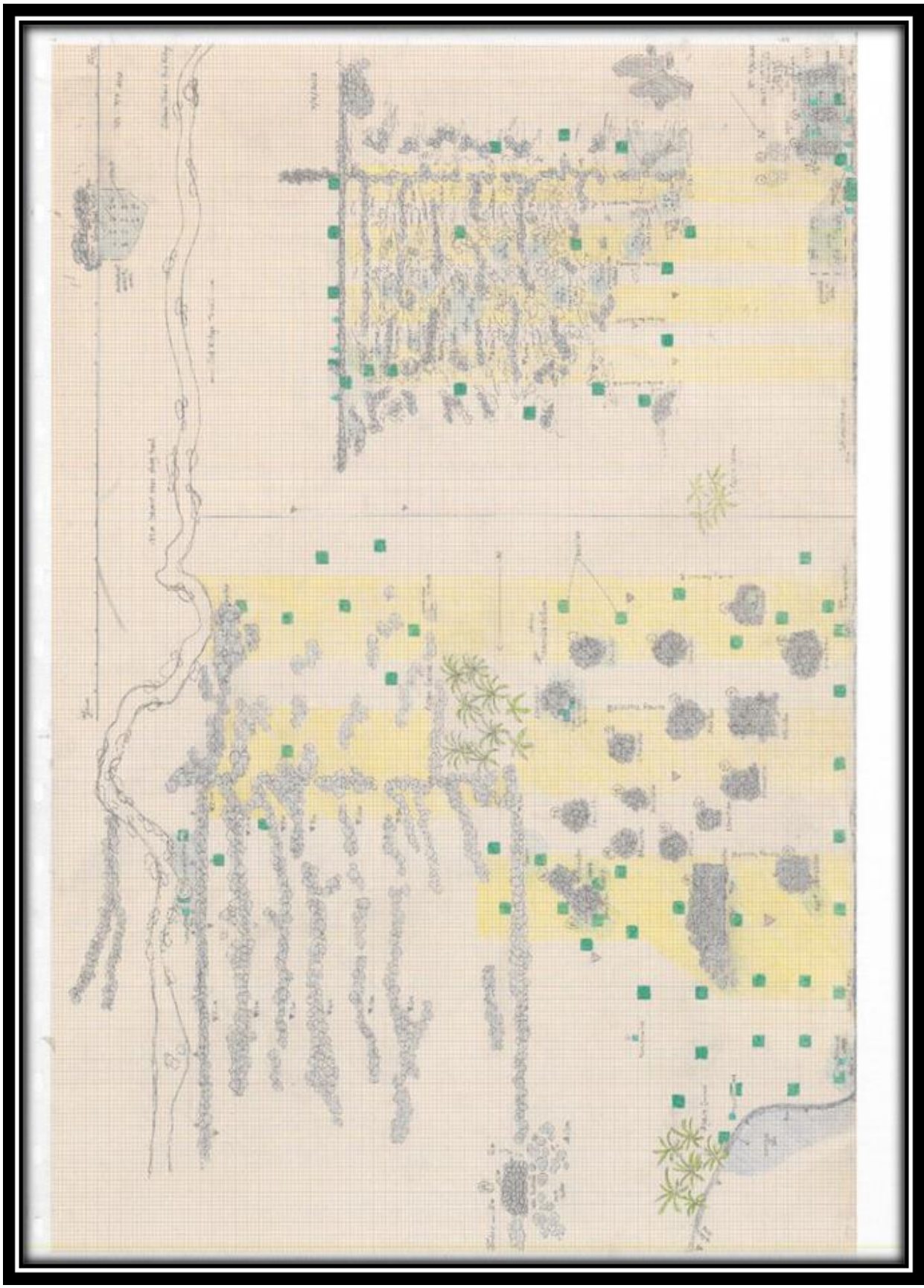


APPENDIX B

FIELD MAP GILBOA HILL: SITES GH9 AND GH10

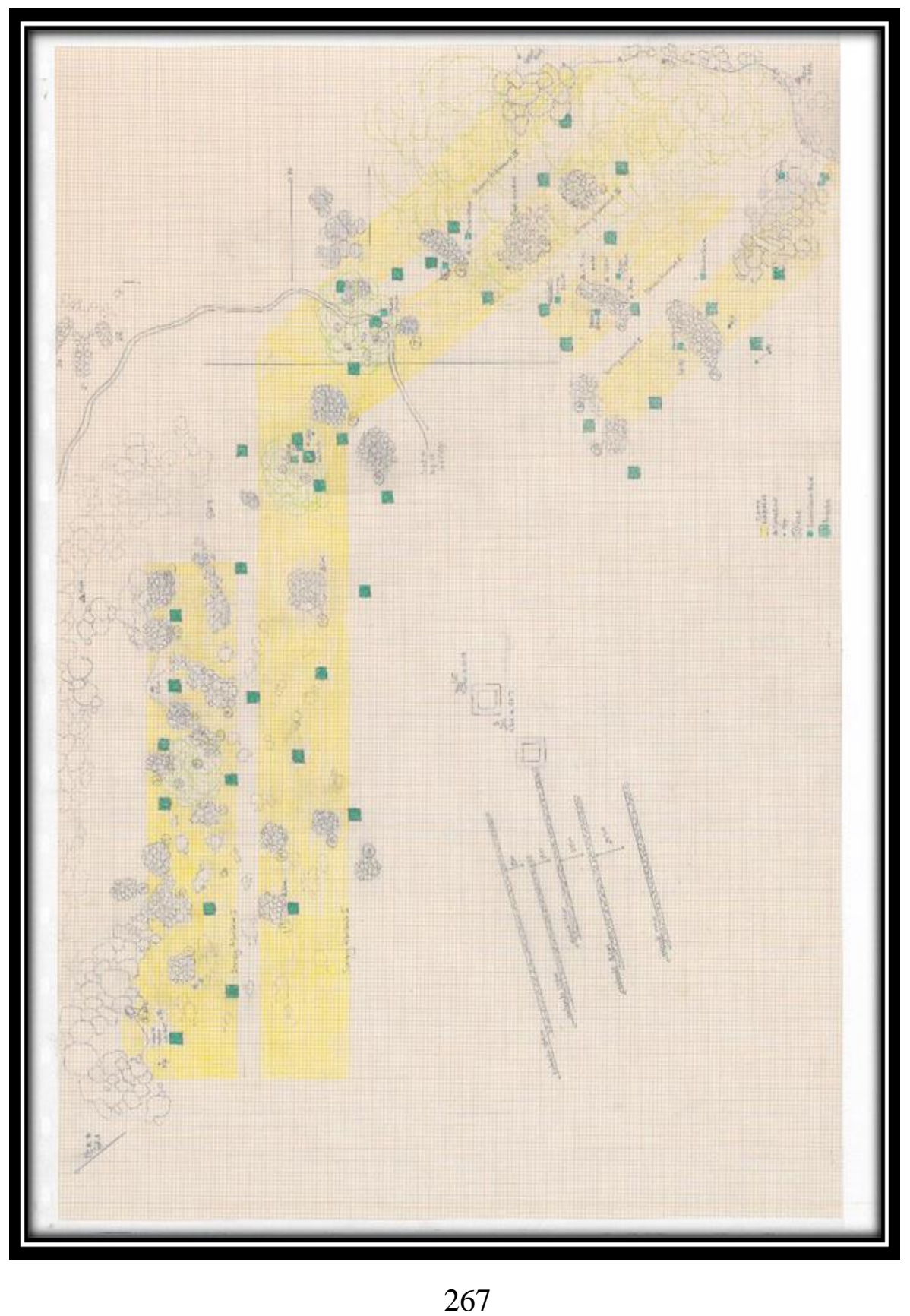


APPENDIX C

GILBOA HILL 50CM X 50CM TEST PIT PROFILES/DEPTHS

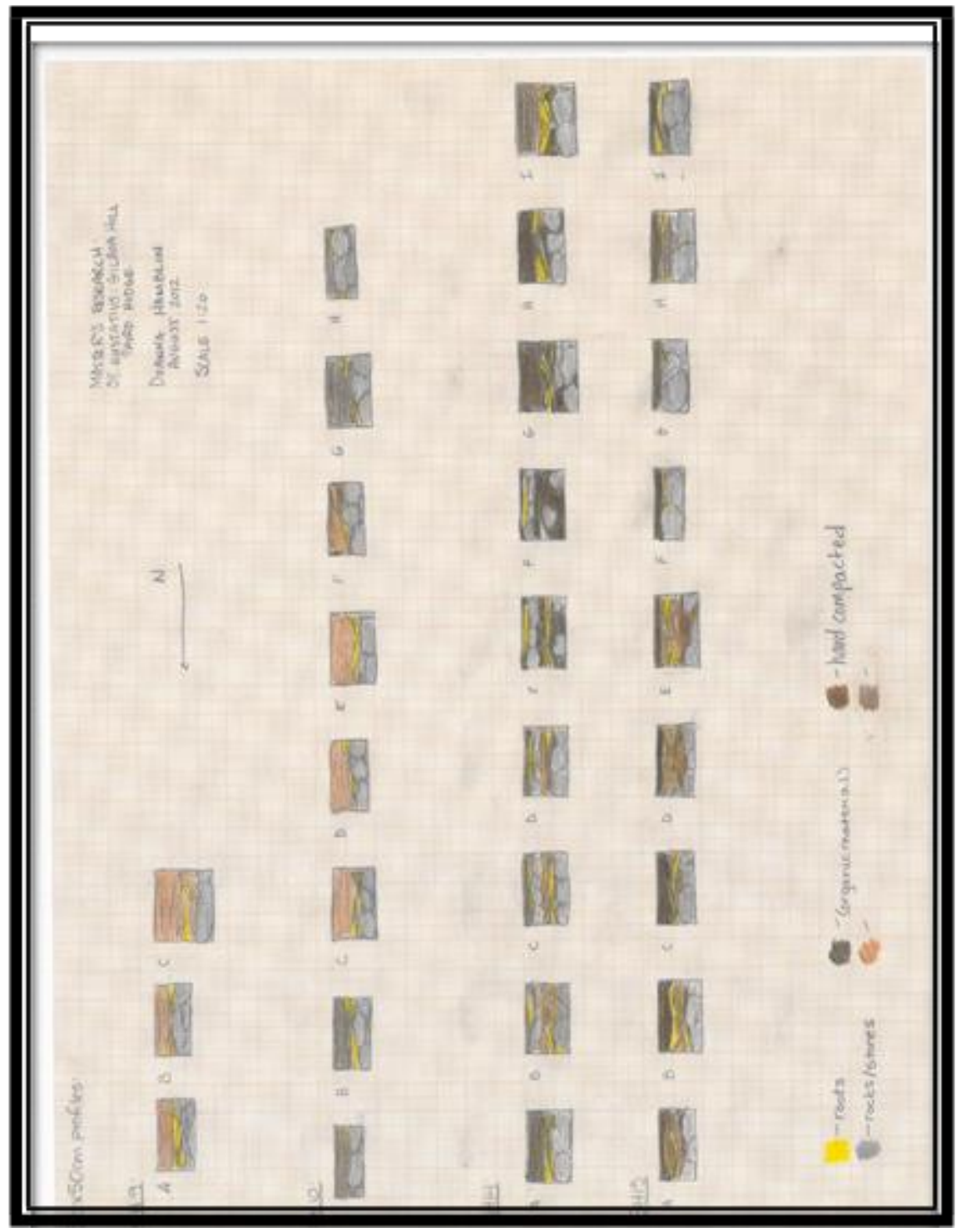




\section{APPENDIX D}

FREE BLACK VILLAGE PLAN MAP

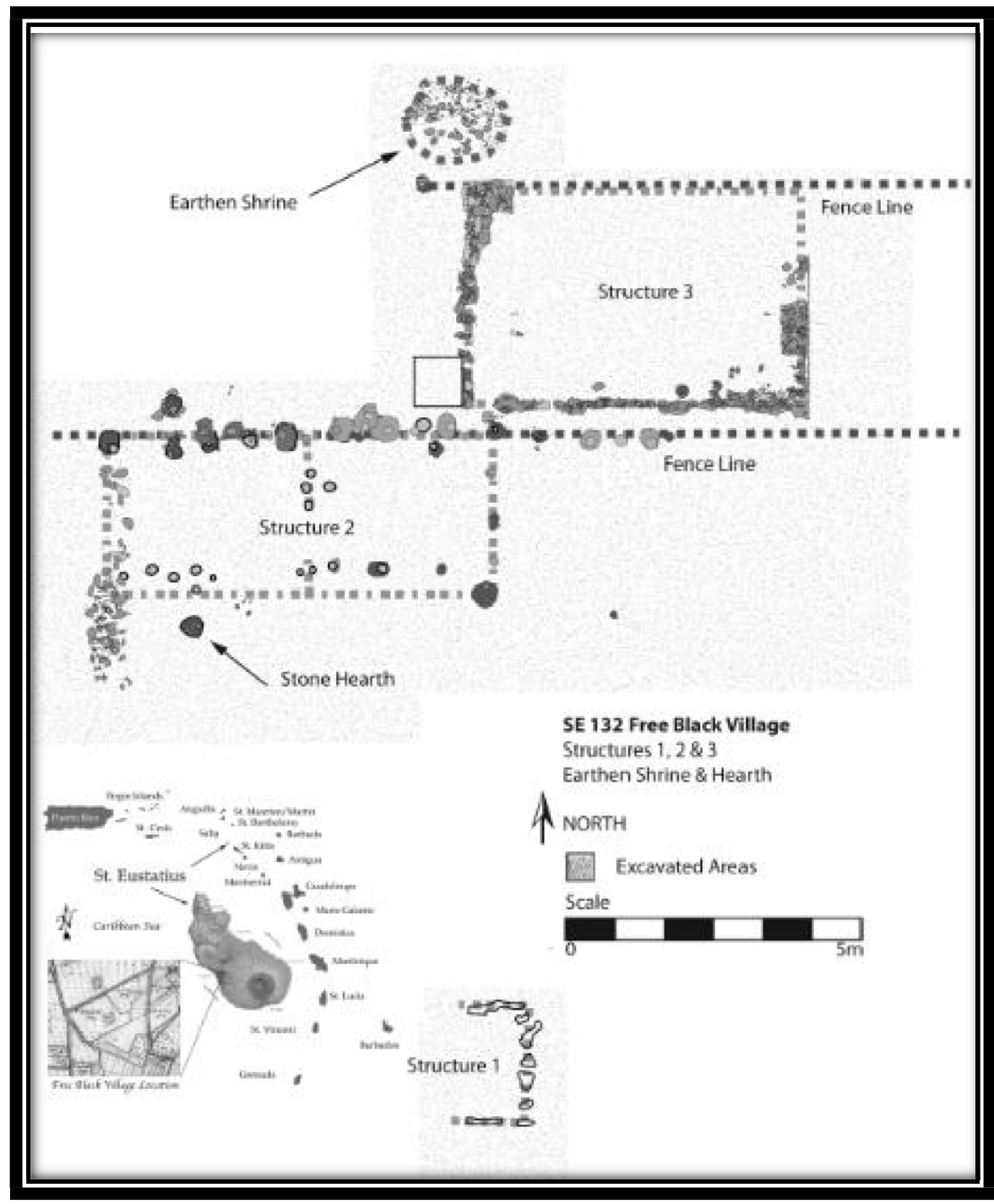


APPENDIX E

SCHOTSENHOEK SLAVE VILLAGE PLAN MAP

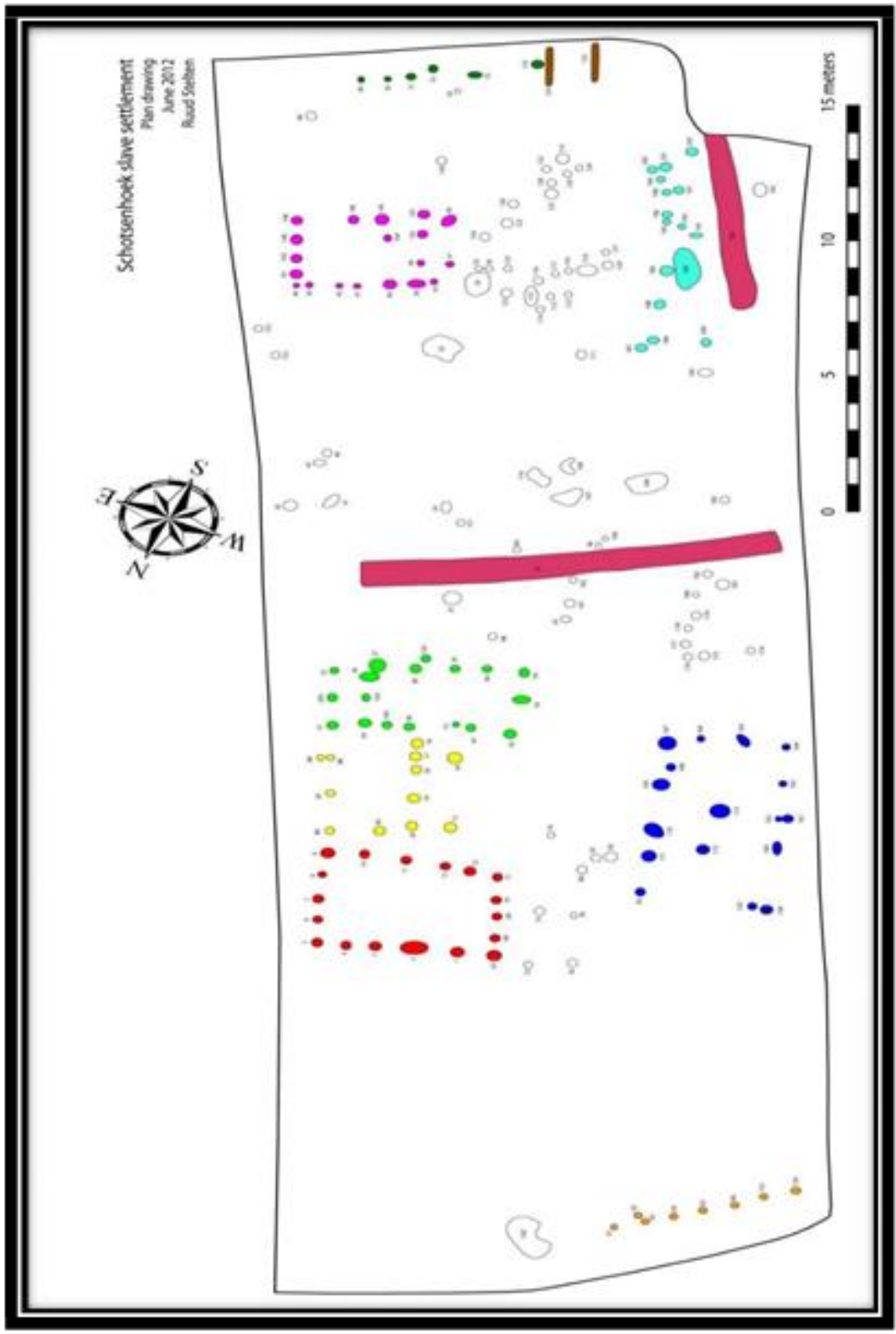




\section{APPENDIX F}

SCHOTSENHOEK SLAVE VILLAGE POSTHOLE PROFILES

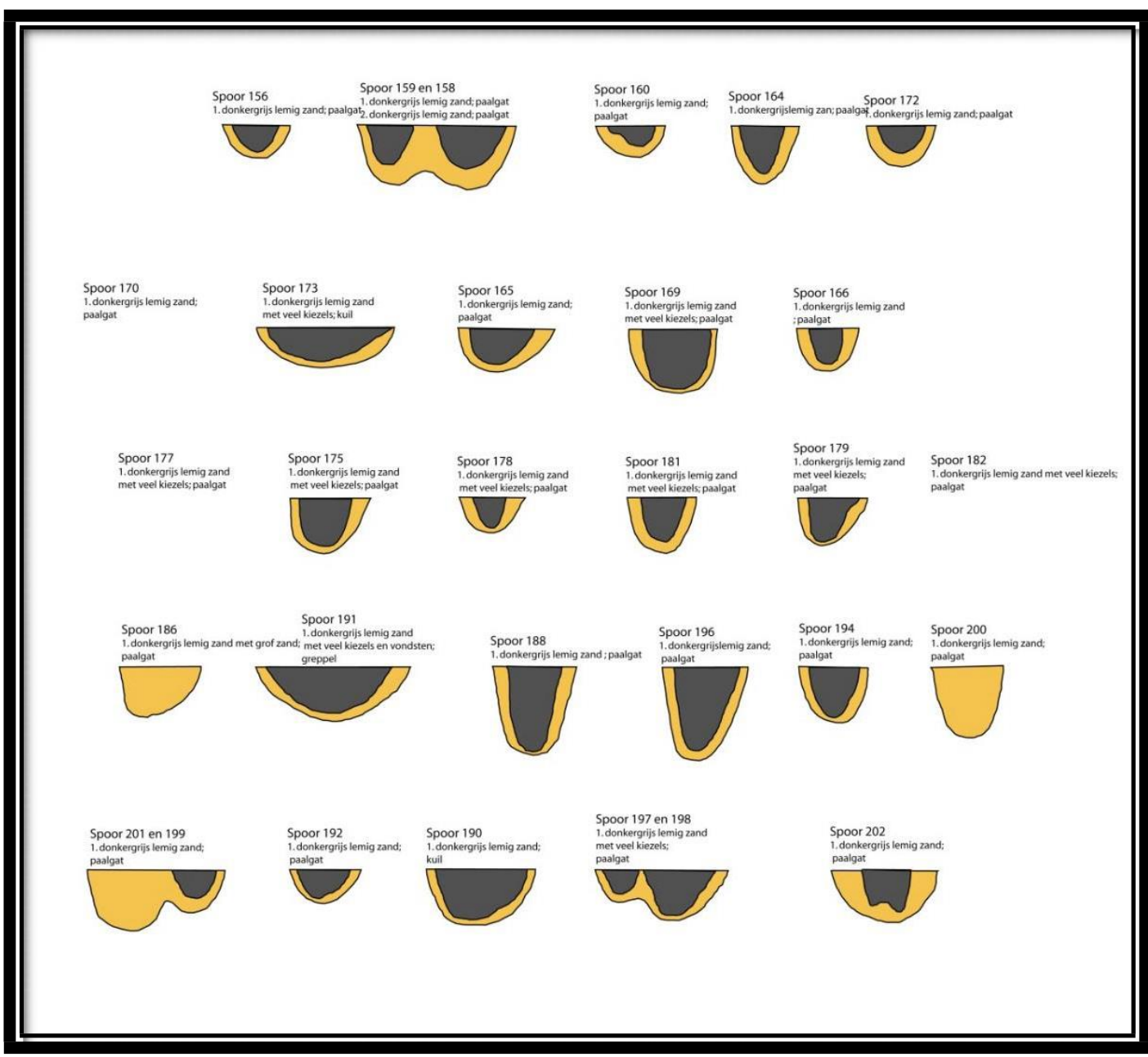




\section{APPENDIX G}

\section{SCHOTENSHOEK SLAVE VILLAGE POSTHOLE DEPTHS}

\begin{tabular}{|c|c|c|c|c|}
\hline Spoor & Depth Total: cm & $\begin{array}{c}\text { Depth Dark: } \\
\text { cm }\end{array}$ & & \\
\hline 170 & $<5 \mathrm{~cm}$ & $<5 \mathrm{~cm}$ & & \\
\hline 177 & $<5 \mathrm{~cm}$ & $<5 \mathrm{~cm}$ & & \\
\hline 182 & $<5 \mathrm{~cm}$ & $<5 \mathrm{~cm}$ & & \\
\hline 160 & 20 & 12.5 & Shallow & \\
\hline 197 & 20 & 15 & Shallow & \\
\hline 192 & 20 & 17.5 & Shallow & \\
\hline 156 & 20.5 & 17.5 & Shallow & \\
\hline 178 & 22.5 & 20 & Shallow & \\
\hline 172 & 25 & 15.75 & Shallow & \\
\hline 173 & 25 & 20 & Shallow & \\
\hline 199 & 27.5 & 17.5 & Shallow & \\
\hline 165 & 27.5 & 22.5 & Shallow & \\
\hline 166 & 27.5 & 22.5 & Shallow & $0-25 \mathrm{~cm}$ \\
\hline 179 & 30 & 27.5 & Deep & $25+\mathrm{cm}$ \\
\hline 202 & 32.5 & 26 & Deep & \\
\hline 198 & 32.5 & 27.5 & Deep & \\
\hline 186 & 32.5 & & Deep & \\
\hline 181 & 35 & 27.5 & Deep & \\
\hline 175 & 35 & 30 & Deep & \\
\hline 191 & 35 & 30 & Deep & \\
\hline 194 & 35 & 32.5 & Deep & \\
\hline 190 & 35 & 32.5 & Deep & \\
\hline 164 & 37.5 & 30 & Deep & \\
\hline 201 & 37.5 & & Deep & \\
\hline 159 & 40 & 25 & Deep & \\
\hline 158 & 40 & 27.5 & Deep & \\
\hline 169 & 40 & 37.5 & Deep & \\
\hline 200 & 45 & & Deep & $\begin{array}{l}\text { super } \\
\text { deep }\end{array}$ \\
\hline 188 & 55 & 52.5 & Deep & $\begin{array}{l}\text { super } \\
\text { deep }\end{array}$ \\
\hline 196 & 60 & 52.5 & Deep & $\begin{array}{l}\text { super } \\
\text { deep }\end{array}$ \\
\hline
\end{tabular}

